\title{
Root Coverage Predictability in the Treatment of Gingival Recessions on Mandibular and Anterior Teeth
}

\author{
Michele Agusto \\ ma0202@mix.wvu.edu
}

Follow this and additional works at: https://researchrepository.wvu.edu/etd

Part of the Periodontics and Periodontology Commons

\section{Recommended Citation}

Agusto, Michele, "Root Coverage Predictability in the Treatment of Gingival Recessions on Mandibular and Anterior Teeth" (2020). Graduate Theses, Dissertations, and Problem Reports. 7721.

https://researchrepository.wvu.edu/etd/7721

This Thesis is protected by copyright and/or related rights. It has been brought to you by the The Research Repository @ WVU with permission from the rights-holder(s). You are free to use this Thesis in any way that is permitted by the copyright and related rights legislation that applies to your use. For other uses you must obtain permission from the rights-holder(s) directly, unless additional rights are indicated by a Creative Commons license in the record and/ or on the work itself. This Thesis has been accepted for inclusion in WVU Graduate Theses, Dissertations, and Problem Reports collection by an authorized administrator of The Research Repository @ WVU. For more information, please contact researchrepository@mail.wvu.edu. 
Michele Agusto

Follow this and additional works at: https://researchrepository.wvu.edu/etd

Part of the Periodontics and Periodontology Commons 
Root coverage predictability in the treatment of gingival recessions on mandibular and anterior teeth

Michele Agusto. DDS

Thesis Submitted to the School of Dentistry

At West Virginia University

In Partial fulfillment of the requirements

For the degree of Master of Science In

Periodontology and Dental Implant Surgery

Gian Pietro Schincaglia, DDS, PhD, Chair

Arif Salman, BDS, MDSc

Matthew Bryington, DMD, MS, FACP

Department of Periodontics

Morgantown, West Virginia

2020

Keywords - gingival recession, root coverage, mandibular anterior teeth Copyright 2020 - Michele Agusto 


\section{ABSTRACT \\ Root coverage predictability in the treatment of gingival recessions on mandibular and anterior teeth \\ Michele Agusto. DDS}

Introduction. Mandibular anterior teeth are most frequently affected by gingival recessions. However, data regarding mucogingival treatment aimed at root coverage in this specific location is limited.

Aim. To systematically review the literature addressing the focused question: "What is the effectiveness, efficacy and efficiency of different surgical approaches on clinical and patient-related outcomes in the treatment of buccal gingival recessions on mandibular anterior teeth?"

Material methods. Electronic (Medline, Scopus, and Cochrane databases) and hand literature searches were performed for studies including at least one arm involving the use of pedicle flaps and/or free soft tissue grafts in the treatment of RT1 and RT2 gingival recessions located on the buccal aspects of mandibular centrals, laterals and canines. A Bayesian single-arm network meta-analysis was performed, and a treatment hierarchy of different surgical technique was based on a 3-12-month follow-up.

Results. Sixteen studies, with a total of 23 arms, were included in the quantitative analysis. The greatest mean root coverage is associated with LPF+CTG (91.2\%) and TUN+CTG (89.4\%), whereas LPF alone, CAF+CTG and FGG showed lower mRC $(79.1 \%, 78.9 \%$ and $68.5 \%$ respectively). TUN+CTG provides significantly greater mean root coverage compared to $\mathrm{CAF}+\mathrm{CTG}$. No difference among the procedures could be observed in terms of keratinized tissue width gain.

Conclusions. Treatment hierarchy generated by an arm-based network metanalysis model indicated in tunnel and laterally positioned flap, both in combination with connective tissue graft, the greatest results in the treatment of mandibular anterior recessions. 


\section{TABLE OF CONTENT}

1. INTRODUCTION - 1 -

1.1 GINGIVAL RECESSION 1 -

1.1.1 Definition - 1 -

1.1.2 Epidemiology - 2 -

1.1.3 Etiology \& Risk Factors - 6 -

1.1.4 Pathogenesis - 15 -

1.1.5 Classification - 16 -

1.1.6 Diagnosis -20 -

1.1.7 Prognosis - 23 -

1.1.8 Treatment - 24 -

1.2 PERIODONTAL PLASTIC SURGERY FOR ROOT COVERAGE - 25 -

1.2.1 Definition - 25 -

1.2.2 Indications - 25 -

1.2.3 Treatment modalities -27 -

1.2.3.1 Flap design -28 -

1.2.3.2 Soft tissue graft -31 -

1.2.3.3 Additional technologies - 32 -

1.2.4 Histologic outcomes - 33 -

1.2.5 Clinical outcomes - 35 -

1.2.6 Predictors of treatment outcome - 37 -

1.2.6.1 Patient-related factors - 37 -

1.2.6.2 Site-related factors - 38 -

1.2.6.3 Surgical factors $\quad$ - 40 -

1.3 FOCUS ON RECESSIONS ON MANDIBULAR ANTERIORS - 42 -

1.3.1 Literature Bias - 42 -

2. AIM - 45 -

3. MATERIAL \& METHODS - 46 -

3.1 PROTOCOL DEVELOPMENT AND FOCUSED QUESTION - 46 -

3.2 STUDY SELECTION CRITERIA (PICOS) - 46 -

3.3 LITERATURE SEARCH - 48 -

3.4 STATISTICAL METHODS - 51 -

4. RESULTS - 54 -

4.1 SUMMARY OF THE LITERATURE SEARCH - 54 - 
4.2 QUALITATIVE ANALYSIS

$-58-$

4.2.1 Study design

-58 -

4.2.2 Follow-up

$-58-$

4.2.3 Population

-59 -

4.2.4 Defect characteristics

-60 -

4.2.5 Root coverage procedures

$-61-$

4.3 QUANTITATIVE ANALYSIS

$-63-$

4.3.1 Treatment groups

-63 -

4.3.1 Mean root coverage

$-64-$

4.3.2 Keratinized Tissue Width change

-72 -

-110 -

Definition of categories

- 110 -

Statistical method

- 106 -

6. CONCLUSION

-113 -

7. FUTURE RESEARCH

$-114-$

8. REFERENCES

- 115 - 


\section{INTRODUCTION}

\subsection{GINGIVAL RECESSION}

\subsubsection{Definition}

According to the Glossary of Terms from the American Academy of Periodontology, gingival recession refers to the exposure of the root surface by an apical shift in the position of the gingiva in relation to the cementoenamel junction (G. Pini Prato, 1999). By definition, gingival recession is always associated with loss of clinical attachment (Cortellini et al., 2018). Gingival recessions can be localized or generalized, so they can affect one tooth or multiple teeth in the same patient, and associated with one or more surfaces in the same tooth (Kassab et al., 2003).

\section{Anatomy}

In health, the free gingival margin, which defines the coronal limit of the gingiva, is located about 1-2 mm coronal to the CEJ, and the level of the epithelial attachment to the tooth is usually at or slightly coronal to the level of the cementoenamel junction (CEJ) (Stahl, 1985). In case of gingival recession, an osseous dehiscence is present and the soft tissues around the tooth, which include free gingiva, attached gingiva and alveolar mucosa, are dislocated apically to the CEJ, with exposure of the root surface to the oral environment (Stern, 1981). Histologic studies have shown in buccal-lingual cross-sections of teeth affected by gingival recession that the gingival unit, which is characterized by a keratinized epithelium, tends to move apically with the increasing recession depth, whereas the position of the mucogingival junction (MGJ) and the alveolar mucosa tend to remain unaltered (Pini-Prato, 2011). These 
findings confirm that with the increase of the recession depth, the width of keratinized tissue tends to decrease, which leads to the partial or complete loss of the attached gingiva. However, even when a recession reaches the MGJ, a minimal amount of keratinized mucosa, representing the free gingiva, is still present (Pini-Prato, 2011). In a cross-sectional study, it was reported that the mean dehiscence depth exceeded the recession depth by 2.76 mm, which represents the space occupied by the supracrestal fiber attachment (Löst, 1984).

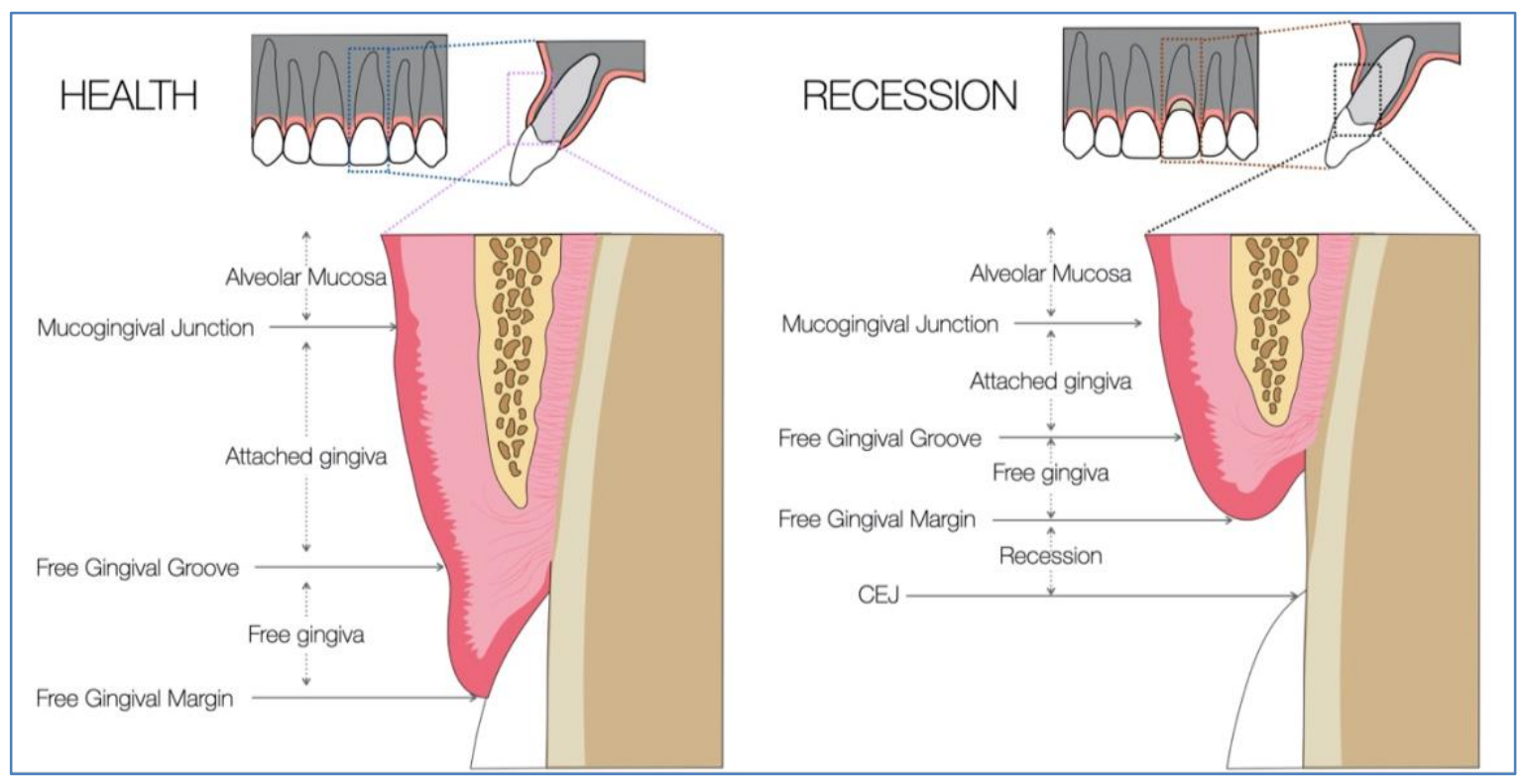

Figure 1. Scheme of microscopic characteristics of dentogingival anatomy in health and recession

\subsubsection{Epidemiology}

Gingival recessions represent a common mucogingival disorder, affecting both the young and old populations (Kassab et al., 2003). Numerous epidemiological studies have reported different results in terms of both general prevalence and severity of gingival recessions, probably due to data heterogeneity related to age, gender, ethnicity, inclusion and exclusion criteria (Marini et al., 2004). 
Age

Population-based studies have shown that the development of gingival recessions is correlated with age (Gorman, 1967; Kassab et al., 2003; Kitchin, 1941). Both prevalence and severity of gingival recessions are lower at younger ages and increase over time (Ainamo et al., 1986; Albandar et al., 1999; Brown et al., 1990; Susin et al., 2004). In a study by Susin (Susin et al., 2004), more than 1,580 individuals aged 14 years and older were examined: through a clinical assessment, recessions of at least $4 \mathrm{~mm}$ depth were identified in $6 \%, 24 \%$, and $54 \%$ of patients aged 14 to 19,20 to 29 , and 30 to 39 years, respectively. A similar trend was confirmed by a sample data from the third National Health and Nutrition Examination Survey (NHANES III), which showed that prevalence, extent and severity of gingival recession increased in individuals aged 30 and over: in particular, $56 \%$ of individuals aged $40-49,71 \%$ of individuals $50-59,80 \%$ of individuals aged $60-69$, $87 \%$ of individuals $70-79$, and $90 \%$ of individuals aged $80-90$ showed $1 \mathrm{~mm}$ or more of gingival recession on at least 1 tooth (Albandar et al., 1999). Similarly, the NPASES I crosssectional data (France) used a multivariate linear regression model to show that age can be considered a risk factor for both the extent and severity of gingival recession (Sarfati et al., 2010).

\section{Gender}

In NHANES III data, it is evident that males aged 30 or more had significantly more recession than females of the same age (Albandar et al., 1999). Other studies corroborate the finding that adult males consistently exhibited a higher prevalence and extent of gingival recession than adult females (Susin et al., 2004). A recent publication reported that males were significantly more affected by gingival recession (60.5\%) compared to females (39.5\%) (Mythri et al., 2015). However, no significant sex differences seem to be present 
for younger ages: for example, no differences in the prevalence of gingival recession were reported between males and females among 17 year old patients (Ainamo et al., 1986).

\section{Ethnicity}

Considering different race/ethnic groups, the NHANES III data showed that non-Hispanic blacks had the highest prevalence and extent of gingival recession (Albandar et al., 1999). Mexican Americans had similar prevalence and extent of gingival recession compared with non-Hispanic whites (Albandar et al., 1999).

\section{Socioeconomic status}

Multiple investigations suggested socioeconomic status as a risk indicator associated with the presence of gingival recessions: in fact, the percentage of teeth with recession has been reported to be significantly higher in the lower socioeconomic groups, irrespective of age (Mythri et al., 2015; Susin et al., 2004).

\section{Location}

Tooth

Mandibular teeth have a significantly higher prevalence of gingival recession than maxillary teeth (Mythri et al., 2015). In an Indian epidemiologic study conducted on 710 subjects aged between 15 years to 60 years, gingival recession was commonly seen in mandibular incisors (43.0\%) followed by maxillary molar (13.2\%), mandibular premolar (12.2\%), maxillary incisor and premolar (8.9\%), mandibular molar (4.9\%), maxillary canine (4.6\%), mandibular canine (4.3\%) (Mythri et al., 2015). This frequency of pattern was confirmed also in other studies (Albandar et al., 1999; van Palenstein Helderman et al., 1998): in fact, according to the NHANES III data, in the mandibular arch, the central incisors and the first 
premolars showed the most recession, with $49.7 \%$ of mandibular central incisors and $43.5 \%$ of mandibular first premolars being affected in the 56-90 year old group. These data were confirmed also for orthodontically treated subjects: during and after orthodontic therapy, mandibular incisors seem to be the most vulnerable to the development of gingival recessions (Renkema et al., 2013b).

Site

Gingival recessions seem to affect the facial surface of the tooth more commonly than its lingual aspect. In a cross-sectional study conducted on 299 Finish school children aged 7 to 17 years, of the 5,895 teeth examined, recession was found on the facial aspect of 512 teeth (8.7\%) and on the lingual aspect of only 16 teeth (0.3\%) (Ainamo et al., 1986). Löe and coauthors presented data which support an increased prevalence of recession on the facial surface as opposed to the lingual surface, which is affected by gingival recession only later in life (Loe et al., 1992). In this parallel study, two different cohorts of individuals, from Norway (1969-1988) and Sri Lanka (1970-1990), covering the age range from 15 to 50 years, were longitudinally followed to describe the occurrence and levels of gingival recession. In the Norwegian cohort, gingival recession began early in life: it occurred in greater than or equal to $60 \%$ of the 20 -year-olds and was confined to the buccal surfaces. At 30 , greater than or equal to $70 \%$ had recession, which still was found mainly on buccal surfaces. As the group approached 50 years of age, more than $90 \%$ had gingival recession; greater than or equal to $25 \%$ of the buccal surfaces were involved, greater than or equal to $15 \%$ of lingual, and 3 to $4 \%$ of the interproximal surfaces. In the Sri Lankan cohort greater than or equal to $30 \%$ exhibited gingival recession before the age of 20 years. By 30 years, $90 \%$ had recession on buccal, lingual, and interproximal surfaces; and at 40 years, $100 \%$ of the Sri Lankans had recession. As they approached 50 years, gingival recession occurred in 
greater than or equal to $70 \%$ of the buccal, greater than or equal to $50 \%$ of the lingual, and $40 \%$ of the interproximal surfaces (Loe et al., 1992). These percentages are also in accordance with the results obtained from a Tanzanian population (20-64 years of age) with limited access to dental care, where gingival recession was found to be most prevalent at buccal surfaces, followed in descending order by lingual and approximal surfaces (van Palenstein Helderman et al., 1998).

\subsubsection{Etiology \& Risk Factors}

Although numerous factors have been implicated in the etiology of gingival recession in both cross-sectional and longitudinal studies (Kassab et al., 2003), the AAP-EFP World Workshop 2017 concluded that the etiology of gingival recession remains unclear (Cortellini et al., 2018). Several predisposing factors have been suggested: mechanical trauma, plaque accumulation, periodontal phenotype and attached gingiva, cervical restorative margins, dental malposition, high frenum attachment and shallow vestibular depth, orthodontic treatment (Cortellini et al., 2018). Based on clinical observations, the occurrence of gingival recession is usually associated with the coexistence of two or more different risk factors or conditions (Cairo, 2017).

\section{Mechanical Trauma}

Several publications have been suggested that mechanical trauma, mainly represented by improper toothbrushing technique, is one of the most important contributing factors to the development and progression of gingival recession (Cortellini et al., 2018; O'Leary et al., 1971; O'Leary et al., 1967; Sangnes et al., 1976; Serino et al., 1994). This is supported by the evidence that a high proportion of individuals presented with gingival recessions in populations with high standards of oral hygiene (Sarfati et al., 2010). Löe and coauthors 
proposed the existence of two basic types of recession: one related to mechanical factors, including tooth brushing, which occurs mainly in the buccal aspect, and the other relating to periodontal disease, which involves also the interproximal sites (Loe et al., 1992). The hypothesis that excessive and incorrect oral hygiene methods can induce a soft tissue recession has been confirmed in multiple papers where a positive association between toothbrushing frequency and gingival recessions was observed (Checchi et al., 1999; Khocht et al., 1993; Kozlowska et al., 2005; Sangnes et al., 1976; Vehkalahti, 1989): in particular, it has been reported that those subjects who brush more than once a day are 2.1 times more likely to develop a gingival recession compared to less frequent brushers (Vehkalahti, 1989). Similarly, other factors related to toothbrushing have been associated with a higher risk for gingival recession development (Rajapakse et al., 2007): duration (Tezel et al., 2001), force (Benz et al., 1987), bristle hardness (Goutoudi et al., 1997), frequency of changing toothbrush (Kozlowska et al., 2005). For example, subjects who brushed for more than 3 minutes had approximately twice the mean severity of gingival recessions as did those subjects who brushed for less than 1 minute (Tezel et al., 2001). However, according to other studies, toothbrushing duration and frequency were not correlated to the development of gingival recession (Kallestal et al., 1992; Murtomaa et al., 1987). In summary, the current consensus is that data to support or refute the association between tooth brushing and gingival recession are inconclusive (Cortellini et al., 2018; Rajapakse et al., 2007). Other traumatic factors have been proposed to play a role in the development of soft tissue recession: for example, in patients wearing a lip piercing, gingival recessions were noted on teeth opposite the stud in $68 \%$ of the cases (Kapferer et al., 2007).

\section{Plaque accumulation}


Gingival recession is a common feature in population with poor oral hygiene (Baelum et al., 1986; Loe et al., 1992; Susin et al., 2004; Yoneyama et al., 1988). As evidenced in animal studies, plaque and calculus formation induce marginal gingival inflammation, with a dense mononuclear cell infiltrate, which can lead to the destruction of periodontal tissue and development of gingival recession (Hopps et al., 1974). The correlation coefficients between gingival recession and calculus at the individual tooth surface have been reported to be statistically significant (van Palenstein Helderman et al., 1998). Toker and colleagues analyzed the association between gingival recession and periodontal clinical parameters in a Turkish population of 831 subjects aged 15-68 years and it was concluded that gingival recession was significantly correlated with a high level of plaque and calculus (Toker et al., 2009). Similar results were presented in a Greek cross-sectional study on 640 subjects aged 18-45 years, where a positive association was observed between soft tissue recession, gingival inflammation and inadequate oral hygiene (Chrysanthakopoulos, 2014). Löe and coauthors concluded that when related to plaque-induced inflammatory mechanisms, gingival recessions usually affect all tooth surfaces, although the prevalence and severity is more pronounced at single-rooted teeth than at molars (Loe et al., 1992).

\section{Thin periodontal phenotype}

A thin periodontal phenotype is considered a risk factor for the development of gingival recession (Cortellini et al., 2018). It was shown that individuals with long narrow crown forms of maxillary central incisors have comparatively thin periodontal biotype and are more susceptible to recession as compared to subjects with a wide-square form and thick periodontium (Olsson et al., 1991). Thin gingival tissues seem to be associated with relatively thin alveolar bone (Fu et al., 2010): a recent systematic review found positive associations between gingival thickness, keratinized tissue and bone morphotype (Zweers 
et al., 2014). The higher risk of gingival recession in case of thin marginal soft tissues compared to a thick periodontium has been described for teeth receiving restoration with inadequate contour and margins (Sanavi et al., 1998) or after periodontal treatment (Claffey et al., 1986). Similar findings emerged also from studies conducted on orthodonticallytreated patients. Yared et al. noted that $93 \%$ of the incisors that developed recession had thicknesses of the free gingival margin $<0.5 \mathrm{~mm}$ and the authors concluded that gingival thickness had greater relevance to recession than final inclination of the incisors (Yared et al., 2006). Melsen and Allais found a significant correlation between the pre-treatment width of keratinized gingiva and gingival biotype and the development or increase in the gingival recession (Melsen et al., 2005). Interestingly, periodontal phenotype has been described as

a decisive factor for a successful treatment outcomes in immediate implant placement: a tendency for more gingival recession was found with immediate single tooth implant restoration in a population with a thin scalloped biotype (Evans et al., 2008) and reduced risk of recession in patients with a thick biotype (Cosyn et al., 2011).

\section{Minimal keratinized tissue width}

Initially, the presence of a wide band of keratinized and attached mucosa around the tooth was considered critical for preventing soft tissue recession and maintaining periodontal health (Bowers, 1963; Corn, 1962; Ruben, 1979). In 1972, a classic trial conducted by Lang \& Löe, it was shown that sites with less than $2 \mathrm{~mm}$ of gingiva tend to exhibit persistent clinical signs of inflammation, assessed with the Gingival Index Score (Lang et al., 1972). However, a consistent series of subsequent clinical studies failed to substantiate the concept of a required minimum dimension of keratinized mucosa (de Trey et al., 1980; Freedman et al., 1999; Hangorsky et al., 1980; Kisch et al., 1986; Lindhe et al., 1980; Miyasato et al., 1977; Schoo et al., 1985; Jan L. Wennström, 1987). For instance, in an elegant split-mouth 
prospective trial by Dorfman, 92 patients with bilateral sites exhibiting less than $2 \mathrm{~mm}$ of keratinized tissue, received a gingival augmentation procedure on one side, which consisted of a free gingival graft, whereas the contralateral side served as control. The follow up at 2 years revealed the attachment level was maintained unchanged in both grafted and nongrafted sites, showing that the occurrence of gingival recession was not linked to the gingival height (Dorfman et al., 1980). Same results were confirmed in the 4- and 6-year follow up reports (Dorfman et al., 1982; Kennedy et al., 1985), regardless of the oral hygiene status of the patient. An additional confirmation of the lack of relationship between gingival height and recession development was provided by Wennström in 1987 in a 5-year prospective study: 26 buccal sites, which had been surgically deprived of all the keratinized tissue, showed no additional attachment loss or soft tissue recession compared to adjacent teeth with wide zone of attached gingiva (Jan L. Wennström, 1987). In the latest consensus report from the American Academy of Periodontology Regeneration Workshop, it was concluded that there is no need for a minimum amount of keratinized tissue for preventing attachment loss and gingival recession, provided that optimal plaque control conditions resulting in the absence of clinical inflammation are established and maintained (Scheyer et al., 2015).

\section{Cervical restorative margins}

Experimental and clinical data suggest that subgingival placement of the margin of a restoration is likely to result in soft tissue recession over time, especially in case of thin marginal soft tissues (Ericsson et al., 1984; Paniz et al., 2016; Parma-Benfenali et al., 1985). An evaluation of 114 patients and 329 total crown restorations, it was shown that most of the crowns (59\%) were located subgingivally at the beginning of the observation period, but after 5 years, only $32 \%$ of the crown margins remained apical to the gingival margin 
(Valderhaug et al., 1976). It was also demonstrated that greater mean attachment loss, represented by gingival recession, was associated with subgingival restorations compared to supragingival margins (1.2 versus $0.6 \mathrm{~mm}$ ) (Valderhaug et al., 1976). These findings were confirmed by other publications: for example, Orkin and coauthors demonstrated that subgingival restorations had a greater chance of bleeding and exhibiting gingival recession than supragingival restorations (Orkin et al., 1987). The latest 2017 World Workshop on the Classification of Periodontal and Peri-Implant Diseases and Conditions reported clinical observations suggesting that sites with minimal or no gingiva associated with intrasulcular restorative margins are more prone to gingival recession and inflammation (Cortellini et al., 2018).

\section{Dental malposition}

There is evidence in support of malpositioned teeth as predisposing factors for gingival recessions (Kassab et al., 2003). Isolated buccally tipped teeth and excessive maxillary incisor proclination had a significant association with gingival recession (Gusmão et al., 2011). Significant associations between gingival height and anterior crowding were reported in a group of 93 children aged 6-12 years (Powell et al., 1981). Trott \& Love examined the presence of recession in the facial surfaces of mandibular incisors in a group of 766 high school students aged 14-19: of the teeth examined, $1.8 \%$ were reported to have recession greater than $3 \mathrm{~mm}$ and tooth malposition was the factor most commonly associated with recession (Trott et al., 1966). Gorman examined 164 subjects aged 16-86 years for recession and observed that in teeth in pronounced labio-version, $61 \%$ were found to have some degree of gingival recession, as well as $15 \%$ of teeth in pronounced linguo-version (Gorman, 1967). 


\section{High frenum attachment \& Shallow vestibule}

Aberrant frenal attachment has been mentioned as a cause of localized recession (Kassab et al., 2003). The association between frenal pull and soft tissue recession has been reported in multiple studies (Stoner et al., 1980; Trott et al., 1966). For example, in a recent Turkish cross-sectional evaluation, the multiple regression analysis showed that high frenum is a significant contributor to gingival recession, especially in males (Toker et al., 2009). However, these data are conflicting with other publications, where the correlation was not found to be significant (Castro-Rodríguez et al., 2017; Powell et al., 1981).

\section{Orthodontic treatment}

Contradictory statements can be found in the literature regarding orthodontic tooth movement as a risk factor for gingival recession. A recent systematic review has investigated the relationship between gingival recession and orthodontic therapy and concluded that the effects of orthodontic treatment (active and/or retention phase) on the periodontium, albeit small, are detrimental (Bollen et al., 2008). The reported prevalence of gingival recession ranges from $5 \%$ to $12 \%$ at the end of treatment (Slutzkey et al., 2008), but an increase of the prevalence up to $47 \%$ in the long-term observation ( 5 years) was described (Renkema et al., 2013a). It has been suggested that the odds ratio for orthodontically treated subjects to have recessions in comparison to untreated subjects is 4.48 (Renkema et al., 2013b). Different mechanisms have been suggested to explain the causative association between orthodontic therapy and recessions(Kassab et al., 2003). In particular, it was suggested that the possibility of development and progression of gingival recession is dependent on the direction of the orthodontic movement (Joss-Vassalli et al., 2010): both animal and human studies showed that more proclined teeth compared with less proclined teeth or untreated teeth and movement of the incisors out of the osseous envelope 
of the alveolar process may be associated with a higher tendency for developing gingival recessions (Allais et al., 2003; Artun et al., 2001; Artun et al., 1987; Batenhorst et al., 1974; Djeu et al., 2002; Engelking et al., 1982; Pearson, 1968; Ruf et al., 1998; Sperry et al., 1977; Steiner et al., 1981; Wennstrom et al., 1987). Interestingly, different reports have failed to find a positive association between the proclination of mandibular incisors and the development of gingival recessions in shot- and long-term observations (Renkema et al., 2015; Steiner et al., 1981), suggesting that a tension in the marginal tissue ("stretching") is created by the forces applied to the teeth regardless of the final inclination of the tooth (Steiner et al., 1981). Similarly, inconsistent results have been reported for the maxillary palatal expansion (Handelman, 1997; Vanarsdall, 1995), so the data are inconclusive. Another possible mechanism is related to the increased plaque retention induced by fixed orthodontic appliances. In a recent study by Klukowska et al, plaque levels ranged from $5.1 \%$ of tooth surfaces to as high as $85.3 \%$ in patients undergoing treatment with fixed appliances, with a mean plaque coverage of $41.9 \%$ (Klukowska et al., 2011). The consensus statement from 2017 AAP-EFP World Workshop concluded that the direction of the tooth movement and the bucco-lingual thickness of the gingiva may play important roles in soft tissue alteration during orthodontic treatment (Cortellini et al., 2018). It was stated that there is a higher probability of recession during tooth movement in areas with thin gingiva, which may serve as a locus minoris resistentiae, so the recommendation is that gingival augmentation can be indicated before the initiation of orthodontic treatment in areas with $<2 \mathrm{~mm}$ of thickness (Cortellini et al., 2018).

\section{Smoking}

A relationship has been proposed between smoking and gingival recession (Gunsolley et al., 1998; Martinez-Canut et al., 1995). The multifactorial mechanism may include 
alterations in the immune response, such as decreases in the phagocytic function of polymorphonuclear leukocytes (Kenney et al., 1977) and in the production of immunoglobulins (Johnson et al., 1990), and changes in the peripheral gingival blood flow (Baab et al., 1987). Tobacco consumption and the number of cigarettes smoked per day has resulted to be a risk factor for the presence of gingival recession (Albandar et al., 2000; Sarfati et al., 2010), particularly in the maxillary anterior region on both buccal and palatal surfaces (Haffajee et al., 2001). Different findings have been reported in a parallel trial, where in a multivariate logistic regression analysis, the risk for recession development appeared not to be influenced by smoking status after adjusting for confounding factors (Muller et al., 2002). A recent investigation has shown that users of smokeless tobacco tend to have more severe gingival recession and clinical attachment loss compared to never users (Anand et al., 2013).

\section{Trauma from occlusion}

Initial periodontal literature has reported a possible role of occlusion in determining detrimental effects on the marginal periodontium and causing soft tissue recession (Stillman, 1917). In particular, a specific mucogingival deformity in response to excessive occlusal forces was described as Stillman's cleft, defined as narrow, triangular-shaped gingival recession on the facial aspect of the tooth (Stillman, 1925). However, this was an empiric observation and the contribution of occlusal forces in the etiology of gingival recession has been clearly rejected by the scientific evidence (Fan et al., 2018). It was shown that mobility, which represents the functional adaptation of the periodontium to excessive forces, is not correlated to gingival recessions: compared with contralateral teeth without recession, teeth with recession showed either no or similar mobility (J.-P. Bernimoulin et al., 1977). A recent retrospective analysis aimed at evaluating the relationship between 
occlusal discrepancies and the changes in the location of the free gingival margin failed to find any associations (Harrel et al., 2004). Moreover, the same study highlighted that occlusal adjustment did not provide any effect on changes in gingival width or thickness (Harrel et al., 2004).

\subsubsection{Pathogenesis}

The pathogenetic mechanism of gingival recession was described in an experimental study by Baker and Seymour 1976 on rats, where pocketing had been induced by replacement of natural incisors with dental implants (Baker et al., 1976). The recession process was examined histologically at intervals by taking transverse serial sections. According to this findings, gingival recession involves a localized inflammatory process, with accumulation of mononuclear cells, which causes breakdown of connective tissue and leads to proliferation of the epithelium into the site of connective tissue destruction. Proliferation of the epithelial cells into the connective tissue brings about a subsidence of the epithelial surface, which is manifest clinically as recession (Baker et al., 1976).

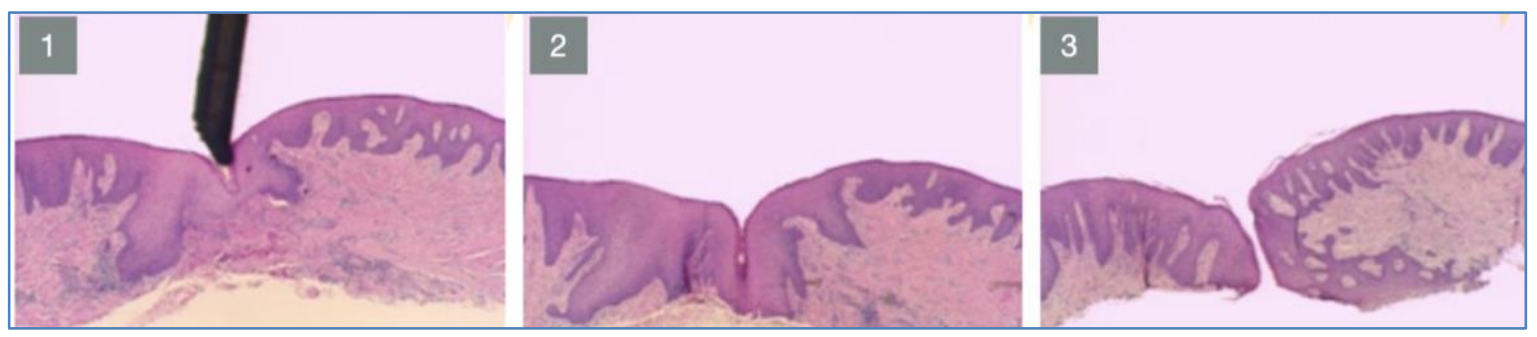

Figure 2. Pathogenetic stages of gingival recession in rat model (Baker et al., 1976)

Three different stages in the genesis of gingival recession have been described in the experiment: 1) Stage I, initial stage where there is no or subclinical inflammation; 2) Stage II, characterized by proliferation of epithelial rete pegs; 3) Stage III, characterized by 
increased epithelial proliferation resulting in loss of connective tissue core and finally leading to the merging of oral and sulcular epithelium resulting in separation and formation of a cleft. According to this model, in the presence of plaque-induced inflammation, a thin marginal soft tissue is more susceptible to complete breakdown than a thick one. This assumption is supported by the evidence that an inflammatory lesion which develops in response to subgingival plaque occupies the connective tissue adjacent to the dentogingival epithelium. Classical measurement suggest that the apical and lateral extension of the inflammatory cell infiltrate is $1.4 \mathrm{~mm}$ on average, rarely exceeding $2 \mathrm{~mm}$ (Waerhaug, 1952). This means that if the free gingiva is voluminous, the inflammatory infiltrate will occupy only a small portion of the connective tissue; however, if it is thin, the entire connective tissue may be engaged. In the latter case, the onset of the inflammatory lesion will lead to the obliteration of the vascular supply and, consequently, to the degeneration of the connective tissue; this is accompanied by the proliferation of epithelial cells from the oral and sulcular epithelium, the zone of connective tissue decreases and it is obliterated by the fusion of these two epithelia.

\subsubsection{Classification}

Several classification systems for gingival recessions have been proposed in the literature, with the aim of creating specific categories including all the relevant information related to diagnosis, prognosis and treatment plan. The main classifications were the following: Sullivan \& Atkins (1968); Mlinek et al (1973); Liu and Solt (1980); Miller (1985); Smith (1997); Nordland \& Tarnow (1998); Mahajan (2010); Cairo (2011); Kumar (2013).

Sullivan \& Atkins (1968) 
This is the first published classification for gingival recessions (Sullivan et al., 1968b). It is based on two different parameters, which include recession depth and recession width, so to identify four different categories: narrow, wide, shallow and deep. No clear measurements were provided by the authors to distinguish the descriptive terms. A modification was proposed by Mlinek in 1973, who introduced a numeric cut-off: shallow defects were defined as the recession $<3 \mathrm{~mm}$, while deep defects were recessions $>3 \mathrm{~mm}$ (Mlinek et al., 1973).

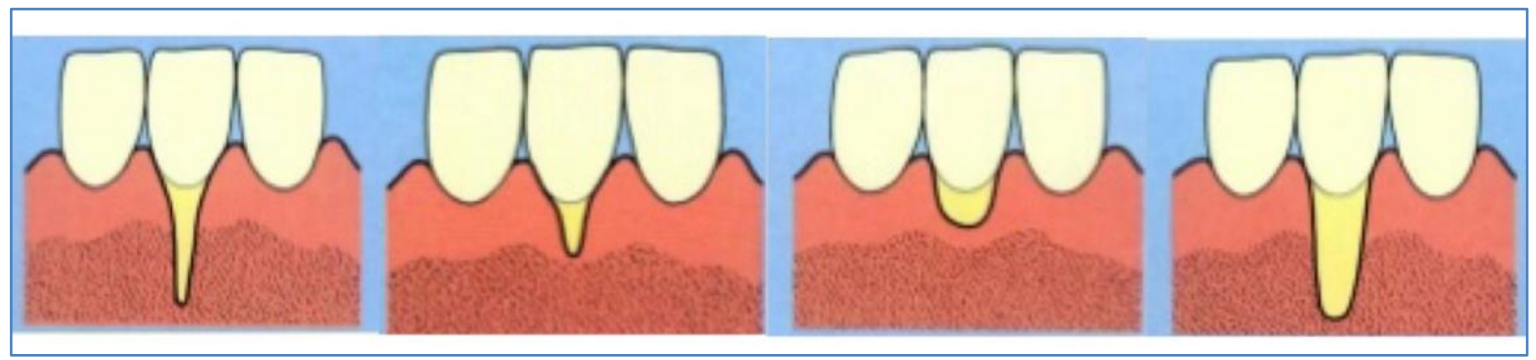

Figure 3. Classification proposed by Sullivan \& Atkins (deep, shallow, wide, narrow)

Miller (1985)

In 1985, Miller proposed a new system based on both level of the gingival margin with respect to the mucogingival junction and the underlying interdental alveolar bone (Miller, 1985). Miller's Classification is still the most widely used of all the classification system world-wide (Pini-Prato, 2011). The innovation is related to the possibility of predicting the final amount of root coverage following a free gingival graft procedure. Four classes of marginal tissue recessions were described (Miller, 1985):

- Class I. Marginal tissue recession, which does not extend to the mucogingival junction (MGJ). There is no periodontal loss (bone or soft tissue) in the inter-dental area, and $100 \%$ root coverage can be anticipated. 
- Class II. Marginal tissue recession, which extends to or beyond the MGJ. There is no periodontal loss (bone or soft tissue) in the inter-dental area, and $100 \%$ root coverage can be anticipated.

- Class III. Marginal tissue recession, which extends to or beyond the MGJ. Bone or soft tissue loss in the interdental area is present or there is a malpositioning of the teeth, which prevents the attempting of $100 \%$ of root coverage. Partial root coverage can be anticipated.

- Class IV. Marginal tissue recession, which extends to or beyond the MGJ. The bone or soft tissue loss in the interdental area and/or malpositioning of teeth is so severe that root coverage cannot be anticipated.

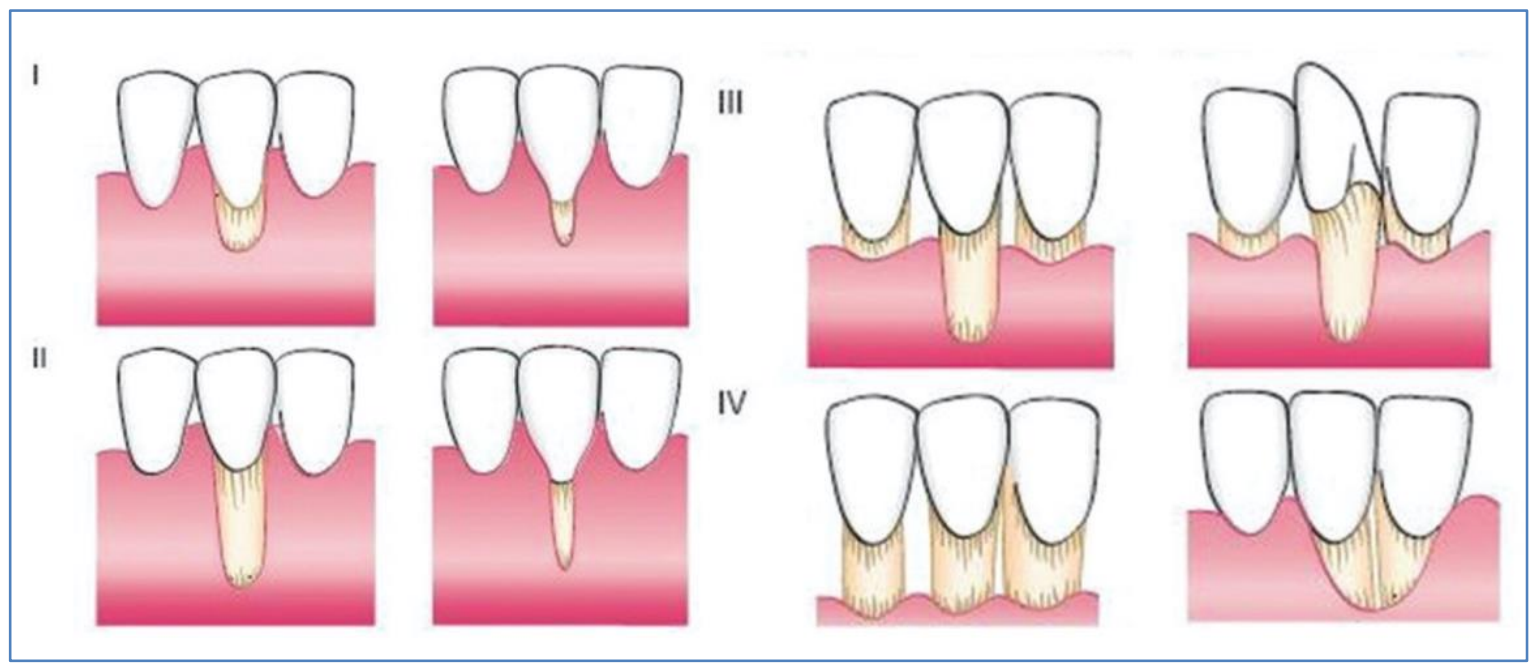

Figure 4. Miller's classification (1985)

Multiple inadequacies have been identified in Miller's classification in terms of both diagnostic and prognostic evaluation (Pini-Prato, 2011): 1) histologic studies showed that a tooth with gingival recession always presents a certain amount of keratinized tissue (free gingiva), so Class II definition is not correct; 2) the differentiation between class III and IV and the classification of tooth malpositioning remain unclear; 3) the classification is not exhaustive because it does not include every case of recession (for example, palatal 
recessions or recessions associated with a missing adjacent tooth cannot be classified); 4) the prognostic anticipation of a certain amount of root coverage in Miller's classification is based on a surgical technique that has nowadays only a limited application for root coverage and does not consider other important factors which have been shown to affect the treatment outcome (patient-related, site-related and technique-related factors).

\section{Smith (1997)}

In 1997, Smith proposed a compound index of recession to assess both vertical and horizontal extent of the defect. The extent of the horizontal component was described with a range from 0 to 5 based on the severity of the CEJ exposure, while the vertical extent of recession was measured in millimeters with a periodontal probe on a range between 0 and 9 (Smith, 1997).

\section{Cairo (2011)}

More recently, Cairo et al introduced a new classification system based on the clinical attachment level at both buccal and interproximal sites and its impact on the final root coverage outcome obtained with different mucogingival techniques (pedicle flaps, free gingival graft, connective tissue grafts, biologics and combinations). Three main types of recession were described:

- Recession Type 1 (RT1): Gingival recession with no loss of interproximal attachment. Interproximal CEJ was clinically not detectable at both mesial and distal aspects of the tooth;

- Recession Type 2 (RT2): Gingival recession associated with loss of interproximal attachment. The amount of interproximal attachment loss (measured from the interproximal CEJ to the depth of the interproximal pocket) was less than or equal 
to the buccal attachment loss (measured from the buccal CEJ to the depth of the buccal pocket);

- Recession Type 3 (RT3): Gingival recession associated with loss of interproximal attachment. The amount of interproximal attachment loss (measured from the interproximal CEJ to the depth of the pocket) was higher than the buccal attachment loss (measured from the buccal CEJ to the depth of the buccal pocket).

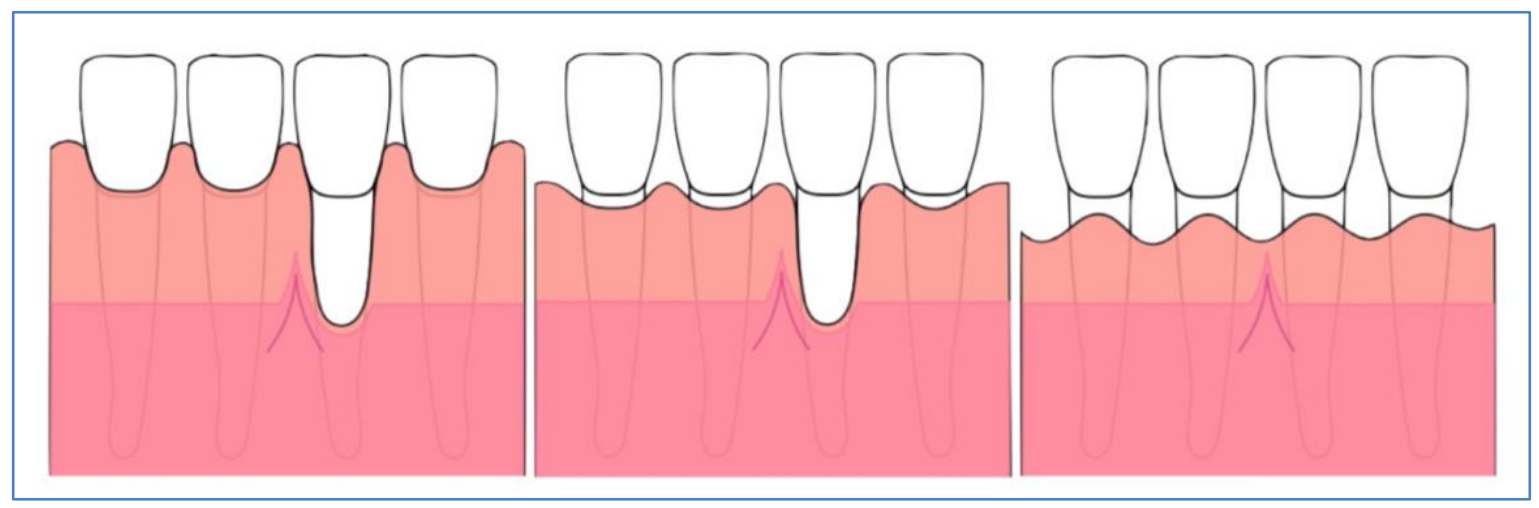

Figure 5. Cairo's classification (2011)

In case mesial and distal site present with different extent of clinical attachment loss, the aspect with the highest clinical attachment loss needs to be considered to identify the recession type. The reproducibility/reliability of the classification system was found to show a very high intraclass correlation coefficient of 0.86 (Cairo et al., 2011). This system was officially accepted in the consensus of 2017 AAP-EFP World Workshop as the new classification for the diagnosis of gingival recession (Caton et al., 2018).

\subsubsection{Diagnosis}

The diagnosis of gingival recession is based on the clinical examination by means of a periodontal probe. The depth of the recession is recorded as the distance in millimeters from the cementoenamel junction, which is more coronal, to the free gingival margin, which is 
more apical (Cortellini et al., 2018). Methods of measuring recession without having to perform a clinical examination have been reported in the literature: these methods are typically used to assess recession as a dichotomous level variable (presence/absence), not to define the recession depth. The two most widely utilized substitutes are dental casts and intraoral photographs. Renkema et al assessed the validity of using dental casts for scoring recessions on 30 adults: the clinical exam and dental cast comparison produced a mean kappa score greater than 0.80, suggesting good agreement (Renkema et al., 2013a). Ruf et al assessed the method error in evaluating gingival recession from intraoral photographs: they conducted replicate analyses of photographs of 10 randomly selected subjects and found a concordance in $80 \%$ of the subjects and $92.5 \%$ of the teeth (Ruf et al., 1998). Allais and Melsen measured the reliability of both of these methods and found that the number of unreadable teeth was larger when performed on casts than when assessed on intraoral photographs (Allais et al., 2003). The authors speculated that the reliability was better for the intraoral photographs compared to the dental casts because the color contrast between the enamel and cementum helped to distinguish the CEJ in the photographs. Also, dental casts may have artifacts around the gingival margin. Trentini et al compared the method of using dental casts and intraoral photographs with the corresponding measurements made during a clinical examination to determine the keratinized tissue width (Trentini et al., 1995). The average difference between the clinical measurements and those calculated using the orthodontic records was small and not statistically significant. The method error was determined to be $0.43 \mathrm{~mm}$ for the clinical measures and $0.32 \mathrm{~mm}$ for the measures calculated from orthodontic records. The reliability of the orthodontic records measurement was slightly greater than the direct clinical measurement, with intra-class correlations of 0.93 and 0.90 , respectively. They concluded that carefully taken photographs and study models provide accurate measures of keratinized tissue width. Furthermore, the method errors 
suggest than an examiner may actually be more reliable measuring from dental casts and intraoral photographs compared to measuring directly in the mouth. This method was also utilized to measure gingival recession as opposed to the width of keratinized gingiva (Djeu et al., 2002). Using dental casts and intraoral slides, examiner reliability was evaluated on 10 randomly selected patients from their study. Paired t-tests indicated that there was no significant difference between the original and repeated values. According to 2017 AAPEFP World Workshop (Cortellini et al., 2018), gingival recession diagnosis is included under mucogingival deformities and conditions around teeth. The diagnosis of gingival recession must include specific determinants: 1) localization (buccal, lingual, interproximal/papillary); 2) severity (Cairo RT1, 2, 3); 3) apico-coronal height; 4) gingival thickness; 5) gingival width; 6) presence of cervical caries or non-carious-cervical lesions; 7) patient esthetic concern (Smile Esthetic Index); 8) presence of hypersensitivity. Moreover, it is recommended to evaluate whether the cementoenamel junction is detectable (Class A) or undetectable (Class B) and whether a root surface concavity is present (Class + , if a cervical step $>0.5 \mathrm{~mm}$ is present; Class -, if the cervical step is absent).

\begin{tabular}{|l|c|l|l|l|l|}
\hline \multicolumn{2}{|l|}{ Gingival site } & \multicolumn{2}{c|}{ Tooth site } \\
\hline & $\begin{array}{c}\text { REC } \\
\text { Depth }\end{array}$ & GT & KTW & $\begin{array}{c}\text { CEJ } \\
(\text { A / B })\end{array}$ & $\begin{array}{c}\text { Step } \\
(+/-)\end{array}$ \\
\hline No recession & & & & & \\
\hline RT1 & & & & & \\
\hline RT2 & & & & & \\
\hline RT3 & & & & & \\
\hline
\end{tabular}

Figure 6. Diagnostic table for gingival recession (Cortellini et al., 2018) 


\subsubsection{Prognosis}

The occurrence of gingival recession is associated with a high risk of progression in the short- and long-term follow up (Cortellini et al., 2018). Matas et al. identified gingival recession in $85 \%$ of dental students; re-examination of the same group of individuals, 10 years later, found a significant increase in the mean number of sites with gingival recession per individual and in mean recession height (Matas et al., 2011). Serino et al. evaluated the prevalence and the progression of attachment loss and gingival recession at buccal tooth surfaces in an adult population sample with a high standard of oral hygiene for 12 years (Serino et al., 1994). In this longitudinal analysis, it was observed that sites with gingival recession showed susceptibility for additional apical displacement of the gingival margin. In particular, it was found that the risk of progression for a gingival recession was directly dependent on the initial depth. Recessions were stratified into two different groups according to the baseline recession depth (REC): shallow recessions, including recession with $\mathrm{REC} \leq 3 \mathrm{~mm}$, and deep recession, including recessions with $\mathrm{REC}>3 \mathrm{~mm}$. According to the stratified data, $67 \%$ of shallow recession sites worsened, $25 \%$ remained stable, $14 \%$ became shallower; $98 \%$ of deep recession sites worsened, $1 \%$ remained stable, $1 \%$ became shallower. These data suggest that the likelihood for a recession to improve spontaneously with time is very low, implying that a surgical correction may be required to prevent further deterioration in the future (Serino et al., 1994). In addition, in the same paper, an association between loss of proximal periodontal support and gingival recession at the buccal surface was noted. Similar findings were presented in a long-term (18 to 35 years) split-mouth study, where periodontal conditions of sites treated with gingival augmentation procedures were compared to untreated homologous contralateral sites (Agudio et al., 2016). Fortyseven patients with 64 sites (test group), with lack of attached gingiva associated with recessions, were treated with free gingival grafts, and 64 contralateral sites, with or without 
recession, were left untreated and served as controls. At the end of the observation period (mean 23.6 years, range 18-35 years), the untreated sites showed a statistically significant tendency for apical migration of the free gingival margin with development of new recessions or progression of existing recession defects (48\% of the cases). However, this increment of recession depth of untreated group was of a small entity $(-0.5 \pm 0.9 \mathrm{~mm})$ and did not impact either periodontal health or tooth survival (Agudio et al., 2016). A recent meta-analysis assessed the long-term outcomes ( $\geq 24$ months) of untreated facial gingival recession defects (L. Chambrone et al., 2016). It was found that a gingival recession experiences a recession depth increase $78.1 \%$ of the time, whereas a decrease or no change is rarer event. The authors concluded that untreated facial gingival recession in subjects with good oral hygiene is highly likely to result in an increase in the recession depth during longterm follow-up (L. Chambrone et al., 2016). However, it was suggested that there is limited evidence that the presence of KT and/or greater gingival thickness decrease the likelihood of a recession depth increase or of development of new gingival recession (Cortellini et al., 2018).

\subsubsection{Treatment}

Root coverage is a successful and predictable procedure in periodontics (Tatakis et al., 2015). Different surgical strategies have been proposed for the correction of gingival recessions, which include free gingival graft, connective tissue grafts, pedicle flaps, guided tissue regeneration with resorbable or non-resorbable membrane. Recent systematic reviews and consensus reports have concluded that connective tissue grafting seems to be the most effective means of root coverage and is the most extensively documented technique (Greenwell et al., 2005). 


\subsection{PERIODONTAL PLASTIC SURGERY FOR ROOT COVERAGE}

\subsubsection{Definition}

The term plastic periodontal surgery includes all surgical procedures aimed at preventing or correcting anatomic, developmental, traumatic or diseased-induced defects of gingiva, alveolar mucosa or bone (J. L. Wennström, 1996).

\subsubsection{Indications}

The main indications for root coverage procedures include: 1) esthetic demands; 2) root hypersensitivity; 3) prevention of root caries and non-carious cervical lesions; 4) patient's discomfort during oral hygiene maneuvers (Cairo, 2017).

\section{Esthetic demands}

A survey of the American Academy of Cosmetic Dentistry (2013) consisting of 659 interviews reported that $89 \%$ of the patients decided to start cosmetic dental treatment in order to improve physical attractiveness and self-esteem (Cortellini et al., 2018). In 2011, Rocha et al showed that when the esthetic perception of smiles was evaluated by 160 dental students, there was a statistically significant difference between smiles with gingival recession and smiles without. In addition, no statistically significant difference in the esthetic perception was found between cases of localized and generalized gingival recession (Rocha et al., 2011). The clinical goal of the recession treatment is to achieve complete root coverage, meaning a location of the gingival margin slightly coronal to the cemento-enamel junction with no residual probing depth and with no detectable inflammation (L. Chambrone et al., 2015). However, the gingival margin position by itself may not ensure a successful esthetic outcome, as poor esthetics can occur in the presence of an irregular profile of the 
gingival margin, poor color matching or scar tissue (Cairo et al., 2009). In this perspective, the final aim of root coverage procedures should be represented by the comprehensive esthetic outcome, not just by the complete root coverage, if esthetic concern was the initial indication for treatment.

\section{Root hypersensitivity}

Dentin hypersensitivity may be a consequence of the cementum damage (e.g. abrasion or erosion) and the exposure of the underlying dentinal surface in a recession site. Al-Wahadni $\&$ Linden demonstrated that gingival recession of $3 \mathrm{~mm}$ or more was the best independent predictor of dentin hypersensitivity (Al-Wahadni et al., 2002). In another study, Costa et al showed that gingival recession was associated with increased dentin hypersensitivity in 1,023 adults aged 35 or older in Brazil (Costa et al., 2014). A multicenter study with 85 subjects demonstrated the benefit of performing root coverage procedures for reduction of sensitivity (Cortellini et al., 2009): at the baseline, approximately $40 \%$ of the subjects reported RS as a reason for seeking treatment and at 6 months after treatment (coronally advanced flap with or without connective tissue graft), the prevalence of root sensitivity reduced to approximately $10 \%$. A recent systematic review (Douglas de Oliveira et al., 2013) analyzed the efficacy of surgical root coverage techniques at reducing cervical dentin hypersensitivity in cases of gingival recession: a reduction in cervical dentin hypersensitivity was reported in all studies reviewed, with a mean percentage of decreased sensitivity of $77.83 \%$. However, since most of the studies had a high risk of bias and cervical dentin hypersensitivity was assessed as a secondary outcome, the authors recommended taking these results with caution and concluded that there is not enough evidence to affirm that surgical root coverage procedures predictably reduce cervical dentin hypersensitivity. 


\section{Root caries or non-carious cervical lesions}

Gingival recession is considered almost certainly a prerequisite for the development of root surface caries (Stamm et al., 1990). Non-carious cervical lesions (NCCLs) are defined as loss of tooth structure at the cementoenamel junction level that is unrelated to dental caries: the prevalence of NCCLs ranges from $11.4 \%$ to $62.2 \%$ and appears to increase with age (Aw et al., 2002). In a sample of 452 adults aged 65 or older, Lawrence et al showed that indicators of poor periodontal status, including gingival recessions, were significantly correlated with an increased risk of root caries development (Lawrence et al., 1995). Additionally, studies that have examined the prevalence of root caries have shown higher levels of lesions in patients with periodontal disease and recession compared to patients without recession (Ravald et al., 1981; Reiker et al., 1999).. The prevalence of tooth deformities associated with gingival recessions is very high (Pini-Prato et al., 2010). PiniPrato found that more than half of the 1,010 screened gingival recessions were associated with tooth deformities: 469 showed an identifiable CEJ without a step on the root surface (Class A-, 46\%); 144 an identifiable CEJ associated with a step (Class A+, 14\%); 244 an unidentifiable CEJ with a step (Class B+, 24\%); and 153 an unidentifiable CEJ without any associated step (Class B-, 15\%). Since the current evidence for the restoration of root caries is poor and data regarding long-term tooth survival are limited (Burrow et al., 2017), treatment of gingival recessions may be justified with the aim of preventing root caries and NCCLs.

\subsubsection{Treatment modalities}

Surgical procedures used in the treatment of gingival recessions can involve the use of pedicle flaps, free soft tissue grafts, additional adjuncts (e.g. PRP, PRF) and combination of the above-mentioned techniques. 


\subsubsection{Flap design}

Pedicle flap procedures can be classified according to the direction in which the flap is moved: 1) rotational flaps, which involve a lateral displacement of the flap (e.g. laterally sliding flap, double papilla flap, oblique rotated flap); 2) advanced flaps, which do not include rotation or lateral movement of the pedicle (e.g. coronally advanced flap, semilunar flap, coronally advanced tunnel).

\section{Laterally positioned flap}

The laterally positioned flap (LPF) was originally introduced by Grupe \& Warren in 1956 as laterally sliding flap: this procedure involves the elevation of a full-thickness flap in a donor site adjacent to the recession defect and its lateral displacement over the recipient site (Harold E. Grupe et al., 1956). The main risk related to this technique is the risk of secondary recession in the donor site. In order to reduce this complication, different modifications have been suggested, for example to perform a para-marginal incision instead of intrasulcular $(\mathrm{H}$. E. Grupe, 1966), or to elevate a split-thickness flap instead of full-thickness (Pfeifer et al., 1971; Staffileno et al., 1966). Variants of the laterally positioned flap include double papilla flap (Cohen et al., 1968), oblique rotational flap (Pennel et al., 1965), rotation flap (Patur, 1977), transpositioned flap (Bahat et al., 1990).

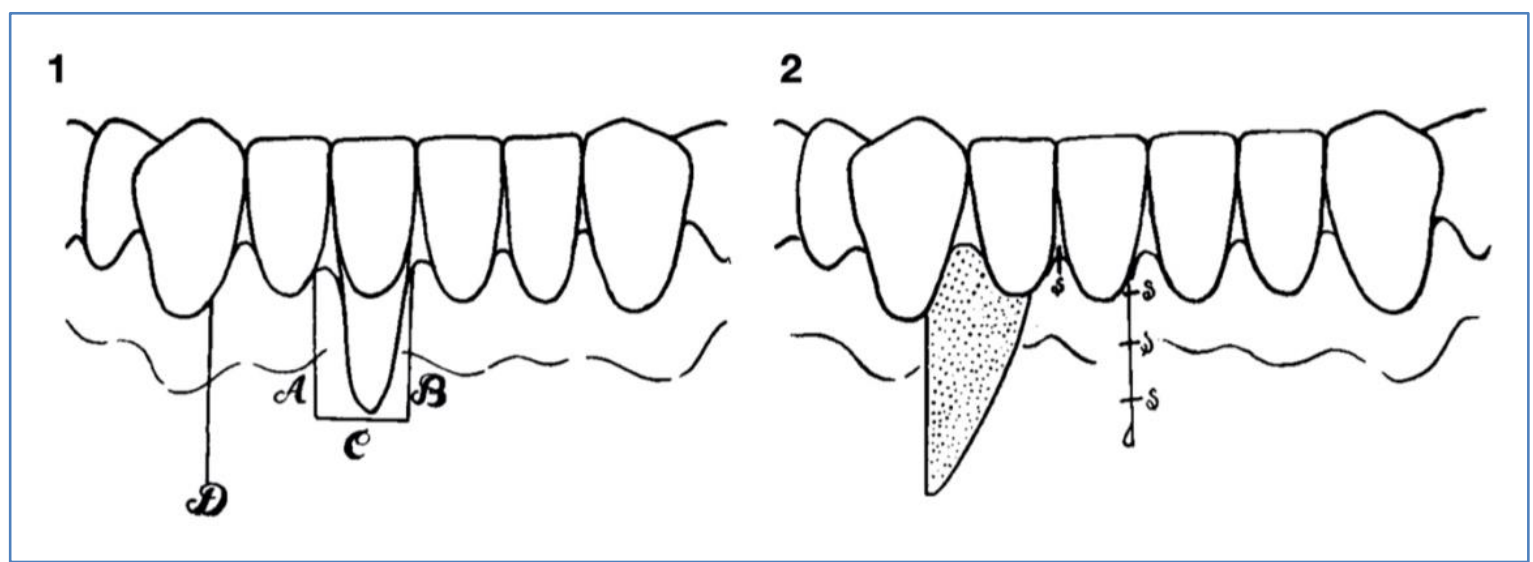

Figure 7. Laterally Positioned Flap (LPF) according to (Harold E. Grupe et al., 1956) 


\section{Coronally advanced flap}

The coronally advanced flap (CAF) procedure was first introduced by Bernimoulin in 1975: it involves a coronal displacement of the soft tissue located apically to the recession to cover the exposed root (J. P. Bernimoulin et al., 1975).

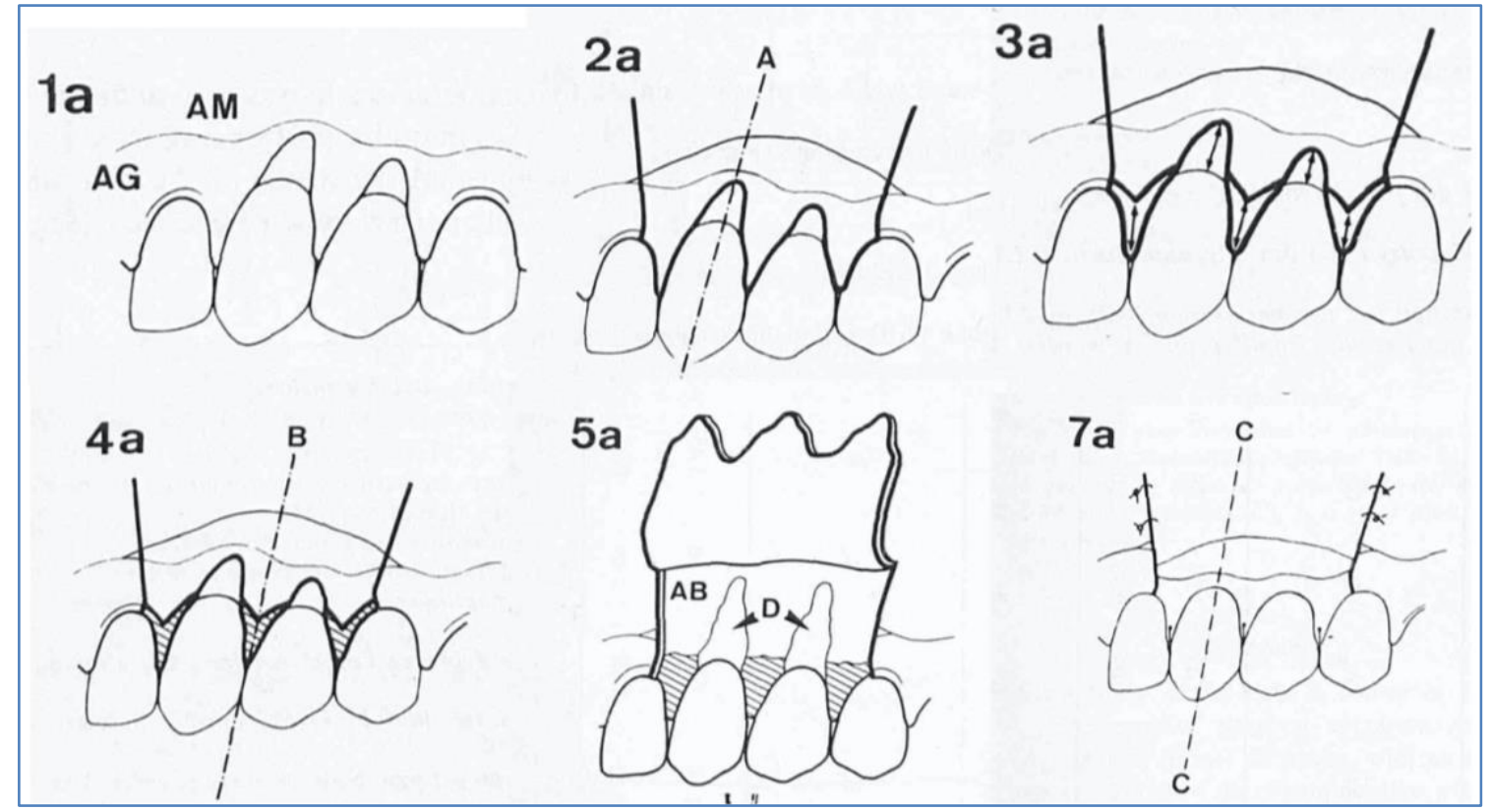

Figure 8. Coronally Advanced Flap (J. P. Bernimoulin et al., 1975)

In the original description, $\mathrm{CAF}$ was performed after a gingival augmentation by means of a free gingival graft. Later, the use of CAF technique was suggested for single recession with no need of previous gingival augmentation if at least $3 \mathrm{~mm}$ of residual keratinized tissue was present (E. P. Allen et al., 1989). Recently, De Sanctis \& Zucchelli proposed a modified coronally advanced flap procedure, characterized by a split-full-split thickness flap elevation (de Sanctis et al., 2007), which can be applied on both single and multiple gingival recessions. The principle of CAF and its variations is based on the elasticity of the alveolar mucosa, which can be stretched in the coronal direction after the detachment of the periosteum. 
Tunneling

Raetze was the first to use an envelope flap technique for covering isolated gingival recessions (Raetzke, 1985). He created a partial-thickness envelope that allowed for the insertion of a connective tissue graft. Later, a modification was proposed by Allen for the treatment of multiple adjacent recessions (A. L. Allen, 1994).

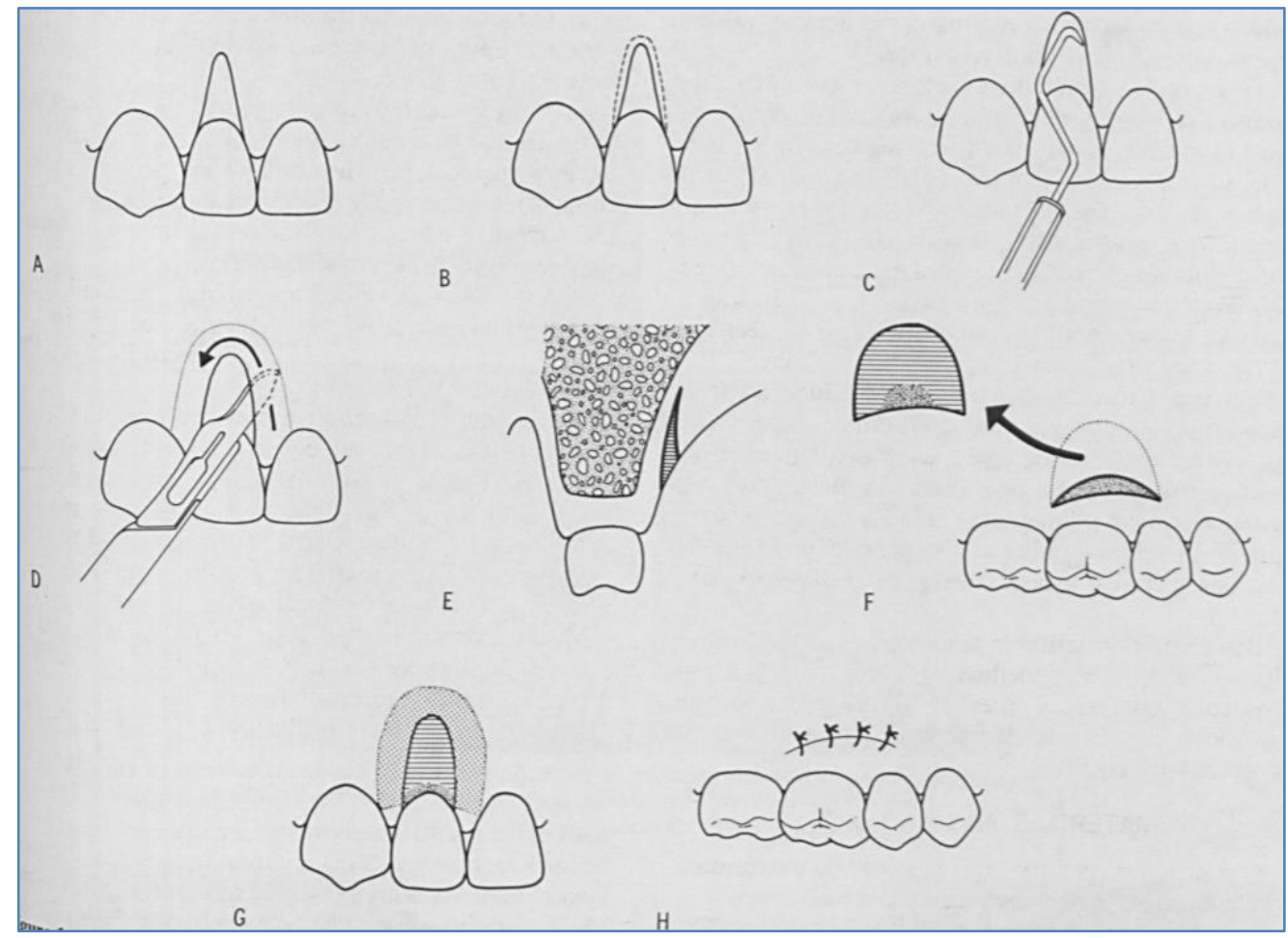

Figure 9. Envelope technique (Raetzke, 1985)

Zabalegui et al. further investigated this approach and coined this technique the "tunnel" approach (Zabalegui et al., 1999). Zuhr et al. introduced a microsurgical approach while designing new instruments (Zuhr et al., 2007). The "coronally advanced modified tunnel technique" proposed by Aroca et al. and comprises a full thickness flap elevation that carefully separates the entire interproximal papillae from bone and places sutures suspended from composite stops at teeth contact points to prevent the flap from collapsing during healing (Aroca et al., 2013). The positive esthetic outcomes are attributable to flap elevation 
that does not dissect the papillae or require vertical releasing incision. A recent systematic review comparing tunnel techniques and CAF showed that CAF seemed to be associated with higher percentage of complete root coverage than was tunnel when the same grafts (connective tissue or acellular dermal matrix) were used in both techniques (Tavelli et al., 2018).

\subsubsection{Soft tissue graft}

The free soft tissue graft procedures can be performed as epithelialized graft or subepithelial connective tissue graft (non-epithelialized).

Free gingival graft

The free gingival graft was initially used to increase the amount of attached gingiva and extend the vestibular depth, but later it was used to attempt coverage of exposed root surfaces (Sullivan et al., 1968a). Great variability in outcome is reported when using free gingival graft for root coverage, probably because of inadequate blood supply when the free gingival flap is placed over an exposed root (Cairo, 2017). The reported amount of root coverage ranges between $11 \%$ and $100 \%$, with a mean of $69 \%$ (Greenwell et al., 2005). Compared with other soft tissue techniques for root coverage, the main disadvantage of free gingival grafts is the unpredictable color match between the grafted tissue and adjacent gingival tissues.

Subepithelial connective tissue graft

The addition of a connective tissue graft (CTG) under the pedicle flap has been suggested as a highly predictable approach to obtain root coverage. The first application of CTG for root coverage was in 1982 by Langer (Langer et al., 1982). Initially, Langer described a 
technique in which the graft was covered by the overlying partial thickness flap. Nelson proposed the use of full thickness flap to cover the CTG (Nelson, 1987). Different flap/graft size modifications have been described, including an 'envelope' approach to position the graft over the exposed root, a repositioned flap with an epithelial-connective and partially exposed graft, and coronally advanced flaps with or without vertical release incisions, or double papilla flaps for covering the connective tissue graft (Cairo, 2017). Studies show mean defect coverage ranging from $57 \%$ to $98 \%$ with a mean for all studies of $84 \%$. (Greenwell et al., 2005)

\subsubsection{Additional technologies}

Other technologies have been used in addition to pedicle flaps and tested for root coverage procedures:

- Enamel matrix derivatives. Enamel matrix derivative plus coronally advanced flap was applied for root coverage to improve the level of the gingival margin and obtain periodontal regeneration along the root (Rasperini et al., 2000). Clinical outcomes from randomized controlled trials showed a mean root coverage ranging from $84 \%$ to $94 \%$ (Cairo et al., 2014). Clinical trials showed that the addition of enamel matrix derivatives to $\mathrm{CAF}$ resulted in more root coverage than did CAF alone, and also produced a significant increase in keratinized tissue (Cairo et al., 2014).

- Collagen matrix (XCM). Histologic analysis revealed that the porcine collagen matrix was able to promote periodontal new attachment and enhance the new cementum formation in experimental recessions in an animal model compared to CAF alone (Vignoletti et al., 2011). CAF + xenogeneic collagen matrix has been shown to achieve greater recession reduction compared to CAF alone in a randomized controlled trial (Jepsen et al., 2013), but less root coverage compared to 
$\mathrm{CAF}+\mathrm{CTG}$ (McGuire et al., 2010). In terms of keratinized tissue gain, the results for CAF+CTG and CAF+ collagen matrix were comparable (McGuire et al., 2010).

- Acellular dermal matrix (ADMG). The mean root coverage obtained with CAF and addition of acellular dermal matrix ranged from $50 \%$ to $97 \%$ and a great variability of the clinical benefits (Cairo et al., 2008), with a mean for all studies of $86 \%$ (Greenwell et al., 2005). A recent systematic review showed no differences between ADMG and CTG for mean root coverage, percent root coverage, and clinical attachment level gain (Gallagher et al., 2017).

- Platelet derivatives. The current evidence about the benefit of platelet derivatives in the treatment of gingival recession is limited. A recent systematic review showed that platelet-rich fibrin membranes does not seem to improve the root coverage, the keratinized tissue width and clinical attachment level of Miller Class I and II gingival recessions (Moraschini et al., 2016).

\subsubsection{Histologic outcomes}

Pedicle flaps

The pattern of healing occurring after a pedicle flap is positioned on a root surface was histologically described in experimental studies on dogs (Wilderman et al., 1965). Four different stages were identified:

- Adaption stage (0-4 days), characterized by a thin fibrin layer interposed between the pedicle flap and the denuded root surface;

- Proliferation stage (4-21 days), characterized by the proliferation of epithelial cells from the coronal edge of the wound and the proliferation of fibroblasts from the periodontal ligament with production of collagen fibers; 
- Attachment stage (27-28 days), characterized by the insertion of collagen fibers into a layer of new cementum in the apical part of the recession;

- Maturation stage (2-3 months), characterized by the continuous formation of collagen fibers.

Histologic studies on monkeys showed that the healing following a pedicle flap results in a combined type of new attachment: it was observed that new connective tissue attachment into new cementum forms in the apical portion of the defect, corresponding to no more than $40 \%$ of the apico-coronal length of the original defect (range 38-44\%), whereas a long junctional epithelium in the most coronal part (Caffesse et al., 1984; Gottlow et al., 1986). The relative amount of connective tissue attachment can be significantly increased by means of enamel matrix derivatives in conjunction with a pedicle flap, as evidenced in an experimental study conducted on recessions in dogs (Sallum et al., 2004).

\section{Soft tissue graft}

As shown in classic histologic studies (Nobuto et al., 1988; Oliver et al., 1968), the healing process of free soft tissue grafts is organized into three different phases:

- Plasmatic circulation (0-3 days), in which the graft is solely dependent upon the diffusion from its host bed;

- Revascularization (2-11 days), in which capillaries proliferate, penetrate into the graft and anastomose with its vasculature;

- Organic union (11-42 days), in which the fibrin clot is organized into a fibrous tissue attachment between the graft and the recipient bed (this process is accompanied by the secondary contraction of the graft).

More recently, the healing and revascularization of the subepithelial connective tissue graft was evaluated histologically in dogs (Guiha et al., 2001). In this study, it was confirmed that 
vascularization of the subepithelial connective tissue graft originates from the periodontal plexus, the supra-periosteal plexus and the overlying flap and is evident by 7 days. In addition, the attachment of the graft to the root surface was mediated by a combination of epithelial downgrowth and connective tissue attachment: in the 28-day specimens, the percentage of epithelial seal varied between $61 \%$ and $77 \%$, whereas the connective tissue attachment ranged between $23 \%$ and $39 \%$. Another finding evidenced in the 60-day specimens is that the potential for new cementum and new bone formation is very limited (Guiha et al., 2001).

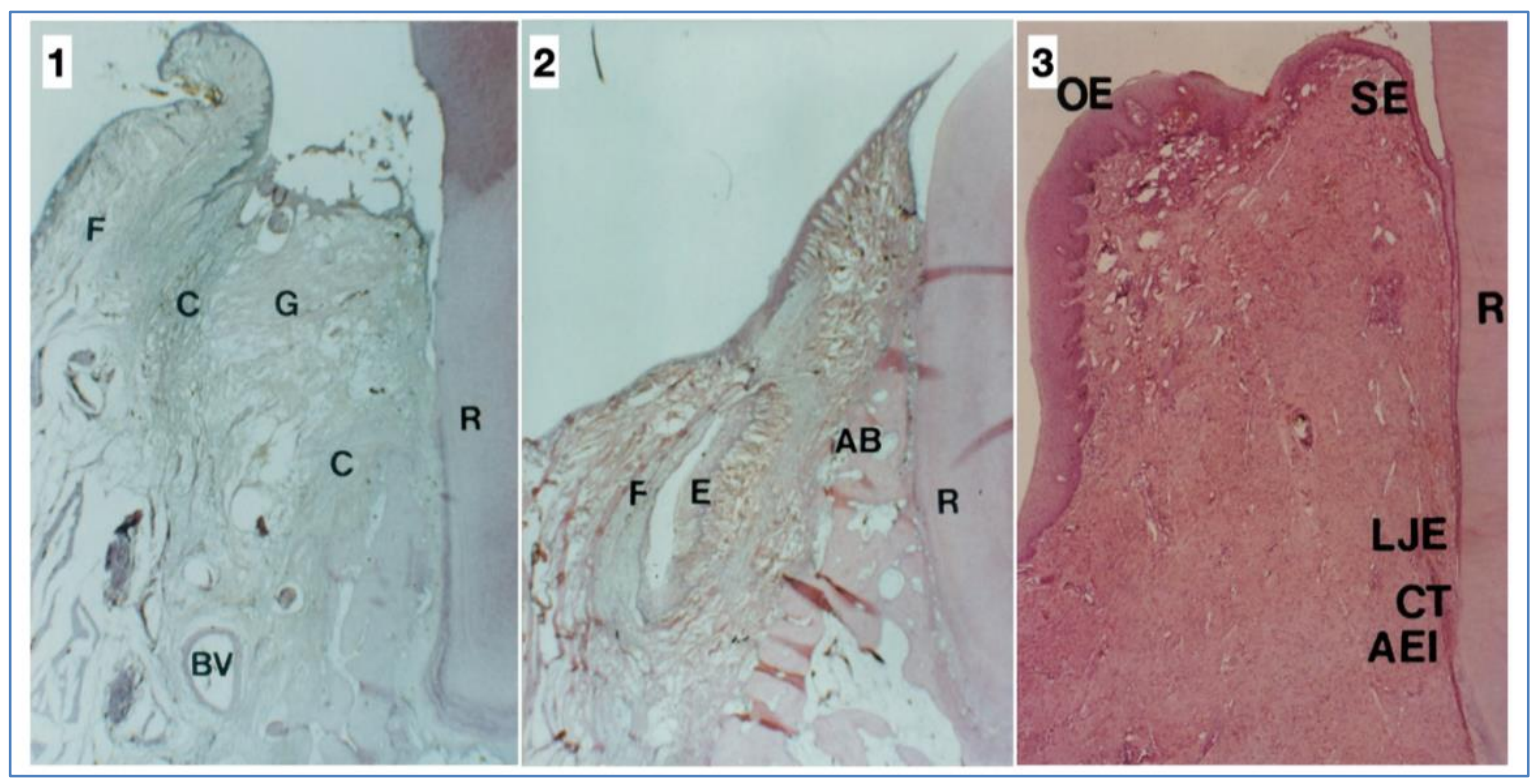

Figure 10. Graft healing at 7 days (1), 14 days (2), 28 days (3) (Guiha et al., 2001)

\subsubsection{Clinical outcomes}

The variability in the treatment outcomes of various root coverage procedures is very large and due to an evident heterogeneity between studies (Cairo et al., 2008; L. Chambrone et al., 2018). In general, with a coronally advanced flap, an average of $70 \%$ root coverage (range 34-87\%) can be expected for RT1 (Miller Class I-II) recessions. Complete root coverage is reached in approximately $35 \%$ of treated cases (15-60\%). This outcome may be 
improved by the adjunctive use of a connective tissue graft or enamel matrix derivatives, with an estimated mean absolute adjunctive effect of $15-25 \%$ for complete root coverage and 13-17\% for reduction in recession depth (Buti et al., 2013; Cairo et al., 2008; L. Chambrone et al., 2018). In fact, in a recent systematic review, according to the results of a Bayesian network meta-analysis, the authors concluded that CAF+CTG can be considered the gold standard in root coverage procedures (Buti et al., 2013). Evidence suggests that guided tissue regeneration does not improve the treatment outcome, since the estimated mean absolute effect is $-17 \%$ for complete root coverage compared to that with a coronally advanced flap alone (Oates et al., 2003; Roccuzzo et al., 2002). In a recent systematic review (Cairo et al., 2014) about the clinical efficacy of the treatment of localized gingival recessions, 51 randomized controlled clinical trials were analyzed, 30 groups of comparisons were identified and 80 meta-analyses were performed. The authors concluded that $\mathrm{CAF}+\mathrm{CTG}$ achieved the best clinical outcomes in single gingival recessions with or without interproximal attachment loss.

\section{Long-term stability}

Subepithelial connective tissue graft with coronally advanced flap has been considered the best and most predictable root coverage procedure not only because of the immediate result obtained at the end of healing process, but also due its stability in the long-term. In 20-year follow up study (G. P. Pini Prato et al., 2018a), it was shown that the root coverage outcome at 1 year was maintained at the end of the observation: in fact, over the course of the study, mean root coverage (MRC) decreased from $74.23 \%$ (1 year) to $67.69 \%$ (20 years). Within maxillary Class I defects, complete root coverage (CRC) at 1-year follow-up was $57.14 \%$ $(\mathrm{n}=12)$ and $47.62 \%(\mathrm{n}=10)$ at the end of study period, whereas MRC decreased from $82.37 \%$ to $77.62 \%$, respectively. Within maxillary Class III recessions, CRC of $20.83 \%$ (n 
= 5) was found at both the 1-year and the 20-year follow-ups. On the other hand, MRC decreased from $66.55 \%$ to $58.18 \%$, respectively (G. P. Pini Prato et al., 2018b). The recurrence of gingival recession appeared associated with sites with attached $\mathrm{KT}<2 \mathrm{~mm}$ (i.e., 5-, 10-, 15- and 20-year follow-ups), to teeth presenting root steps (i.e., 10- and 20year follow-ups), and smoking (i.e., 15-year follow-up). The same group of authors showed that treatment of single recession defects with CAF + CTG provides more gingival stability long term than does treatment with CAF alone (G. P. Pini Prato et al., 2018b), probably because of the increased gingival thickness or larger amount of keratinized tissue, but control of traumatic toothbrushing may be the most important factor in preventing recurrence of gingival recession (Cairo, 2017).

\subsubsection{Predictors of treatment outcome}

Different factors have been shown to influence the degree of root coverage that can be obtained with mucogingival surgical correction. These factors are related to the patient, to the site and to the surgical technique adopted.

\subsubsection{Patient-related factors}

Patient-related factors include:

- Poor plaque control. A suboptimal oral hygiene negatively affects the success of root coverage procedures (Caffesse et al., 1987).

- Smoking. Root coverage has been reported to be less favorable in smokers than nonsmokers in multiple studies about guided tissue regeneration (Trombelli et al., 1997; Zucchelli et al., 1998). Martins et al found that after treatment of Miller Class I and II recessions with a CTG-based procedure, smokers achieve a lower percentage of root coverage $(58.84 \% \pm 13.68 \%)$ compared to non-smokers $(74.73 \% \pm 14.72 \%)$ 
(Martins et al., 2004). Similar findings were reported in another trial, where statistically more recession coverage at 6 months was found in smokers compared to non-smokers (98.3\% versus $82.3 \%$ ) (Erley et al., 2006). Silva et al observed that after coronally advanced flap in Miller Class I recessions lead to complete root coverage in $50 \%$ of the cases in the non-smoking group and in $0 \%$ of the smokers. Again, the intergroup analysis demonstrated that smokers presented a lower percentage of root coverage (69.3\% versus 91.3\%) (Silva et al., 2006). In a systematic review, it was reported that less improvement in gingival recession, less gain in clinical attachment and more incomplete root coverage was observed after CTG-based procedures in smokers than in nonsmokers (L. Chambrone et al., 2009). However, other studies failed to find any detrimental effect exerted by smoking (Harris, 1994; Tolmie et al., 1991).

\subsubsection{Site-related factors}

Multiple site-related factors may affect the root coverage outcome:

- Recession Depth \& Width. The dimensions of the recession defect are negatively associated with the possibility of achieving complete root coverage: the wider and the deeper the recession, the less favorable outcome (Holbrook et al., 1983; G. Pini Prato et al., 1992). Wennstrom \& Zucchelli showed that when defects associated with an initial recession $\geq 5 \mathrm{~mm}$ underwent complete root coverage in only $50 \%$ of the time, compared to $96 \%$ for shallower defects (J. L. Wennström et al., 1996).

- Keratinized Tissue Width. In a study of patients with single recessions found that the deeper the baseline recession and the smaller the amount of apico-coronal keratinized tissue, the lower the probability for complete root coverage and longterm stability of the gingival margin (G. P. Pini Prato et al., 2018b). 
- Interdental Attachment Level. The classification system proposed by Cairo (RT1, 2, 3) was able to predict the final recession reduction with a high level of confidence, thus supporting the importance of analyzing baseline interdental clinical attachment loss to assess the prognosis of gingival recession treatment (Cairo et al., 2011). In case of RT2 and RT3 the root coverage procedure is more challenging and the technique to adopt should be carefully evaluated: studies have shown more than $80 \%$ of gingival recessions with $\leq 3 \mathrm{~mm}$ of interdental bone loss, which were treated with $\mathrm{CAF}+\mathrm{CTG}$, showed complete root coverage, which remained stable for at least 3 years, underscoring the benefit of adding a connective tissue graft in the treatment of interdental bone loss (Cairo et al., 2015). Complete root coverage was also accomplished in $38 \%$ of multiple RT2 recessions treated with a modified tunnel/connective tissue graft technique (Mercado et al., 2019).

- Interdental Papilla. Saletta et al. indicates that the root coverage following CAF procedure in Miller Class I recessions is not significantly correlated to papilla dimension (Saletta et al., 2001), but there was a tendency for complete root coverage to occur more frequently when the papilla was short, suggesting a greater probability of complete root coverage for thick periodontal biotypes with short interdental papillae. Opposite findings were reported by a randomized controlled trial comparing connective tissue graft and acellular dermal matrix under a coronally advanced flap: it was found that papilla height and papilla width were significant positive predictors of root coverage, and that papilla height of $\geq 5 \mathrm{~mm}$ was associated with complete root coverage (Haghighati et al., 2009).

- Presence of NCCLs. The presence of NCCL is associated with a reduced probability for complete root coverage (Pini-Prato et al., 2010). Recently, in a 20-year follow up, it was shown that gingival recessions associated with root steps have a higher 
tendency to relapse after treatment with both $\mathrm{CAF}$ and CAF+CTG (G. P. Pini Prato et al., 2018a).

\subsubsection{Surgical factors}

Factors related to the surgical technique adopted include:

- Flap thickness. It was shown that the thickness of the surgical flap is positively correlated to recession reduction: the critical threshold thickness for complete root coverage was found to be $1.1 \mathrm{~mm}$ (Hwang et al., 2006). A recent randomized controlled clinical trial compared a "split-full-split" thickness flap elevation versus a "split" thickness approach performed during CAF for the treatment of single maxillary recessions (Clementini et al., 2018). After 12 months, complete root coverage was reported in only $35 \%$ of the cases in the split-thickness group compare to $80 \%$ of the test group, indicating a possible benefit of periosteum inclusion on wound healing and flap stability. However, other studies have shown no difference in the treatment outcome between the use of a full-thickness and split-thickness flap (Espinel et al., 1981).

- Flap tension. For coronally advanced flaps, a significant negative association was shown between the magnitude of residual tension in the flap and the amount of recession reduction (G. Pini Prato et al., 2000)) 45\% of sites achieved complete root coverage when the flap was tension-free, whereas only $18 \%$ of the defects achieved complete root coverage when residual tension of the flap was present (mean $6.5 \mathrm{~g}$ ).

- Flap position. The probability of complete root coverage is influenced by the position of the gingival margin relative to the cemento-enamel junction after suturing (G. P. Pini Prato et al., 2005): in particular, this probability is higher if the flap is secured $2 \mathrm{~mm}$ coronal to the CEJ. 
- Connective tissue graft thickness. Some studies indicate that the thickness of the connective tissue graft influences the final root coverage outcome and recommend harvesting a $2 \mathrm{~mm}$ thick graft (Borghetti et al., 1990). However, more recent papers reported different findings. Zucchelli et al failed to find any differences in terms of root coverage outcome when using CAF in conjunction with a graft of $<2 \mathrm{~mm}$ thickness compared to using grafts thicker than $2 \mathrm{~mm}$ (Zucchelli et al., 2014b). Similarly, a recent randomized clinical trial, comparing CTG graft of different thickness (1 mm versus $2 \mathrm{~mm})$, concluded that similar root coverage and similar increase in the width and thickness of keratinized tissue can be achieved at 3 months whether a 1- or 2-mm thick CTG is used (Moisa et al., 2019).

- $\quad$ Root debridement. Some controlled clinical studies have failed to demonstrate any difference in terms of mean root coverage or residual probing depth between teeth that had been root planed or polished only before mucongingival surgery (Oles et al., 1988; Pini-Prato et al., 1999). Zucchelli et al failed to demonstrate any superiority, in terms of root-coverage results, for hand instruments over ultrasonic treatment of the root surface in combination with coronally advanced flap mucogingival surgery (Zucchelli et al., 2009).

- Root conditioning. A recent systematic review (Oliveira et al., 2012) concluded that there is no evidence that root surface biomodification with citric acid, EDTA or laser prior to soft tissue grafting improves the root coverage outcome.

- Microsurgical instruments. A comparison between conventional macro-surgical and a minimally invasive treatment approach, based on the use of magnification system, illumination and micro-instruments, has been performed in a randomized controlled clinical trial (Burkhardt et al., 2005). The study population consisted of 10 patients with bilateral Class I and Class II recessions at maxillary canines. In split-mouth 
design, the defects were randomly selected for recession coverage either by a microsurgical (test) or macro-surgical (control) approach. Immediately after the intervention and after 3 and 7 days of healing, graft vascularization was evaluated through fluorescent angiograms. The results at test sites revealed a vascularization of $8.9( \pm 1.9 \%)$ immediately after the procedure. After 3 days and after 7 days, the vascularization rose to $53.3( \pm 10.5 \%)$ and $84.8( \pm 3.5 \%)$ respectively. The corresponding vascularization at control sites were $7.95( \pm 1.8 \%), 44.5( \pm 5.7 \%)$ and $64.0( \pm 12.3 \%)$ respectively. All these differences between test and control group were found to be statistically significant. Furthermore, the clinical assessment showed a mean root coverage of $99.4( \pm 1.7 \%)$ for the test and $90.8( \pm 12.1 \%)$ for the control sites after the first month of healing. Again, this difference was statistically significant. The percentage of root coverage, both in test and control sites, remained stable during the first year at $98 \%$ and $90 \%$, respectively.

\subsection{FOCUS ON RECESSIONS ON MANDIBULAR ANTERIORS}

\subsubsection{Literature Bias}

According to the latest Cochrane systematic review, evidence indicates a greater gingival recession reduction for subepithelial connective tissue graft (CTG) with coronally advanced flap (CAF) for treating single or multiple gingival recession compared to all the other mucogingival techniques described in the periodontal literature (L. Chambrone et al., 2019). For this reason, the combination of CAF and CTG is considered the "gold-standard" approach for root coverage in both single and multiple recessions (Cairo, 2017). 
However, as highlighted in several reviews, the results of the different studies evaluating the predictability of CAF are being compared without regard to the specific teeth treated (L. Chambrone et al., 2015).

Chambrone et al conducted an individual patient data meta-analysis of randomized controlled clinical trials (RCTs) to evaluate which factors can influence the achievement of complete root coverage (CRC) (L. Chambrone et al., 2012). In the analysis of the data pooled from 22 studies, the authors noted an interesting element related to the tooth location: $407(67.6 \%)$ defects were located in the maxilla and only $59(9.8 \%)$ in the mandible and, for $136(22.6 \%)$ defects, the location was not reported. When the data were stratified according to the tooth type, $257(42.7 \%)$ defects were canines, $149(24.8 \%)$ premolars, 20 (3.3\%) incisors, and $14(2.3 \%)$ molars were treated. For $26(4.3 \%)$ teeth, it was reported only that they were canines or premolars, whereas for 136 teeth $(22.6 \%)$, the tooth type was not informed. This indicates that several clinical studies have investigated only certain areas limited to maxillary canines and premolars.

Recently, the efficacy of coronally advanced flap has been systematically investigated according to the tooth location (Zucchelli et al., 2018). In this systematic review, the authors included eighteen articles reporting 399 localized GRs treated with CAF with or without CTG and/or EMD and concluded that tooth location has a significant influence on the mean root coverage and complete root coverage that can achieved with CAF. Another interesting finding was that only $3.3 \%$ of the outcomes reported for CAF regarded mandibular anterior teeth (mandibular central incisors, lateral incisors and canines). 
Comparing the treatment of maxillary and mandibular gingival recessions, multiple studies reported better clinical outcomes for maxillary teeth (L. A. Chambrone et al., 2009; Hofmänner et al., 2012). In 2006, Chambrone et al evaluated the 6-month clinical outcomes of the combination of a connective tissue graft and a coronally advanced flap performed on 28 patients. Statistically significant differences between maxillary and mandibular recessions were observed for recession depth reduction, complete root coverage, keratinized tissue width and attachment level. In particular, complete root coverage was achieved in $82 \%$ of the maxillary recessions, and only $57 \%$ in the mandibular defects (L. A. Chambrone et al., 2006).

Therefore, it can be speculated that the available information for mean and complete root coverage of $\mathrm{CAF}+\mathrm{CTG}$ reflects the expected results on the maxillary teeth, especially canines and first premolars, and may not be applicable to the other tooth types, in particular mandibular anterior teeth.

Considered the high prevalence of gingival recessions in the mandibular anterior region and the limited data regarding mucogingival treatment in this specific location, it appears useful for the clinician to identify the predictability of root coverage of mandibular anterior teeth and identify which mucogingival procedure can yield to better results, in terms of both clinical parameters and patient-related outcomes. 


\section{AIM}

The general purpose of the present systematic review is to identify which surgical approach provides the best clinical and patient-related outcomes for the treatment of buccal gingival recession on mandibular anterior teeth. The following focused questions were addressed:

FQ1. <What is the effectiveness of different surgical approaches on clinical outcomes in the treatment of buccal gingival recessions on mandibular anterior teeth?>.

FQ2. <What is the efficacy of different surgical approaches on clinical outcomes in the treatment of buccal gingival recessions on mandibular anterior teeth?>.

FQ1. <What is the efficiency of different surgical approaches on patient-centered outcomes in the treatment of buccal gingival recessions on mandibular anterior teeth?>. 


\section{MATERIAL \& METHODS}

\subsection{PROTOCOL DEVELOPMENT AND FOCUSED QUESTION}

The protocol of the present systematic review was prepared a priori in accordance with the Cochrane Handbook for Systematic Reviews of Interventions (J. P. T. Higgins et al., 2011) and the guidelines of Transparent Reporting of Systematic Reviews and Meta-Analyses (PRISMA) (Moher et al., 2009). The following focused question was addressed: “What is the effectiveness, efficacy and efficiency of different surgical approaches on clinical and patient-related outcomes in the treatment of buccal gingival recessions on mandibular anterior teeth?".

\subsection{STUDY SELECTION CRITERIA (PICOS)}

- Population. The population of the studies included in the present systematic review satisfy the following inclusion criteria:

o patients with a diagnosis of single or multiple gingival recession (Miller Class I, II, III or RT1, RT2) on the buccal aspect of mandibular anterior teeth (central incisors, lateral incisors, canines)

o at least 10 patients for each investigated treatment arm;

0 at least 1 gingival recession for per patient;

o patients smoking > 10 cigarettes/day or with uncontrolled systemic conditions were excluded;

o follow-up 3-12 months; 
- Intervention. Any type of mucogingival surgical procedure involving the use of pedicle flaps and/or soft tissue graft (auto-, allo-, xeno-geneic grafts) was included, irrespective of the additional use of biologics (e.g. EMD, rhPDGF-BB, L-PRF) and the adjunctive administration of systemic antibiotics; any procedure involving the use of bone grafting material with or without barrier membranes (guided tissue regeneration) was excluded.

- Comparison (control group): any of the above-mentioned interventions;

- Outcome measures. For each study, data were extracted preferentially for the 6month follow-up visit; if the latter was not available, data related to the 12-month follow up visit were extracted; if this was not performed, the first available followup visit between 3 and 12 months was chosen. The following outcomes were included:

o Primary outcome

- Mean root coverage (mRC), expressed as percentage (\%);

o Secondary outcomes

- Complete root coverage (CRC), expressed in percentage (\%);

- Change in keratinized tissue width $(\Delta \mathrm{KTW})$, expressed in $\mathrm{mm}$;

- Residual recession depth (residual RD), expressed in mm;

- Change in probing depth $(\triangle \mathrm{PPD})$, expressed in mm;

- Residual probing depth (residual PPD), expressed in mm;

- Change in recession width $(\Delta \mathrm{RW})$, expressed in $\mathrm{mm}$;

- Patient-centered outcomes (including type and incidence of adverse effects; type and incidence of post-treatment signs, symptoms and 
complications, i.e., discomfort, edema, bruising, dentine hypersensitivity; perception of esthetics as self-assessed by either the patient or the operator or assessed through ; post-treatment pain level as self-recorded by the patient; type and number of analgesics used in the postoperative period, as self-recorded by the patient; interference with daily activities during the post-treatment period, as self-reported by the patient; overall patient satisfaction with the final result).

- Study design: (i) prospective or retrospective; (ii) randomized controlled trial (RCT), non-randomized controlled trials (CTs), cohort studies, case series; (iii) follow-up of between 3 and 12 months following the intervention(s). Single treatment arms of RCTs, CTs or cohort studies were included for analysis.

\subsection{LITERATURE SEARCH}

Electronic search

A broad literature search was conducted on the Medline database (www.pubmed.com) and Elsevier Scopus (www.scopus.com) up to March 2020. The following MeSH terms were used: ("gingival recession"[MeSH Terms] OR ("gingival"[All Fields] AND "recession"[All Fields]) OR "gingival recession"[All Fields]) AND ("root coverage"[All Fields] OR “mucogingival”[All Fields]) AND (“mandibular" [All Fields] OR "lower" [All Fields] OR "mandibular teeth" [All Fields] OR "lower teeth" [All Fields]). Only full text articles written in the English language were considered. Electronic searches of the websites of related journals, including Journal of Clinical Periodontology, Journal of Periodontal Research, Journal of Periodontology, Journal of Dental Research, International Journal of Periodontics and Restorative Dentistry, was also performed. Finally, previous systematic 
reviews investigating root coverage procedures for gingival recessions were screened for article identification.

\section{Screening methods}

The titles and abstracts of all studies identified through the searches were evaluated independently by two reviewers (M.A. and D.C.), who then selected studies that potentially met the inclusion criteria. After this phase, full-text versions were obtained for the studies that appeared to meet the inclusion criteria or for which the title and abstract provided insufficient information to make a clear decision. Disagreements concerning eligibility were resolved by consensus or, if disagreement persisted, by arbitration through a third reviewer (G.P.S.). The papers that fulfilled all inclusion criteria were processed for data extraction.

\section{Data extraction: characterization of the intervention}

Extracted data included details of the population, intervention, comparison outcome and study characteristics. In particular, the following information were retrieved: study design, population (statistical unit, patient number, defect number), type of soft tissue graft (if any), flap design, treatment outcomes (mRC, CRC, $\triangle \mathrm{KTW}$, residual RD, $\triangle \mathrm{PPD}$, residual PPD, $\Delta \mathrm{RW}$, patient-related outcomes), follow-up.

\section{Quality assessment (risk of bias in individual studies)}

For the included RCTs, methodological quality assessment was performed according to the Revised Cochrane risk-of-bias tool for randomized trials (RoB 2.0) (J. A. C. Sterne et al., 2019). Five main domains for risk of bias were assessed: randomization process, deviations from the intended interventions, missing outcomes, measurement of the outcomes, and selection of the reported result. A risk of bias judgment (among "low risk of bias", "high 
risk of bias" or "some concerns") was assigned to either each domain (depending on the descriptions given for each individual field) or the entire study. For the included nonrandomized studies, methodological quality assessment was performed according to the "Risk of Bias In Non-randomized Studies - of Interventions" (ROBINS-I) (J. A. Sterne et al., 2016). Seven main domains for risk of bias were assessed: bias due to confounding, bias in selection of participants into the study, bias in classification of interventions, bias due to deviations from intended interventions, bias due to missing data, bias in measurement of outcomes, bias in selection of the reported results. A risk of bias judgment (among "low risk of bias", "moderate risk of bias", "serious risk of bias", "critical risk of bias", or "no information") was assigned to either each domain (depending on the descriptions given for each individual field) or the entire study.

\section{Selection of studies and outcome variables for each $F Q$}

- $\quad$ FQ1

- For FQ1, study arms of RCTs, CTs, cohort studies or case series including at least one of the following outcome variables will be analyzed: Mean root coverage (mRC); Complete root coverage (CRC); Change in keratinized tissue width $(\Delta \mathrm{KTW})$; Residual recession depth (residual RD); Change in probing depth $(\triangle \mathrm{PPD})$; Residual probing depth (residual PPD; Change in recession width $(\Delta \mathrm{RW})$.

- $\quad \mathrm{FQ} 2$

- For FQ2, only RCTs comparing two different surgical procedures for at least one of the following outcome variables will be analyzed: Mean root coverage $(\mathrm{mRC})$; Complete root coverage (CRC); Change in keratinized tissue width ( $\triangle \mathrm{KTW}$ ); Residual recession depth (residual RD); Change in probing depth 
$(\triangle \mathrm{PPD})$; Residual probing depth (residual PPD; Change in recession width $(\Delta \mathrm{RW})$.

- $\mathrm{FQ3}$

For FQ1, study arms of RCTs, CTs, cohort studies or case series including at least one of the following outcome variables will be analyzed: type and incidence of adverse effects; type and incidence of post-treatment signs, symptoms and complications, i.e., discomfort, edema, bruising, dentine hypersensitivity; perception of esthetics as self-assessed by either the patient or the operator or assessed through ; post-treatment pain level as selfrecorded by the patient; type and number of analgesics used in the postoperative period, as self-recorded by the patient; interference with daily activities during the post-treatment period, as self-reported by the patient; overall patient satisfaction with the final result.

\subsection{STATISTICAL METHODS}

The studies have been classified according to two different variables: 1) flap design (CAF, TUN, LPF); 2) soft tissue graft (FGG, CTG). A network meta-analysis was performed to estimate the effectiveness of each surgical procedure for each outcome. An arm-based model for multiple treatment comparison with a disconnected network was used as follows:

$$
\begin{gathered}
g\left(p_{i k}\right)=\mu_{k}+v_{i k} \\
\left(v_{i 1}, v_{i 2}, \ldots, v_{i K}\right)^{\mathrm{T}} \sim \operatorname{MVN}\left(0, \Sigma_{K}\right)
\end{gathered}
$$

where $\Sigma_{K}$ is the variance-covariance matrix of the vector of random effects specific to study $i$. The $\mu_{k}$ are treatment-specific parameters reflecting absolute effects. The $\mathrm{R}$ package pcnetmeta was used for calculation (Lin et al., 2017), which performs network metaanalysis using the arm-based model and provides estimates for various effect sizes. This 
package is available from the Comprehensive $\mathrm{R}$ Archive Network (CRAN) at https://CRAN.R-project.org/package=pcnetmeta. It uses the convergence of Markov chain Monte Carlo (MCMC) algorithms for parameter estimation on the R platform through JAGS (Plummer 2003, 2016). JAGS is a program for analyzing Bayesian hierarchical models using MCMC simulation, which is available for diverse computer platforms including Windows and Mac OS X. JAGS was used to generate 4 chains of 100,000 MCMC samples each after 1,100,000 iterations. To evaluate the model fitting, the deviance information criterion (DIC) was reported: a smaller penalized deviance implies a good fitting of the model (J. P. Higgins et al., 2002). The following functions were used:

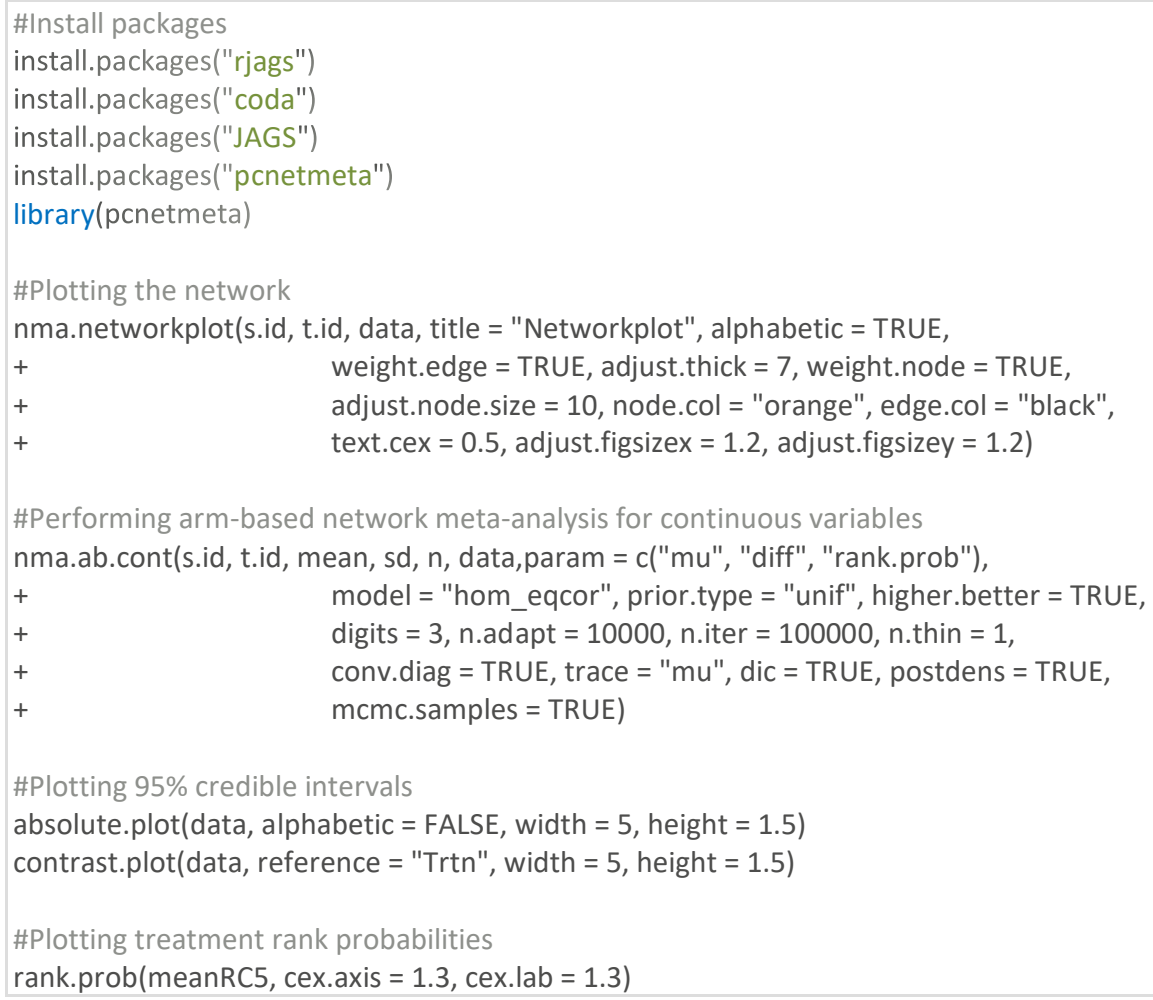

In case of missing or not reported SD from the summary results of a study arm, R software used Bracken's (1992) approach to impute SD using the coefficient of variation from all complete cases.

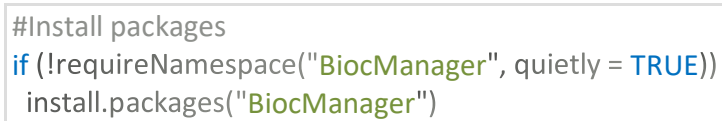


BiocManager::install("EBImage")

install.packages("metagear")

library(metagear)

\#Impute missing SDs

library(data.table)

file_read $=$ fread $($ 'data')

tmp = impute_SD(file_read, 'sd', c('t.id','mean'), method = "Bracken1992",

$+\quad$ range $=3, M=1$ ) 


\section{RESULTS}

\subsection{SUMMARY OF THE LITERATURE SEARCH}

Fig. 11 illustrates the numbers of papers identified, screened, assessed for eligibility and included. One hundred and fifteen were assessed for eligibility following title and abstract screening. Of these, 87 of potential interest were identified. Sixteen articles fulfilled the inclusion criteria and were included for analysis (Figure 11). In total, 23 study arms have been identified for data extraction. The characteristics of the included study are described in Table 1.

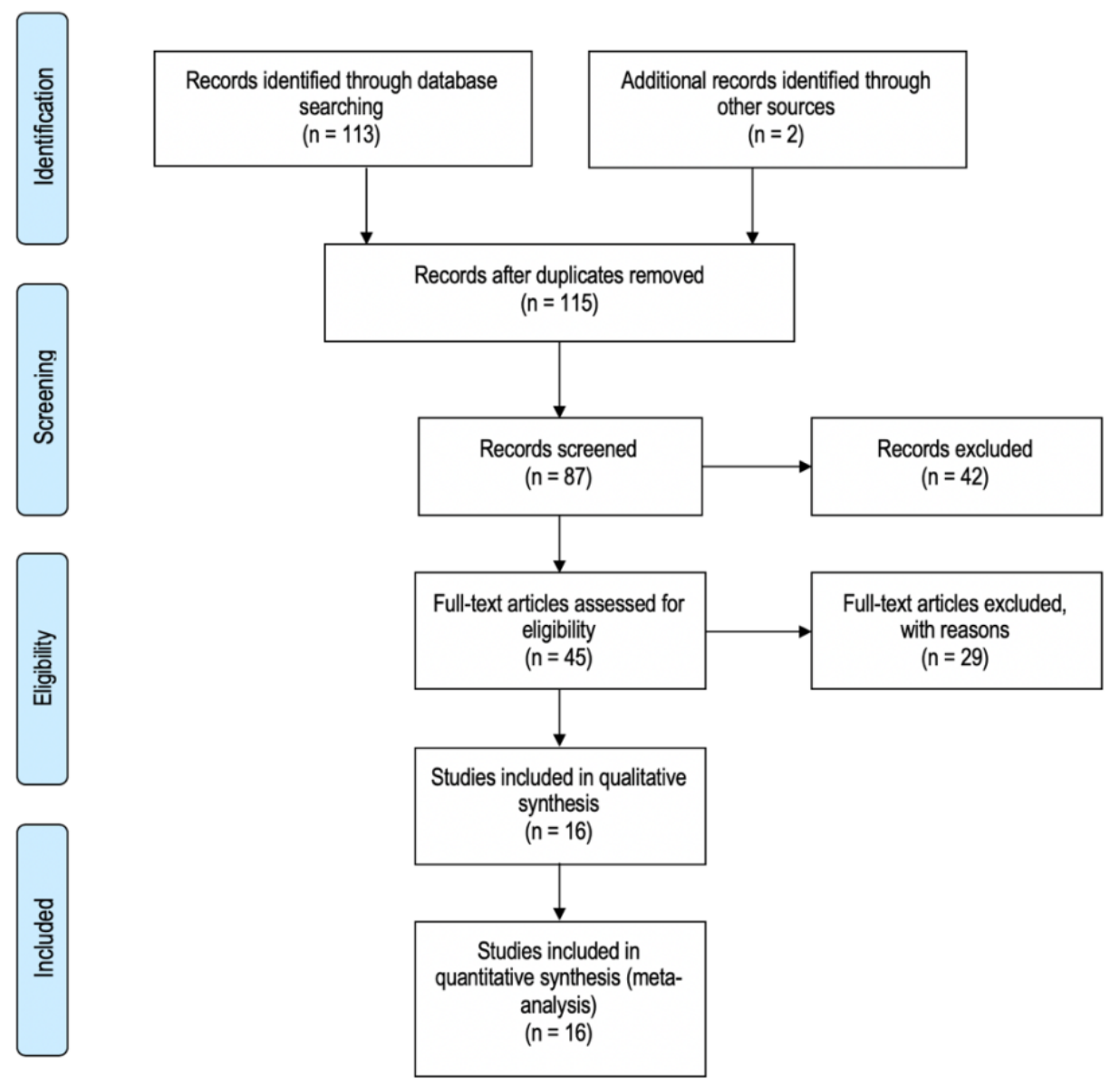

Figure 11. PRISMA flowchart for selection process 
Table 1. Characteristics of included studies

\begin{tabular}{|c|c|c|c|c|c|c|c|c|}
\hline $\begin{array}{l}\text { Author } \\
\text { (Year) }\end{array}$ & $\begin{array}{l}\text { Study } \\
\text { Design }\end{array}$ & $\begin{array}{c}\text { Follow } \\
\text { up } \\
\text { (months) }\end{array}$ & Flap Design & $\begin{array}{l}\text { Reparative } \\
\text { technology }\end{array}$ & $\begin{array}{c}\text { Patients } \\
\text { (n) }\end{array}$ & $\begin{array}{c}\text { Defects } \\
\text { (n) }\end{array}$ & $\begin{array}{c}\text { Recession } \\
\text { type }\end{array}$ & Outcome measures \\
\hline Mercado 2019 & $\mathrm{RCT}$ & 12 & CAF & CTG+EMD & 20 & 79 & RT2 & $\mathrm{mRC}, \mathrm{CRC}, \Delta \mathrm{KT}, \Delta \mathrm{PPD}$ \\
\hline Mercado 2019 & $\mathrm{RCT}$ & 12 & CAF & CTG & 21 & 77 & RT2 & $\mathrm{mRC}, \mathrm{CRC}, \Delta \mathrm{KT}, \Delta \mathrm{PPD}$ \\
\hline Sebaoun 2019 & $\begin{array}{l}\text { Case } \\
\text { series }\end{array}$ & 8 & TUN & CTG & 14 & 18 & RT1, RT2 & $\mathrm{mRC}, \mathrm{CRC}, \Delta \mathrm{RW}, \Delta \mathrm{KT}$ \\
\hline Goyal 2019 & $\begin{array}{l}\text { Case } \\
\text { series }\end{array}$ & 9 & $\begin{array}{c}\text { Partial } \\
\text { thickness }\end{array}$ & FGG & 10 & 12 & RT1 & $\mathrm{mRC}, \Delta \mathrm{RW}, \Delta \mathrm{KT}, \Delta \mathrm{PPD}$ \\
\hline Nunez 2018 & $\begin{array}{l}\text { Case } \\
\text { series }\end{array}$ & 12 & TUN & CTG & 10 & 11 & RT1, RT2 & $\mathrm{mRC}, \mathrm{CRC}, \Delta \mathrm{KT}, \Delta \mathrm{PPD}$ \\
\hline Sculean 2018 & $\begin{array}{l}\text { Case } \\
\text { series }\end{array}$ & 12 & LCT & CTG+EMD & 24 & 24 & RT1, RT2 & $\mathrm{mRC}, \mathrm{CRC}, \Delta \mathrm{KT}$ \\
\hline $\begin{array}{c}\text { Thalmair } \\
2016\end{array}$ & $\begin{array}{l}\text { Case } \\
\text { series }\end{array}$ & 6 & TUN & CTG & 20 & 63 & RT1, RT2 & $\mathrm{mRC}, \mathrm{CRC}, \Delta \mathrm{KT}, \mathrm{GT}$ \\
\hline Rajaram 2015 & CT & 6 & DLSBF & PRF & 10 & 20 & RT1 & $\mathrm{mRC}, \mathrm{CRC}, \Delta \mathrm{RW}, \Delta \mathrm{KT}, \Delta \mathrm{PPD}$ \\
\hline Rajaram 2015 & CT & 6 & DLSBF & l & 10 & 20 & RT1 & $\mathrm{mRC}, \mathrm{CRC}, \Delta \mathrm{RW}, \Delta \mathrm{KT}, \Delta \mathrm{PPD}$ \\
\hline $\begin{array}{c}\text { De Angelis } \\
2015\end{array}$ & $\begin{array}{l}\text { Case } \\
\text { series }\end{array}$ & 12 & LPF & I & 15 & 15 & RT1 & $\mathrm{mRC}, \mathrm{CRC}, \Delta \mathrm{RW}, \Delta \mathrm{PPD}$ \\
\hline
\end{tabular}




\begin{tabular}{|c|c|c|c|c|c|c|c|c|}
\hline $\begin{array}{c}\text { Author } \\
\text { (Year) }\end{array}$ & $\begin{array}{l}\text { Study } \\
\text { Design }\end{array}$ & $\begin{array}{c}\text { Follow } \\
\text { up } \\
\text { (months) }\end{array}$ & Flap Design & $\begin{array}{l}\text { Reparative } \\
\text { technology }\end{array}$ & $\begin{array}{l}\text { Patients } \\
\text { (n) }\end{array}$ & $\begin{array}{l}\text { Defects } \\
\text { (n) }\end{array}$ & $\begin{array}{c}\text { Recession } \\
\text { type }\end{array}$ & Outcome measures \\
\hline Rubins 2014 & $\begin{array}{c}\text { Case } \\
\text { series }\end{array}$ & 6 & CAF & CTG & 11 & 11 & RT1 & $\mathrm{mRC}, \Delta \mathrm{RW}, \Delta \mathrm{KT}, \Delta \mathrm{PPD}$ \\
\hline $\begin{array}{c}\text { Zucchelli } \\
2014\end{array}$ & RCT & 12 & CAF & CTG+EMD & 25 & 25 & RT1 & $\mathrm{mRC}, \mathrm{CRC}, \Delta \mathrm{KT}, \Delta \mathrm{PPD}, \mathrm{GT}$ \\
\hline $\begin{array}{c}\text { Zucchelli } \\
2014\end{array}$ & RCT & 12 & V-CAF & CTG+EMD & 25 & 25 & RT1 & $\mathrm{mRC}, \mathrm{CRC}, \Delta \mathrm{KT}, \Delta \mathrm{PPD}, \mathrm{GT}$ \\
\hline Sculean 2014 & $\begin{array}{l}\text { Case } \\
\text { series }\end{array}$ & 12 & MCAT & CTG+EMD & 16 & 16 & RT1 & $\mathrm{mRC}, \mathrm{CRC}, \Delta \mathrm{KT}, \Delta \mathrm{PPD}$ \\
\hline Singhal 2013 & $\mathrm{RCT}$ & 3 & LPF & I & 11 & 11 & RT1 & $\mathrm{mRC}, \Delta \mathrm{KT}$ \\
\hline Singhal 2013 & RCT & 3 & $\begin{array}{c}\text { Partial } \\
\text { thickness }\end{array}$ & FGG & 11 & 11 & RT1 & $\mathrm{mRC}, \Delta \mathrm{KT}$ \\
\hline Nart 2012 & $\begin{array}{l}\text { Case } \\
\text { series }\end{array}$ & 12 & CAF & CTG & 10 & 14 & RT1, RT2 & $\mathrm{mRC}, \mathrm{CRC}, \Delta \mathrm{KT}$ \\
\hline Baghele 2012 & $\mathrm{CT}$ & 4 & LPF & I & 10 & 10 & RT1 & $\mathrm{mRC}, \Delta \mathrm{RW}, \Delta \mathrm{KT}, \Delta \mathrm{PPD}$ \\
\hline Baghele 2012 & $\mathrm{CT}$ & 4 & CAF & CTG & 10 & 10 & RT1 & $\mathrm{mRC}, \Delta \mathrm{RW}, \Delta \mathrm{KT}, \Delta \mathrm{PPD}$ \\
\hline $\begin{array}{l}\text { Cortellini } \\
2012\end{array}$ & $\begin{array}{l}\text { Case } \\
\text { series }\end{array}$ & 12 & $\begin{array}{c}\text { Partial } \\
\text { thickness }\end{array}$ & FGG & 12 & 12 & RT1 & $\mathrm{mRC}, \mathrm{CRC}, \Delta \mathrm{KT}$ \\
\hline
\end{tabular}




\begin{tabular}{|c|c|c|c|c|c|c|c|c|}
\hline $\begin{array}{c}\text { Author } \\
\text { (Year) }\end{array}$ & $\begin{array}{c}\text { Study } \\
\text { Design }\end{array}$ & $\begin{array}{c}\text { Follow } \\
\text { up } \\
\text { (months) }\end{array}$ & Flap Design & $\begin{array}{c}\text { Reparative } \\
\text { technology }\end{array}$ & $\begin{array}{c}\text { Patients } \\
\text { (n) }\end{array}$ & $\begin{array}{c}\text { Defects } \\
\text { (n) }\end{array}$ & $\begin{array}{c}\text { Recession } \\
\text { type }\end{array}$ & Outcome measures \\
\hline Harris 2006 & CT & 3 & CAF & CTG & 21 & 41 & RT1 & $\mathrm{mRC}, \mathrm{CRC}, \Delta \mathrm{KT}, \Delta \mathrm{PPD}$ \\
\hline Harris 2006 & $\mathrm{CT}$ & 3 & $\mathrm{DP}$ & $\mathrm{CTG}$ & 21 & 39 & $\mathrm{RT} 1$ & $\mathrm{mRC}, \mathrm{CRC}, \Delta \mathrm{KT}, \Delta \mathrm{PPD}$ \\
\hline Harris 2006 & $\mathrm{CT}$ & 3 & TUN-LAT & $\mathrm{CTG}$ & 21 & 38 & $\mathrm{RT} 1$ & $\mathrm{mRC}, \mathrm{CRC}, \Delta \mathrm{KT}, \Delta \mathrm{PPD}$ \\
\hline
\end{tabular}




\subsection{QUALITATIVE ANALYSIS}

\subsubsection{Study design}

Among the selected articles, 7 are controlled clinical trials, of which 3 have a randomized design, whereas 4 have a non-randomized design. The other 10 papers are prospective case series.

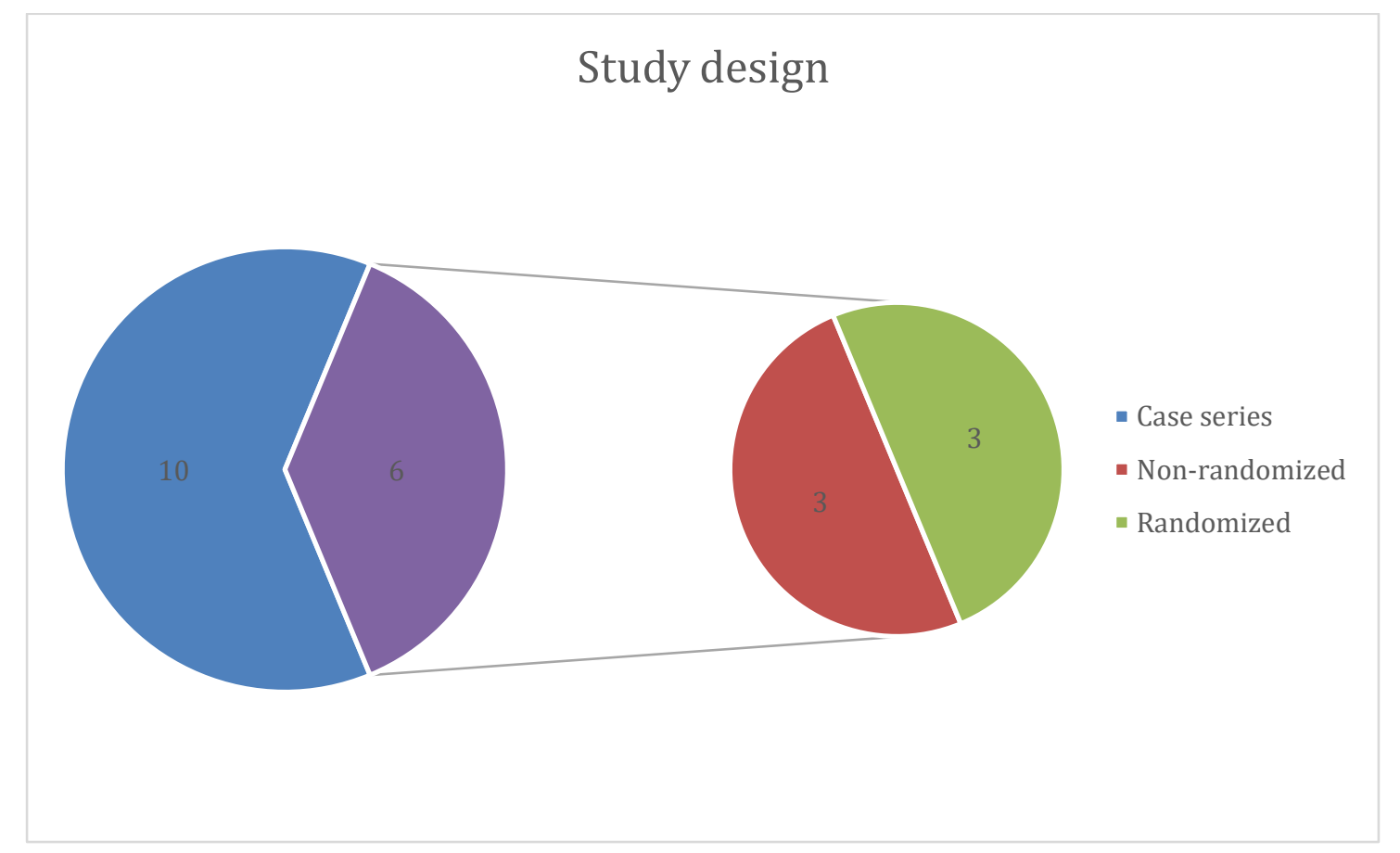

Figure 12. Study design

\subsubsection{Follow-up}

The average follow-up period ranges from 3 to 12 months, with a median of 6 months and a mean of $7.86( \pm 3.77)$ months. In particular, data extraction was based on the 3-month visit for 2 studies (Singhal 2013, Harris 2006), on the 4-month visit for 1 study (Baghele 2012), on the 6-month visit for 4 studies (Akcan 2018, Thalmair 2016, Rajaram 2015, Rubins 2014), on the 8-month visit for 1 study (Sebaoun 2019), on the 9-month visit for 1 study (Goyal 2019), and on the 12-month for 8 studies (Mercado 2019, Nunez 2018, Sculean 2018, De Angelis 2015, Zucchelli 2014, Sculean 2014, Nart 2012, Cortellini 2012). 


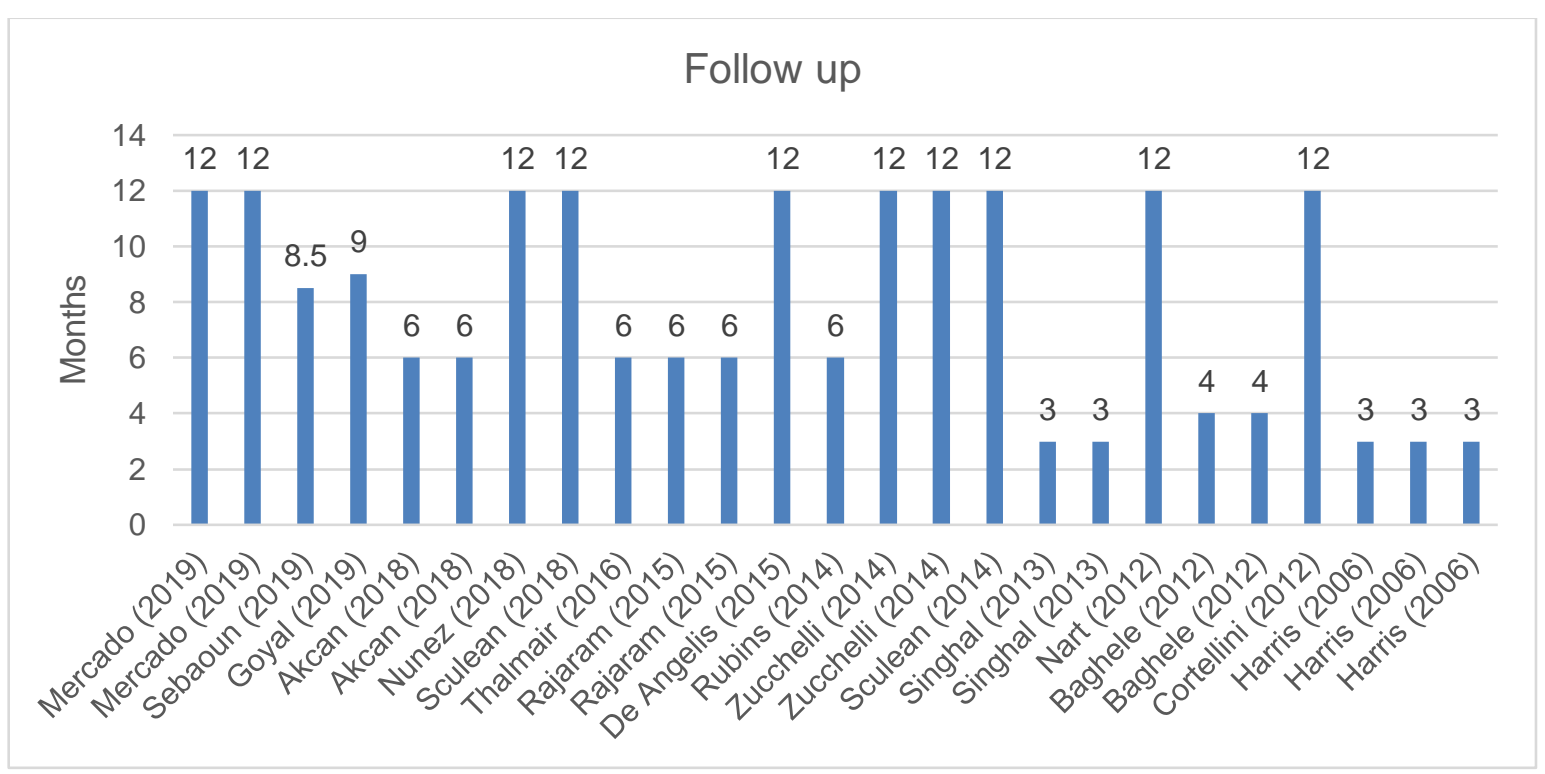

Figure 13. Follow up

\subsubsection{Population}

The number of patients included in the different studies ranges between 10 and 25, with a mean of $15.56( \pm 5.41)$. The average age is $31.75( \pm 6.65)$ years, with a minimum of 21.5 and a maximum of 44.3 years. In 13 studies, gender is specified, whereas this datum is not reported in the other 4 papers: in particular, a higher number of females has been analyzed compared to males (average of $11.05 \pm 4.84$ for females and $4.72 \pm 4.23$ for males).

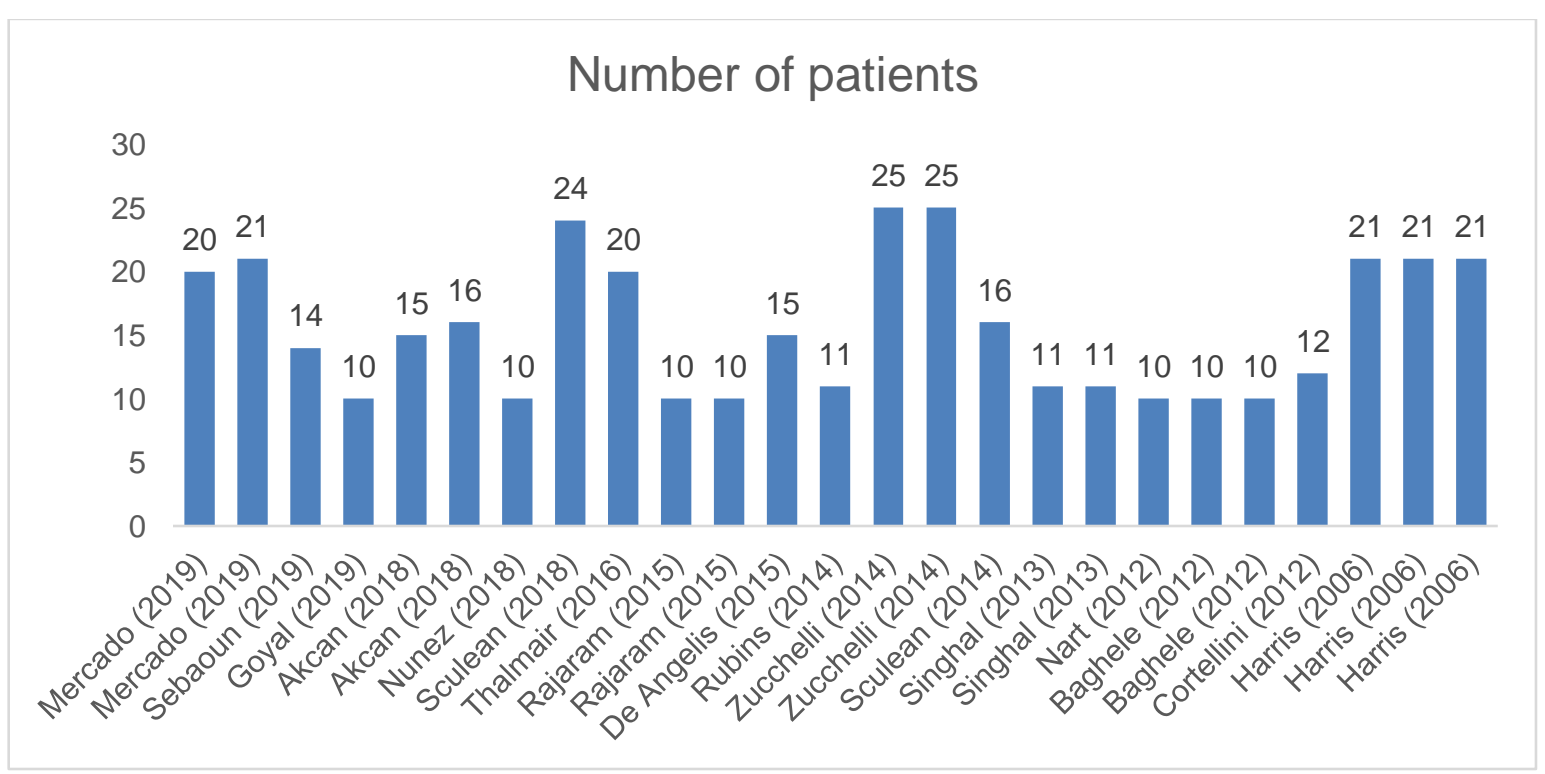

Figure 14. Number of patients 


\subsubsection{Defect characteristics}

The average number of recessions defects was $25.68( \pm 20.10)$, with a minimum of 10 and a maximum of 79 . According to the severity, Only RT1 recessions were included in the majority of the treatment arms (16), whereas both RT1 and RT2 were included in 7 treatment arms.

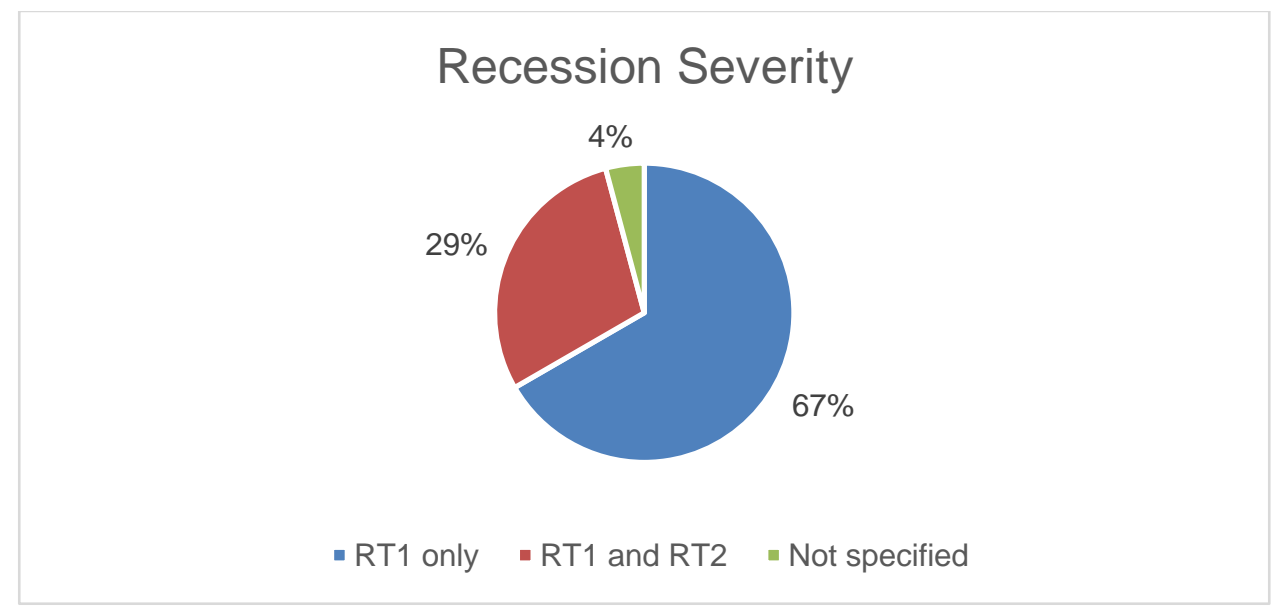

Figure 15. Study distribution based on recession type

The majority of the study arms included only isolated defects (12), whereas 9 arms included both single and multiple recessions and 1 included multiple recessions only; however, in three study arms (Mercado 2019, Goyal 2019) this information is missing.

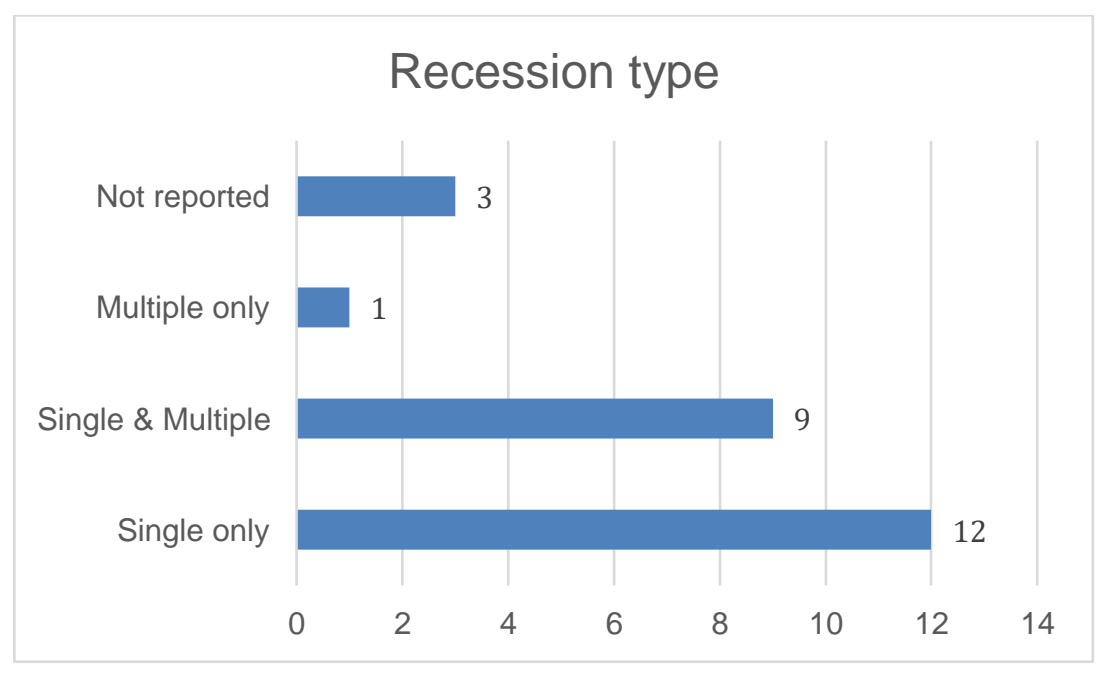

Figure 16. Study classification based on single or multiple recessions 
As for location, mandibular incisors (both centrals and laterals) were the most frequently treated teeth, whereas recessions on mandibular canines were included in only 7 study arms. Only in 1 study (Rubins 2014), the specific tooth location of the recessions included is not reported.

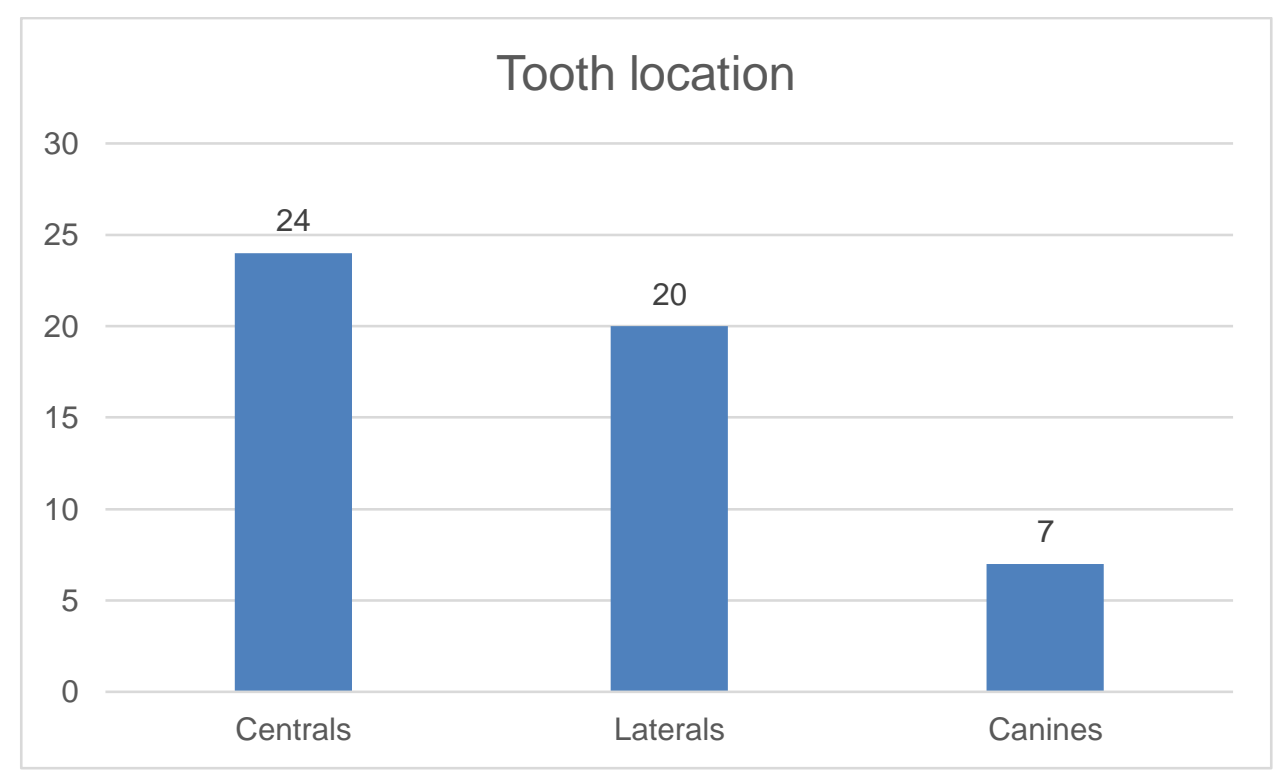

Figure 17. Gingival recessions distributed per tooth location

\subsubsection{Root coverage procedures}

The majority of the treatment arms investigate the effectiveness of root coverage procedures based on the use of CTG, whereas in 10 study arms other approaches have been applied. In particular, the latter group includes FGG in 5 study arms, PRF in 1 study arms and no reparative device in 4 study arms. As for flap design, 8 study arms analyze the use of coronally advanced flap and variants, 6 the use of laterally positioned flap and variants, 5 tunnel and variants. In summary, 8 different main treatments have been identified:

1. CAF + CTG in 5 study arms (Mercado 2019, Rubins 2014, Nart 2012, Baghele 2012, Harris 2006)

2. CAF + CTG + EMD in 3 study arms (Mercado 2019, Zucchelli 2014, Zucchelli 2014) 
3. TUN + CTG in 4 study arms (Sebaoun 2019, Nunez 2018, Thalmair 2016, Harris 2006)

4. TUN + CTG + EMD in 2 study arms (Sculean 2018, Sculean 2014)

5. LPF alone in 4 study arms (Rajaram 2015, De Angelis 2015, Singhal 2013, Baghele 2012)

6. LPF + PRF in 1 study arms (Rajaram 2015)

7. $\mathrm{LPF}+\mathrm{CTG}$ in 1 study arms (Harris 2006)

8. Partial thickness bed + FGG in 5 study arms (Goyal 2019, Akcan 2018, Akcan 2018, Singhal 2013, Cortellini 2012)

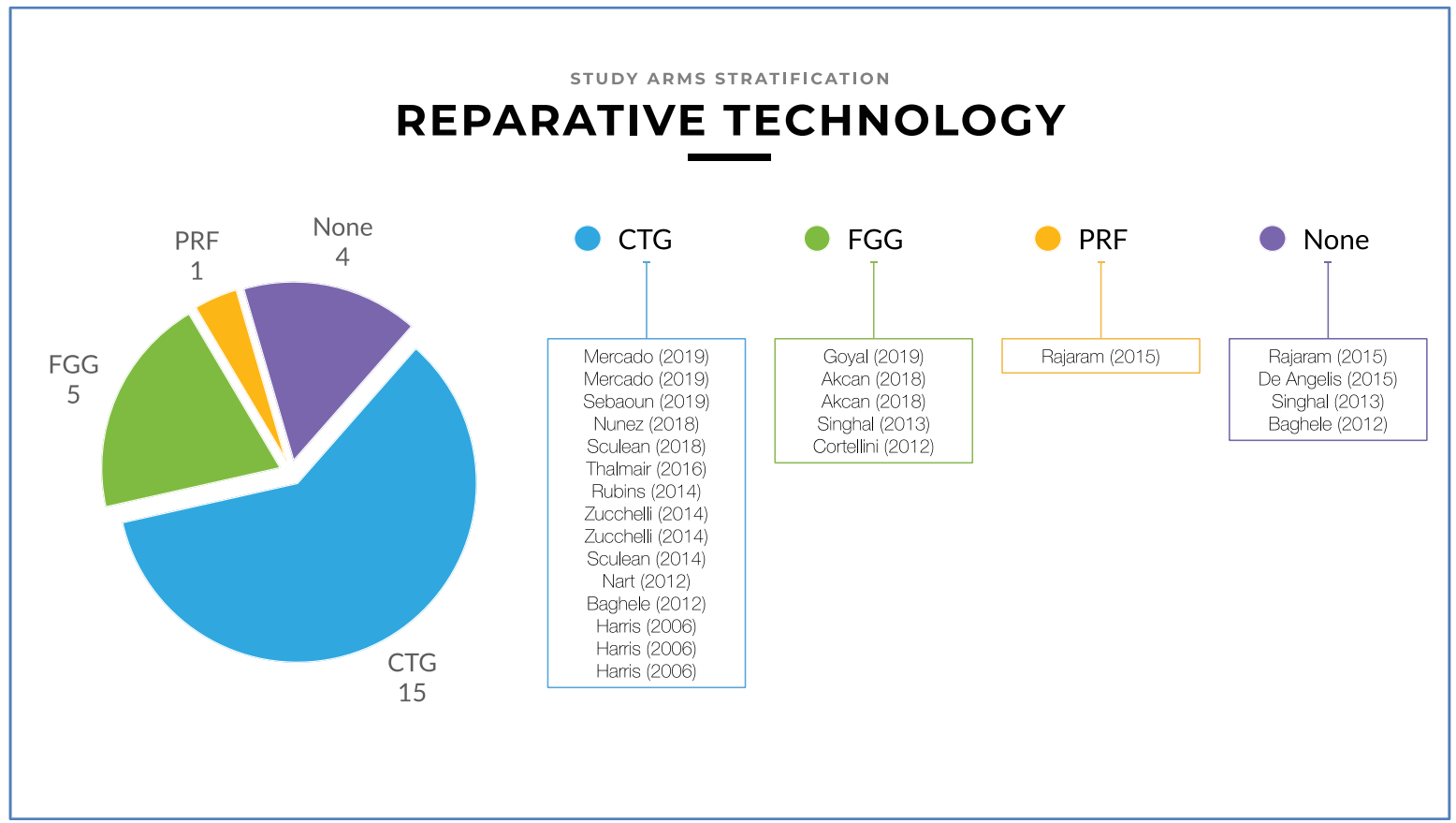

Figure 18. Study arm classification based on reparative technology 


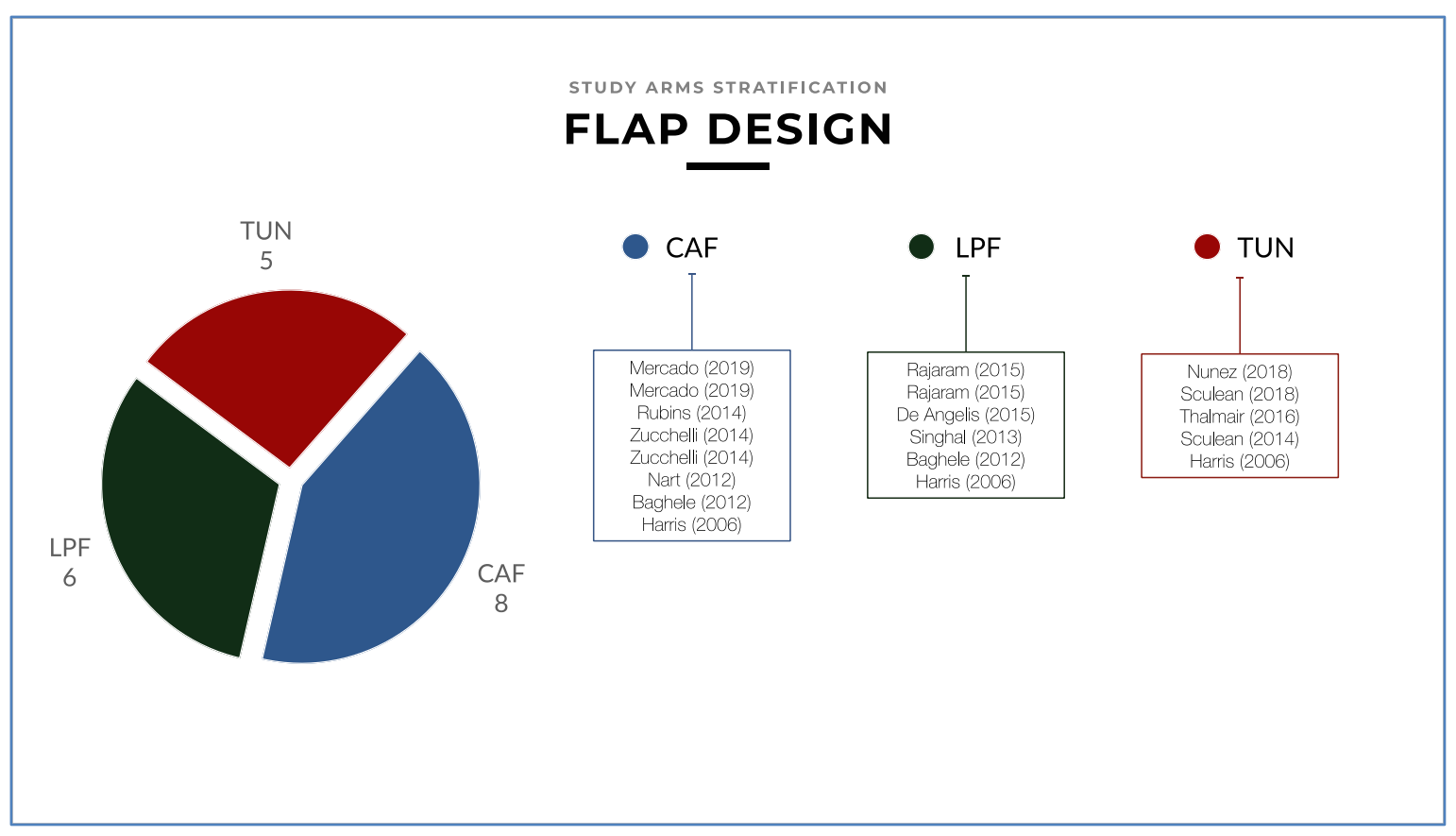

Figure 19. Study arm classification based on flap design

\subsection{QUANTITATIVE ANALYSIS}

\subsubsection{Treatment groups}

The above-mentioned procedures have been categorized into 5 broad treatment groups, according to the flap design (CAF, TUN, LPF) and the use and type of soft tissue graft (none, CTG, FGG):

1. CAF + CTG. This group includes all the treatment arms using use a coronally advanced flap (and its variants) and a connective tissue graft, with or without the additional use of adjuncts ( \pm EMD, rhPDGF-BB). In particular, 8 study arms were included in this category (Mercado 2019, Rubins 2014, Zucchelli 2014, Nart 2012, Baghele 2012, Harris 2006).

2. TUN + CTG. This group includes all the treatment arms using use a tunnel procedure (and its variants) and a connective tissue graft, with or without the 
additional use of adjuncts ( \pm EMD). In particular, 6 study arms were included in this category (Sebaoun 2019, Nunez 2018, Sculean 2018, Thalmair 2016, Sculean 2014, Harris 2006).

3. LPF + CTG. This group includes all the treatment arms using use a laterally positioned flap (and its variants) and a connective tissue graft. In particular, only 1 study was included in this category (Harris 2006)

4. LPF alone. This group includes all the treatment arms using use a laterally positioned flap (and its variants) alone. No distinction was made if an adjunct other than soft tissue graft was used (e.g. PDGF). In particular, 5 study arms were included in this group (Rajaram 2015, De Angelis 2015, Singhal 2013, Baghele 2012).

5. FGG. This group includes all the treatment arms using use a partial thickness flap with a free gingival graft. In particular, 3 study arms were included in this category (Goyal 2019, Singhal 2013, Cortellini 2012). In this group, Akcan 2018 was excluded since no information was available about the type of recessions treated (whether RT3 recessions were included in the analysis).

\begin{tabular}{|l|c|c|c|c|c|c|}
\hline & CAF+CTG & TUN+CTG & LPF+CTG & LPF alone & FGG & Total \\
\hline $\begin{array}{l}\text { Number of } \\
\text { study arms }\end{array}$ & 8 & 6 & 1 & 5 & 3 & 23 \\
\hline
\end{tabular}

Figure 20. Distribution of study arms

The results of treatment comparison from the network meta-anslysis model are reported separately for each treatment outcome. 


\subsubsection{Mean root coverage $(\mathrm{mRC})$}

For mRC, the dataset consisted of 23 study arms, in particular 8 for CAF+CTG, 6 for TUN+CTG, 1 for LPF+CTG, 5 for LPF alone and 3 for FGG. The network plot is shown in

Fig. 21. The network meta-analysis showed the following results:

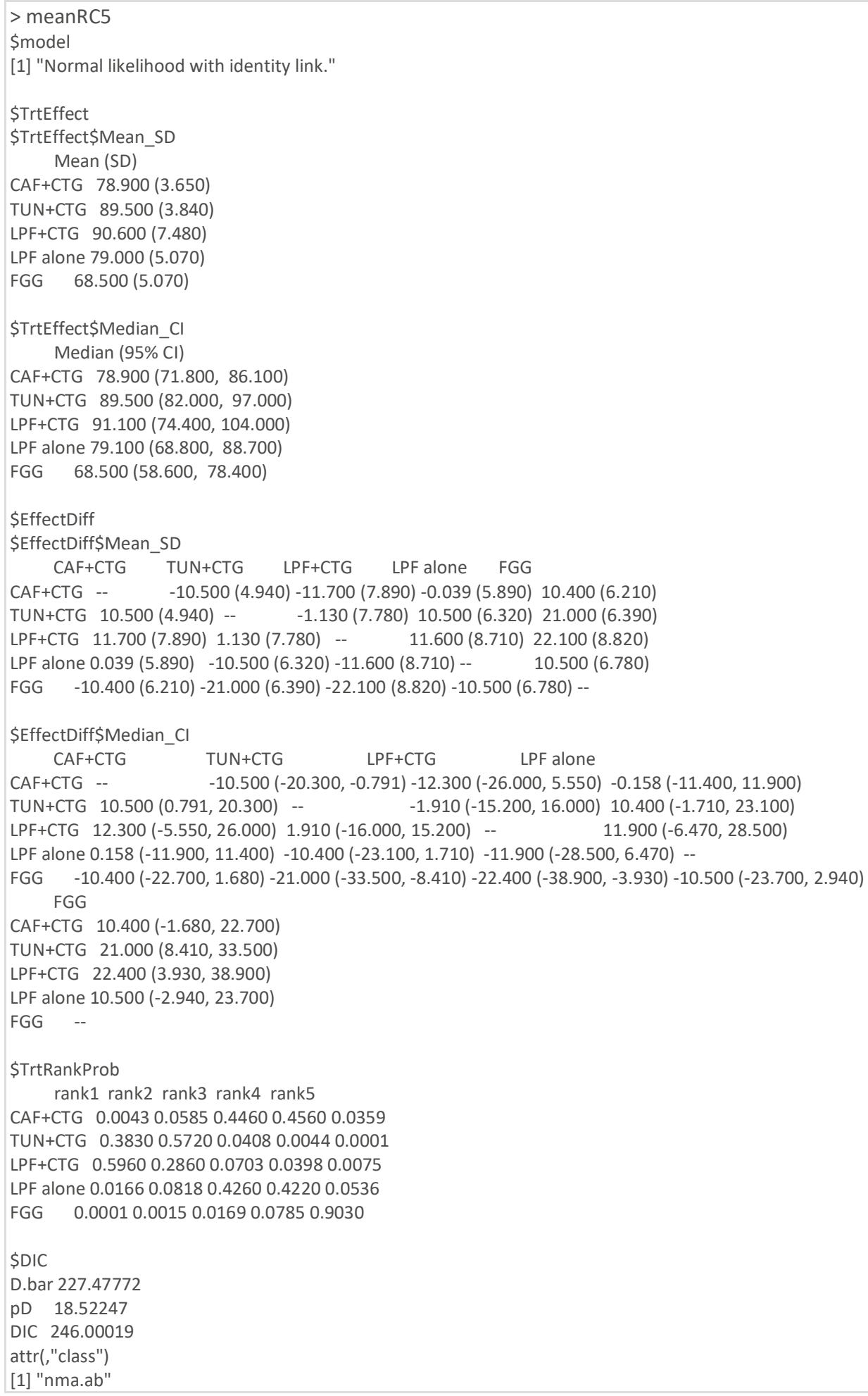


Figures 21-27 show the network plot, the posterior density plot and the trace plots for each treatment group. The greatest $\mathrm{mRC}$ is associated with $\mathrm{LPF}+\mathrm{CTG}(91.1 \%)$ and TUN+CTG (89.5\%), whereas LPF alone and CAF+CTG showed lower mRC (79.1\%, 78.9\%). FGG is associated with the lowest mRC (68.5\%). The absolute plot (Fig. 28) shows consistency in the width of the credible intervals for all the treatment groups, except for LPF+CTG which presents a wider CrI due to the low numerosity. Comparing the treatment effect sizes, it emerges that the $95 \% \mathrm{CrIs}$ for $\mathrm{TUN}+\mathrm{CTG}$ and $\mathrm{CAF}+\mathrm{CTG}$ do not overlap, indicating a statistically significant difference in favor of TUN+CTG (10.6\% difference in mRC) (see contrast plots, Fig. 29-33). Absence of overlapping in the 95\% CrI can be observed also between TUN+CTG and FGG (20.9\% difference in mRC), as well as between LPF+CTG and FGG (22.5\% difference in $\mathrm{mRC})$.

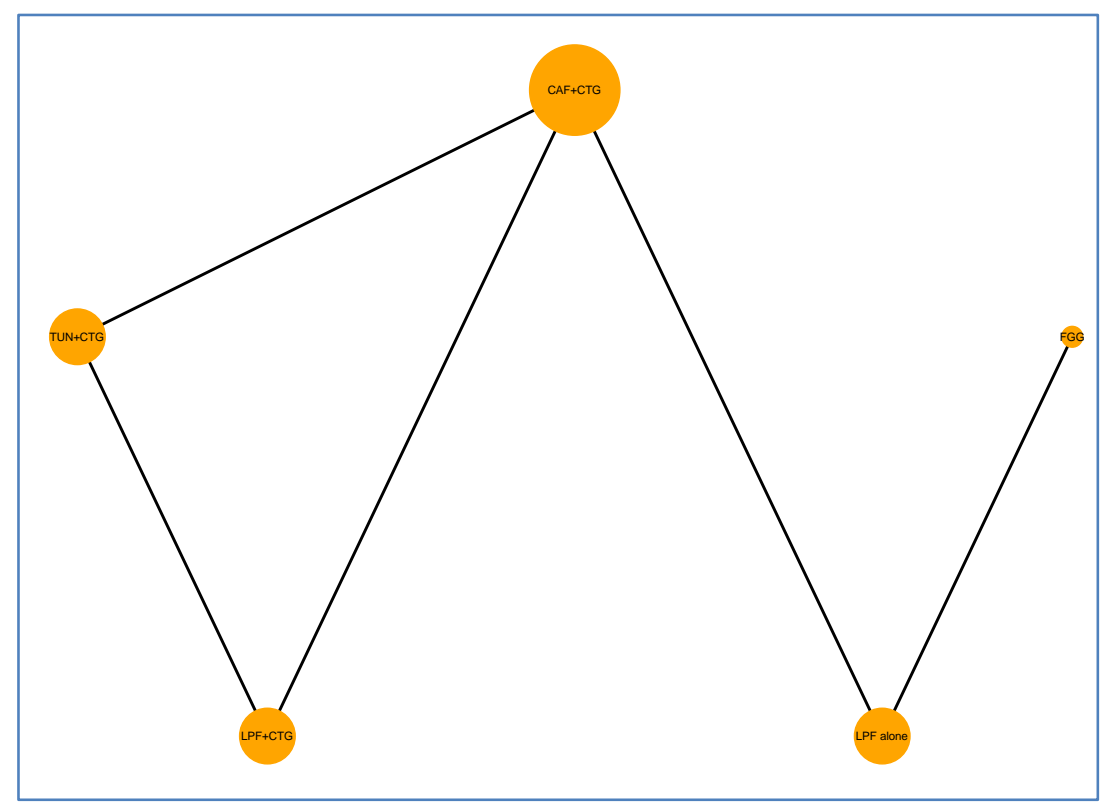

Figure 21. Network Plot for mRC - 5 treatment arms 


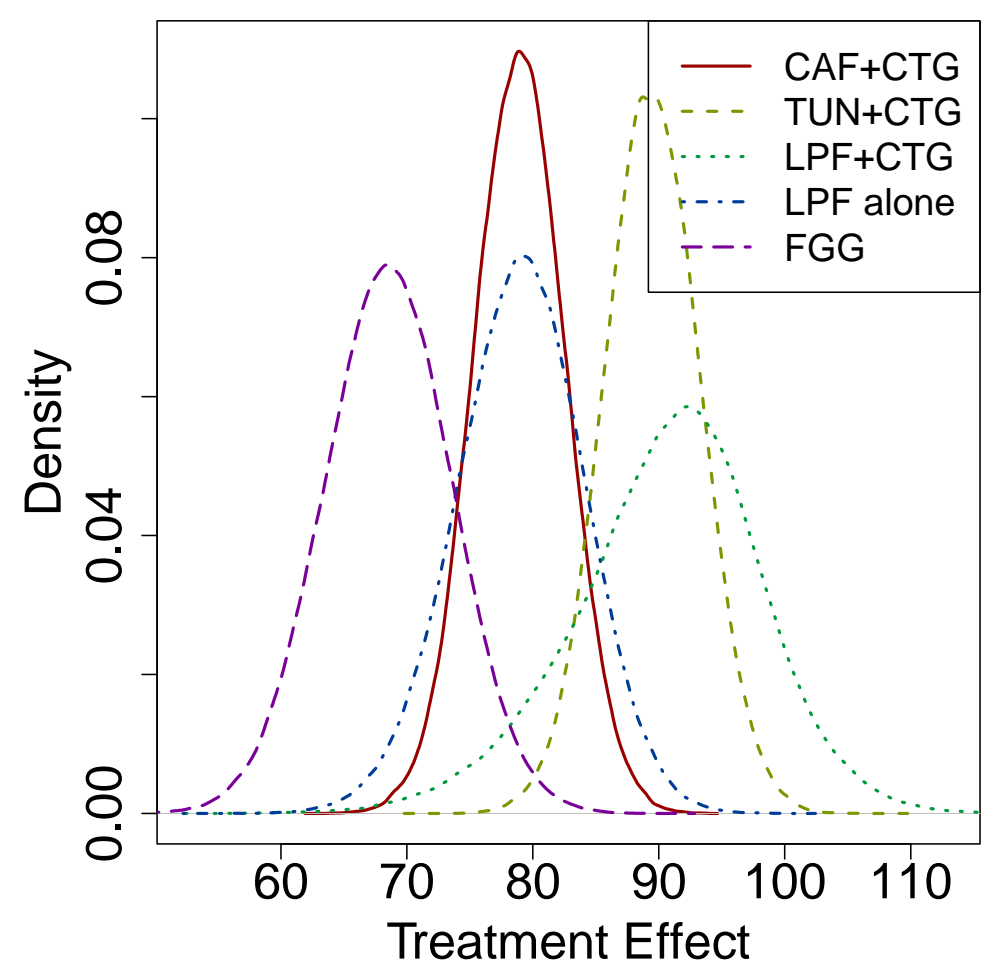

Figure 22. Density plot for treatment effect - mRC 5 treatment arms

Chain 1

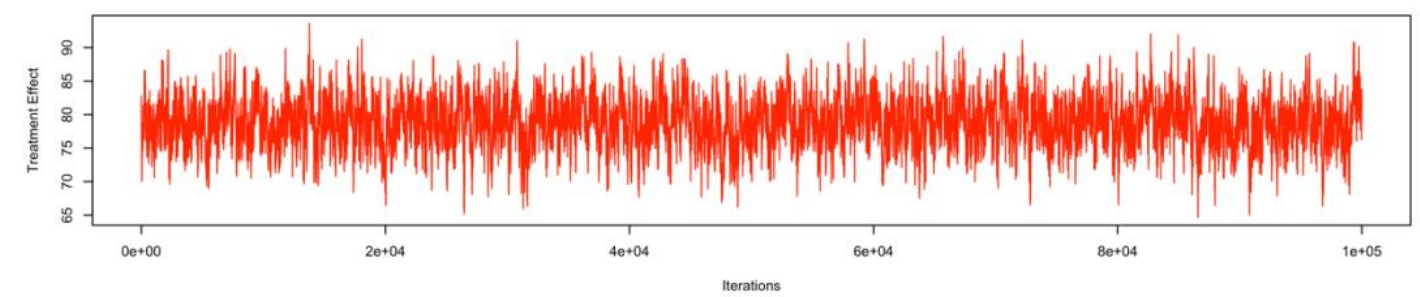

Chain 2

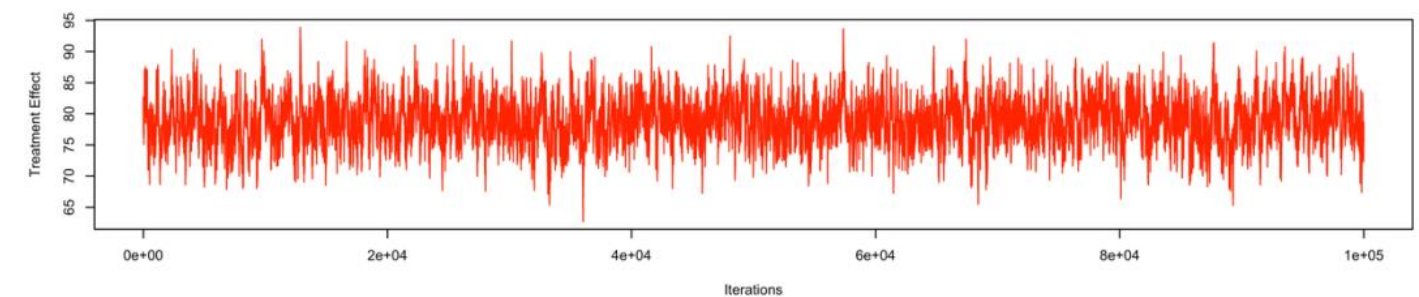

Chain 3

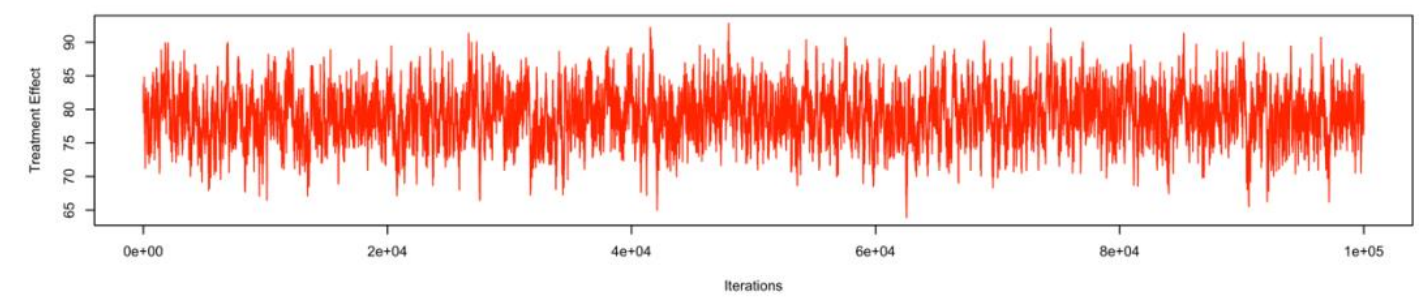

Figure 23. Trace plot $C A F+C T G$ 
Chain 1
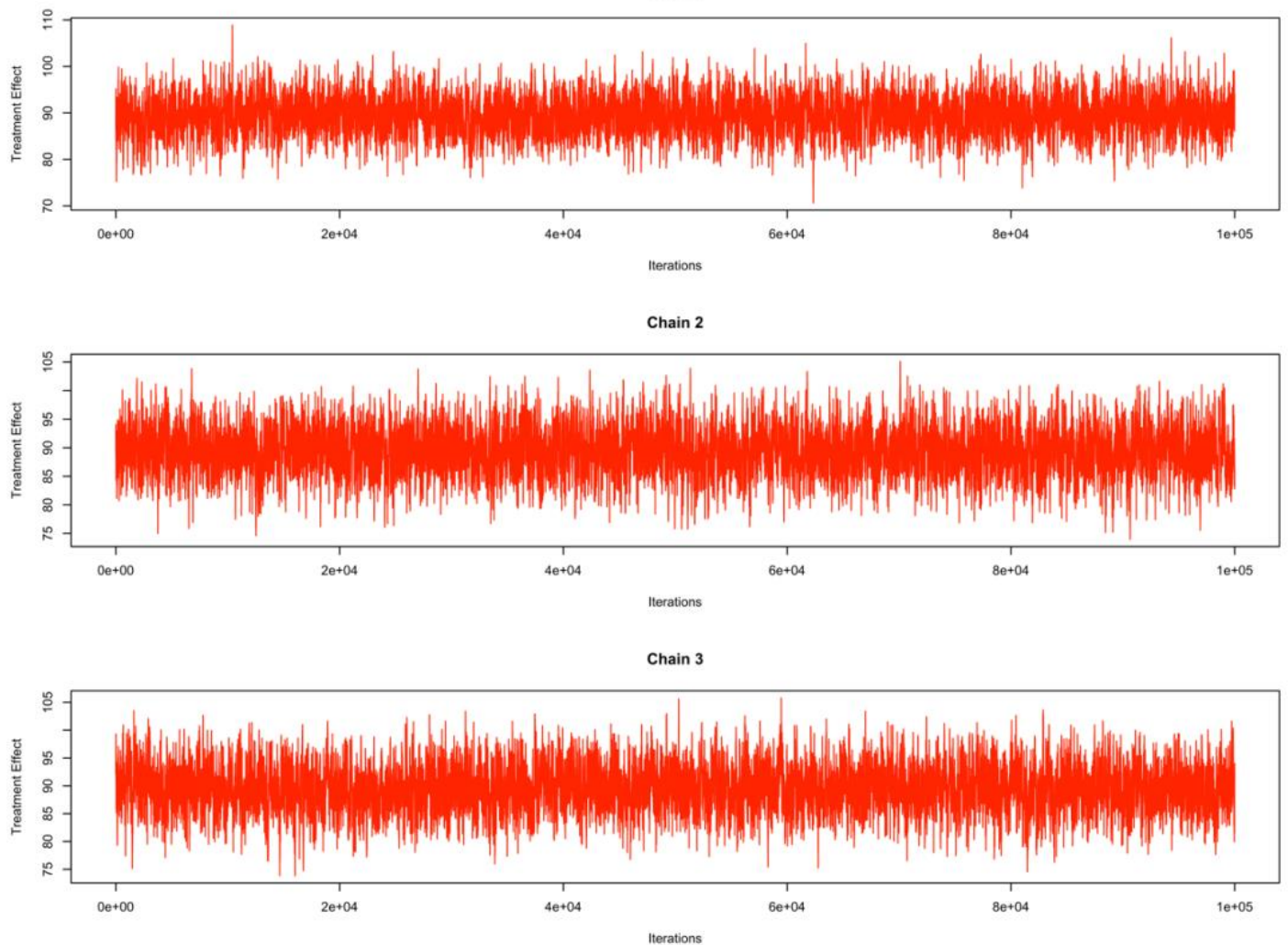

Figure 24. Trace plot TUN + CTG

Chain 1
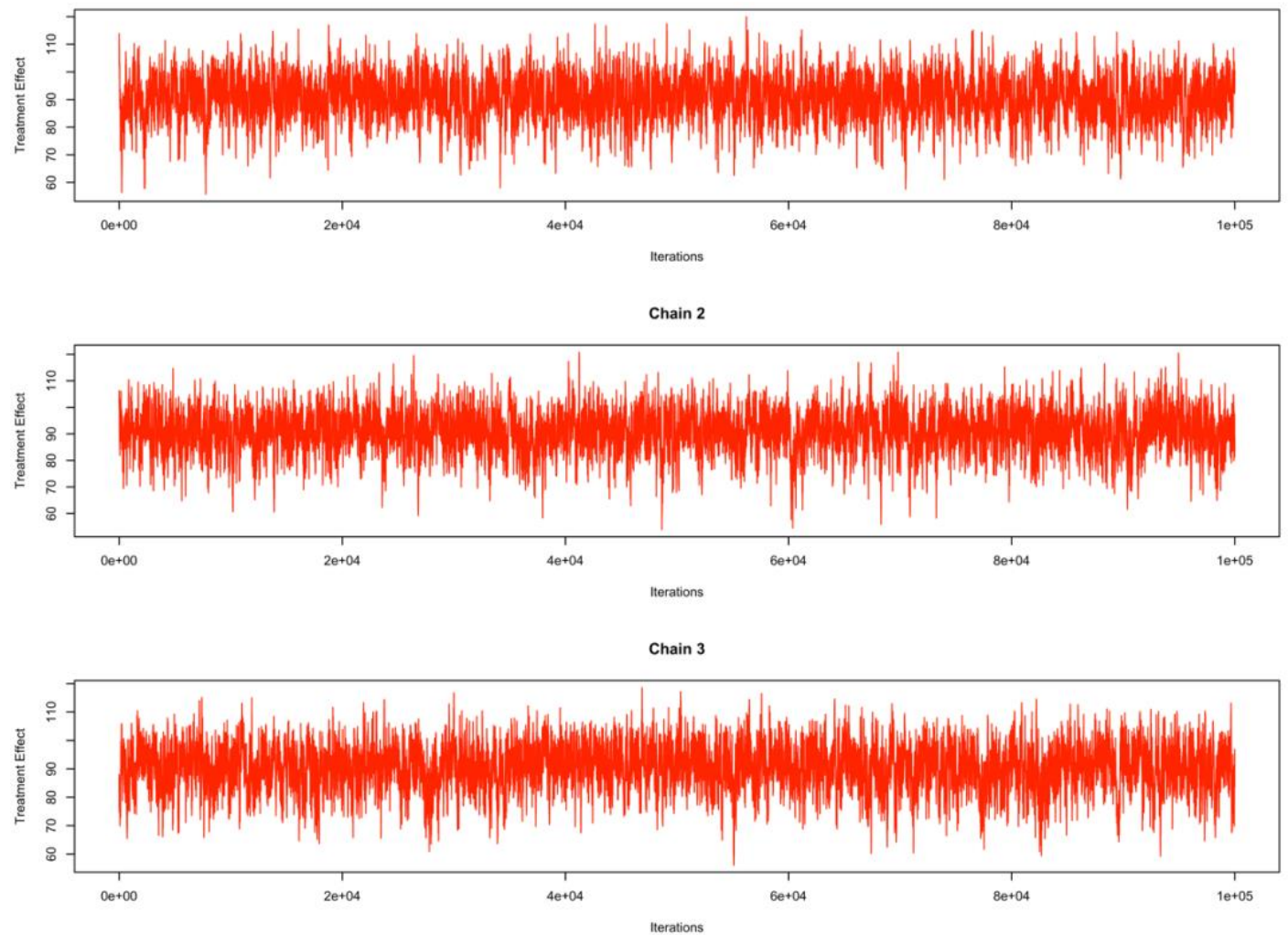

Figure 25. Trace plot $L P F+C T G$ 
Chain 1
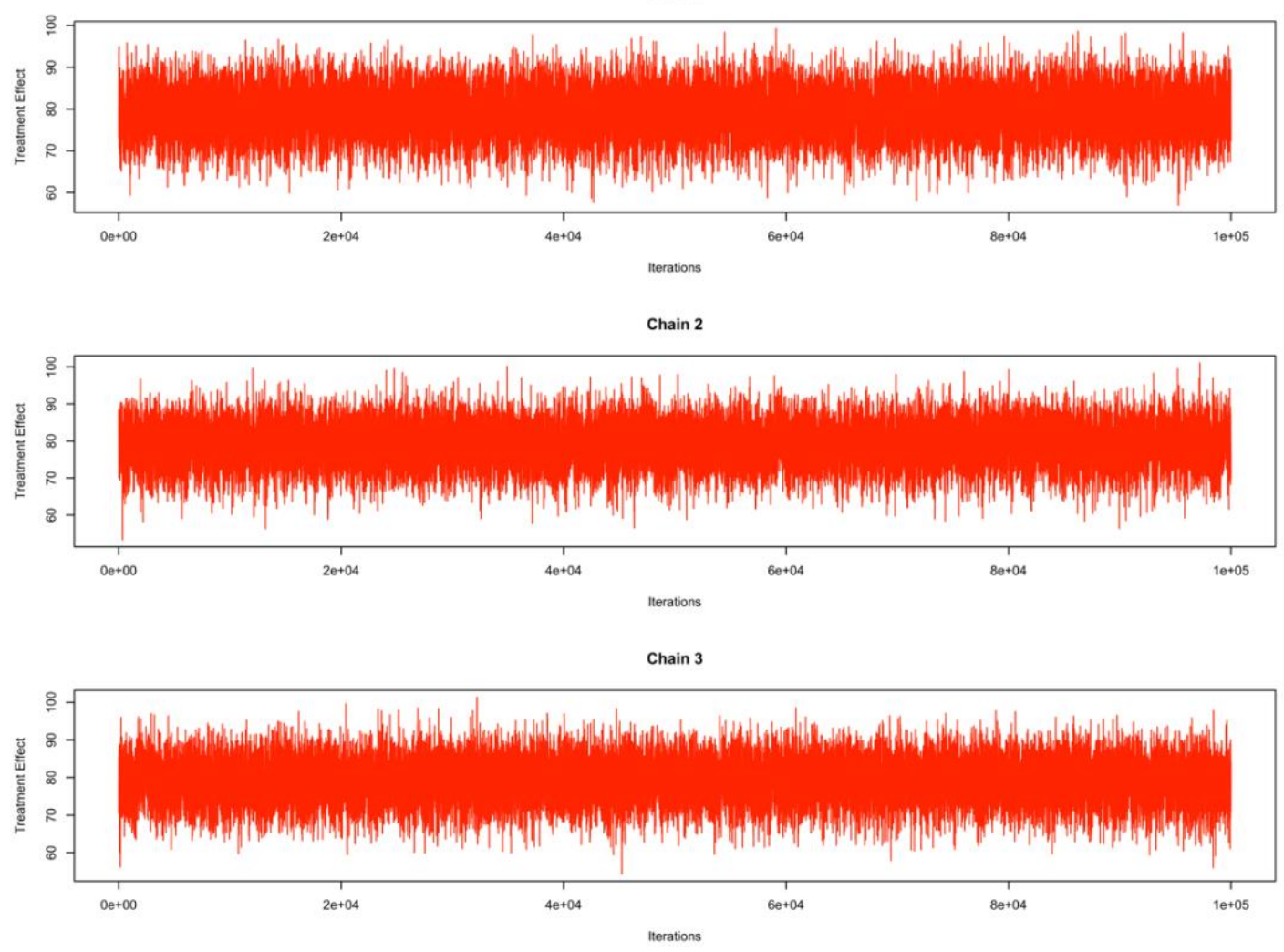

Figure 26. Trace plot LPF alone

Chain 1
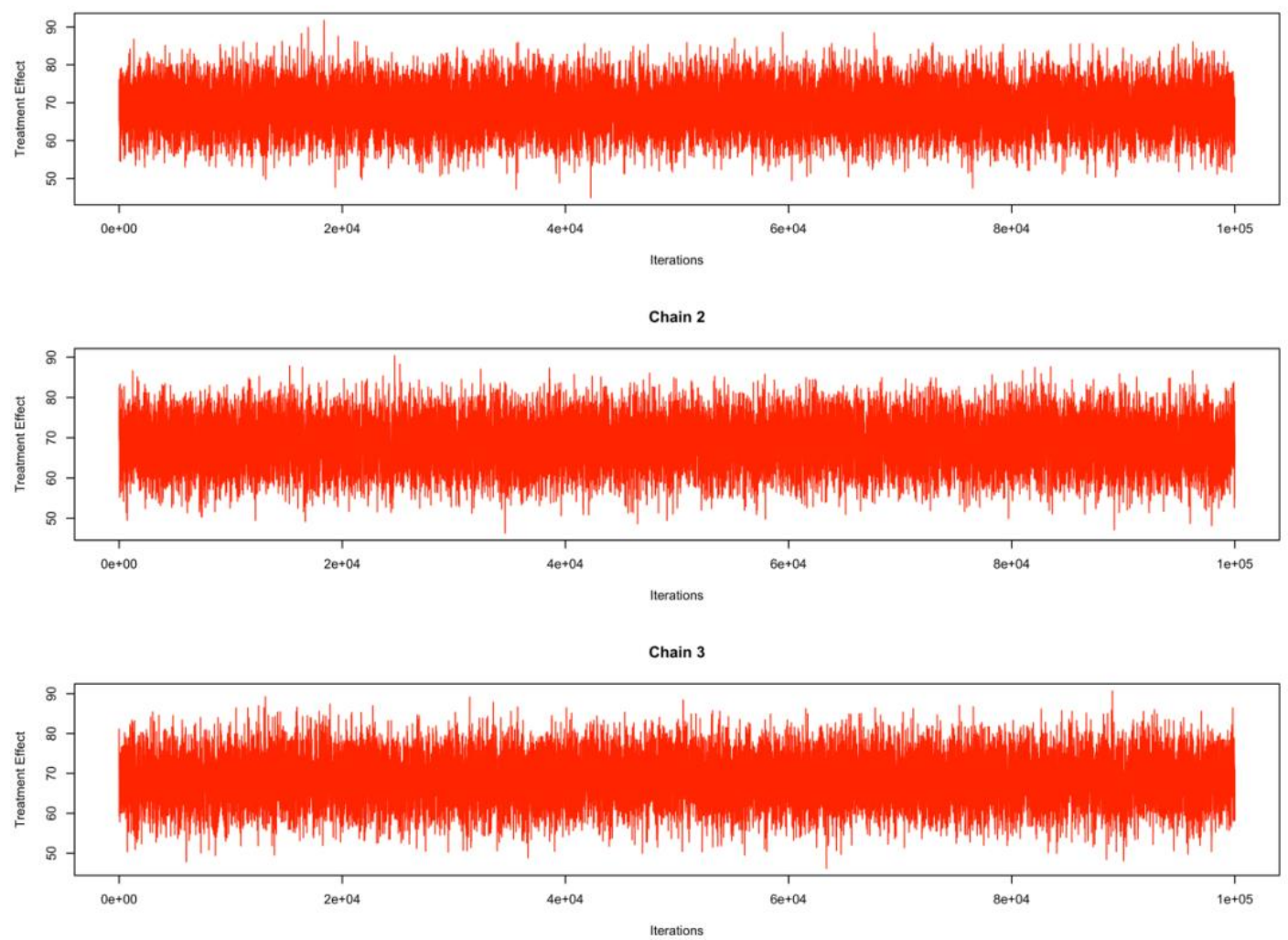

Figure 27. Trace plot FGG 


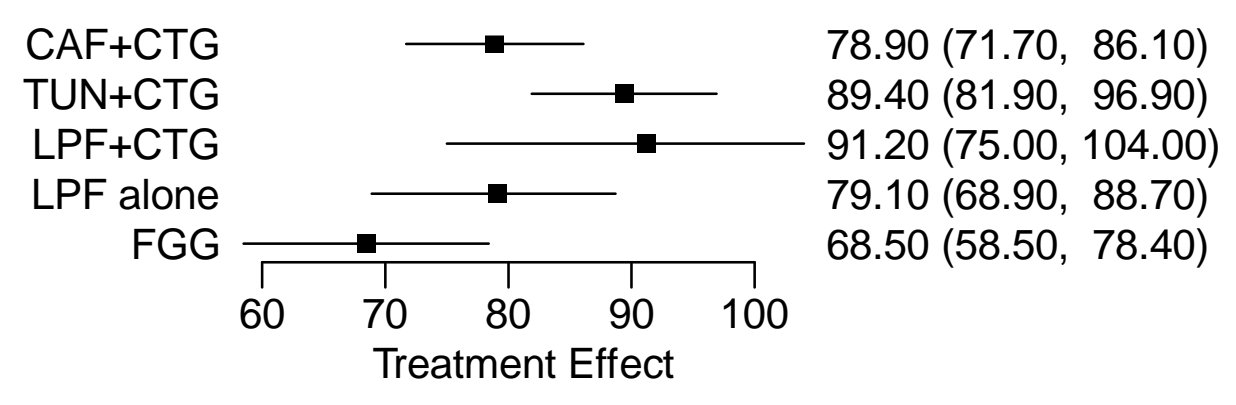

Figure 28. Absolute effect - mRC 5 treatment arms

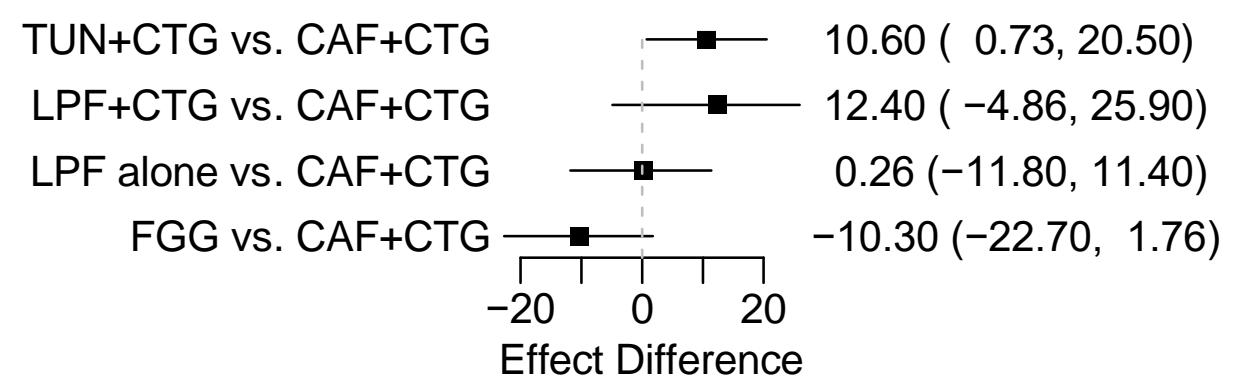

Figure 29. Contrast plot - CAF+CTG as reference

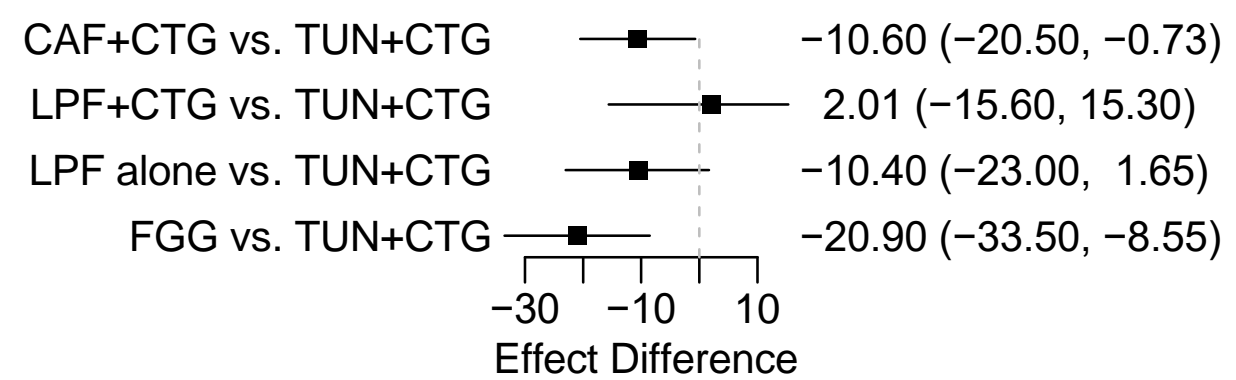

Figure 30. Contrast plot-TUN+CTG as reference

$\mathrm{CAF}+\mathrm{CTG}$ vs. $\mathrm{LPF}+\mathrm{CTG}$ $T U N+C T G$ vs. $L P F+C T G$ $\mathrm{LPF}$ alone vs. $\mathrm{LPF}+\mathrm{CTG}$

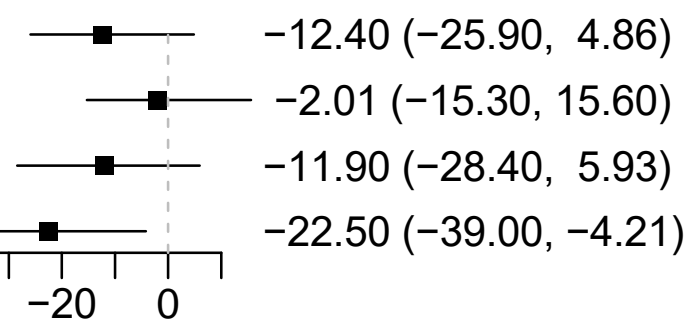

Effect Difference

Figure 31. Contrast plot - LPF+CTG as reference 
$\mathrm{CAF}+\mathrm{CTG}$ vs. LPF alone

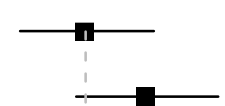
$-0.26(-11.40,11.80)$

TUN+CTG vs. LPF alone $10.40(-1.65,23.00)$

LPF+CTG vs. LPF alone

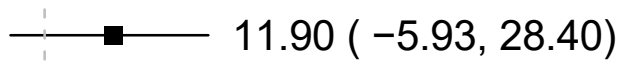

FGG vs. LPF alone

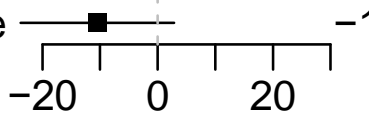

$-10.50(-23.80,2.85)$

Effect Difference

Figure 32. Contrast plot - LPF alone as reference

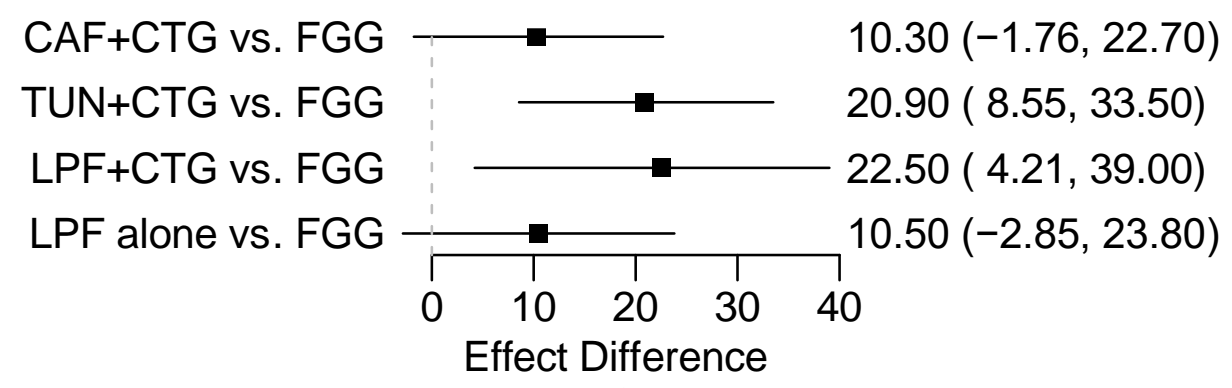

Figure 33. Contrast plot - FGG as reference

Fig. 34 graphs the probability of each treatment having each of the different possible ranks among the treatments. LPF+CTG has the highest probability of being the best treatment in terms of mean root coverage (59.6\%), followed by TUN+CTG (38.3\%).

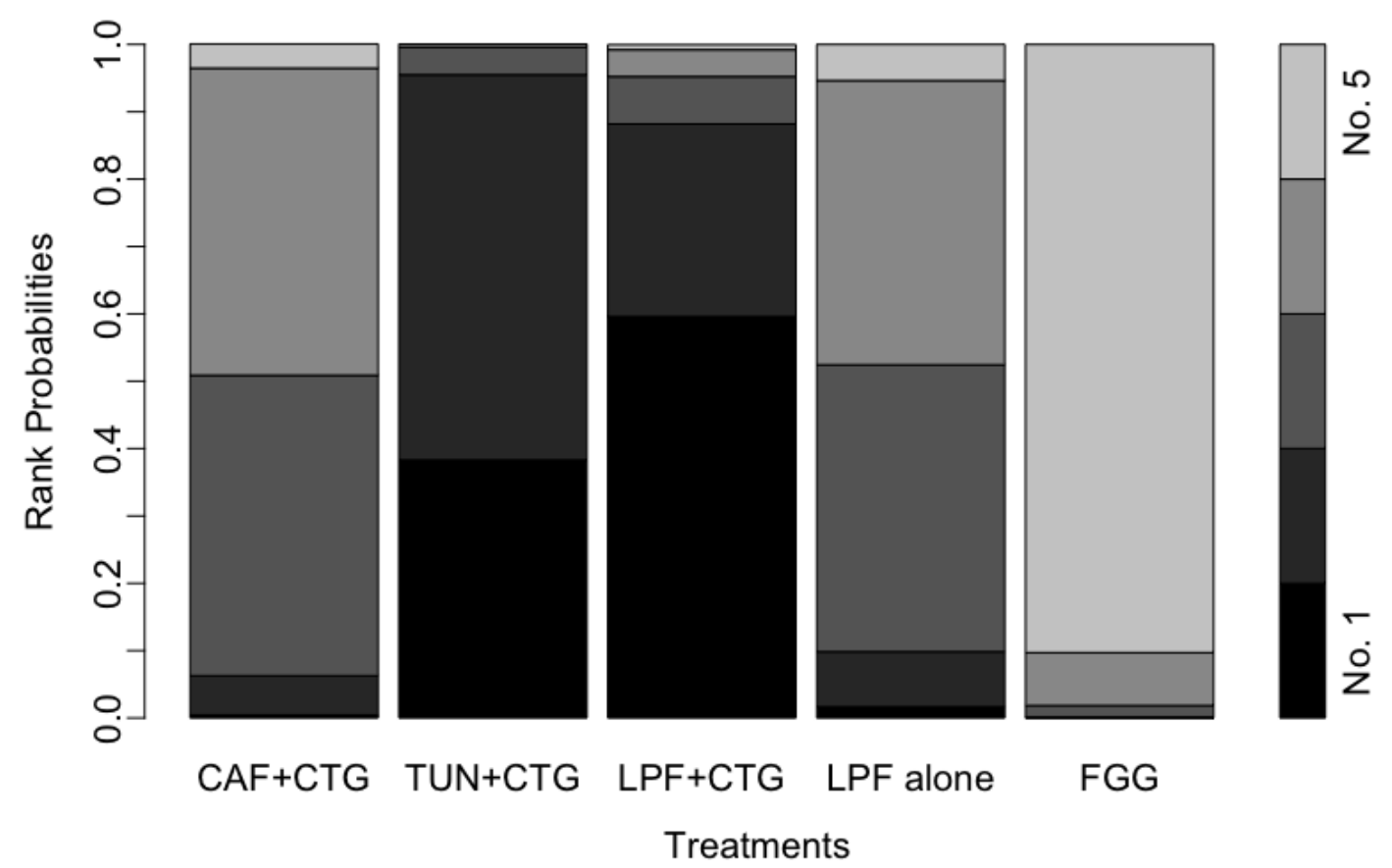

Figure 34. Rank probability treatment effect $-m R C$ 


\subsubsection{Keratinized Tissue Width change (KTW change)}

For KTW change, the dataset consisted of 23 study arms, in particular 8 for CAF+CTG, 6 for TUN+CTG, 1 for LPF+CTG, 5 for LPF alone and 3 for FGG. Since all the study arms report the KTW change, the network plot for KTW change is the same as mRC (Fig. 21).

The network meta-analysis showed the following results:

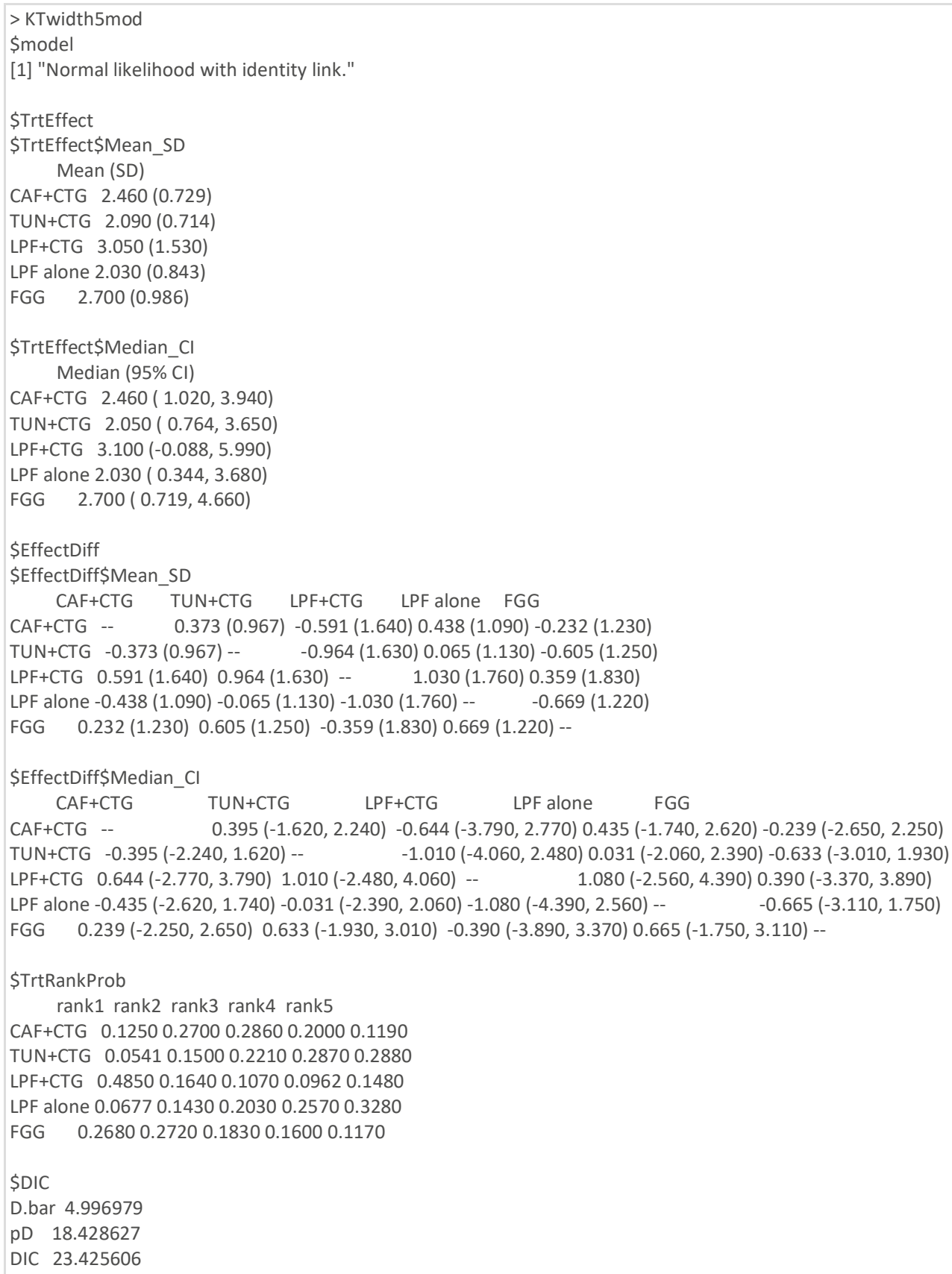


Figures 36-41 show the the posterior density plot and the trace plots for each treatment group. The median of the treatment effects amounts to $3.1 \mathrm{~mm}$ for $\mathrm{LPF}+\mathrm{CTG}, 2.7 \mathrm{~mm}$ for FGG, $2.46 \mathrm{~mm}$ for CAF+CTG, $2.05 \mathrm{~mm}$ for TUN+CTG and $2.03 \mathrm{~mm}$ for LPF alone. No difference among treatments is likely to exist, since all the $95 \% \mathrm{CrI}$ for each treatment in every contrast plot contains 0 , so there is no sufficient evidence to identify any difference. This finding is confirmed by the posterior density plot (Fig. 36), where the overlap regions of densities for the different treatments are large. In terms of ranking probability, $\mathrm{LPF}+\mathrm{CTG}$ is more likely to be the best treatment approach for KT gain (48.5\% probability), followed by FGG $(26.8 \%)$.

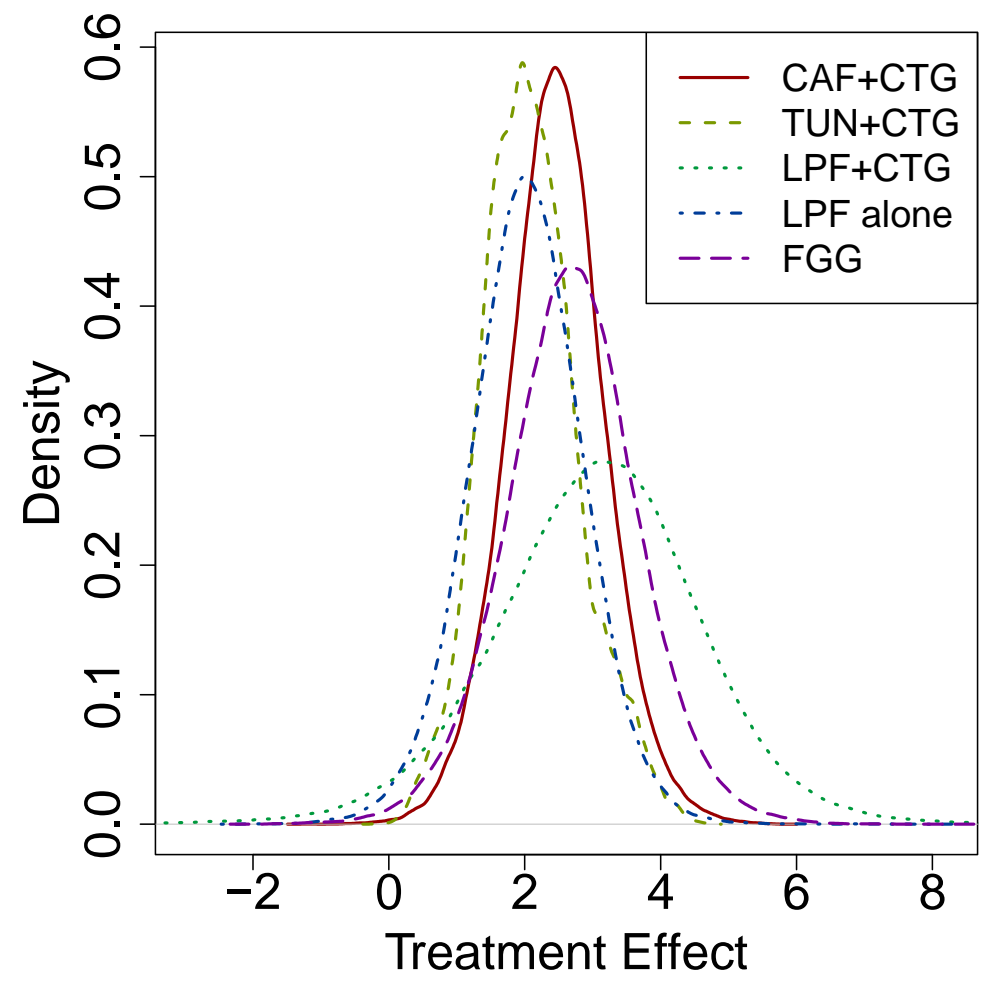

Figure 35. Density plot KTW change 
Chain 1
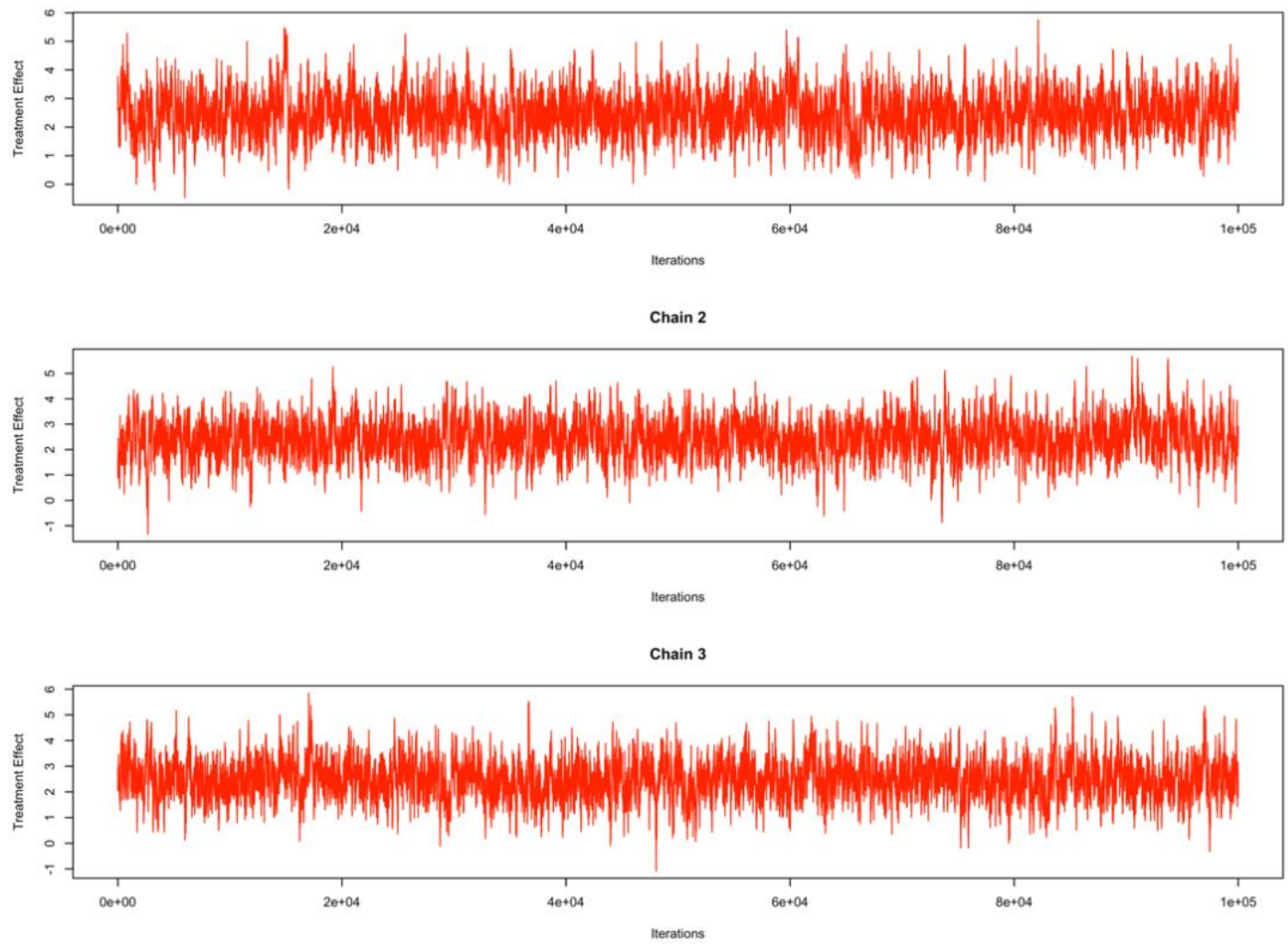

Figure 36. Trace plot KT width modified - CAF+CTG

Chain 1
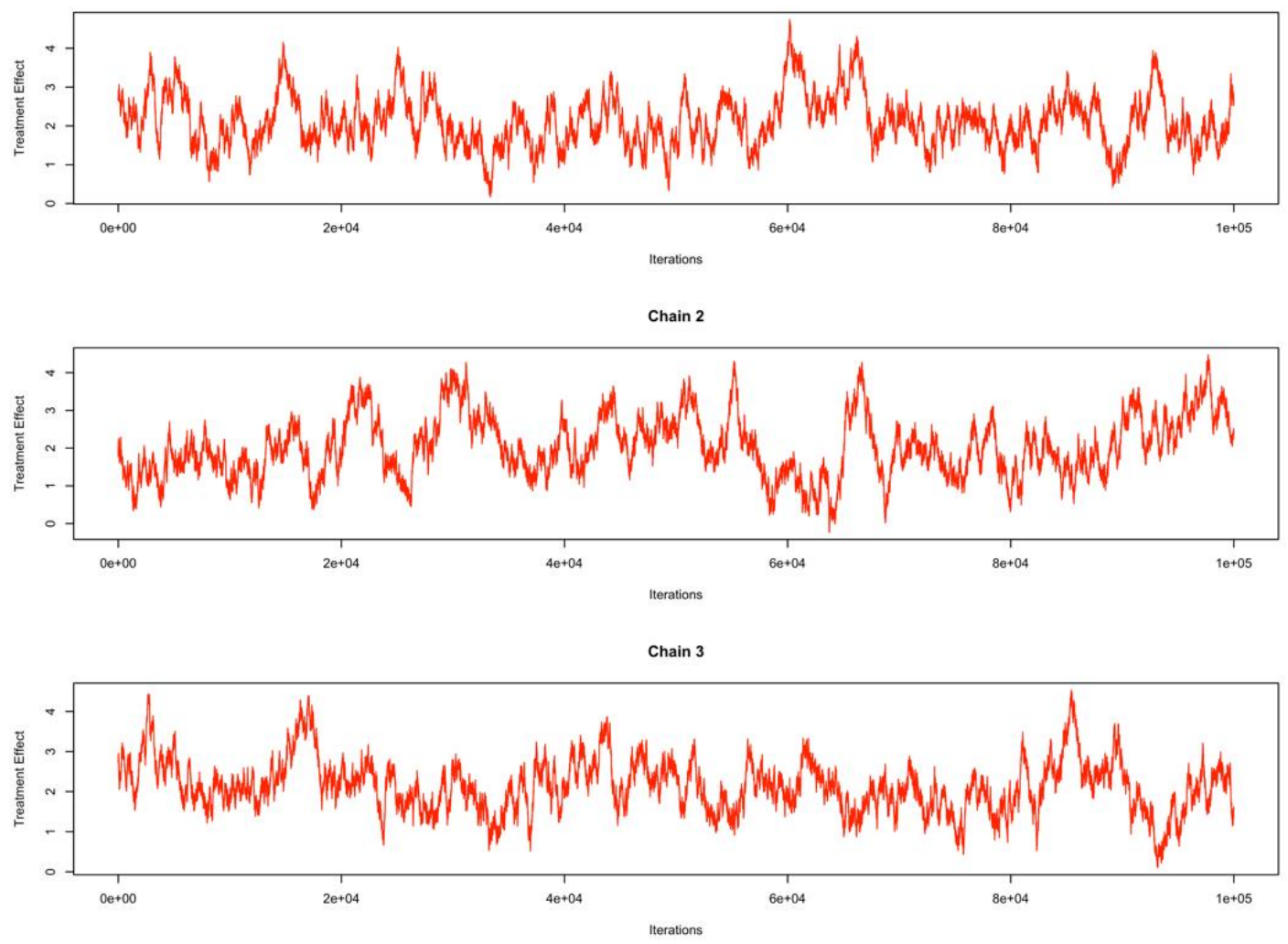

Figure 37. Trace plot KT width modified - TUN+CTG 
Chain 1
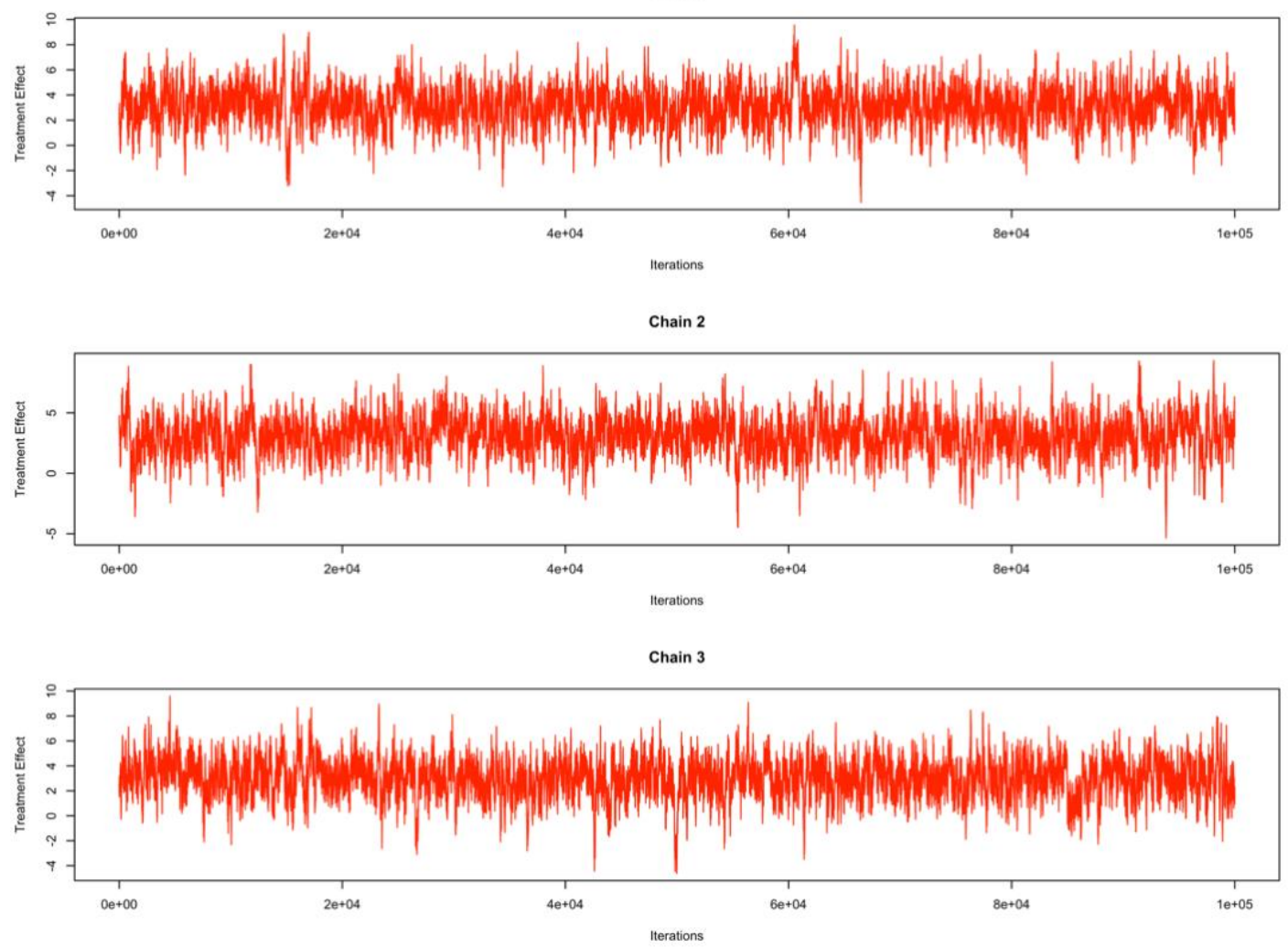

Figure 38. Trace plot KT width modified $-L P F+C T G$

Chain 1
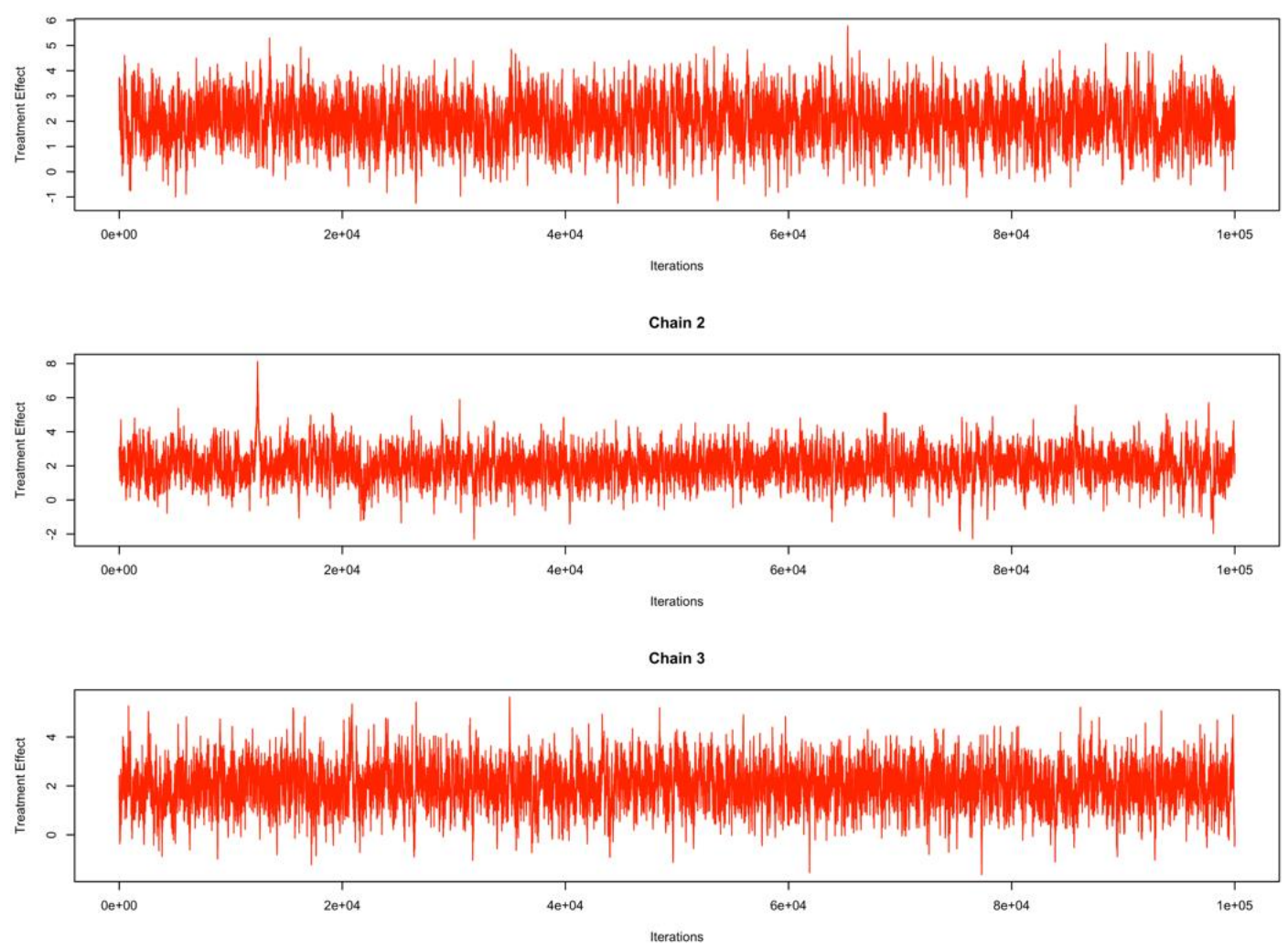

Figure 39. Trace plot KT width modified-LPF alone 
Chain 1
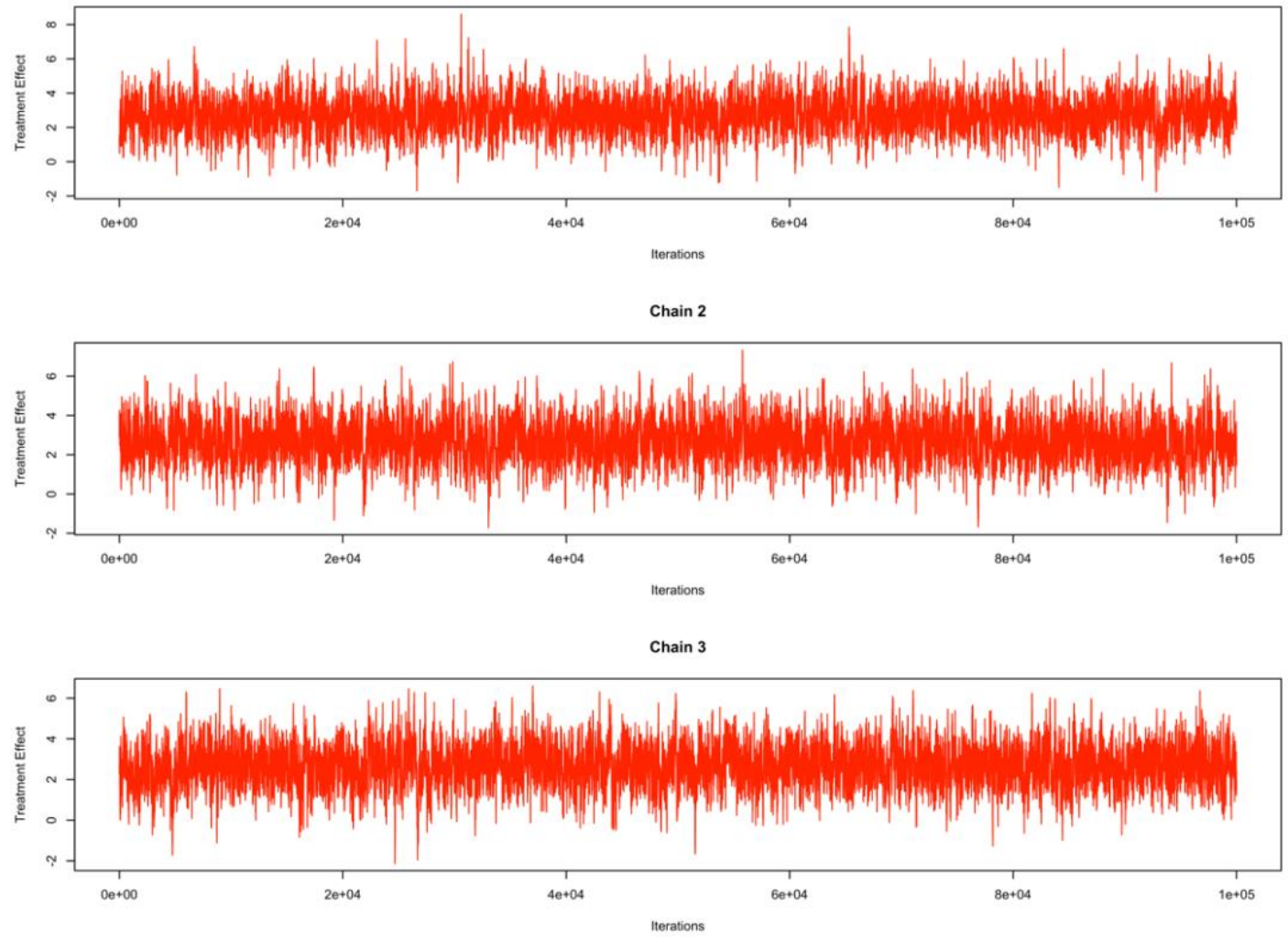

Figure 40. Trace plot KT width modified - FGG

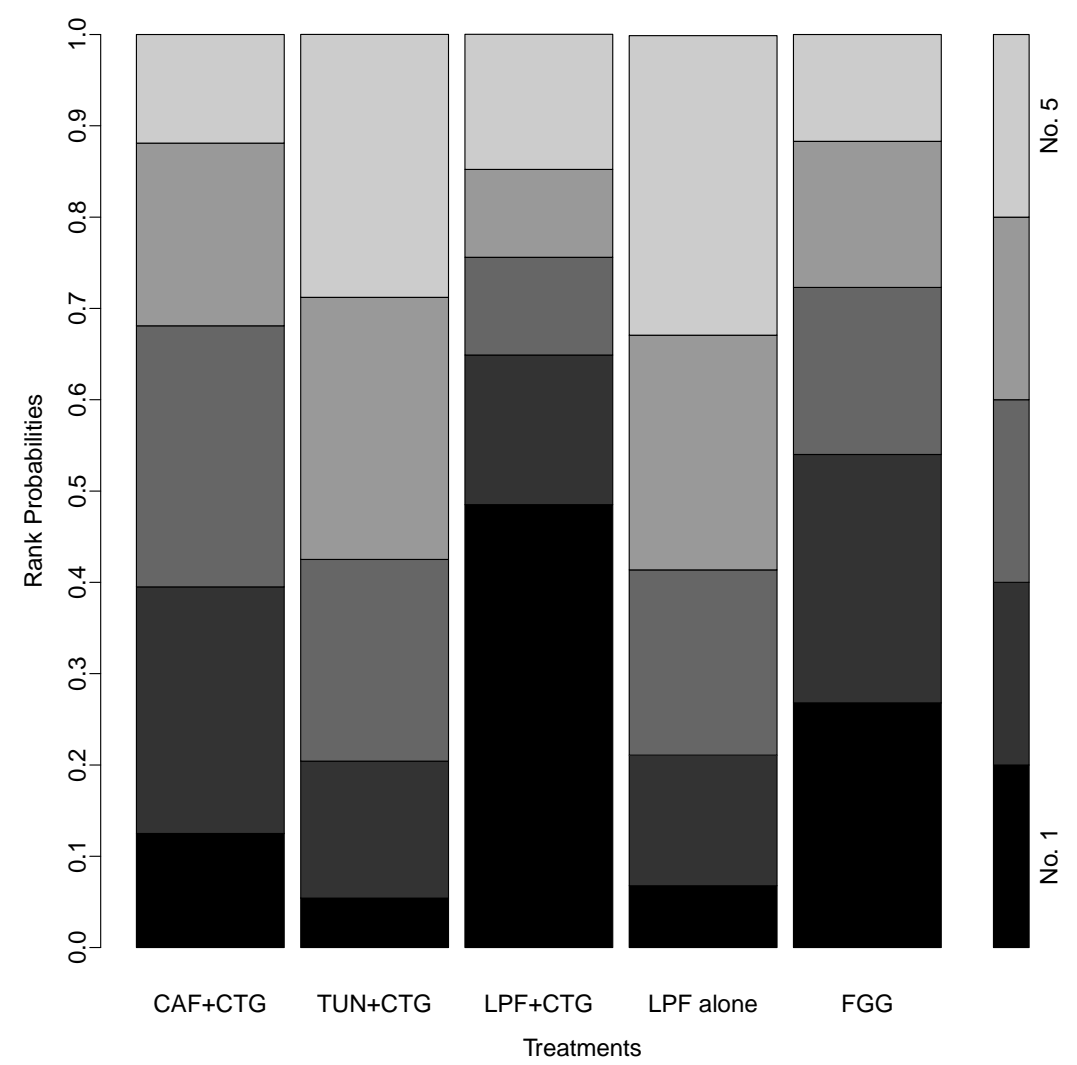

Figure 41. Ranking probability KT width modified 


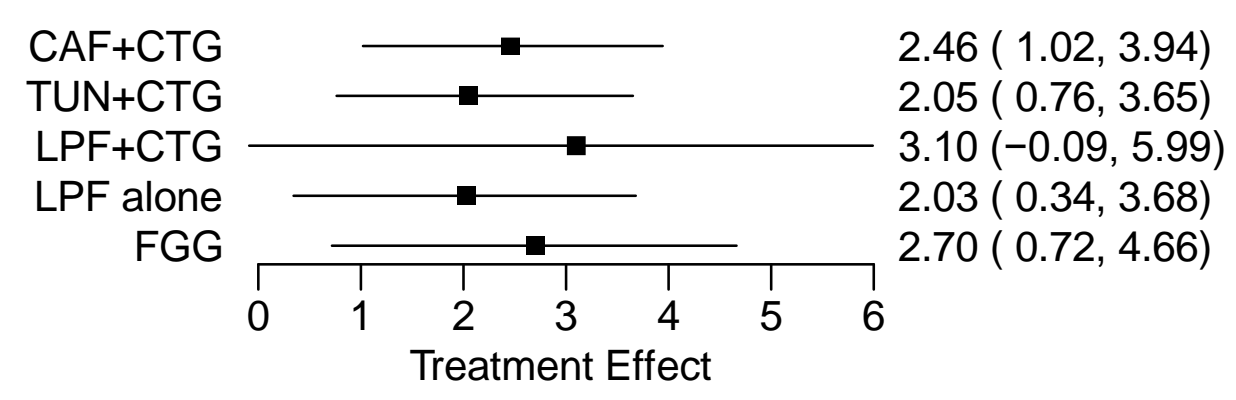

Figure 42. Absolute effect KT width modified

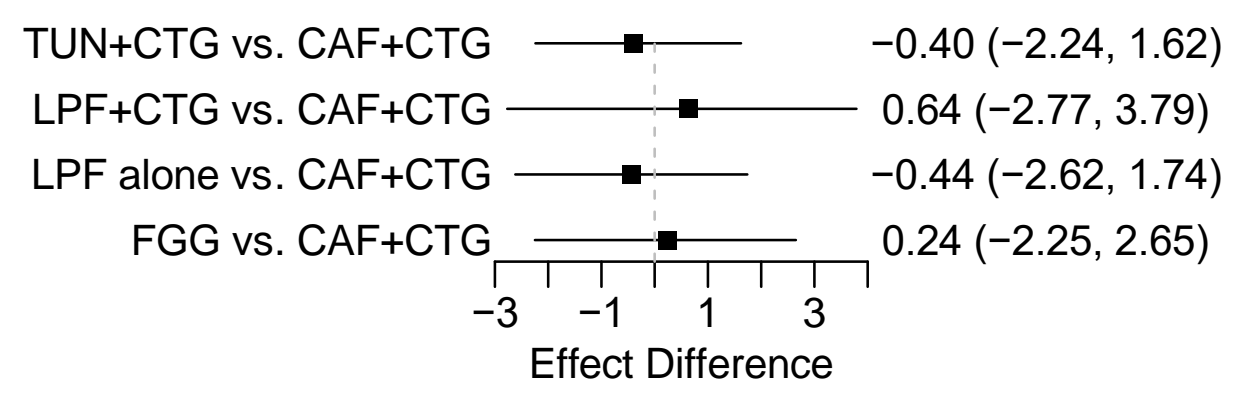

Figure 43. Contrast plot KT width modified - CAF+CTG as reference

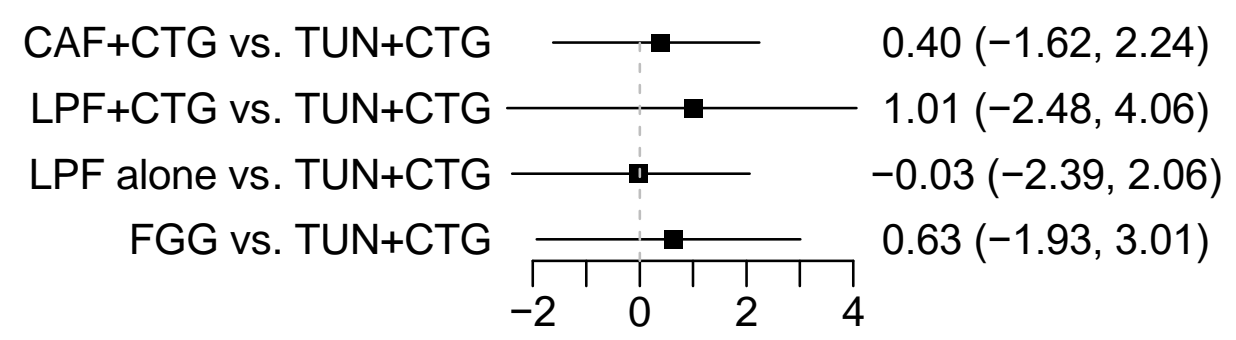

Effect Difference

Figure 44. Contrast plot KT width modified $-T U N+C T G$

$\mathrm{CAF}+\mathrm{CTG}$ vs. $\mathrm{LPF}+\mathrm{CTG}$

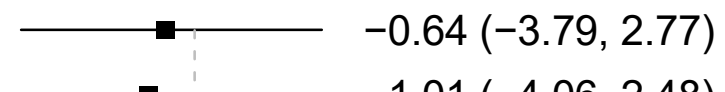

$\mathrm{TUN}+\mathrm{CTG}$ vs. $\mathrm{LPF}+\mathrm{CTG} \longrightarrow-1.01(-4.06,2.48)$

$\mathrm{LPF}$ alone vs. $\mathrm{LPF}+\mathrm{CTG} \longrightarrow-1.08(-4.39,2.56)$

$F G G$ vs. $L P F+C T G$

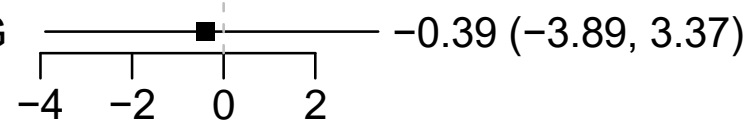

Effect Difference 


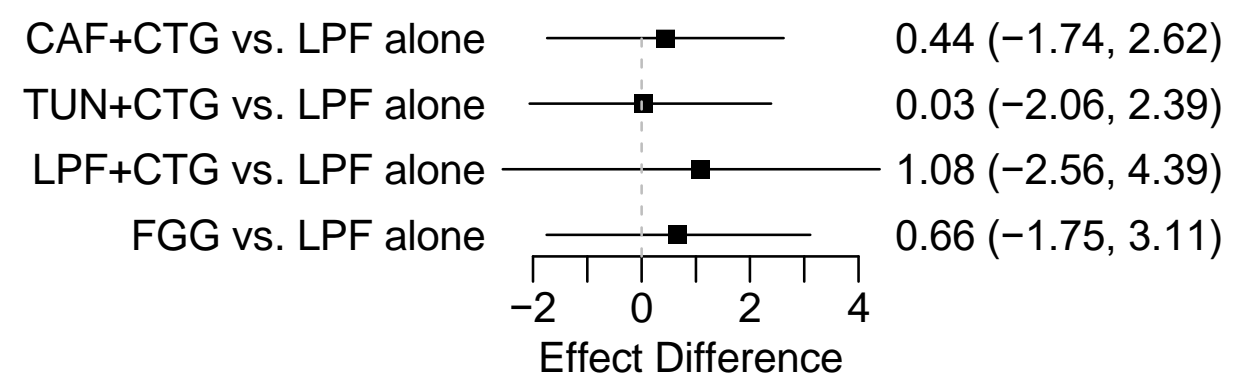

Figure 46. Contrast plot KT width modified - LPF alone

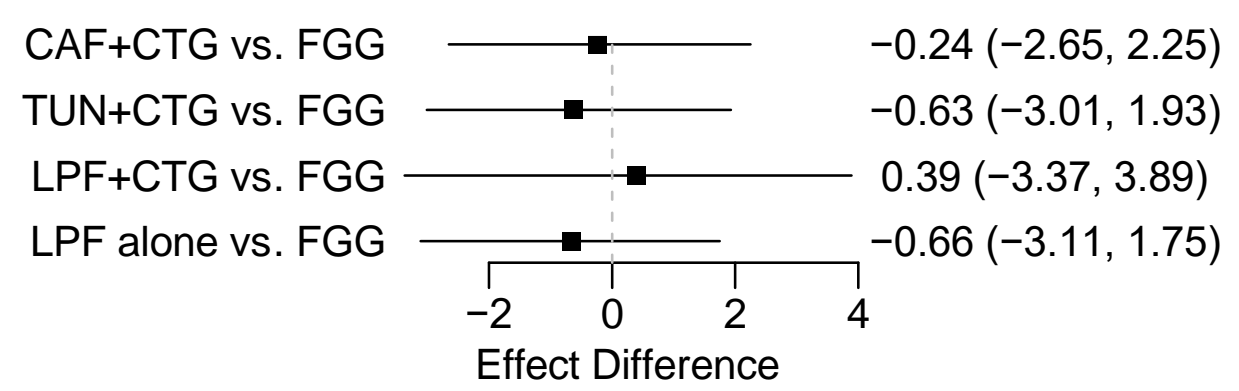

Figure 47. Contrast plot KT width modified - FGG

\subsubsection{Residual Recession Depth (residual RD)}

For residual RD, the dataset consisted of 22 study arms, in particular 8 for $\mathrm{CAF}+\mathrm{CTG}, 5$ for TUN+CTG, 1 for LPF+CTG, 5 for LPF alone and 3 for FGG. Compared to the dataset selected for the primary outcome (mRC), only 1 study (Sculean 2014) did not report the residual RD at follow up. The network plot is shown in Fig. 49. The network meta-analysis showed the following results:

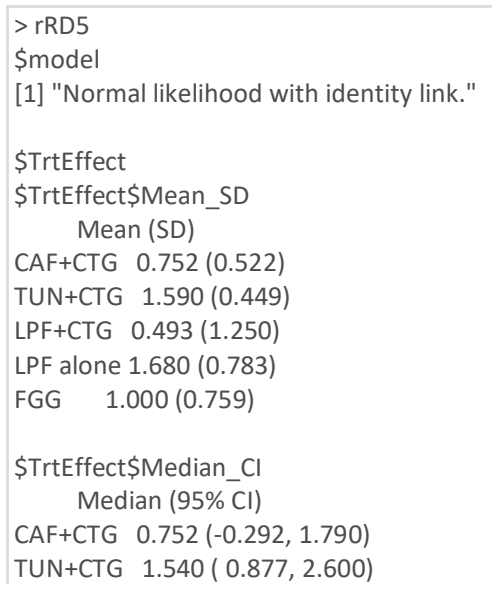




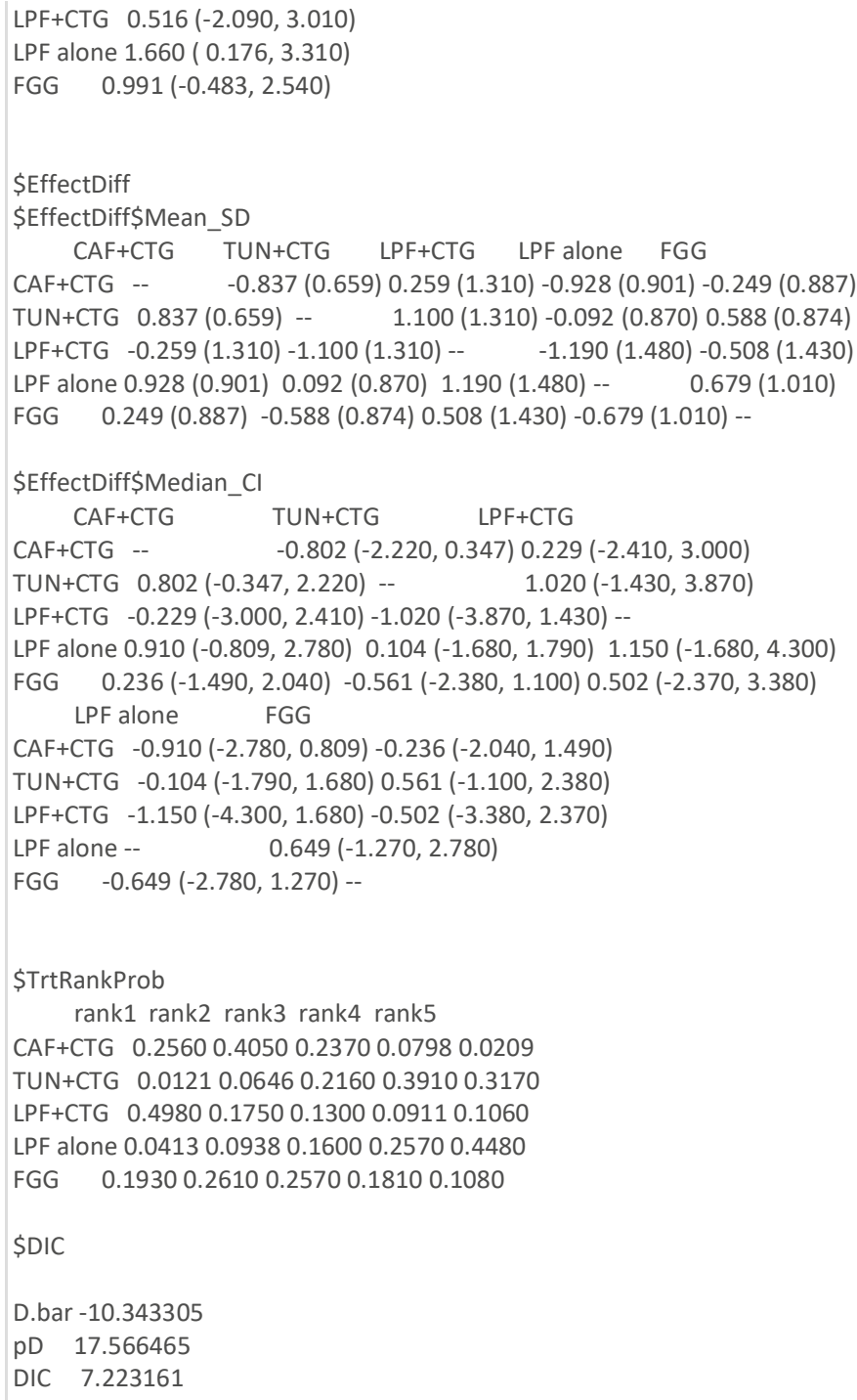

Posterior density plot and the trace plots for each treatment group are reported in Fig. 5055. The residual recession depth at the follow-up visit is $0.51 \mathrm{~mm}$ for $\mathrm{LPF}+\mathrm{CTG}, 0.75 \mathrm{~mm}$ for CAF+CTG, 0.99 for FGG, 1.54 for TUN+CTG and 1.66 for LPF alone. However, the contrast plots showed consistent overlapping of 95\% CrI among treatments, which indicates that there is not enough evidence to identify any significant difference between the different procedures. According to the ranking plot, the highest probability of being the best treatment approach, so the one that most likely yields the lowest residual recession depth, is $49.8 \%$ for $\mathrm{LPF}+\mathrm{CTG}, 25.6 \%$ for CAF+CTG and $19.3 \%$ for FGG. 


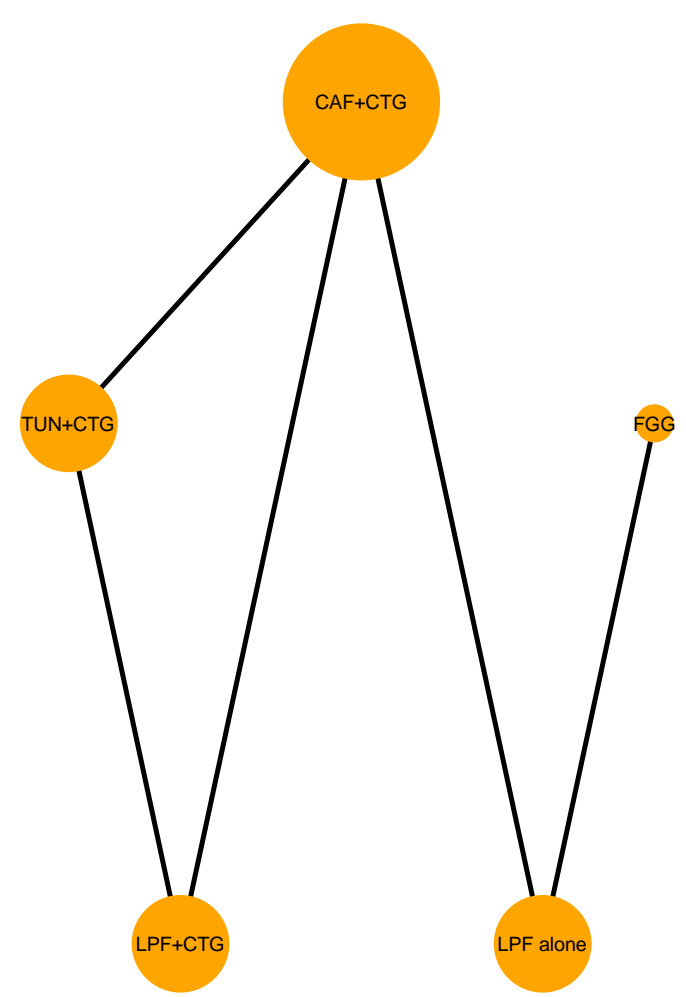

Figure 48. Network plot Residual REC

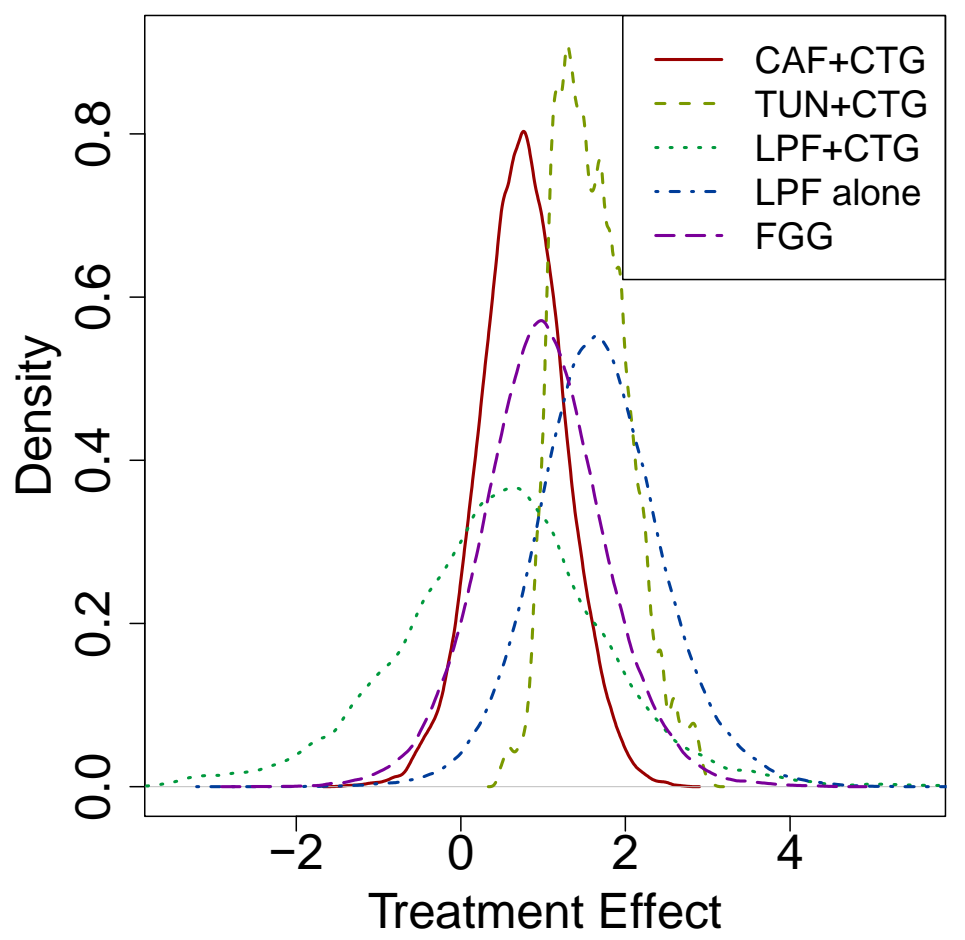

Figure 49. Density plot Residual REC 

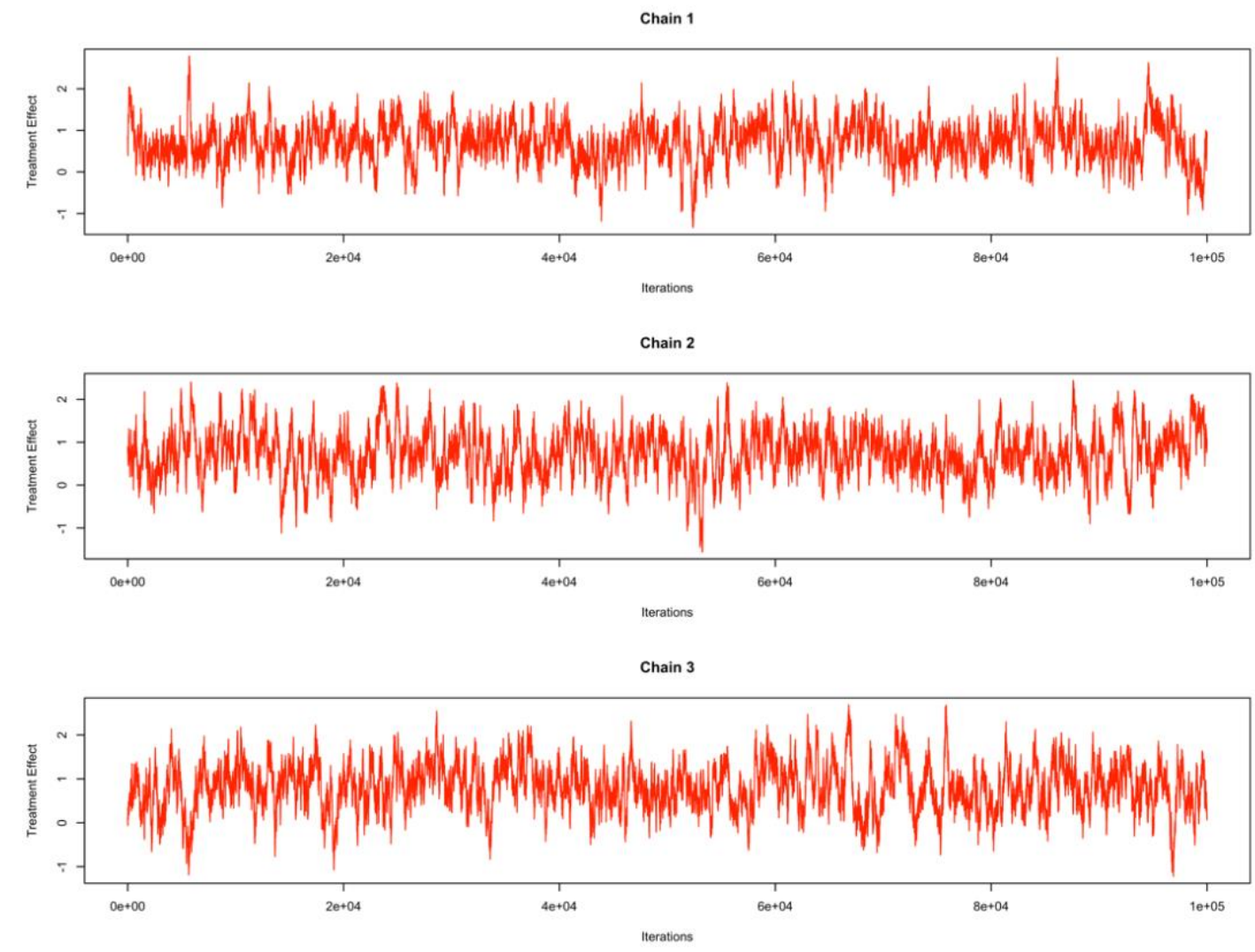

Figure 50. Trace plot Residual REC - CAF+CTG
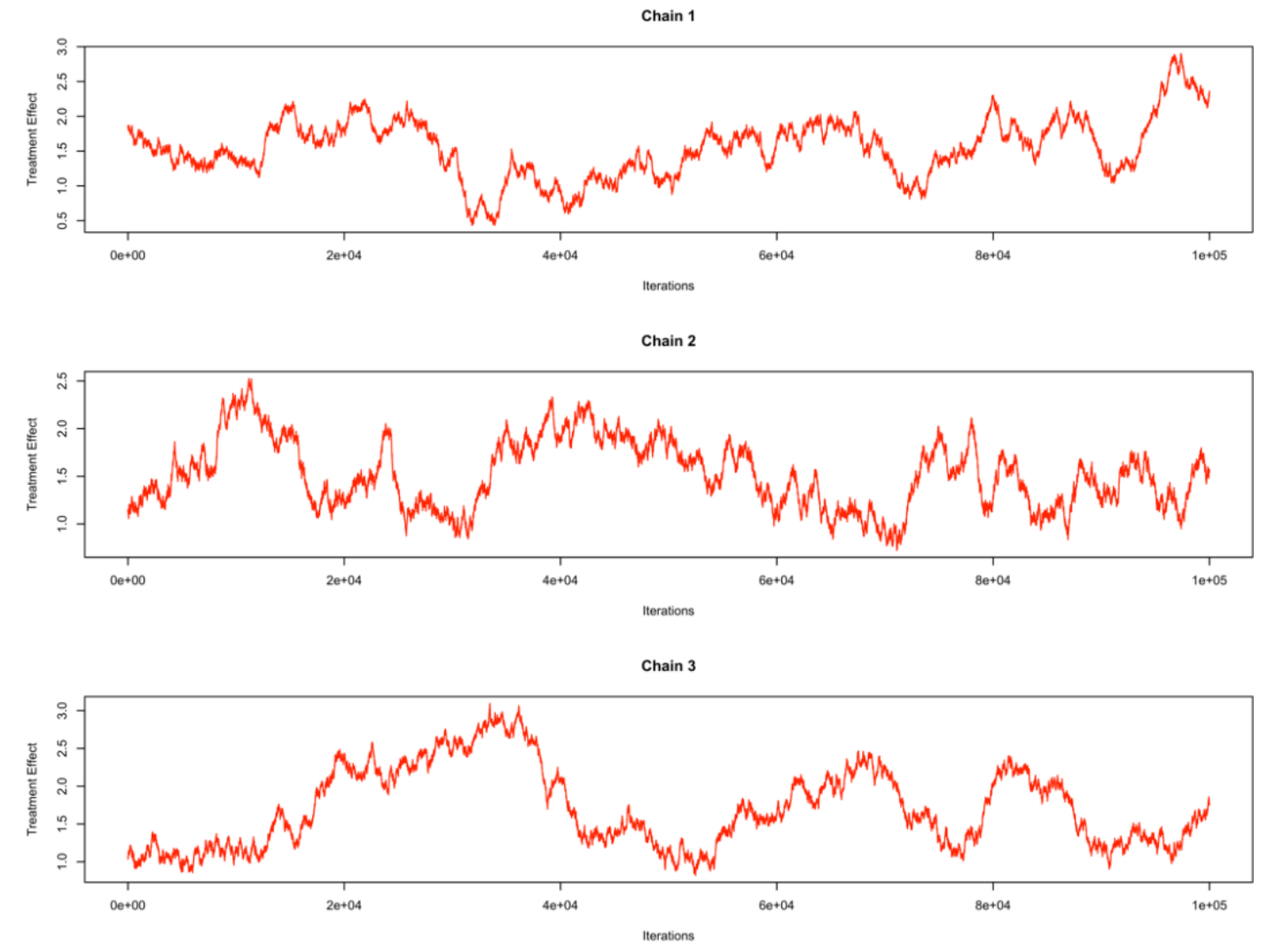

Figure 51. Trace plot Residual REC - TUN+CTG 
Chain 1
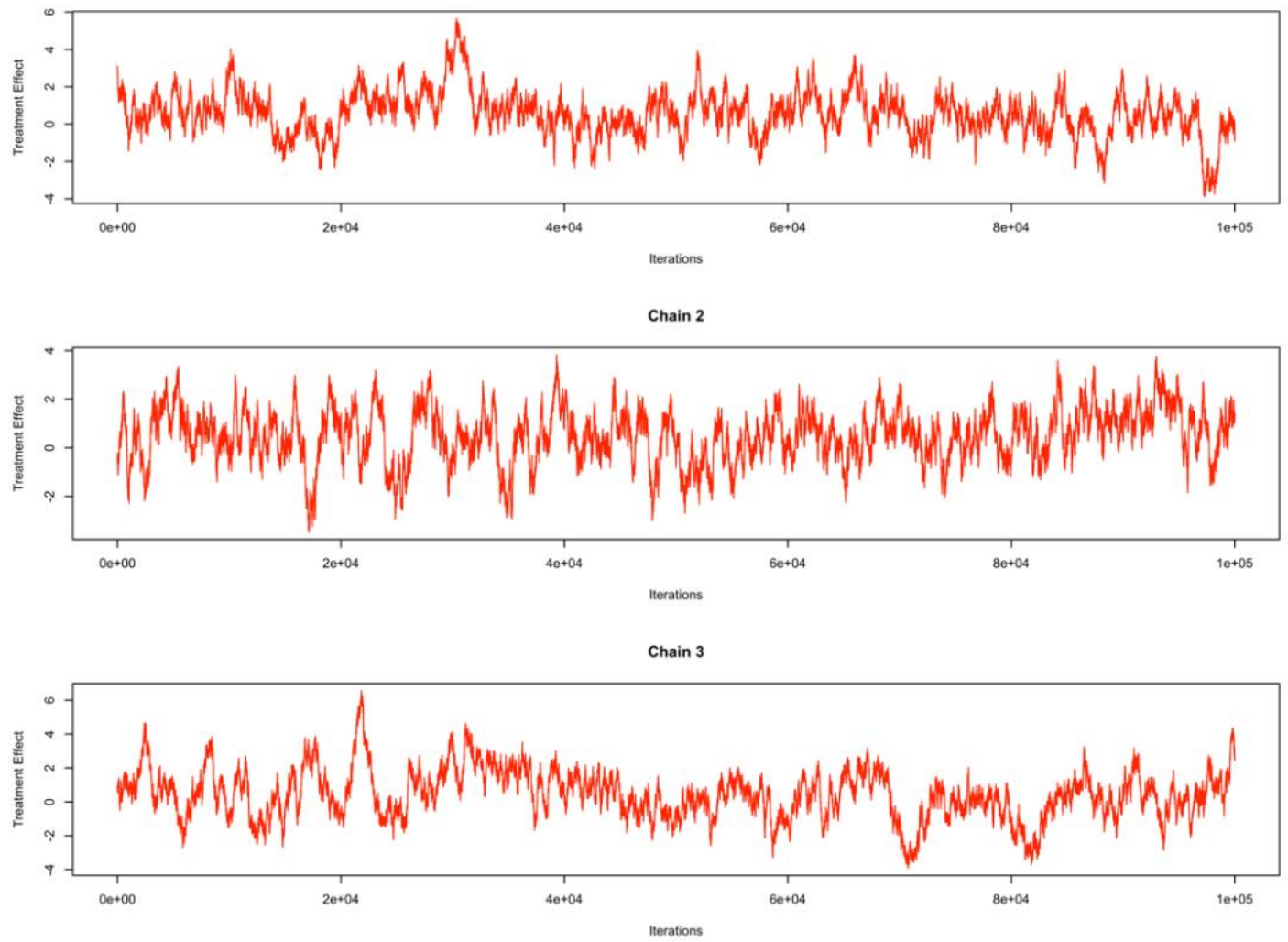

Figure 52. Trace plot Residual REC - LPF+CTG

Chain 1

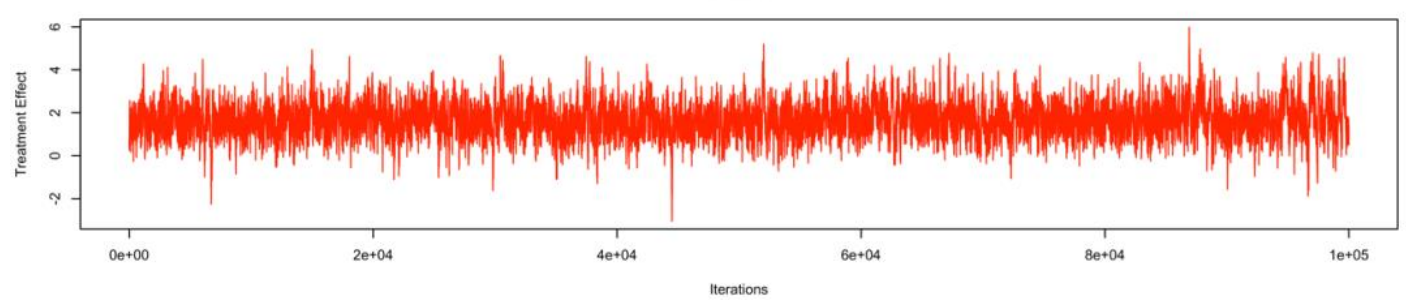

Chain 2

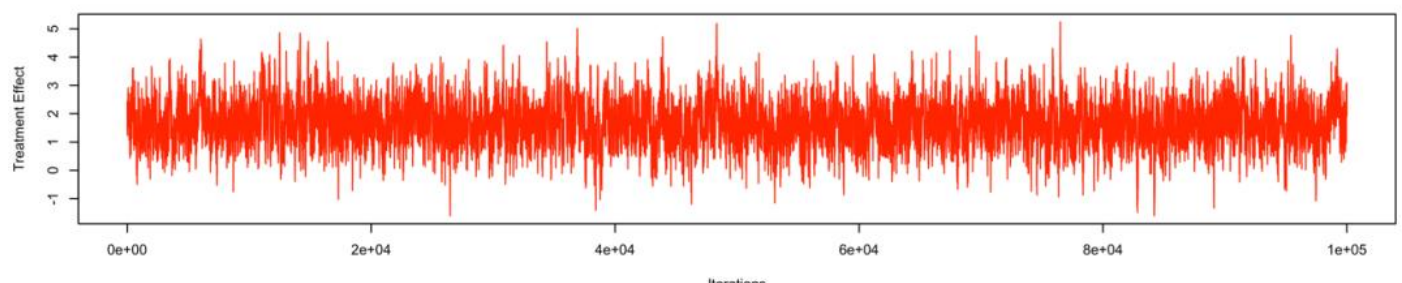

Chain 3

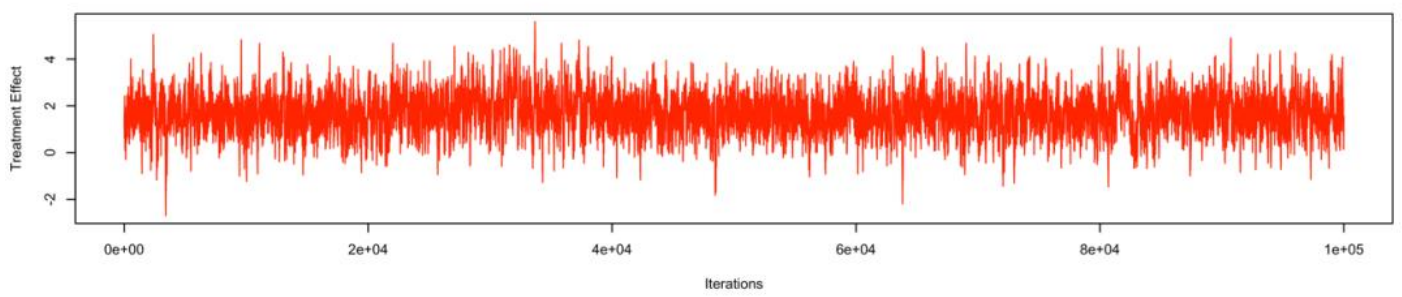

Figure 53. Trace plot Residual REC - LPF alone 
Chain 1
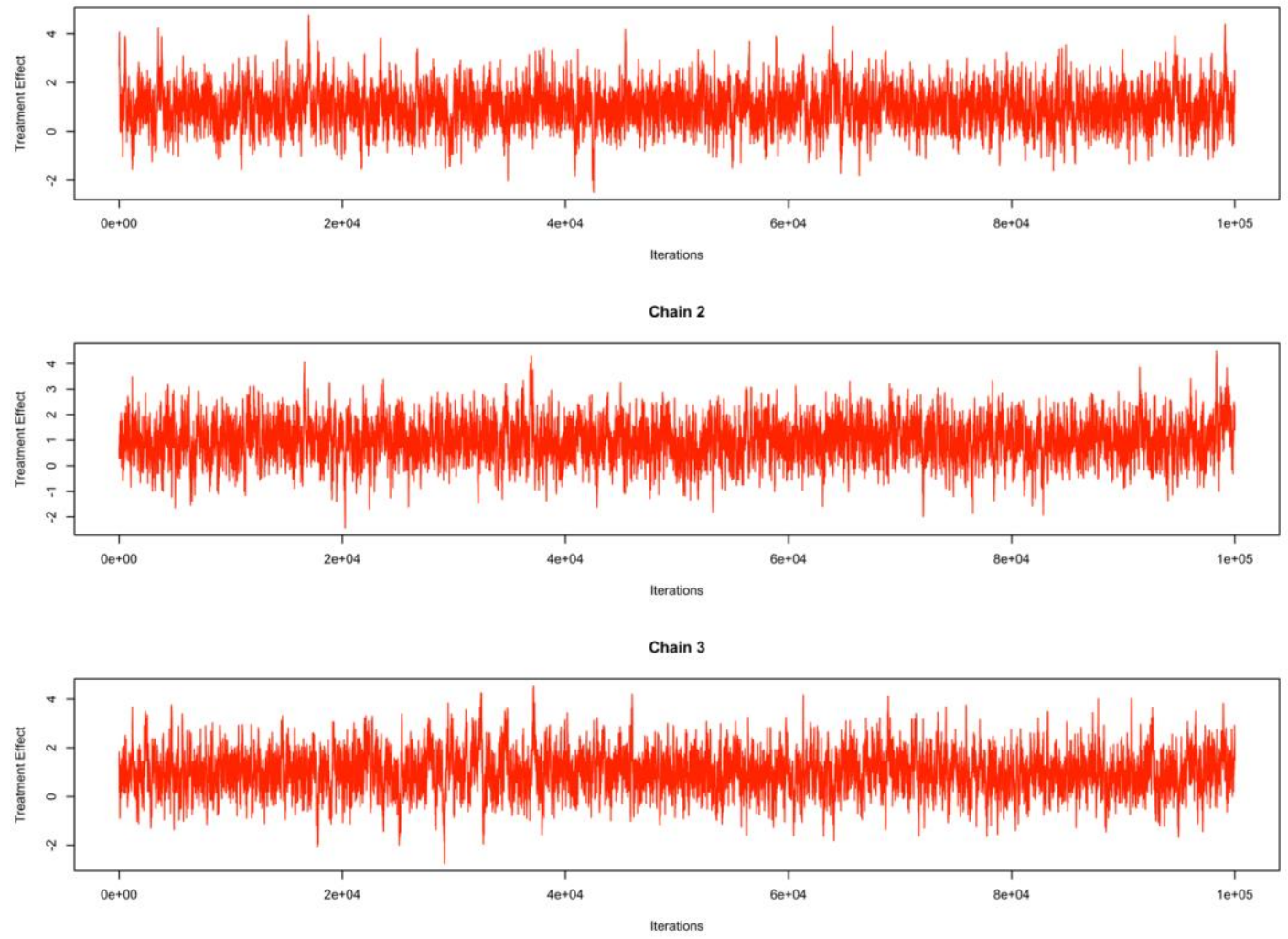

Figure 54. Trace plot Residual REC-FGG

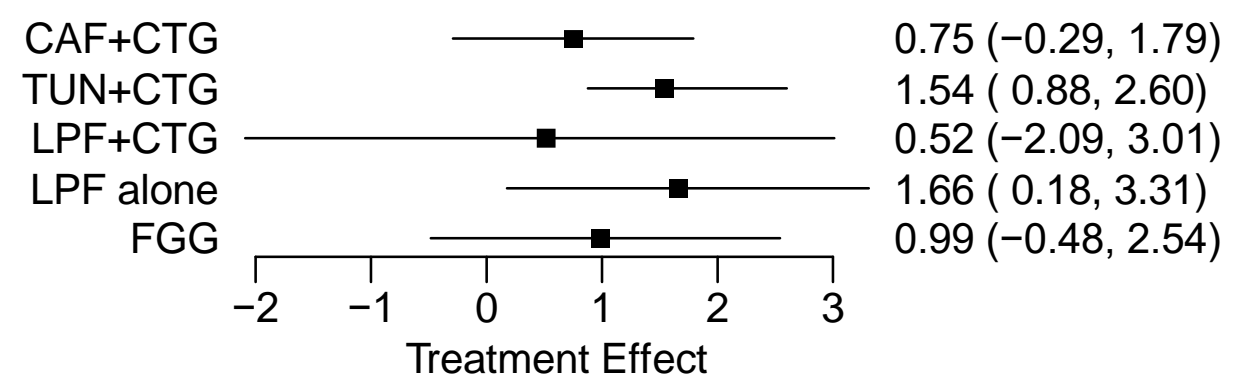

Figure 55. Absolute plot Residual REC

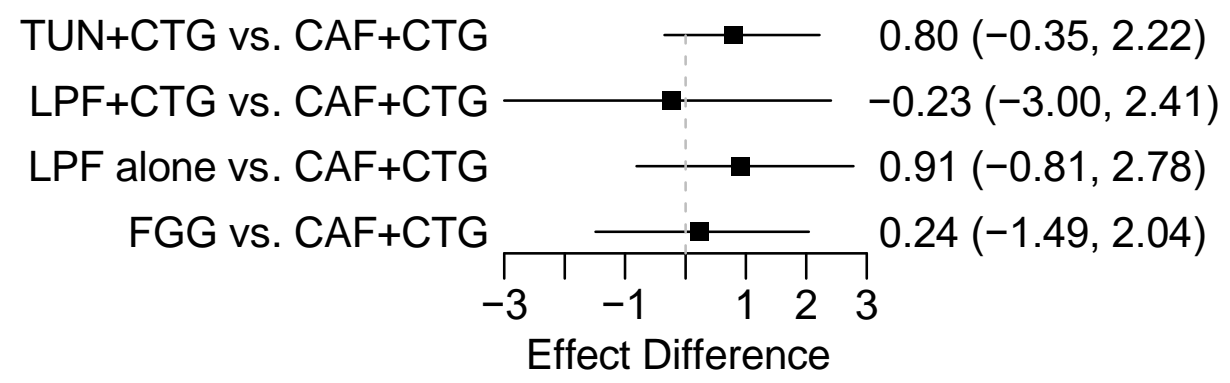

Figure 56. Contrast plot Residual REC-CAF+CTG as reference 


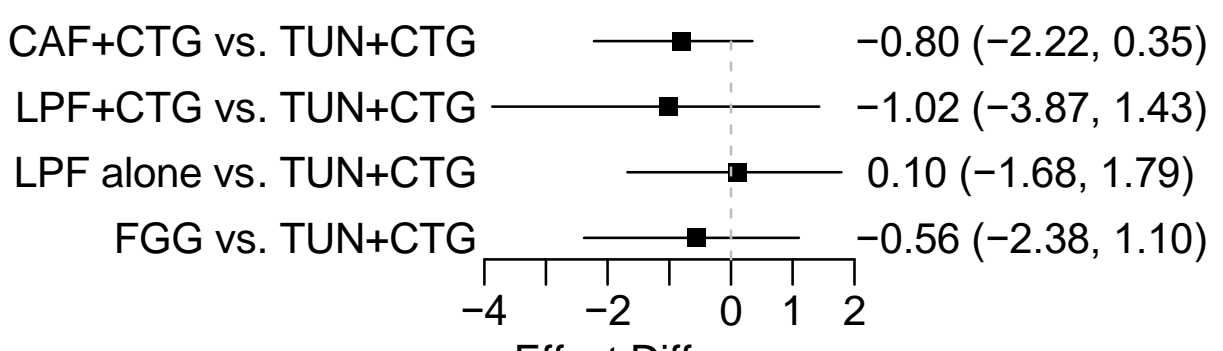

Effect Difference

Figure 57. Contrast plot Residual REC - TUN+CTG as reference

$\mathrm{CAF}+\mathrm{CTG}$ vs. $\mathrm{LPF}+\mathrm{CTG}$

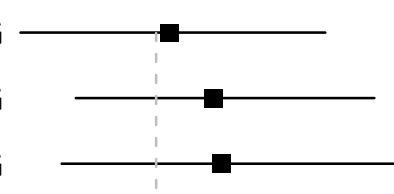

$0.23(-2.41,3.00)$

$\mathrm{TUN}+\mathrm{CTG}$ vs. $\mathrm{LPF}+\mathrm{CTG}$

$1.02(-1.43,3.87)$

$\mathrm{LPF}$ alone vs. $\mathrm{LPF}+\mathrm{CTG}$

$1.15(-1.68,4.30)$

$F G G$ vs. $L P F+C T G$

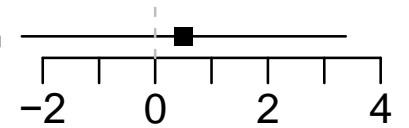

$0.50(-2.37,3.38)$

Effect Difference

Figure 58. Contrast plot Residual REC - LPF+CTG as reference

$\mathrm{CAF}+\mathrm{CTG}$ vs. LPF alone TUN+CTG vs. LPF alone $\longrightarrow-0.91(-2.78,0.81)$ $\mathrm{LPF}+\mathrm{CTG}$ vs. LPF alone $-0.10(-1.79,1.68)$ FGG vs. LPF alone

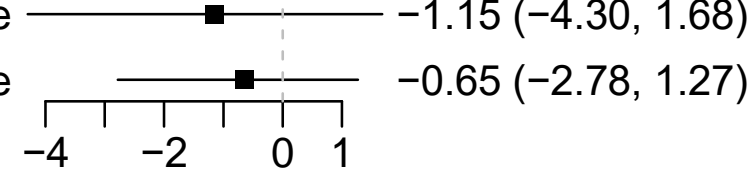

Effect Difference

Figure 59. Contrast plot Residual REC - LPF alone

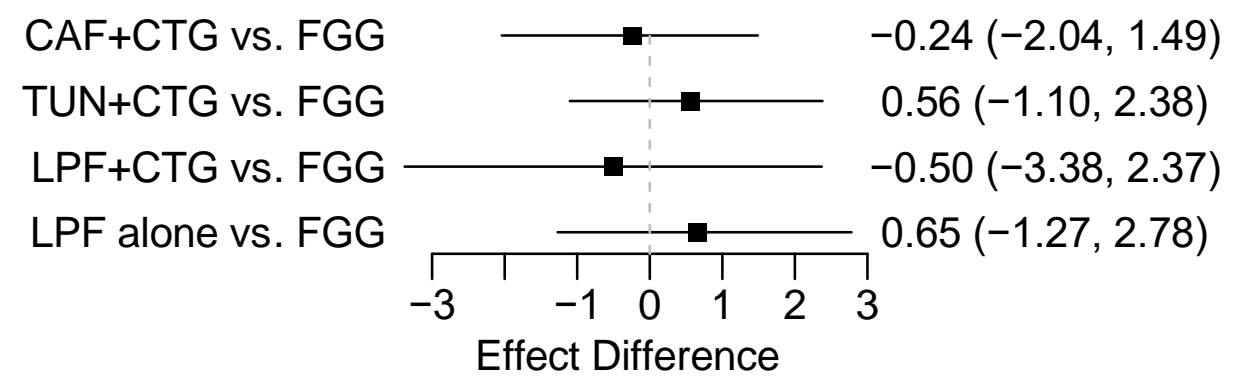

Figure 60. Contrast plot Residual REC - FGG 


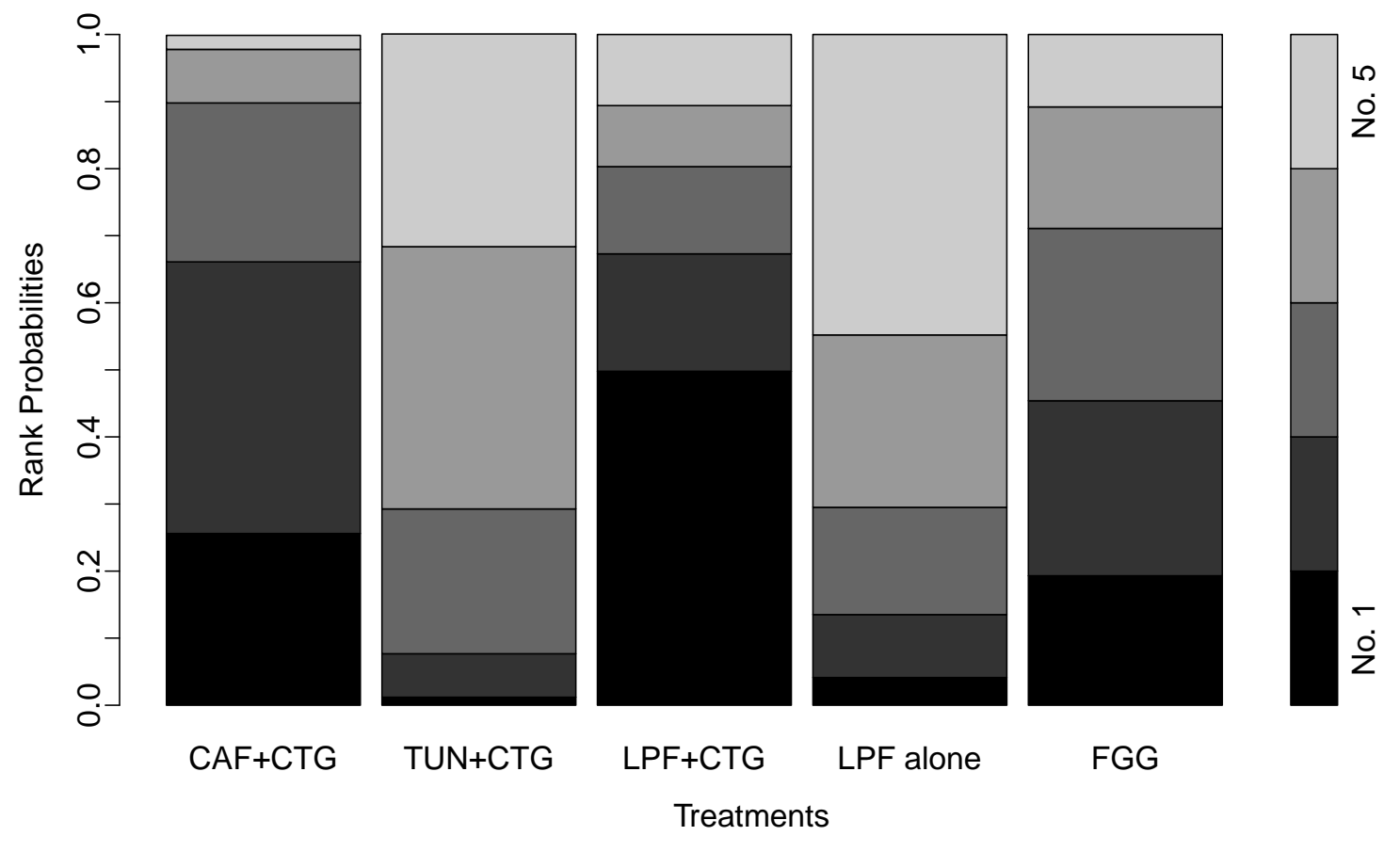

Figure 61. Ranking plot Residual Recession

\subsubsection{Change in probing depth (PPD change)}

For PPD change, the dataset consisted of 16 study arms, in particular 7 for CAF+CTG, 3 for TUN+CTG, 1 for LPF+CTG, 4 for LPF alone and 1 for FGG. The network plot is shown in Fig. 63: FGG is not connected to any other treatment groups directly or indirectly. The network meta-analysis showed the following results:

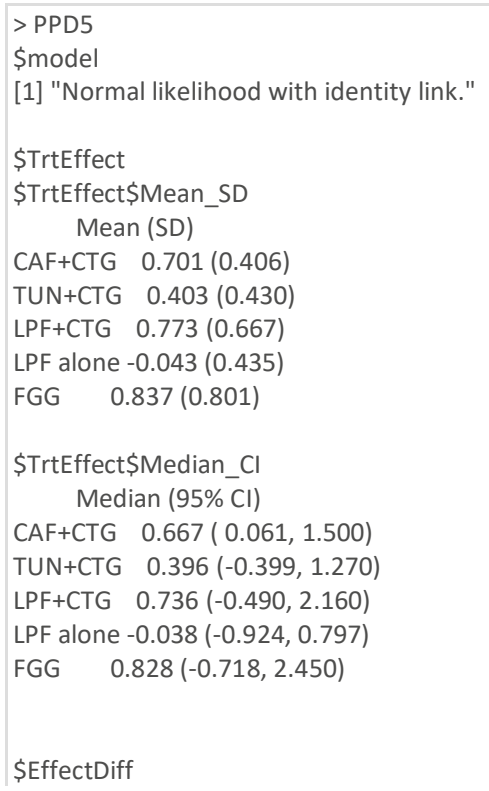




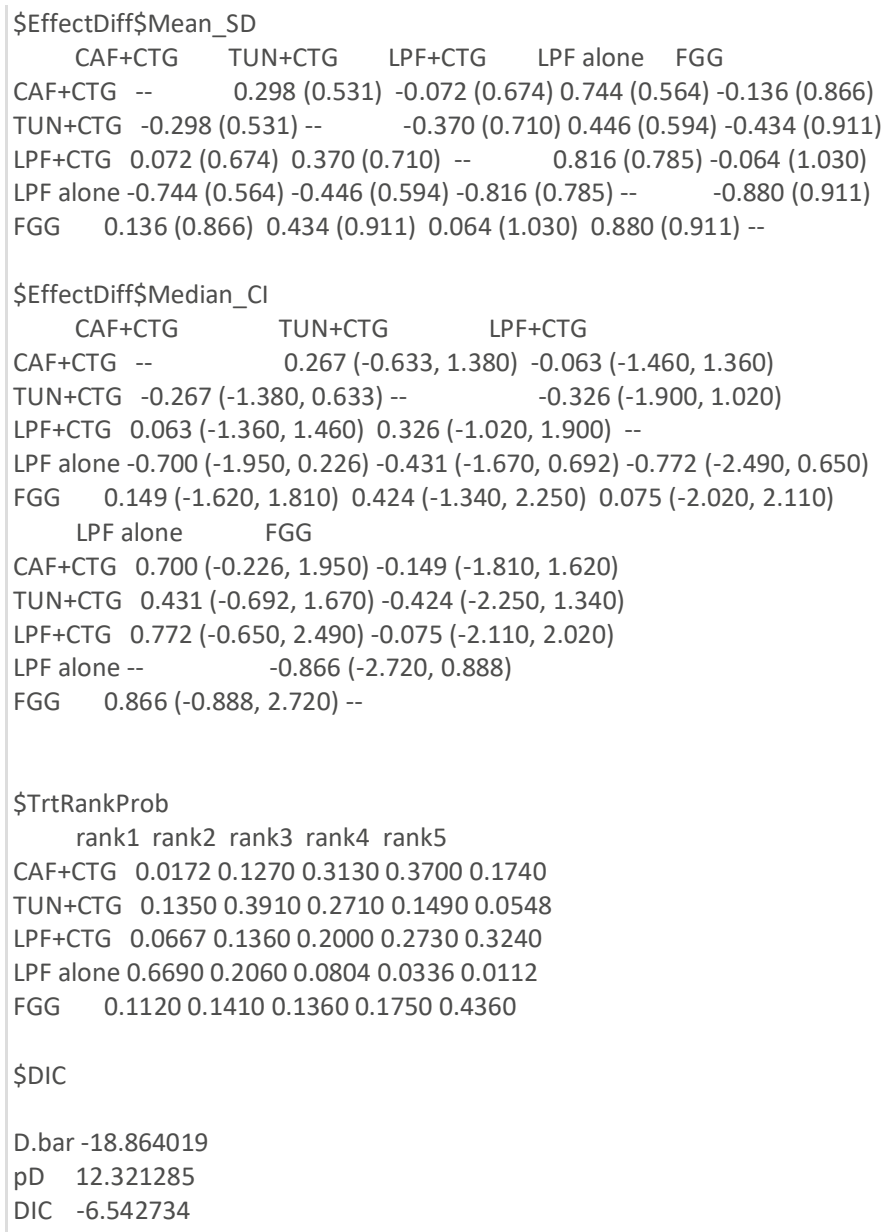

Posterior density plot and the trace plots for each treatment group are reported in Fig. 6469. The results from the network meta-analysis show that all the surgical procedures analyzed tend to increase the probing depth after intervention, except for LPF alone which is associate with a stability of the gingival margin ( $0.03 \mathrm{~mm}$ decrease in PPD). The increase in PPD following the other surgical approaches ranges between $0.39 \mathrm{~mm}$ with TUN+CTG and $0.83 \mathrm{~mm}$ with FGG. In all the cases, these differences are within $1 \mathrm{~mm}$. According to rank plot, the treatment with the highest probability of being the best, so not increasing the probing depth, is LPF alone (67\%), followed by TUN+CTG (13\%) and FGG (11\%). 


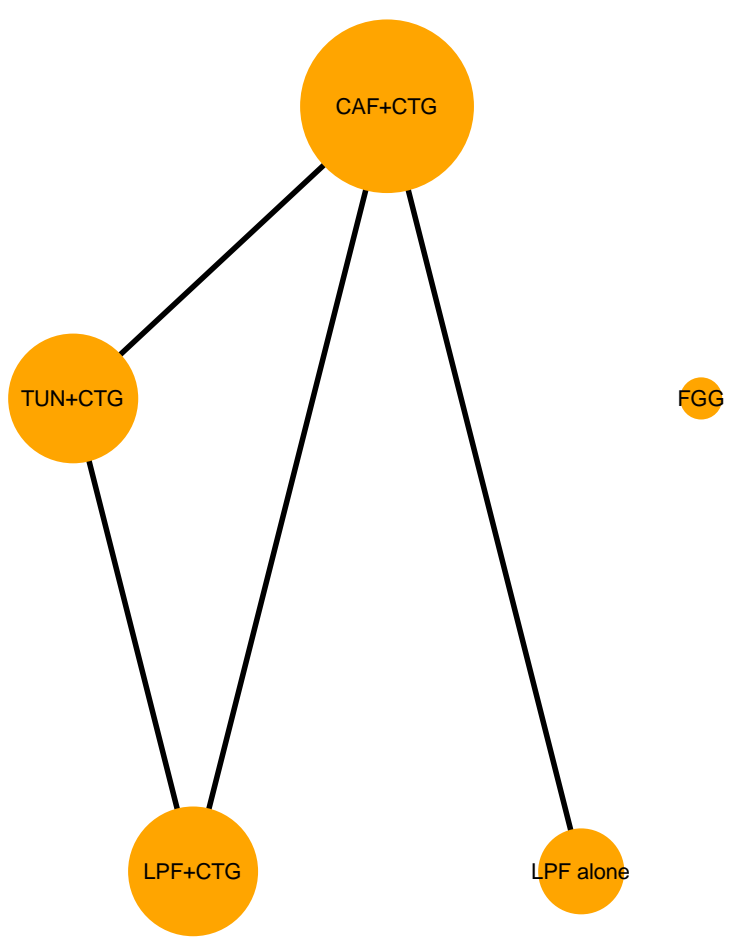

Figure 62. Network plot PPD

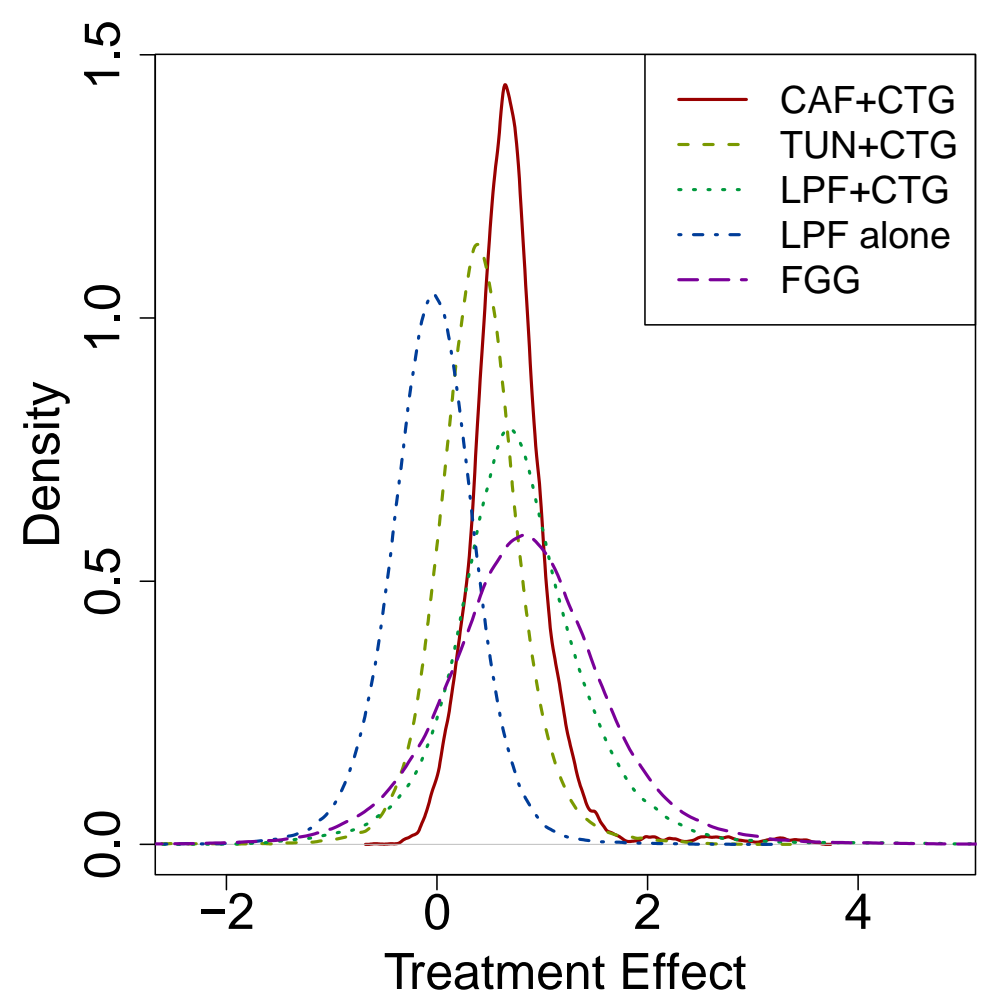

Figure 63. Density plot PPD 
Chain 1
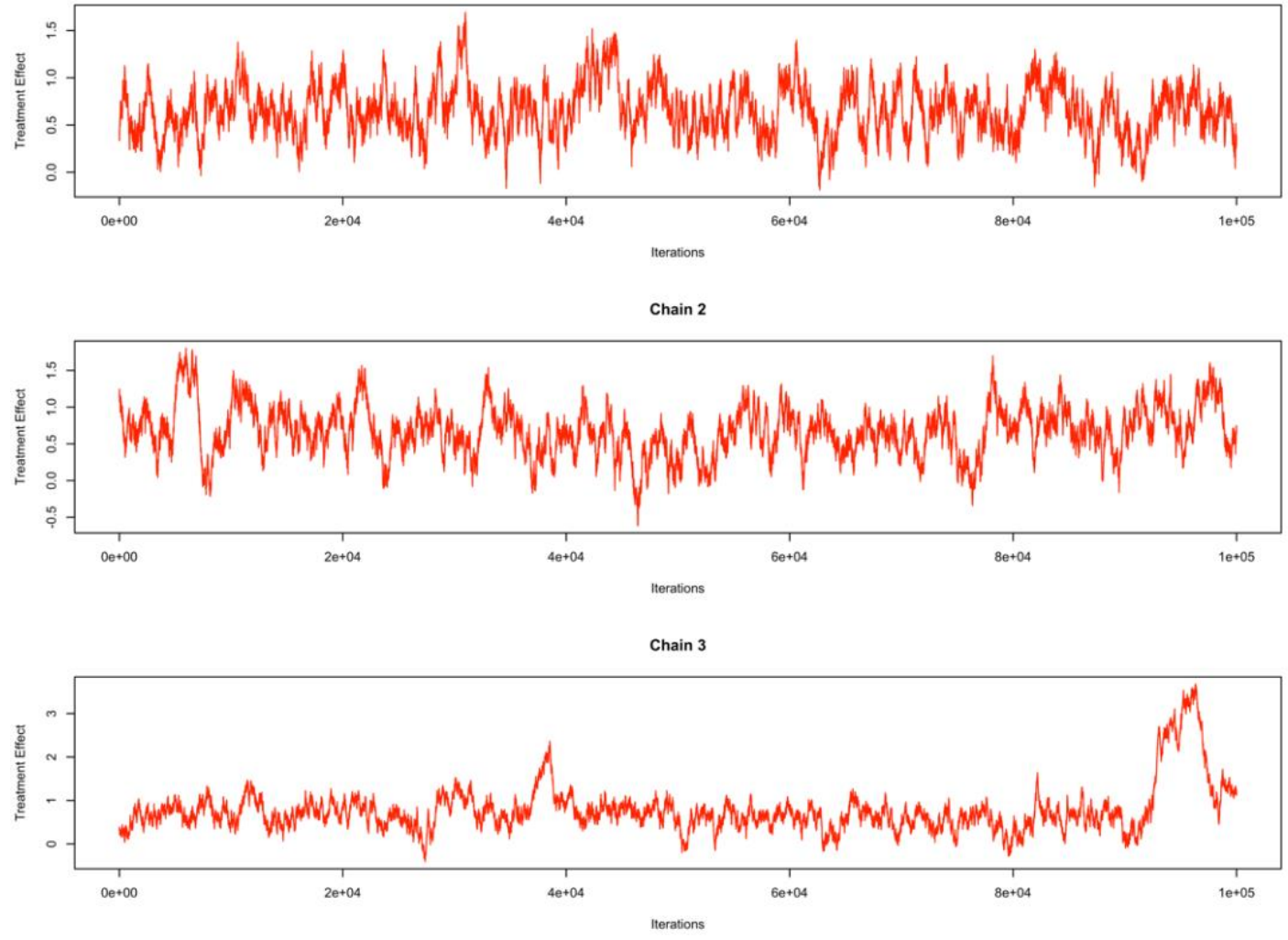

Figure 64. Trace plot PPD - CAF+CTG

Chain 1
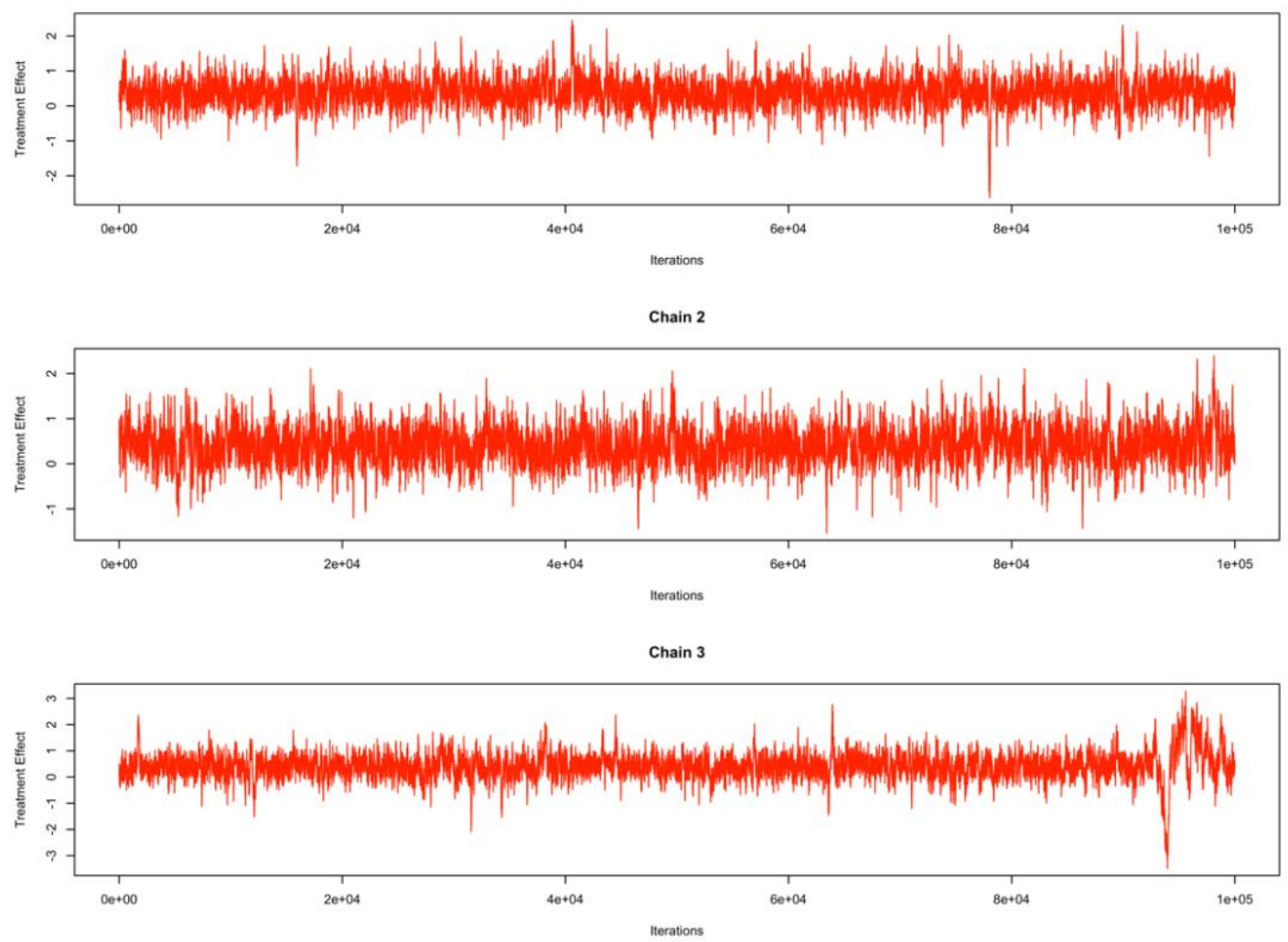

Figure 65. Trace plot PPD - TUN+CTG 
Chain 1
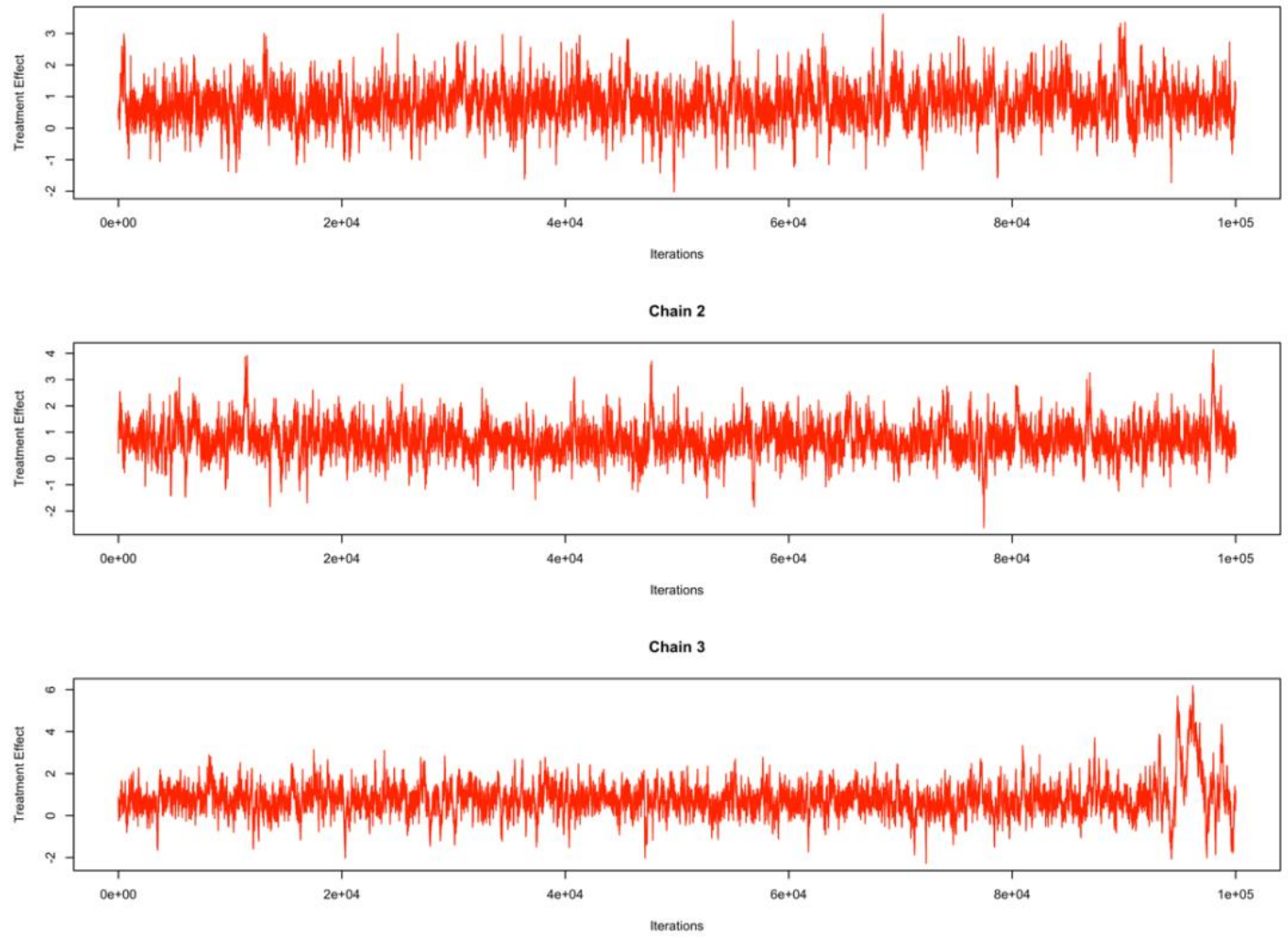

Figure 66. Trace plot PPD - $L P F+C T G$
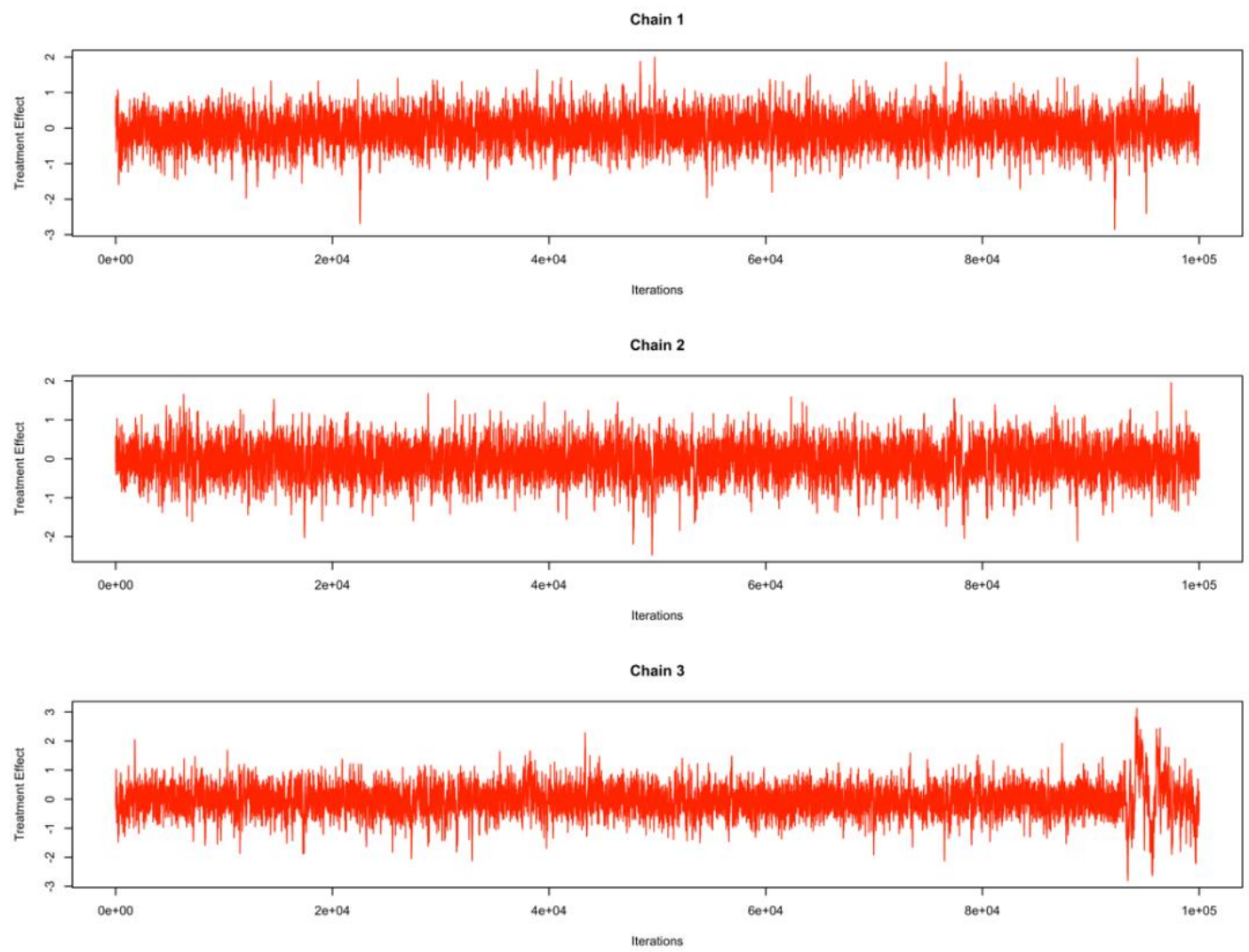

Figure 67. Trace plot PPD - LPF alone 
Chain 1
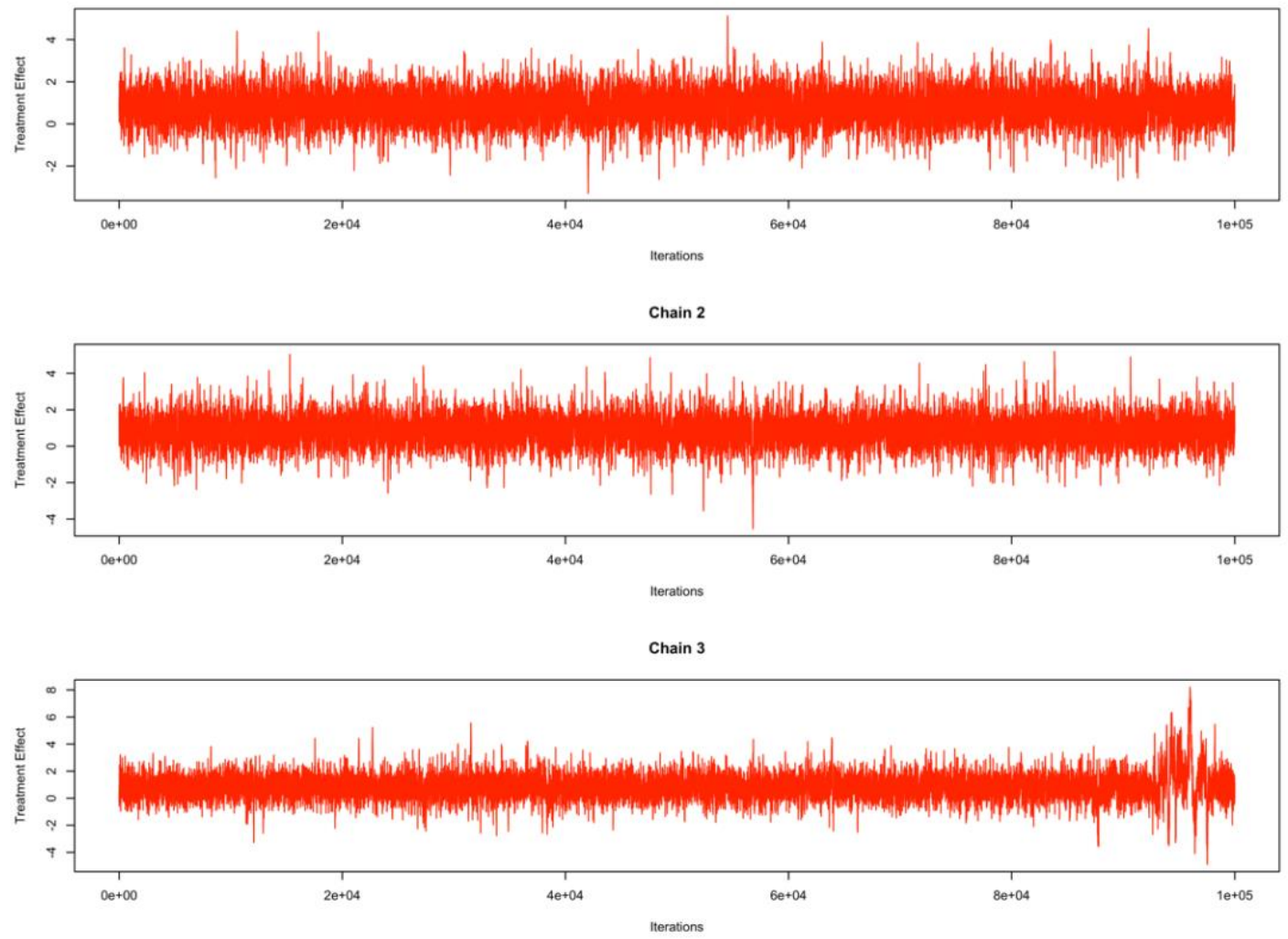

Figure 68. Trace plot PPD - FGG

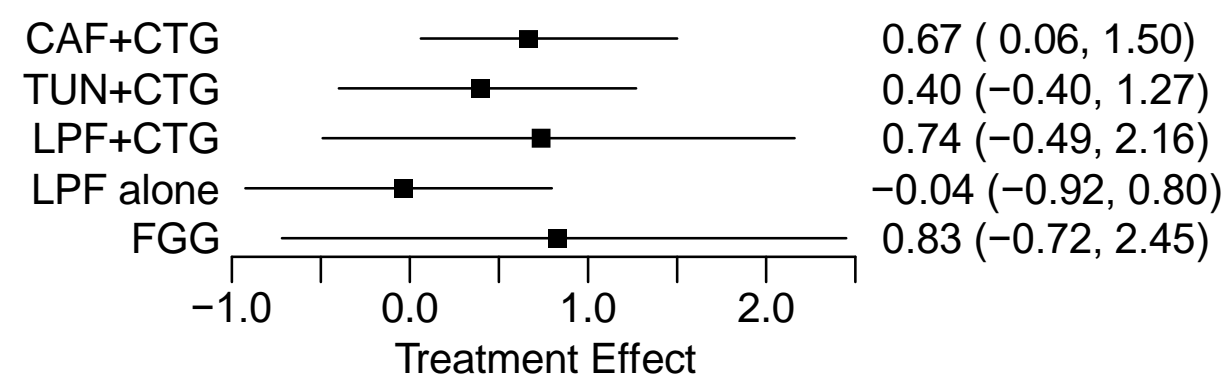

Figure 69. Absolute plot PPD

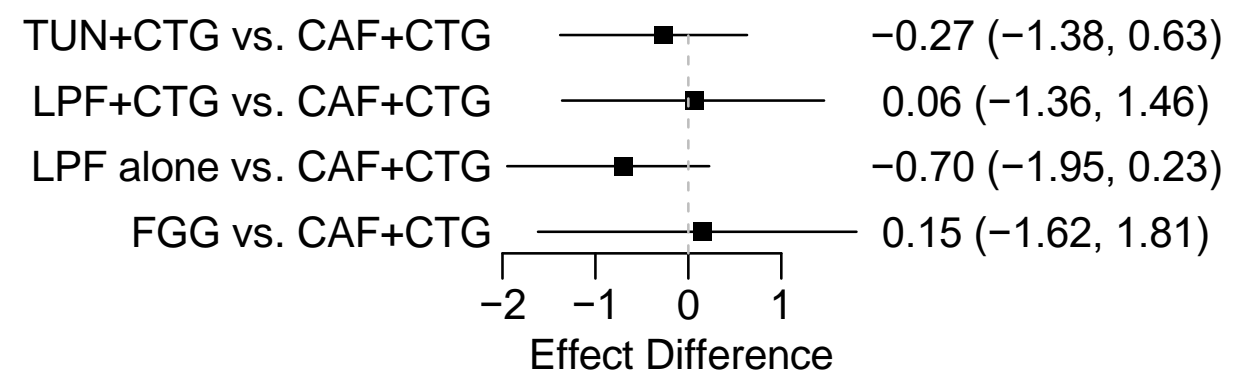

Figure 70. Contrast plot PPD - CAF+CTG as reference 
$\mathrm{CAF}+\mathrm{CTG}$ vs. $\mathrm{TUN}+\mathrm{CTG}$

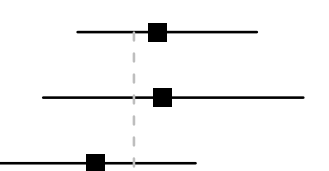

$0.27(-0.63,1.38)$

$\mathrm{LPF}+\mathrm{CTG}$ vs. TUN+CTG

$0.33(-1.02,1.90)$

LPF alone vs. TUN+CTG

$-0.43(-1.67,0.69)$

FGG vs. TUN+CTG

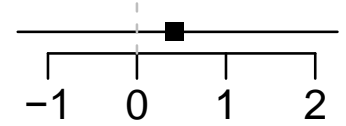

$0.42(-1.34,2.25)$

Effect Difference

Figure 71. Contrast plot PPD - TUN+CTG as reference

$\mathrm{CAF}+\mathrm{CTG}$ vs. $\mathrm{LPF}+\mathrm{CTG}$ $\mathrm{TUN}+\mathrm{CTG}$ vs. $\mathrm{LPF}+\mathrm{CTG}$

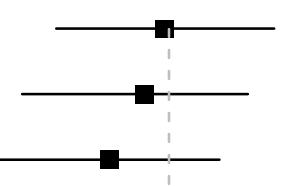

$-0.06(-1.46,1.36)$

$\mathrm{LPF}$ alone vs. $\mathrm{LPF}+\mathrm{CTG}$ $-0.33(-1.90,1.02)$

$F G G$ vs. $L P F+C T G$

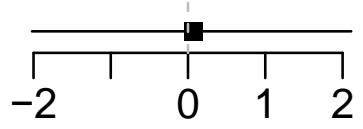

$-0.77(-2.49,0.65)$

$0.07(-2.02,2.11)$

Effect Difference

Figure 72. Contrast plot PPD - $L P F+C T G$ as reference

$\mathrm{CAF}+\mathrm{CTG}$ vs. LPF alone TUN+CTG vs. LPF alone

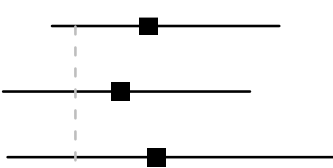

$0.70(-0.23,1.95)$

$\mathrm{LPF}+\mathrm{CTG}$ vs. LPF alone $0.43(-0.69,1.67)$

FGG vs. LPF alone

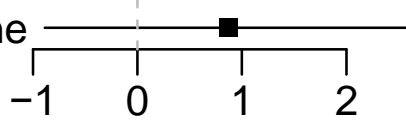

$0.77(-0.65,2.49)$ $0.87(-0.89,2.72)$

Effect Difference

Figure 73. Contrast plot PPD - LPF alone as reference

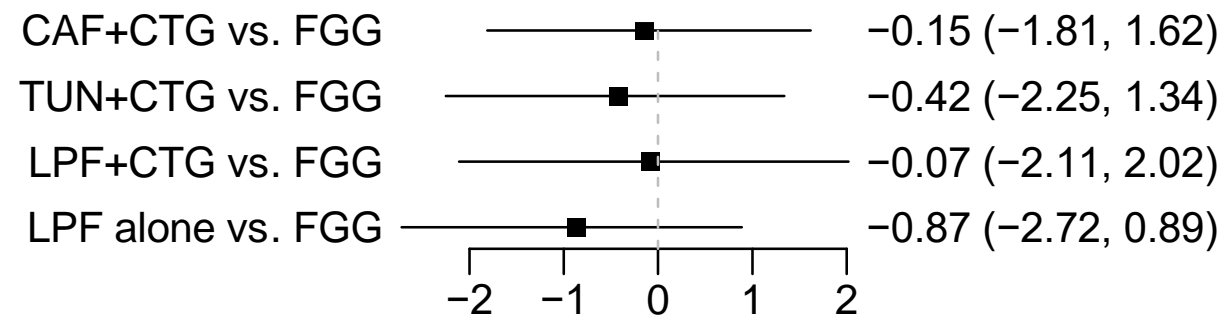

Effect Difference

Figure 74. Contrast plot PPD - FGG as reference 


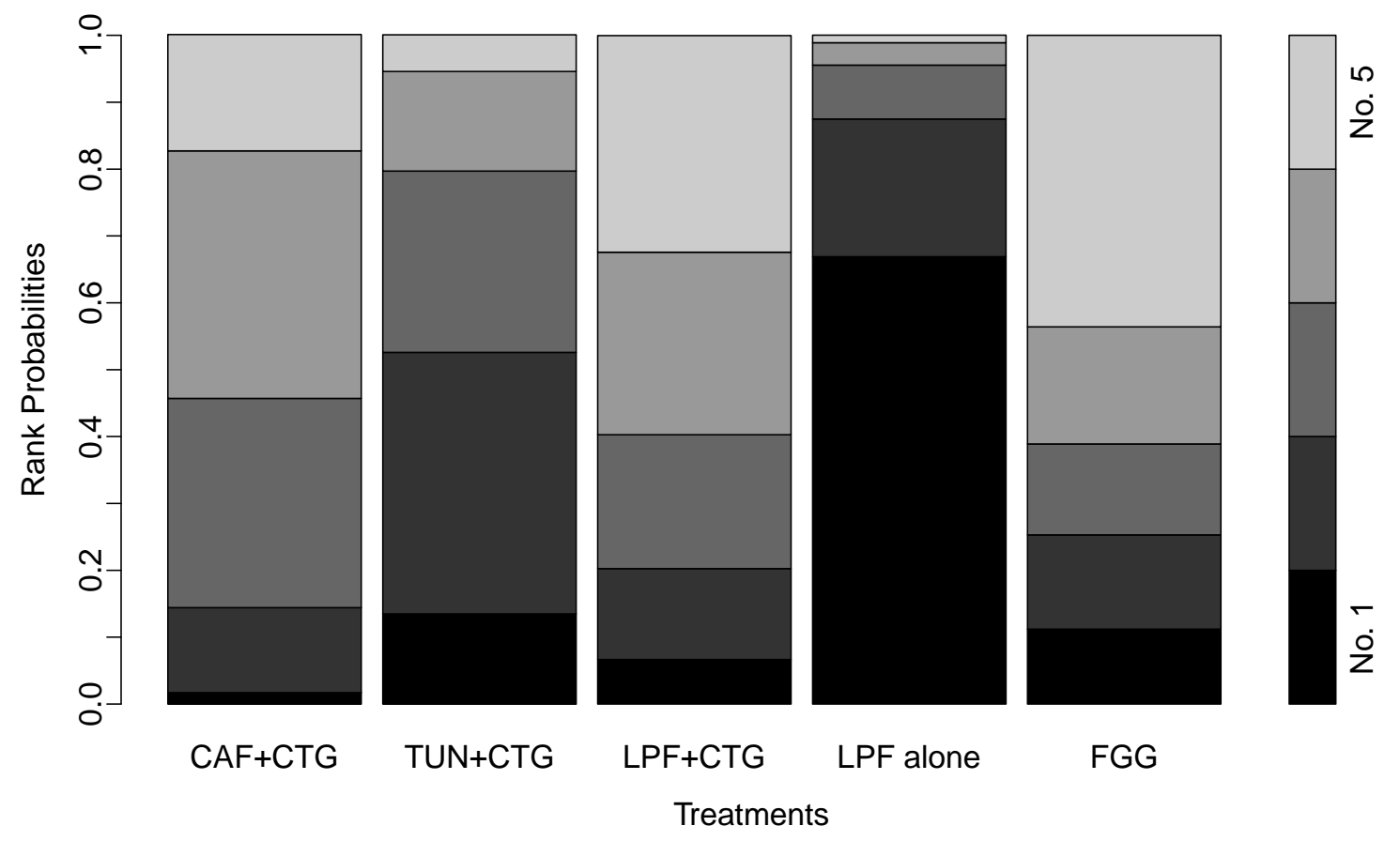

Figure 75. Ranking plot PPD

\subsubsection{Residual PPD}

For residual PPD, the dataset consisted of 16 study arms, in particular 7 for CAF+CTG, 3 for TUN+CTG, 1 for LPF+CTG, 4 for LPF alone and 1 for FGG. The network plot is shown in Fig. 77. The network meta-analysis showed the following results:

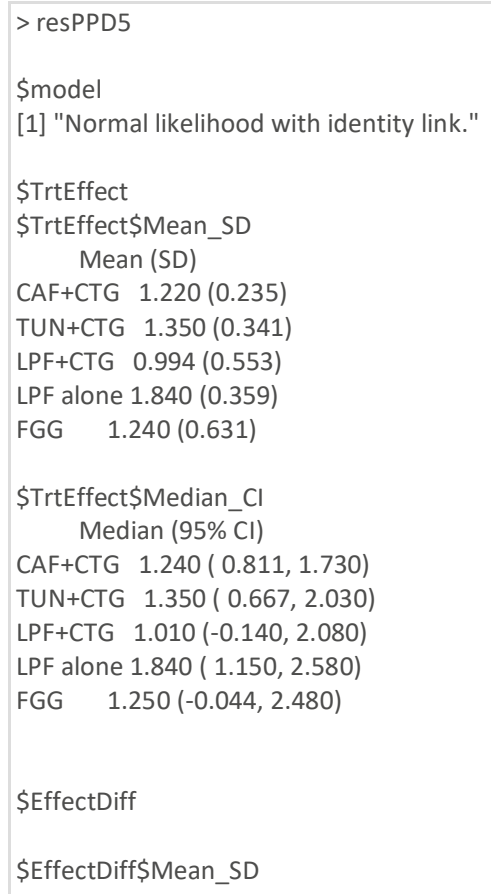




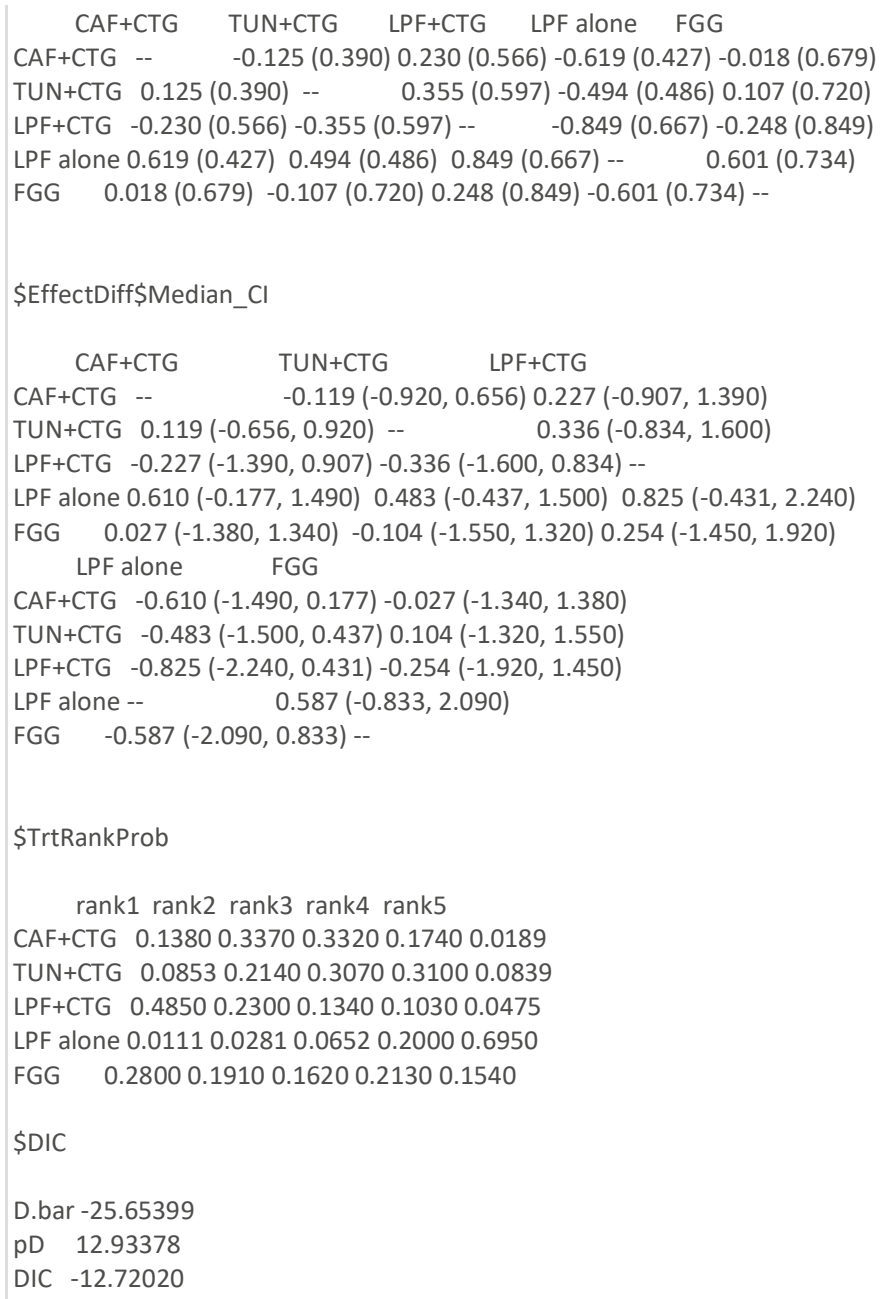

Posterior density plot and the trace plots for each treatment group are reported in Fig. 7883. The residual PPD amounts to $1.01 \mathrm{~mm}$ for $\mathrm{LPF}+\mathrm{CTG}, 1.24 \mathrm{~mm}$ for $\mathrm{CAF}+\mathrm{CTG}, 1.25$ mm for FGG, $1.35 \mathrm{~mm}$ for TUN+CTG and 1.84 for LPF alone. No significant differences among treatments are present. Probabilistically, LPF+CTG is associated with the higher chance (48.5\%) of being the best treatment, that is LPF+CTG is more likely to be associated with the shallowest residual PPD. 


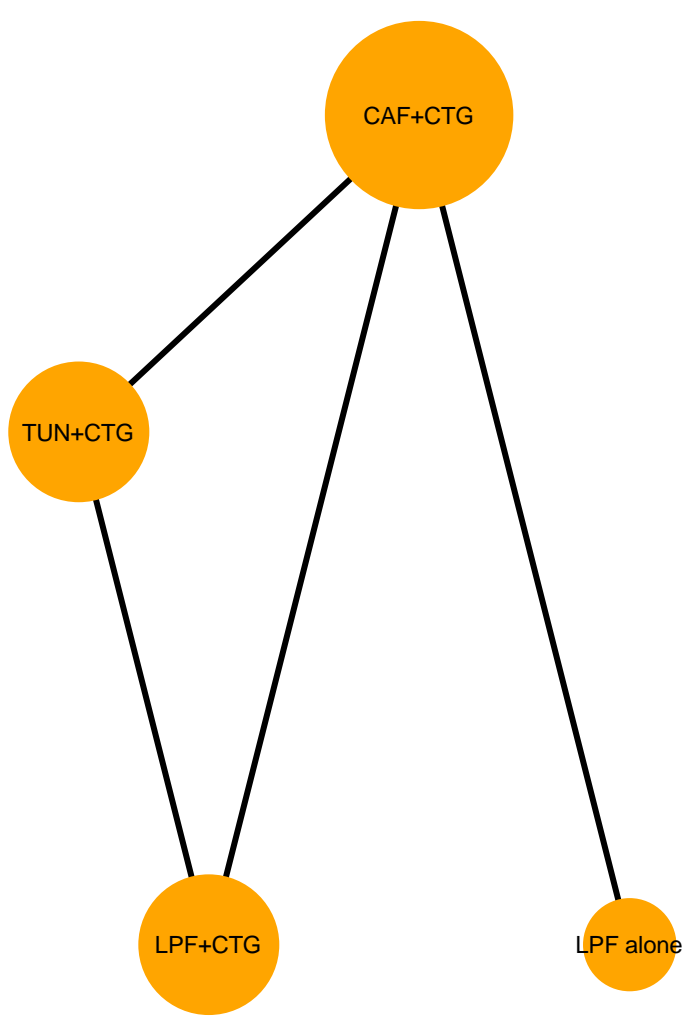

Figure 76. Network plot Residual PPD

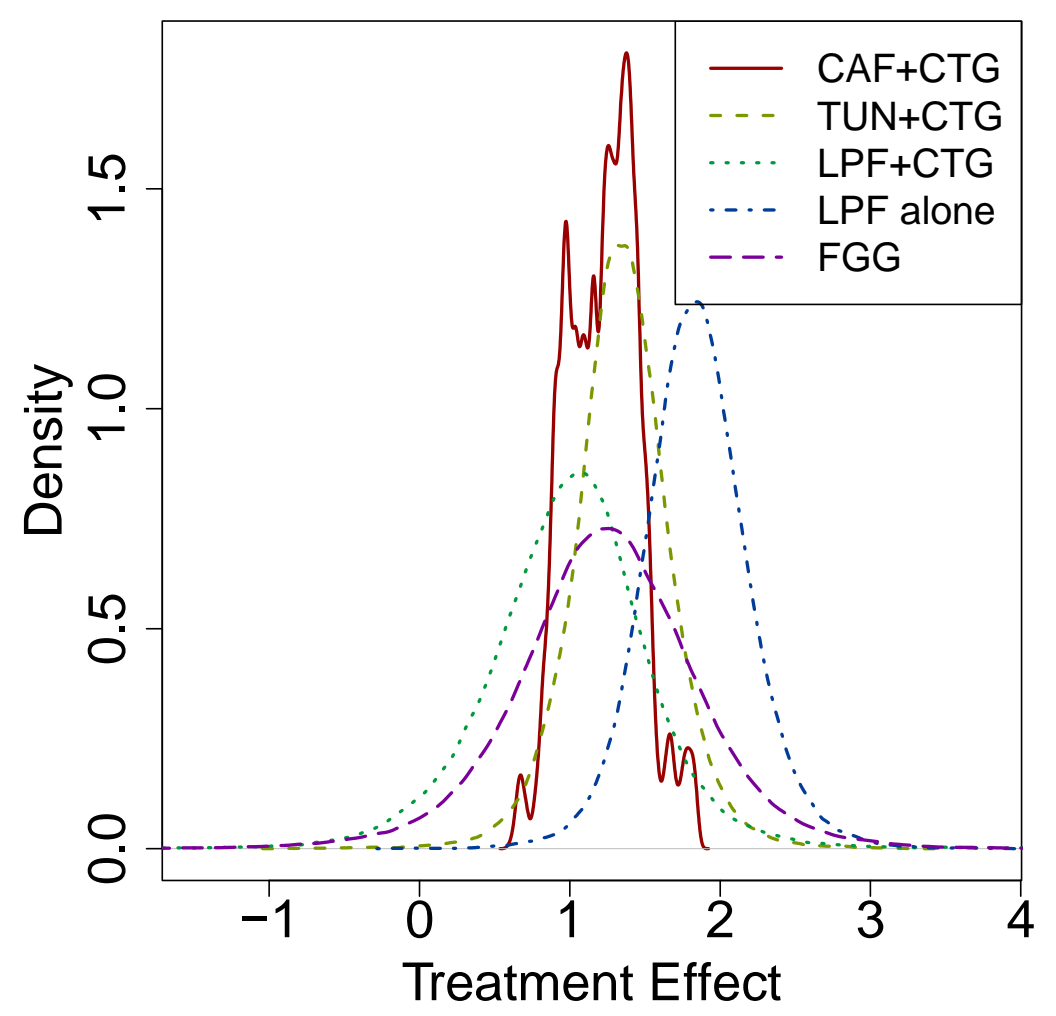

Figure 77. Density plot Residual PPD 
Chain 1
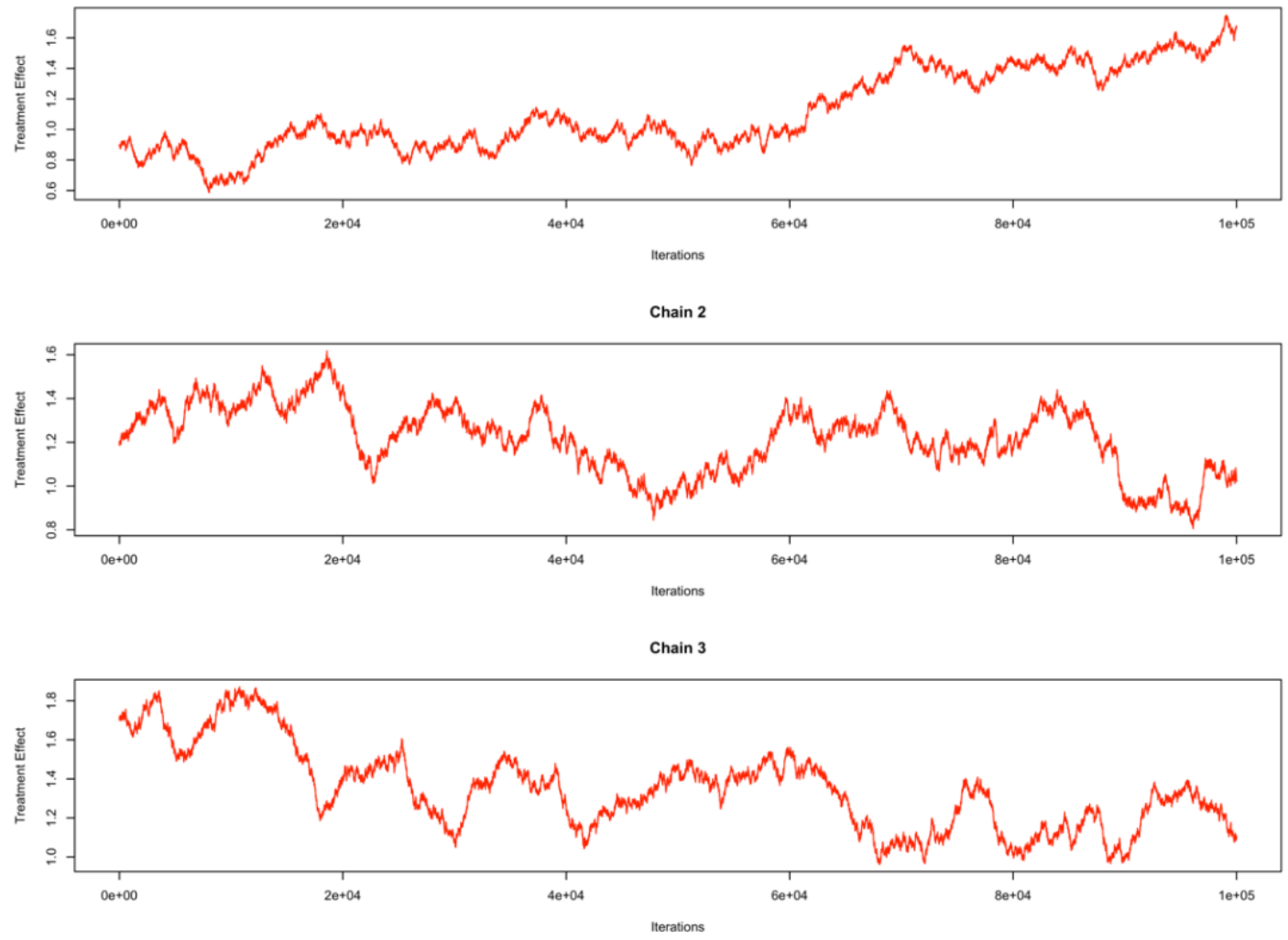

Figure 78. Trace plot Residual PPD - CAF+CTG
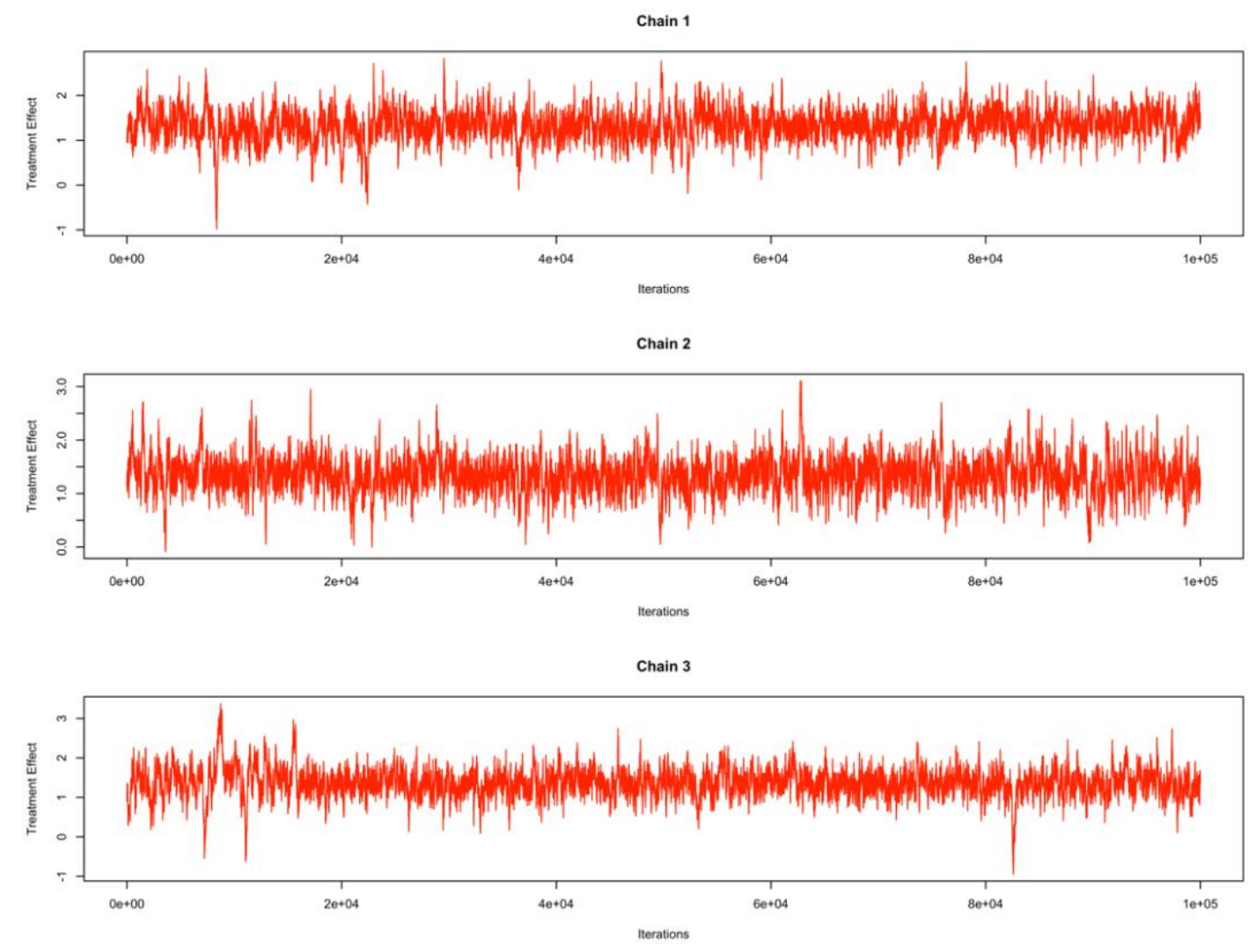

Figure 79. Trace plot Residual PPD - TUN+CTG 
Chain 1
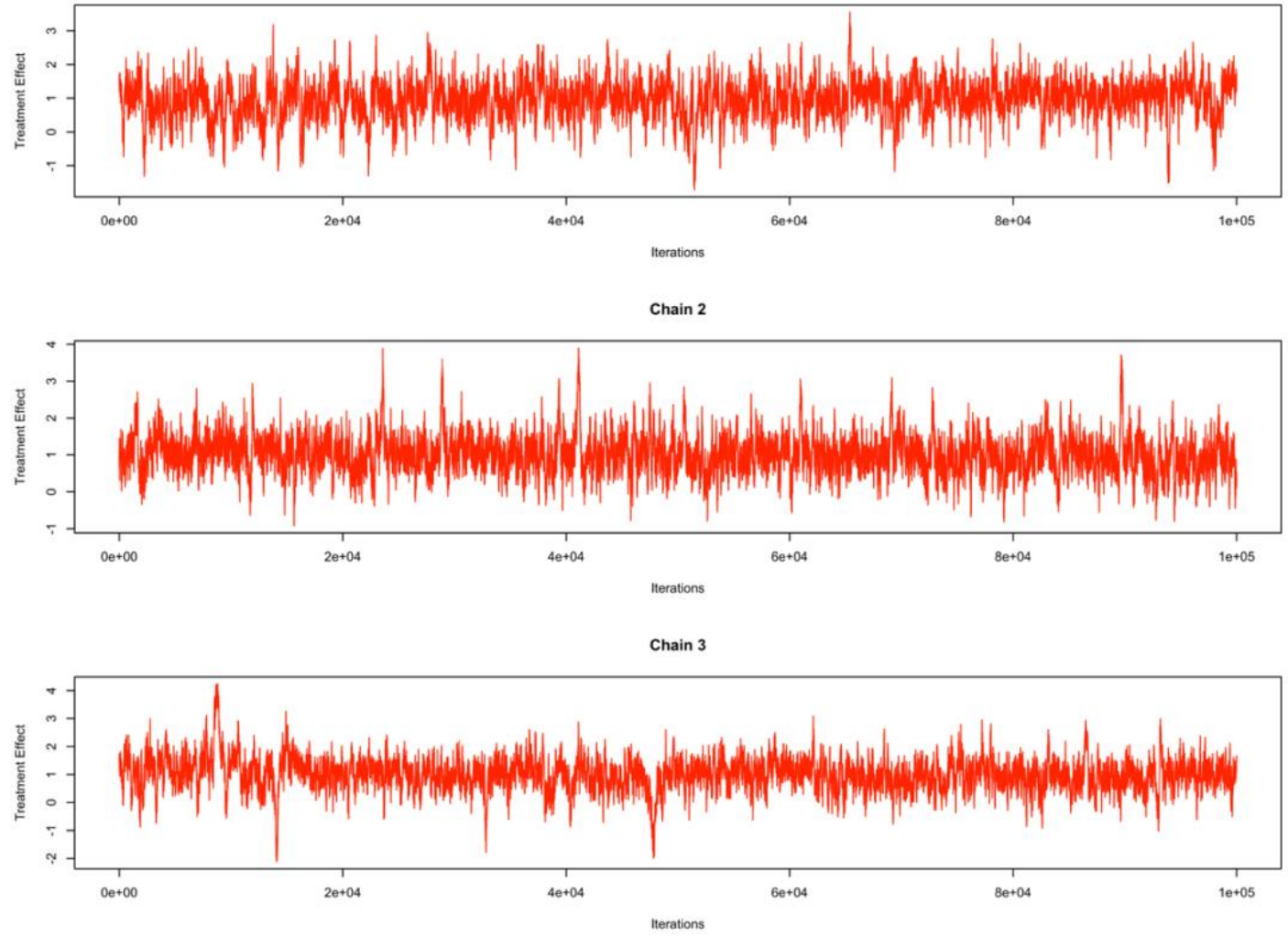

Figure 80. Trace plot Residual PPD - LPF+CTG

Chain 1
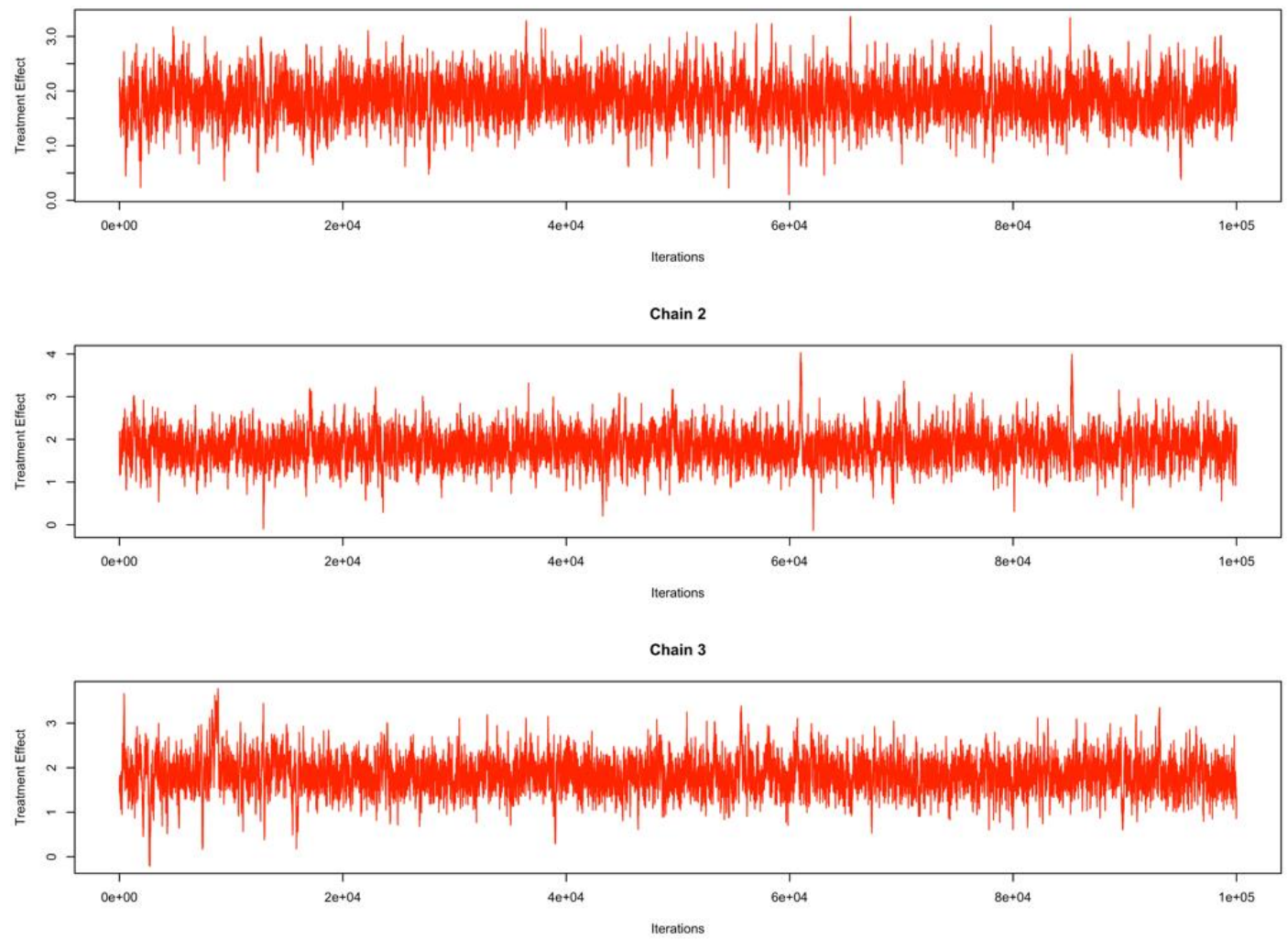

Figure 81. Trace plot Residual PPD - LPF alone 
Chain 1
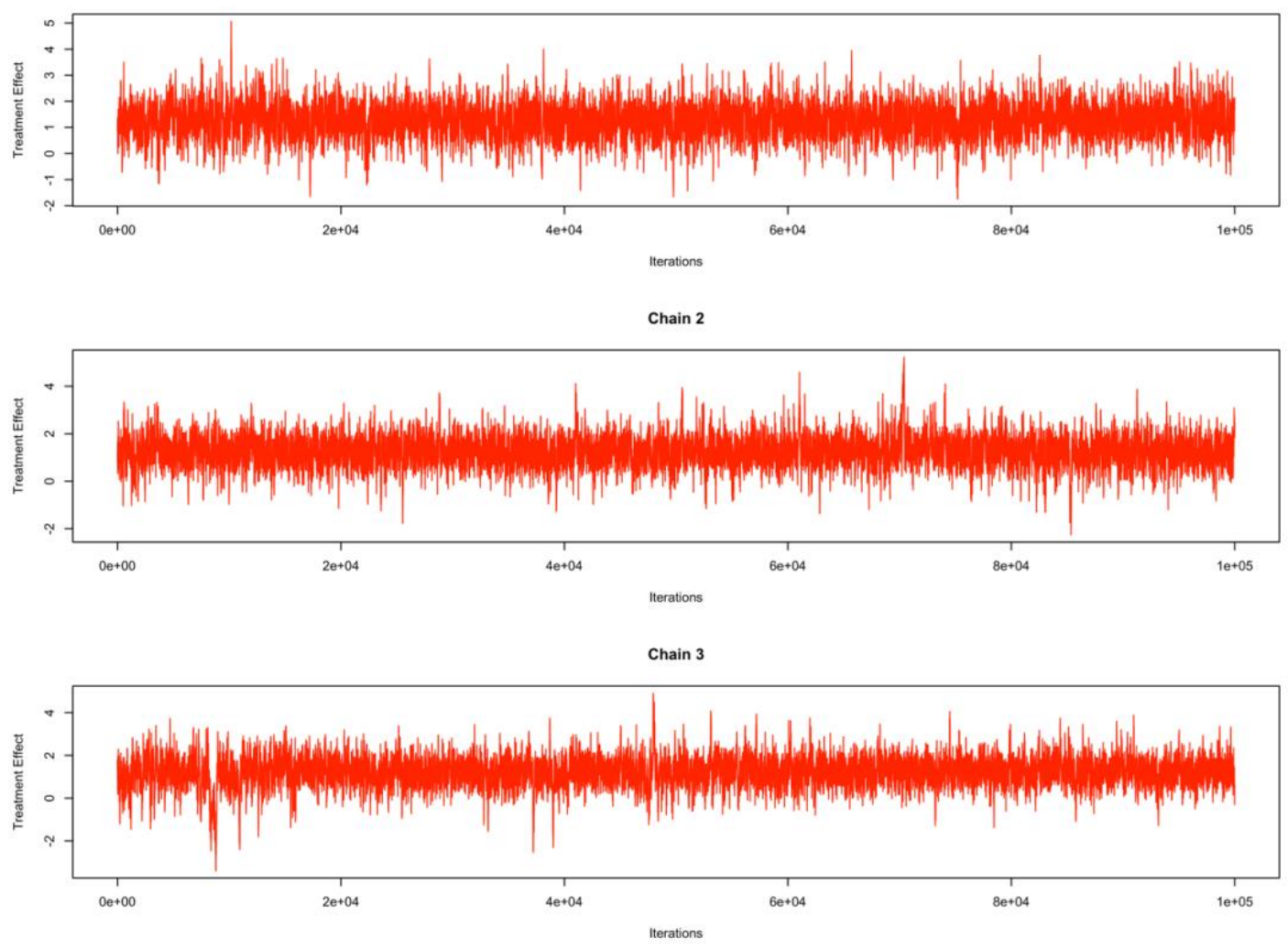

Figure 82. Trace plot Residual PPD - FGG

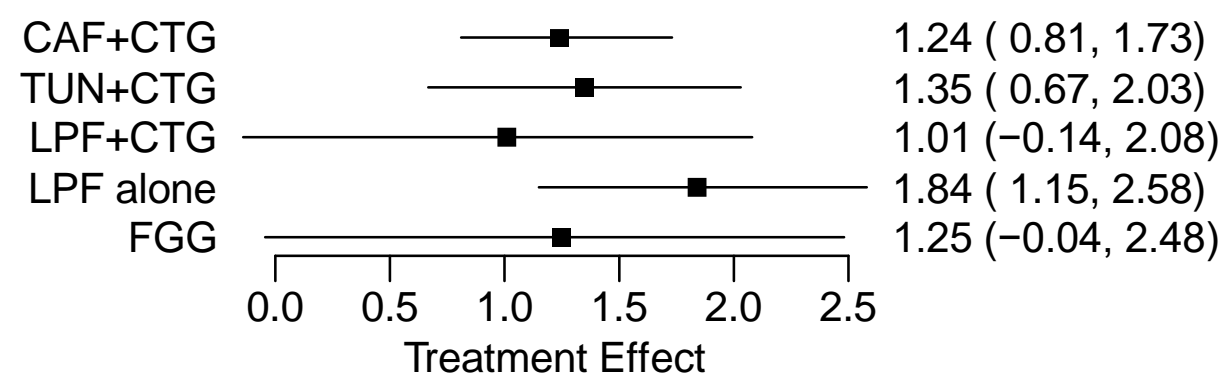

Figure 83. Absolute plot Residual PPD

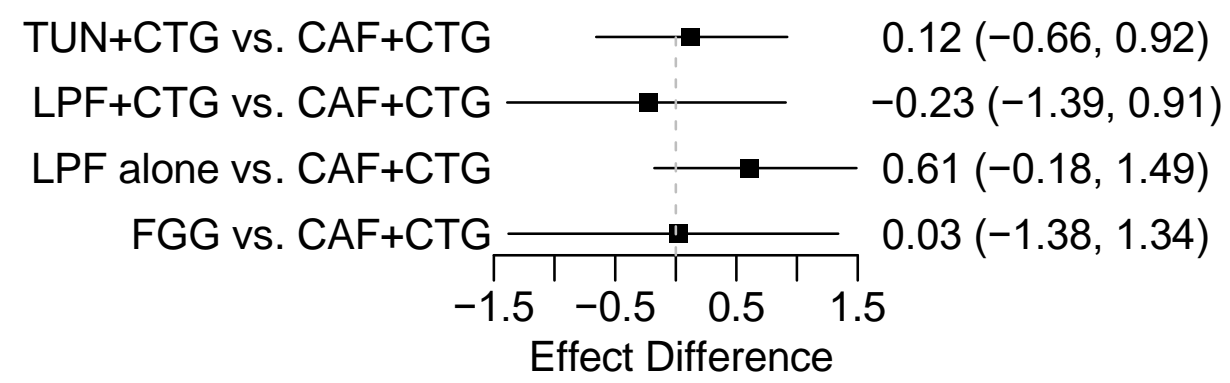

Figure 84. Contrast plot Residual PPD $-C A F+C T G$ as reference 


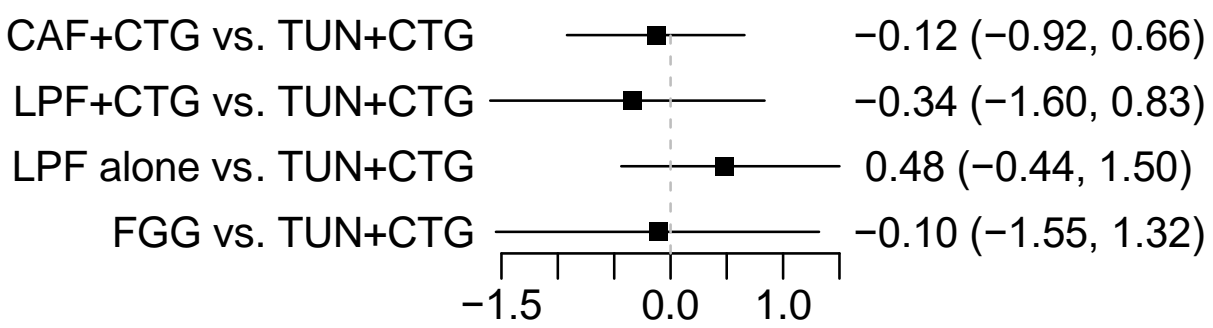

Effect Difference

Figure 85. Contrast plot Residual PPD - TUN+CTG as reference

$\mathrm{CAF}+\mathrm{CTG}$ vs. $\mathrm{LPF}+\mathrm{CTG}$ $\mathrm{TUN}+\mathrm{CTG}$ vs. $\mathrm{LPF}+\mathrm{CTG}$ $\mathrm{LPF}$ alone vs. $\mathrm{LPF}+\mathrm{CTG}$

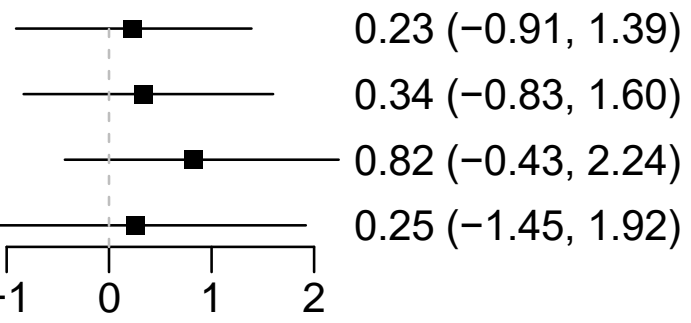

Effect Difference

Figure 86. Contrast plot Residual PPD $-L P F+C T G$ as reference

$\mathrm{CAF}+\mathrm{CTG}$ vs. LPF alone $T U N+C T G$ vs. LPF alone $\longrightarrow \quad-0.61(-1.49,0.18)$ $\mathrm{LPF}+\mathrm{CTG}$ vs. LPF alone $\longrightarrow-0.48(-1.50,0.44)$ FGG vs. LPF alone

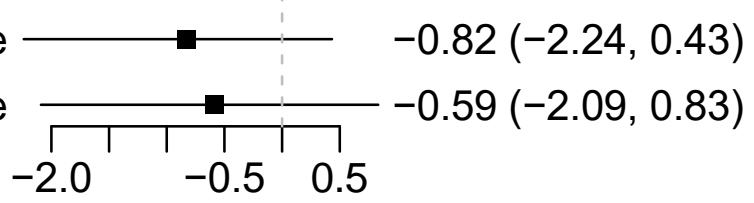

Effect Difference

Figure 87. Contrast plot Residual PPD - LPF alone

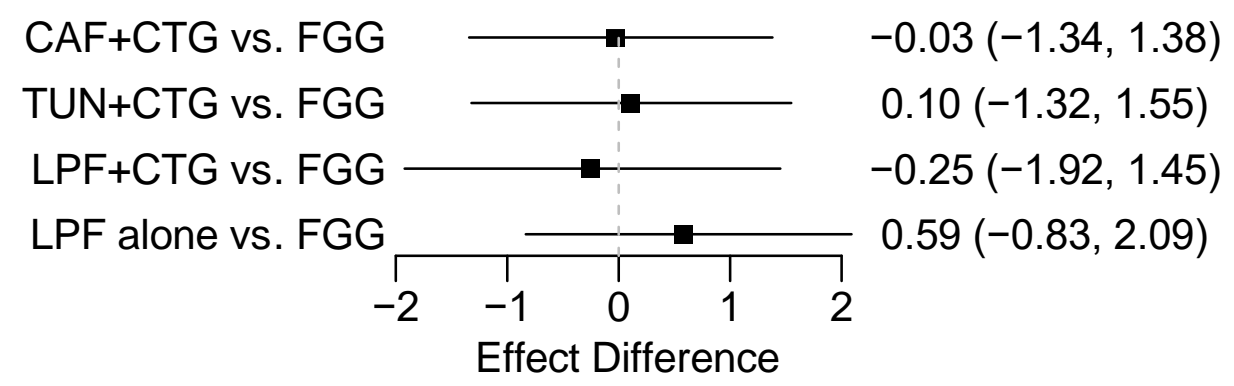

Figure 88. Contrast plot Residual PPD - FGG 


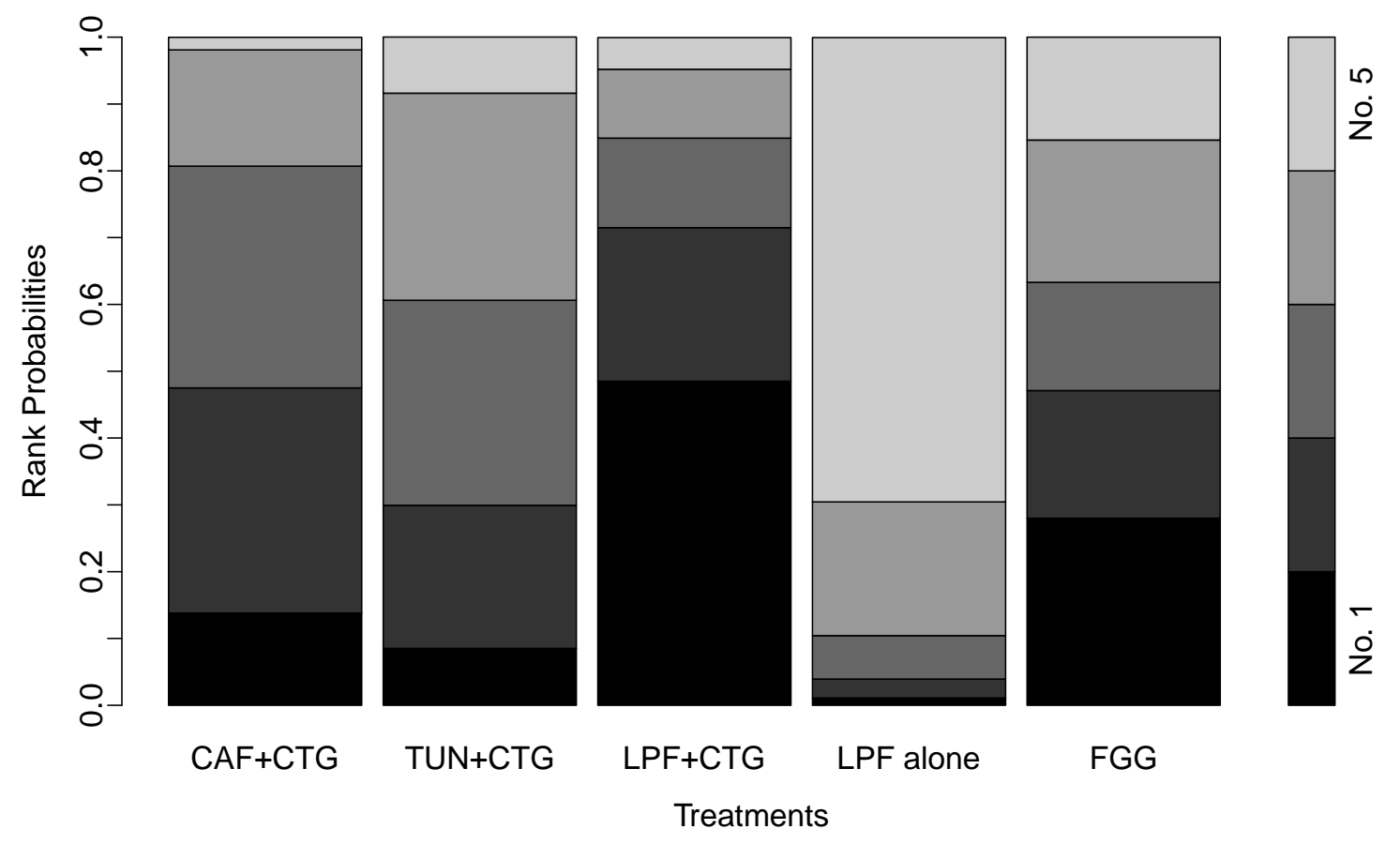

Figure 89. Ranking plot Residual PPD

\subsubsection{Change in Recession Width (RW)}

For RW change, the dataset consisted of 8 study arms, in particular 2 for CAF+CTG, 1 for TUN+CTG, 4 for LPF alone and 1 for FGG. No study arm report RW change in LPF+CTG group. The network plot is shown in Fig. 91. The network meta-analysis showed the following results:

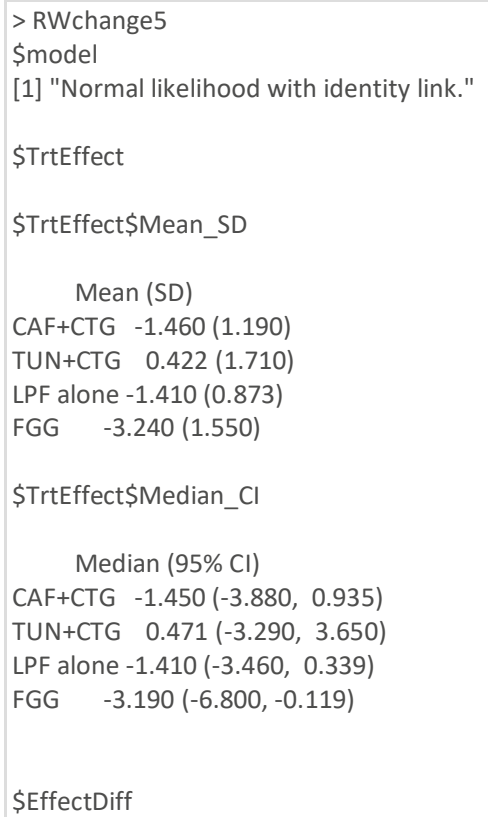

\$EffectDiff 


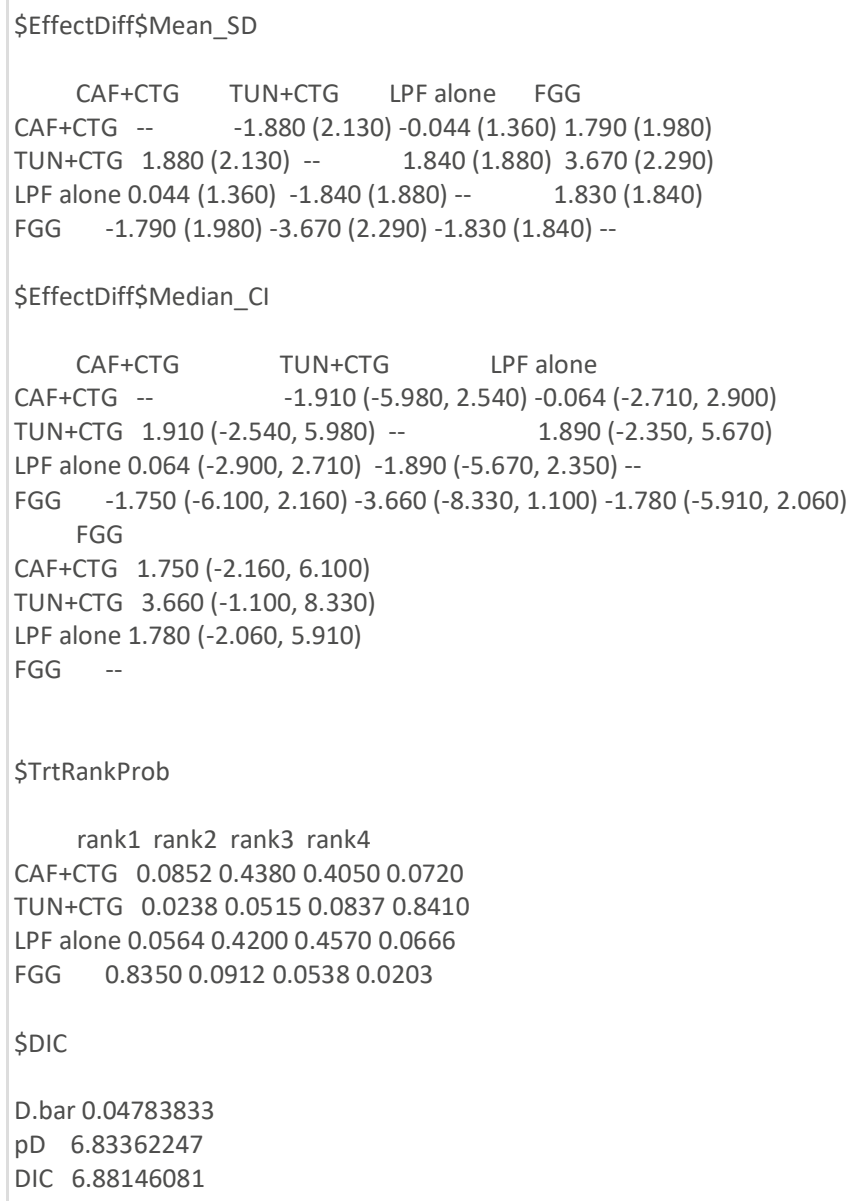

Posterior density plot and the trace plots for each treatment group are reported in Fig. 9296. FGG is associated with the highest RW reduction $(3.2 \mathrm{~mm})$, whereas TUN+CTG is associated with a RW increase $(0.47 \mathrm{~mm})$. According to the ranking plot, FGG is associated with the highest probability of determining the greatest RW reduction ( $83.5 \%$ probability). However, the differences among treatments for RW change are non-significant; moreover, the low number of study arms available for the statistical analysis impairs the quality of the evidence, as shown by the effective number of parameters $(\mathrm{pD})$ and deviance information criterion (DIC). 


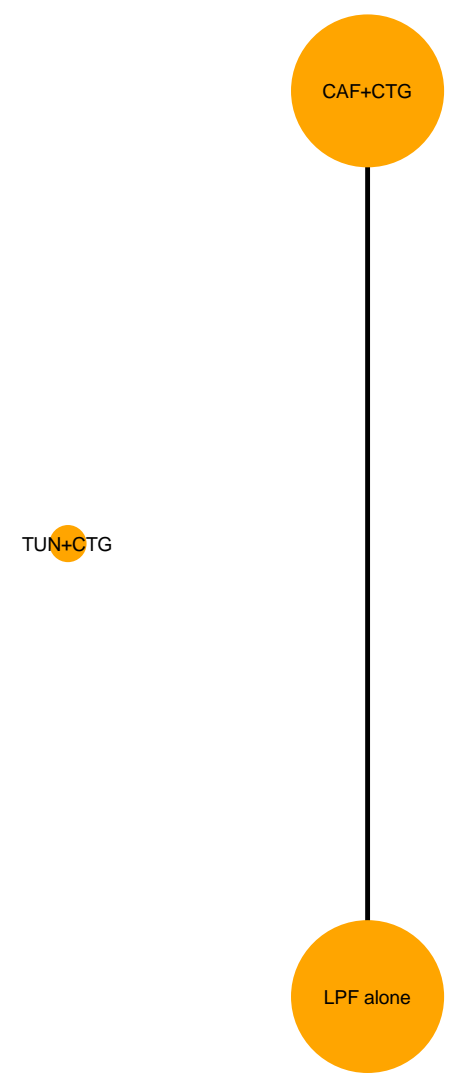

FGG

Figure 90. Network plot RW change

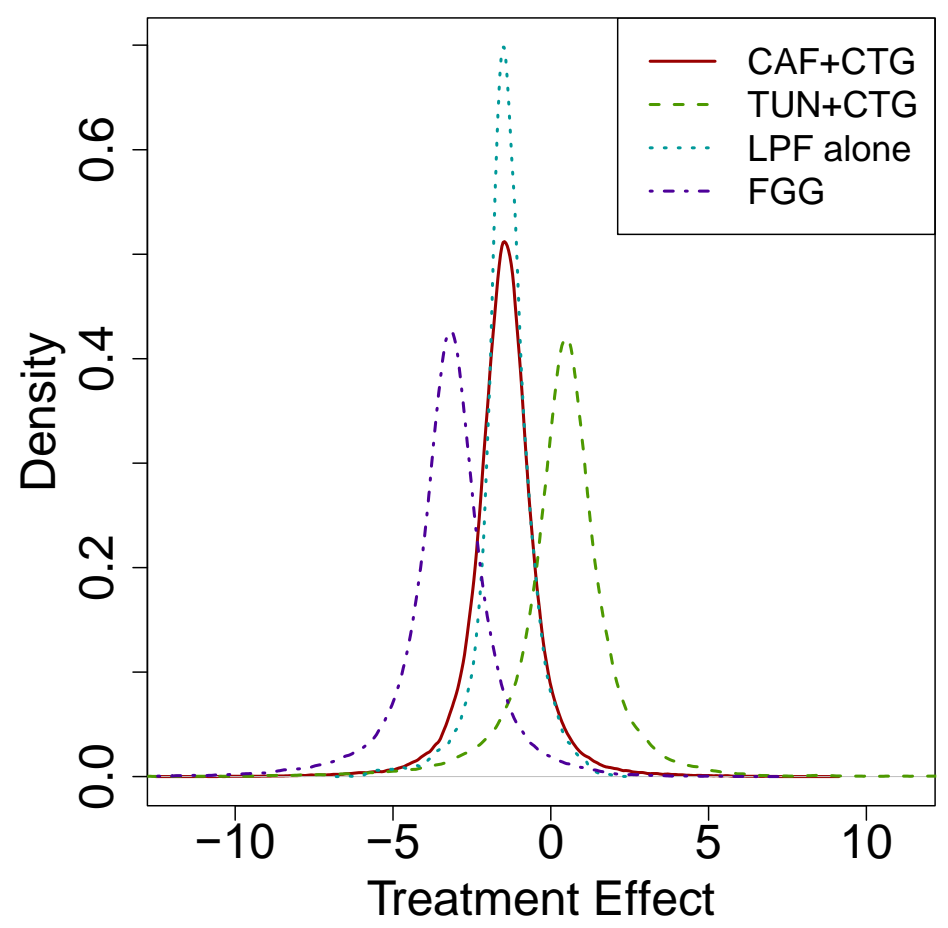

Figure 91. Density plot RW change 

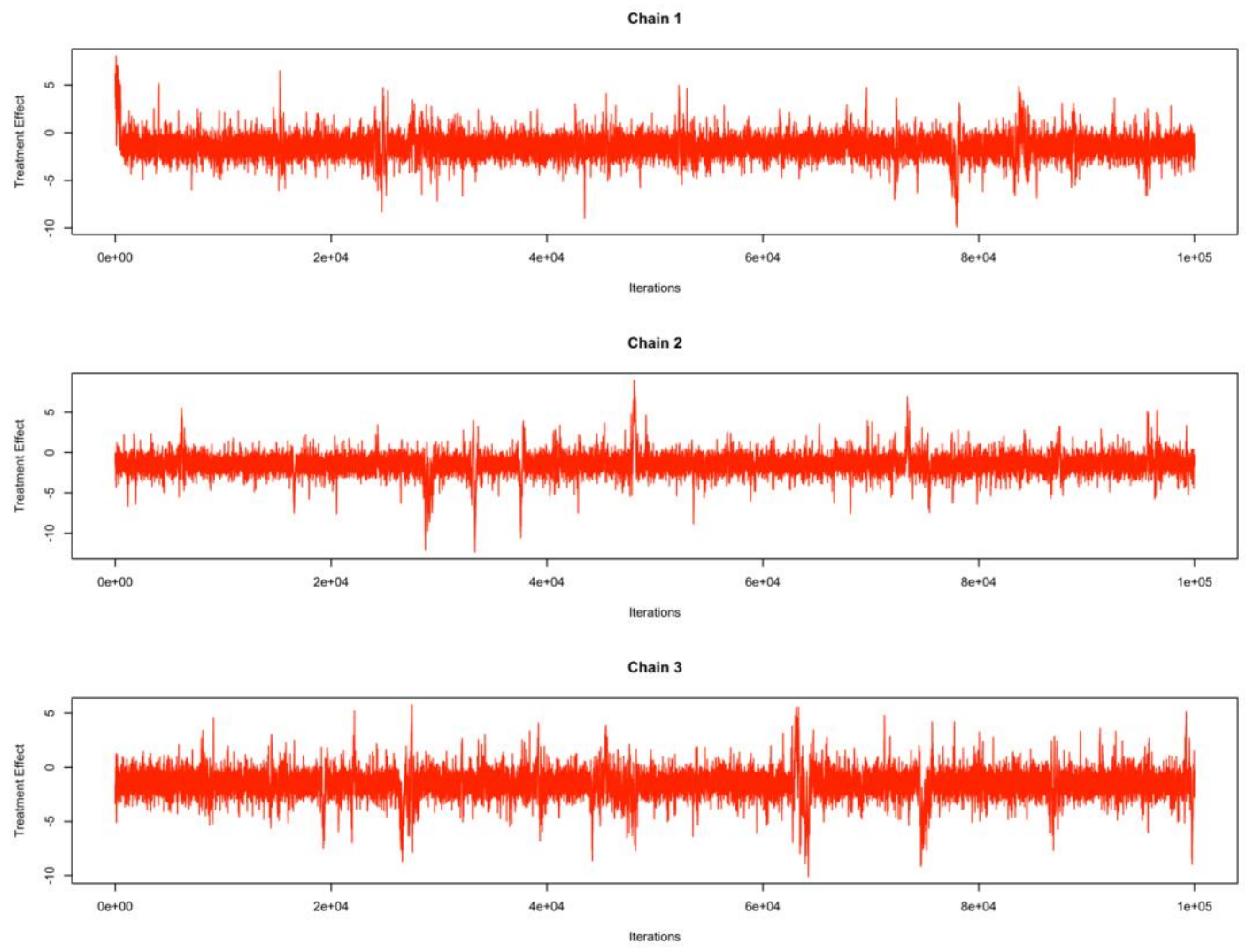

Figure 92. Trace plot $R W$ change - CAF+CTG as reference
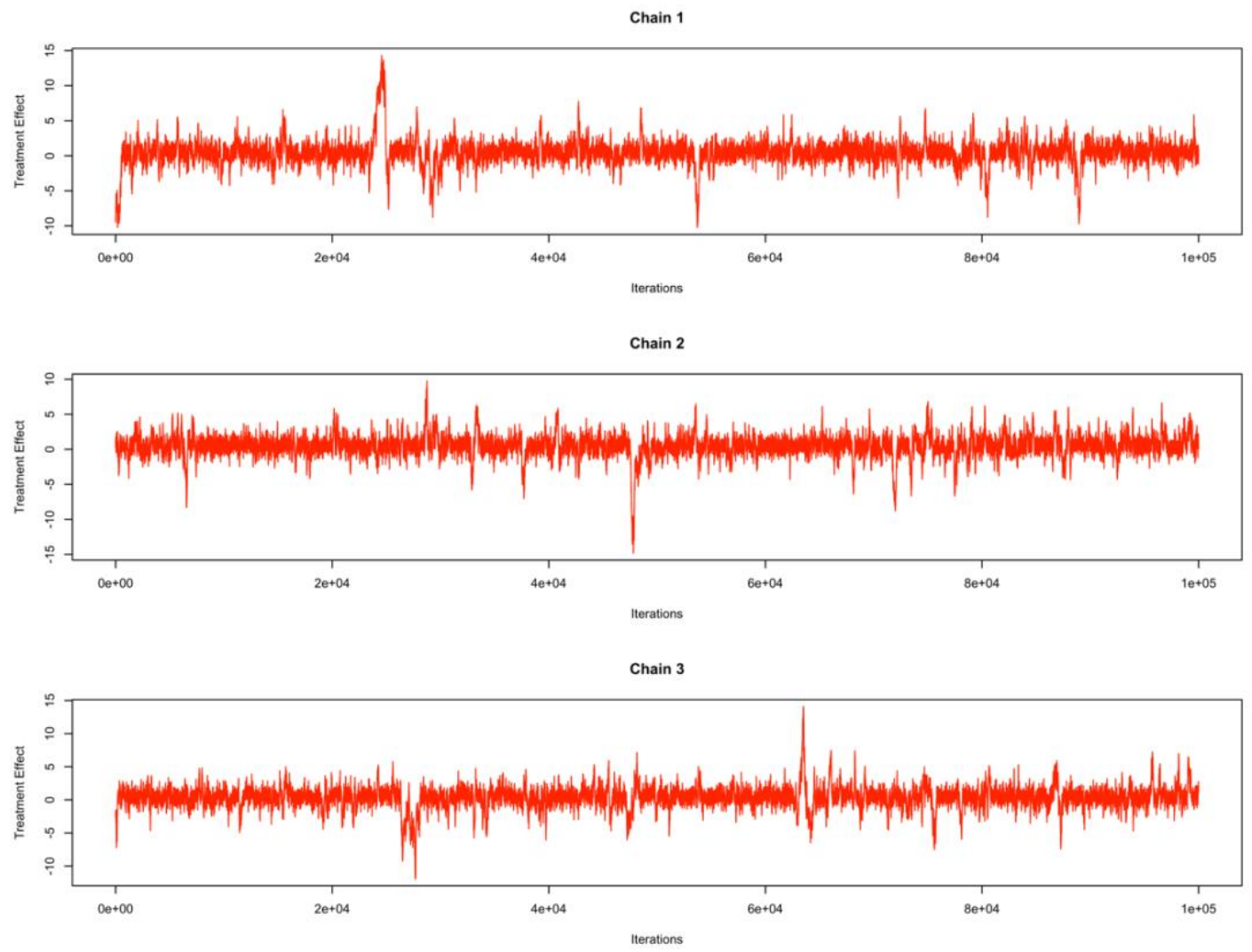

Figure 93. Trace plot $R W$ change - TUN+CTG as reference 
Chain 1
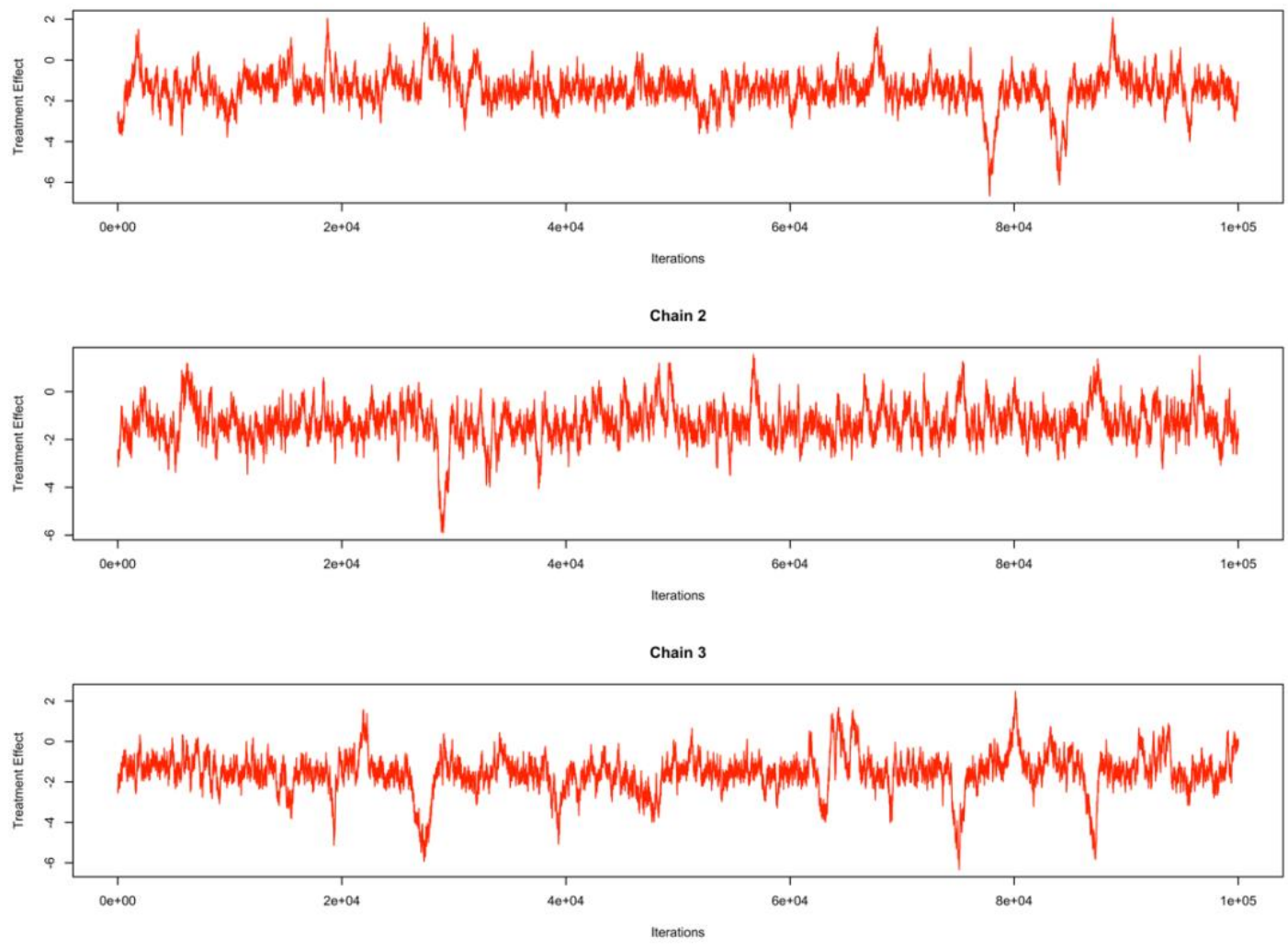

Figure 94. Trace plot $R W$ change - LPF alone
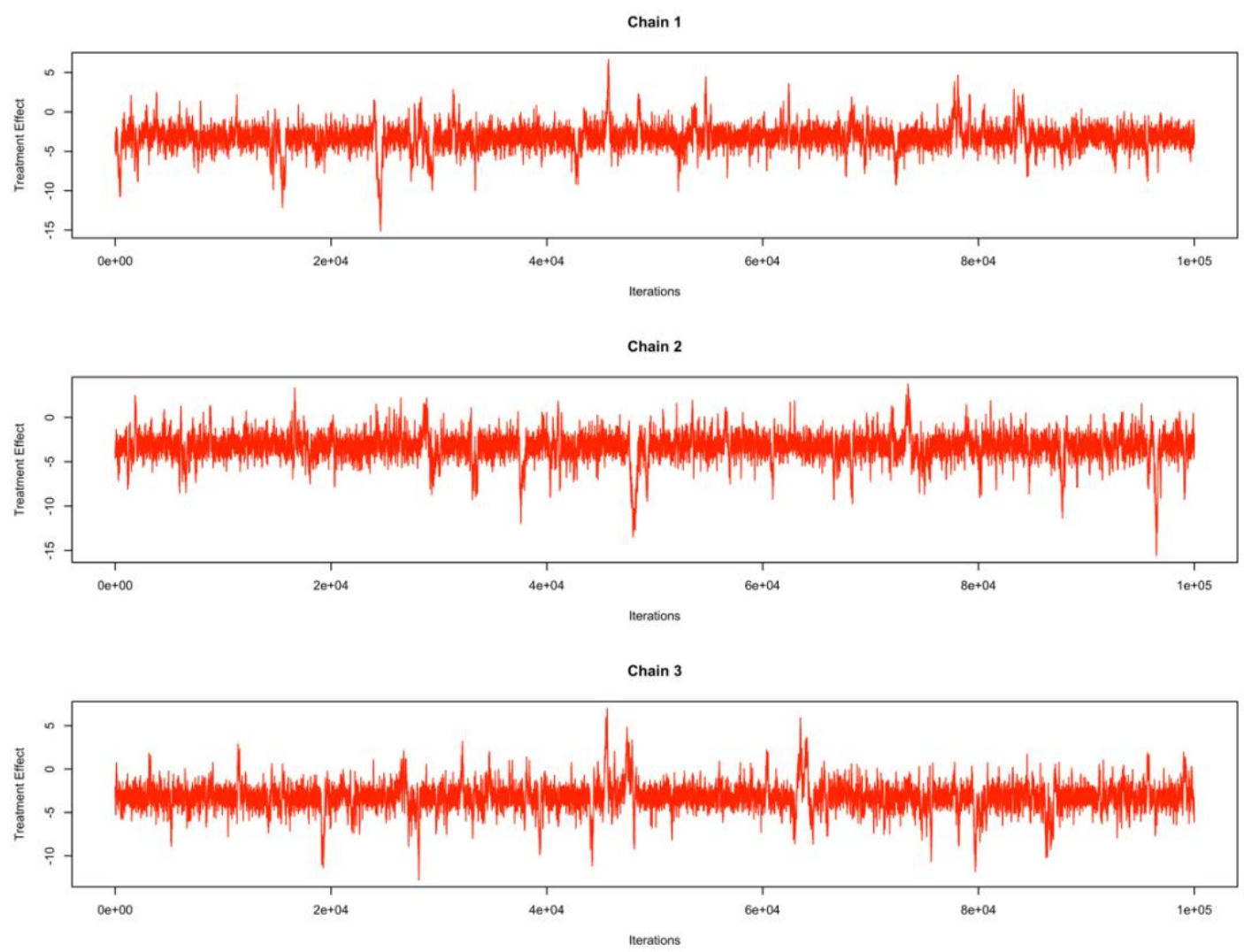

Figure 95. Trace plot RW change - FGG 


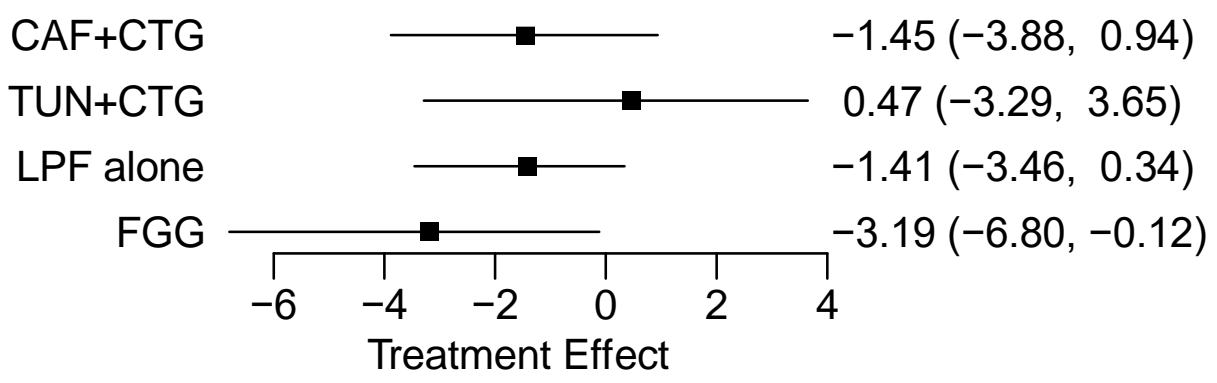

Figure 96. Absolute plot $R W$ change

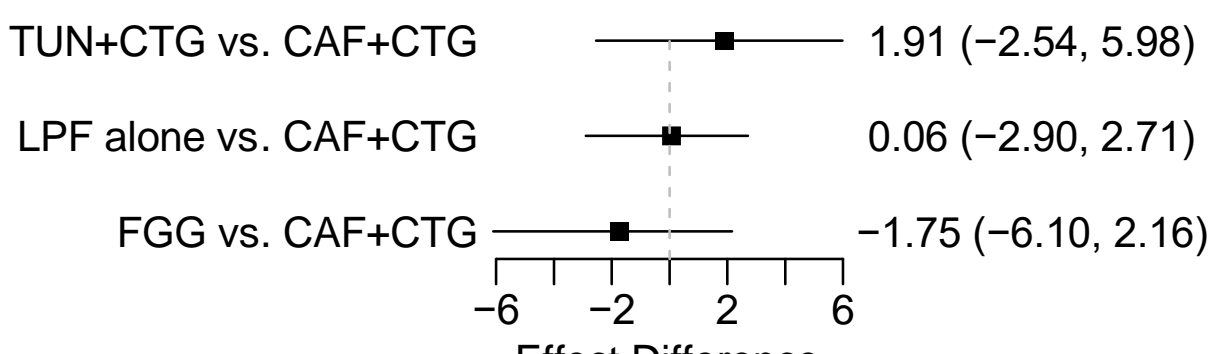

Effect Difference

Figure 97. Contrast plot $R W$ change - CAF+CTG as reference

$\mathrm{CAF}+\mathrm{CTG}$ vs. $\mathrm{TUN}+\mathrm{CTG}$

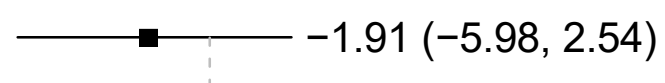

LPF alone vs. TUN+CTG

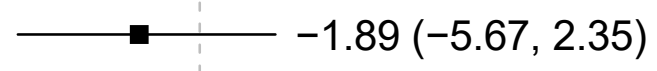

FGG vs. TUN+CTG

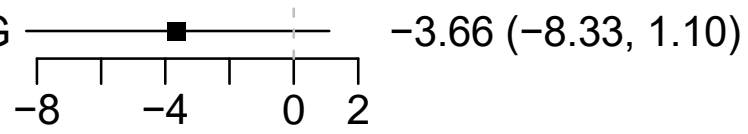

Effect Difference

Figure 98. Contrast plot $R W$ change - TUN+CTG as reference

$\mathrm{CAF}+\mathrm{CTG}$ vs. LPF alone

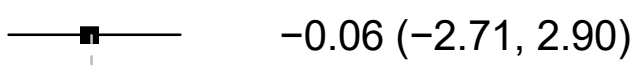

TUN+CTG vs. LPF alone

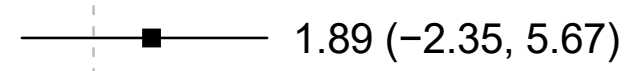

FGG vs. LPF alone

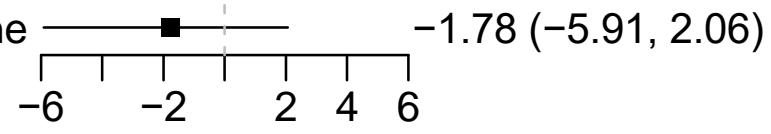

Effect Difference

Figure 99. Contrast plot $R W$ change - $L P F+C T G$ as reference 


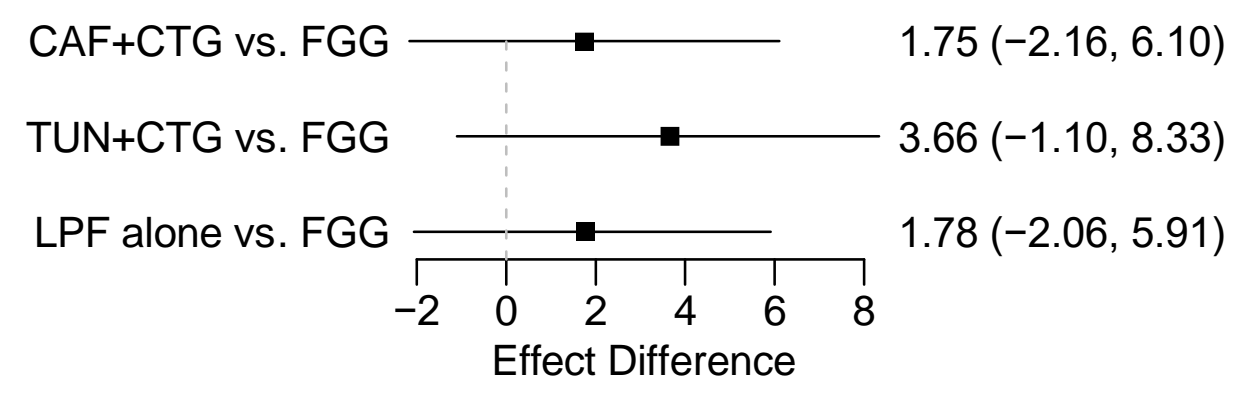

Figure 100. Contrast plot $R W$ change - FGG

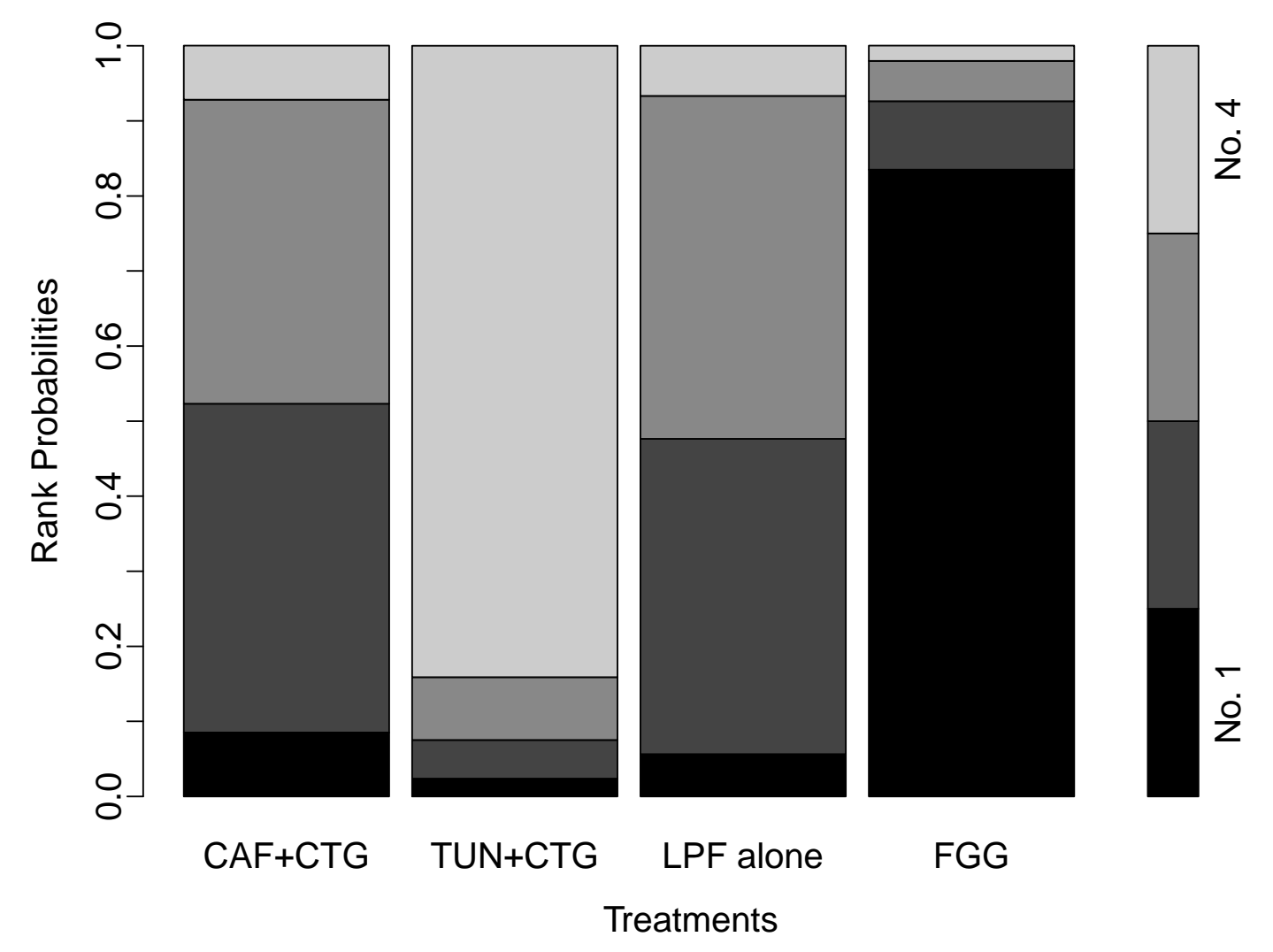

Figure 101. Ranking plot RW change

\subsubsection{Results for efficacy}

Only three RCTs counting for six study arms have been included in the analysis. In summary, only three surgical approaches are analyzed in RCTs: CAF+CTG, LPF alone and FGG. Considering that not all the surgical procedures are present in RCTs and considering 
the limited amount of data, no contrast-based network metanalysis can be performed. Therefore, results for efficacy cannot be derived by the present systematic review.

\subsubsection{Results for efficiency}

The patient-related outcomes reported in each study are summarized in Table 2. Esthetic assessment was performed in only 7 study arms: the recession esthetic score (RES) was used in three study arms, whereas a VAS scale was used in other three studies and an unspecified questionnaire was used in one study. Postoperative pain was assessed in only three study arms through VAS scale, number of analgesics consumed by the patient and hypersensitivity sequelae. The limited number of data regarding patient related outcomes did not allow to perform a quantitative analysis.

\section{Table 2. Patient-related outcomes}

\begin{tabular}{|c|c|c|c|}
\hline & Esthetics & Post-op discomfort & Others \\
\hline Mercado (2019) & Questionnaire at $36 \mathrm{~m}$ & $\begin{array}{l}\text { Pain VAS at } 2,7,14 \text { days } \\
\text { Number of analgesics at } 7 \text { days }\end{array}$ & I \\
\hline Sebaoun (2019) & I & / & I \\
\hline Goyal (2019) & Color VAS at $1,3,6 \mathrm{~m}$ & / & l \\
\hline Nunez (2018) & RES at $12 \mathrm{~m}$ & Hypersensitivity VAS at $2 \mathrm{~m}$ & / \\
\hline Sculean (2018) & / & / & / \\
\hline Thalmair (2016) & / & / & / \\
\hline Rajaram (2015) & / & / & / \\
\hline De Angelis (2015) & RES at $5 y$ & / & / \\
\hline Rubins (2014) & / & / & / \\
\hline Zucchelli (2014) & Esthetic VAS at $12 \mathrm{~m}$ & Pain VAS at 7 days & / \\
\hline Sculean (2014) & $/$ & / & I \\
\hline
\end{tabular}




\begin{tabular}{|c|l|l|l|}
\hline Singhal (2013) & / & / & / \\
\hline Nart (2012) & Esthetic VAS at 12m & / & $/$ \\
\hline Baghele (2012) & / & / & $/$ \\
\hline Cortellini (2012) & RES at 12m & $/$ & $/$ \\
\hline Harris (2006) & / & $/$ & $/$ \\
\hline
\end{tabular}

\section{RISK OF BIAS ASSESSMENT}

The risk of bias for the included in RCTs and non-RCTs studies is reported in Table 3 and

Table 4, respectively. Within RCTs, 2 studies where at overall low risk of bias, while some concerns were raised for one study mainly related to the randomization process. Higher overall risk of bias was found for non-RCTs studies, with two studies showing a moderate risk of bias and one studies showing a serious risk of bias. 
Table 3. Consensus results of the risk of bias assessment: RCTs (RoB 2)

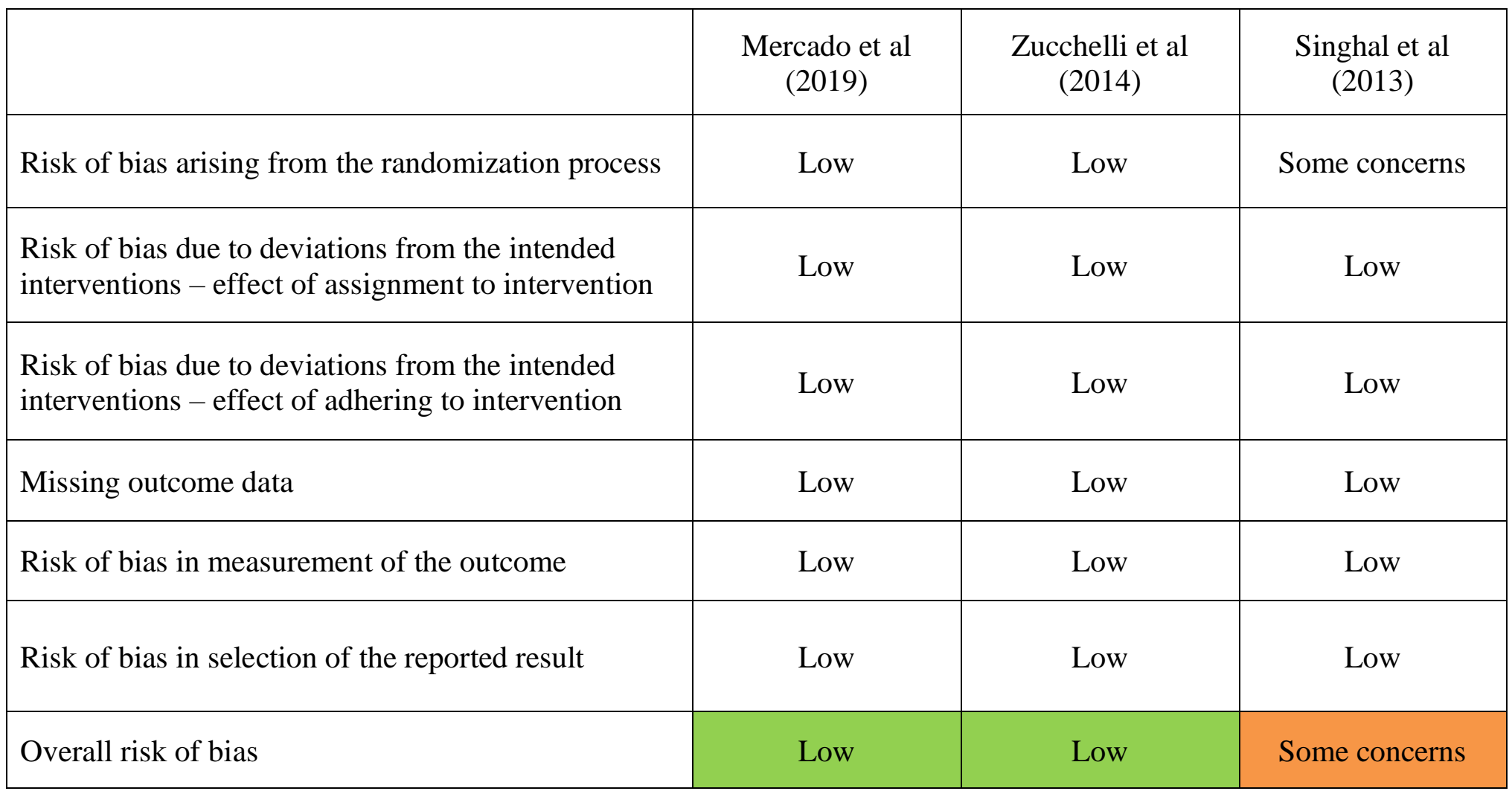


Table 4. Consensus results of the risk of bias assessment: Non-RCTs (ROBINS-I assessment tool)

\begin{tabular}{|c|c|c|c|}
\hline & Rajaram et al (2015) & Baghele et al (2012) & Harris et al (2006) \\
\hline Risk of bias due to confounding & Moderate & Moderate & Moderate \\
\hline Risk of bias in selection of participants into the study & Moderate & Serious & Moderate \\
\hline Risk of bias in classification of interventions & Low & Low & Low \\
\hline Risk of bias due to deviation from intended interventions & Low & Moderate & Low \\
\hline Risk of bias due to missing data & Moderate & Moderate & Low \\
\hline Risk of bias in measurement of outcomes & Low & Low & Low \\
\hline Risk of bias in selection of the reported result & Low & Low & Low \\
\hline Overall risk of bias & Moderate & Serious & Moderate \\
\hline
\end{tabular}




\section{DISCUSSION}

In the present systematic review, the effectiveness of different mucogingival approaches was evaluated for the treatment of gingival recessions on mandibular anterior teeth. Five main treatment groups have been identified based on the flap design (coronally advanced flap, tunnel procedure, laterally positioned flap) and the use of soft tissue grafts (connective tissue graft, free gingival graft). No distinction was made if biologics (e.g. EMD, rhPDGF$\mathrm{BB}, \mathrm{L}-\mathrm{PRF}$ ) or other reparative adjuncts were added to soft tissue grafts.

Among the surgical approaches, treatment hierarchy generated by the present network metaanalysis showed that both TUN and LPF, both in combination with CTG, are associated with higher values of mean root coverage and gain in KT width in gingival recessions on mandibular anterior teeth. Yet, the other techniques investigated, CAF+CTG and LPF alone, showed more limited results.

Overall, these findings support the use of connective tissue graft for the treatment of gingival recessions in the mandibular anterior sextant, rather than techniques with a different or no reparative device (e.g. FGG). However, when CTG is applied, the effect of the flap design is evident: in particular, a lateral mobilization of the flap or the creation of an envelope tunnel in the recipient site seem to lead to more favorable results in terms of both $\mathrm{mRC}$ and $\mathrm{KT}$ width gain, compared to procedures based on the coronal advancement of the flap. However, due to the low level of evidence ( 1 study only), the results obtained with LPF+CTG must be interpreted with caution. 
Treatment of gingival recessions in the mandibular anterior area represents a major clinical challenge owing to several anatomical conditions, such as high insertion of labial frenum and muscular fibers, limited vestibular depth, thin tissues and lack of keratinized mucosa (Zucchelli et al., 2014a). These factors compromise the predictability of root coverage procedures, because of an increased risk for flap perforation and inadequate primary wound stability, as well as insufficient passivation of the flap, with high tendency of early dehiscence. For these reasons, approaches such as tunnel or LPF provide less tension when compared to the $\mathrm{CAF}$, hence reducing the chance of flap dehiscence or mobilization and graft exposure in close proximity of the recession defect. This risk appears to be more significant in presence of shallow vestibule or inserting frenula, where the coronal mobilization of a tension-free flap is extremely difficult.

This statistical model for the secondary clinical outcomes (residual probing depth, change in probing depth, residual recession depth, change in recession width) showed a high level of autocorrelations of the iterations, that is the model chain is not converged and the results are not reliable. Most likely, the reason for the trace plots not being uniform is related to the limited amount of data available for the analysis. Therefore, no conclusion can be derived from the statistical analysis regarding residual probing depth, change in probing depth, residual recession depth, change in recession with achieved by the different surgical procedures in the treatment of gingival recessions on mandibular anterior teeth.

Recently, some methods to evaluate aesthetic outcomes after root coverage have been suggested in order to standardize the qualitative assessment of healed soft tissue over root surface (Cairo et al., 2009). In addition, the collection of patient-related outcomes including aesthetics satisfaction has been recommended for clinical trials on root coverage procedures 
(Tonetti et al., 2014). However, no comparison among treatments for mandibular anterior gingival recessions can be made as for patient-related outcomes, considered the extent of missing data and the lack of standardization in the mode and time of assessment. 


\section{CONCLUSIONS}

In conclusion, the present systematic review showed that:

1) Gingival recessions on mandibular incisors represent a common clinical finding in the population, but the amount of periodontal literature dedicated to their treatment is limited;

2) Although coronally advanced flap in combination with connective tissue graft $(\mathrm{CAF}+\mathrm{CTG})$ is considered the gold-standard procedure for root coverage, the use of $\mathrm{CAF}+\mathrm{CTG}$ in the mandibular anterior area seems to yield limited results in terms of both mean root coverage and keratinized tissue gain;

3) Treatment hierarchy generated by an arm-based network metanalysis model indicated in tunnel and laterally positioned flap, both in combination with CTG, the greatest results in the treatment of mandibular anterior recessions, with TUN+CTG yielding significantly greater mean root coverage compared to $\mathrm{CAF}+\mathrm{CTG}$;

4) Gain in keratinized tissue of at least $2 \mathrm{~mm}$ can be achieved with different surgical procedures, which indicates the possibility of using techniques other than FGG even when the main indication for treatment is lack of gingiva;

5) No comparison among treatments can be made as for patient-related outcomes, considered the extent of missing data and the lack of standardization in the mode and time of assessment. 


\section{FUTURE RESEARCH}

Future research needs to be directed towards the design of randomized controlled clinical trials (RCTs) aimed at evaluating and comparing different mucogingival procedures in the treatment of buccal gingival recessions on mandibular anterior teeth. Only high-quality RCTs with low risk of bias can provide data to support or confute the findings of the present systematic review and arm-based network meta-analysis. 


\section{REFERENCES}

Agudio, G., Cortellini, P., Buti, J., \& Pini Prato, G. (2016). Periodontal Conditions of Sites Treated With Gingival Augmentation Surgery Compared With Untreated Contralateral Homologous Sites: An 18- to 35-Year Long-Term Study. J Periodontol, 87(12), 1371-1378. doi:10.1902/jop.2016.160284

Ainamo, J., Paloheimo, L., Nordblad, A., \& Murtomaa, H. (1986). Gingival recession in schoolchildren at 7, 12 and 17 years of age in Espoo, Finland. Community Dent Oral Epidemiol, 14(5), 283-286. doi:10.1111/j.1600-0528.1986.tb01073.x

Al-Wahadni, A., \& Linden, G. J. (2002). Dentine hypersensitivity in Jordanian dental attenders. A case control study. J Clin Periodontol, 29(8), 688-693. doi:10.1034/j.1600-051x.2002.290804.x

Albandar, J. M., \& Kingman, A. (1999). Gingival recession, gingival bleeding, and dental calculus in adults 30 years of age and older in the United States, 1988-1994. J Periodontol, 70(1), 30-43. doi:10.1902/jop.1999.70.1.30

Albandar, J. M., Streckfus, C. F., Adesanya, M. R., \& Winn, D. M. (2000). Cigar, pipe, and cigarette smoking as risk factors for periodontal disease and tooth loss. $J$ Periodontol, 71(12), 1874-1881. doi:10.1902/jop.2000.71.12.1874

Allais, D., \& Melsen, B. (2003). Does labial movement of lower incisors influence the level of the gingival margin? A case-control study of adult orthodontic patients. Eur J Orthod, 25(4), 343-352. doi:10.1093/ejo/25.4.343

Allen, A. L. (1994). Use of the supraperiosteal envelope in soft tissue grafting for root coverage. I. Rationale and technique. Int J Periodontics Restorative Dent, 14(3), 216-227.

Allen, E. P., \& Miller, P. D., Jr. (1989). Coronal positioning of existing gingiva: short term results in the treatment of shallow marginal tissue recession. J Periodontol, 60(6), 316-319. doi:10.1902/jop.1989.60.6.316

Anand, P. S., Kamath, K. P., Bansal, A., Dwivedi, S., \& Anil, S. (2013). Comparison of periodontal destruction patterns among patients with and without the habit of smokeless tobacco use--a retrospective study. J Periodontal Res, 48(5), 623-631. doi:10.1111/jre.12048

Aroca, S., Molnár, B., Windisch, P., Gera, I., Salvi, G. E., Nikolidakis, D., \& Sculean, A. (2013). Treatment of multiple adjacent Miller class I and II gingival recessions with a Modified Coronally Advanced Tunnel (MCAT) technique and a collagen matrix or palatal connective tissue graft: a randomized, controlled clinical trial. J Clin Periodontol, 40(7), 713-720. doi:10.1111/jcpe.12112

Artun, J., \& Grobety, D. (2001). Periodontal status of mandibular incisors after pronounced orthodontic advancement during adolescence: a follow-up evaluation. Am J Orthod Dentofacial Orthop, 119(1), 2-10. doi:10.1067/mod.2001.111403

Artun, J., \& Krogstad, O. (1987). Periodontal status of mandibular incisors following excessive proclination. A study in adults with surgically treated mandibular prognathism. Am J Orthod Dentofacial Orthop, 91(3), 225-232. doi:10.1016/08895406(87)90450-1

Aw, T. C., Lepe, X., Johnson, G. H., \& Mancl, L. (2002). Characteristics of noncarious cervical lesions: A clinical investigation. The Journal of the American Dental Association, 133(6), 725-733. doi:10.14219/jada.archive.2002.0268 
Baab, D. A., \& Oberg, P. A. (1987). The effect of cigarette smoking on gingival blood flow in humans. $J$ Clin Periodontol, 14(7), 418-424. doi:10.1111/j.1600051x.1987.tb01547.x

Baelum, V., Fejerskov, O., \& Karring, T. (1986). Oral hygiene, gingivitis and periodontal breakdown in adult Tanzanians. $J$ Periodontal Res, 21(3), 221-232. doi:10.1111/j.1600-0765.1986.tb01454.x

Bahat, O., Handelsman, M., \& Gordon, J. (1990). The transpositioned flap in mucogingival surgery. Int J Periodontics Restorative Dent, 10(6), 472-482.

Baker, D. L., \& Seymour, G. J. (1976). The possible pathogenesis of gingival recession. Journal of Clinical Periodontology, 3(4), 208-219. doi:10.1111/j.1600051X.1976.tb00040.x

Batenhorst, K. F., Bowers, G. M., \& Williams, J. E., Jr. (1974). Tissue changes resulting from facial tipping and extrusion of incisors in monkeys. J Periodontol, 45(9), 660668. doi:10.1902/jop.1974.45.9.660

Benz, C., Schwarz, P., \& Sonnabend, E. (1987). [Various physical parameters of toothbrushing and their relation to the appearance of non-inflammatory gingival recession]. ZWR, 96(10), 930, 935.

Bernimoulin, J.-P., \& Curilović, Z. (1977). Gingival recession and tooth mobility. Journal of Clinical Periodontology, 4(2), 107-114. doi:10.1111/j.1600051X.1977.tb01890.x

Bernimoulin, J. P., Lüscher, B., \& Mühlemann, H. R. (1975). Coronally repositioned periodontal flap. Clinical evaluation after one year. J Clin Periodontol, 2(1), 1-13. doi:10.1111/j.1600-051x.1975.tb01721.x

Bollen, A. M., Cunha-Cruz, J., Bakko, D. W., Huang, G. J., \& Hujoel, P. P. (2008). The effects of orthodontic therapy on periodontal health: a systematic review of controlled evidence. J Am Dent Assoc, 139(4), 413-422. doi:10.14219/jada.archive.2008.0184

Borghetti, A., \& Gardella, J. P. (1990). Thick gingival autograft for the coverage of gingival recession: a clinical evaluation. Int J Periodontics Restorative Dent, 10(3), 216-229.

Bowers, G. M. (1963). A Study of the Width of Attached Gingiva. The Journal of Periodontology, 34(3), 201-209. doi:10.1902/jop.1963.34.3.201

Brown, L. J., Oliver, R. C., \& Loe, H. (1990). Evaluating periodontal status of US employed adults. J Am Dent Assoc, 121(2), 226-232. doi:10.14219/jada.archive.1990.0252

Burkhardt, R., \& Lang, N. P. (2005). Coverage of localized gingival recessions: comparison of micro- and macrosurgical techniques. J Clin Periodontol, 32(3), 287-293. doi:10.1111/j.1600-051X.2005.00660.x

Burrow, M. F., \& Stacey, M. A. (2017). Management of Cavitated Root Caries Lesions: Minimum Intervention and Alternatives. Monogr Oral Sci, 26, 106-114. doi:10.1159/000479352

Buti, J., Baccini, M., Nieri, M., La Marca, M., \& Pini-Prato, G. P. (2013). Bayesian network meta-analysis of root coverage procedures: ranking efficacy and identification of best treatment. J Clin Periodontol, 40(4), 372-386. doi:10.1111/jcpe.12028

Caffesse, R. G., Alspach, S. R., Morrison, E. C., \& Burgett, F. G. (1987). Lateral sliding flaps with and without citric acid. Int J Periodontics Restorative Dent, 7(6), 42-57.

Caffesse, R. G., Kon, S., Castelli, W. A., \& Nasjleti, C. E. (1984). Revascularization following the lateral sliding flap procedure. J Periodontol, 55(6), 352-358. doi:10.1902/jop.1984.55.6.352

Cairo, F. (2017). Periodontal plastic surgery of gingival recessions at single and multiple teeth. Periodontol 2000, 75(1), 296-316. doi:10.1111/prd.12186 
Cairo, F., Cortellini, P., Tonetti, M., Nieri, M., Mervelt, J., Pagavino, G., \& Pini-Prato, G. P. (2015). Stability of root coverage outcomes at single maxillary gingival recession with loss of interdental attachment: 3-year extension results from a randomized, controlled, clinical trial. J Clin Periodontol, 42(6), 575-581. doi:10.1111/jcpe. 12412

Cairo, F., Nieri, M., Cincinelli, S., Mervelt, J., \& Pagliaro, U. (2011). The interproximal clinical attachment level to classify gingival recessions and predict root coverage outcomes: an explorative and reliability study. J Clin Periodontol, 38(7), 661-666. doi:10.1111/j.1600-051X.2011.01732.x

Cairo, F., Nieri, M., \& Pagliaro, U. (2014). Efficacy of periodontal plastic surgery procedures in the treatment of localized facial gingival recessions. A systematic review. J Clin Periodontol, 41 Suppl 15, S44-62. doi:10.1111/jcpe.12182

Cairo, F., Pagliaro, U., \& Nieri, M. (2008). Treatment of gingival recession with coronally advanced flap procedures: a systematic review. J Clin Periodontol, 35(8 Suppl), 136-162. doi:10.1111/j.1600-051X.2008.01267.x

Cairo, F., Rotundo, R., Miller, P. D., \& Pini Prato, G. P. (2009). Root coverage esthetic score: a system to evaluate the esthetic outcome of the treatment of gingival recession through evaluation of clinical cases. J Periodontol, 80(4), 705-710. doi:10.1902/jop.2009.080565

Castro-Rodríguez, Y., \& Grados-Pomarino, S. (2017). Frecuencias e indicadores de riesgo de las recesiones gingivales en una muestra peruana. Revista clínica de periodoncia, implantología y rehabilitación oral, 10, 135-140.

Caton, J. G., Armitage, G., Berglundh, T., Chapple, I. L. C., Jepsen, S., Kornman, K. S., . . . Tonetti, M. S. (2018). A new classification scheme for periodontal and peri-implant diseases and conditions - Introduction and key changes from the 1999 classification. Journal of Clinical Periodontology, 45(S20), S1-S8. doi:10.1111/jcpe.12935

Chambrone, L., Chambrone, D., Pustiglioni, F. E., Chambrone, L. A., \& Lima, L. A. (2009). The influence of tobacco smoking on the outcomes achieved by root-coverage procedures: a systematic review. $J$ Am Dent Assoc, 140(3), 294-306. doi:10.14219/jada.archive.2009.0158

Chambrone, L., Ortega, M. A. S., Sukekava, F., Rotundo, R., Kalemaj, Z., Buti, J., \& Prato, G. P. P. (2019). Root coverage procedures for treating single and multiple recessiontype defects: An updated Cochrane systematic review. J Periodontol, 90(12), 13991422. doi:10.1002/jper.19-0079

Chambrone, L., Pannuti, C. M., Tu, Y. K., \& Chambrone, L. A. (2012). Evidence-based periodontal plastic surgery. II. An individual data meta-analysis for evaluating factors in achieving complete root coverage. J Periodontol, 83(4), 477-490. doi:10.1902/jop.2011.110382

Chambrone, L., Salinas Ortega, M. A., Sukekava, F., Rotundo, R., Kalemaj, Z., Buti, J., \& Pini Prato, G. P. (2018). Root coverage procedures for treating localised and multiple recession-type defects. Cochrane Database Syst Rev, 10, CD007161. doi:10.1002/14651858.CD007161.pub3

Chambrone, L., \& Tatakis, D. N. (2015). Periodontal soft tissue root coverage procedures: a systematic review from the AAP Regeneration Workshop. J Periodontol, 86(2 Suppl), S8-51. doi:10.1902/jop.2015.130674

Chambrone, L., \& Tatakis, D. N. (2016). Long-Term Outcomes of Untreated Buccal Gingival Recessions: A Systematic Review and Meta-Analysis. J Periodontol, 87(7), 796-808. doi:10.1902/jop.2016.150625 
Chambrone, L. A., \& Chambrone, L. (2006). Subepithelial connective tissue grafts in the treatment of multiple recession-type defects. J Periodontol, 77(5), 909-916. doi:10.1902/jop.2006.050249

Chambrone, L. A., \& Chambrone, L. (2009). Treatment of Miller Class I and II localized recession defects using laterally positioned flaps: a 24-month study. Am J Dent, 22(6), 339-344.

Checchi, L., Daprile, G., Gatto, M. R., \& Pelliccioni, G. A. (1999). Gingival recession and toothbrushing in an Italian School of Dentistry: a pilot study. J Clin Periodontol, 26(5), 276-280. doi:10.1034/j.1600-051x.1999.260502.x

Chrysanthakopoulos, N. A. (2014). Gingival recession: prevalence and risk indicators among young greek adults. J Clin Exp Dent, 6(3), e243-249. doi:10.4317/jced.51354

Claffey, N., \& Shanley, D. (1986). Relationship of gingival thickness and bleeding to loss of probing attachment in shallow sites following nonsurgical periodontal therapy. $J$ Clin Periodontol, 13(7), 654-657. doi:10.1111/j.1600-051x.1986.tb00861.x

Clementini, M., Discepoli, N., Danesi, C., \& de Sanctis, M. (2018). Biologically guided flap stability: the role of flap thickness including periosteum retention on the performance of the coronally advanced flap-A double-blind randomized clinical trial. J Clin Periodontol, 45(10), 1238-1246. doi:10.1111/jcpe.12998

Cohen, D. W., \& Ross, S. E. (1968). The double papillae repositioned flap in periodontal therapy. J Periodontol, 39(2), 65-70. doi:10.1902/jop.1968.39.2.65

Corn, H. (1962). Periosteal Separation-Its Clinical Significance. The Journal of Periodontology, 33(2), 140-153. doi:10.1902/jop.1962.33.2.140

Cortellini, P., \& Bissada, N. F. (2018). Mucogingival conditions in the natural dentition: Narrative review, case definitions, and diagnostic considerations. $J$ Clin Periodontol, 45 Suppl 20, S190-S198. doi:10.1111/jcpe.12948

Cortellini, P., Tonetti, M., Baldi, C., Francetti, L., Rasperini, G., Rotundo, R., . . Prato, G. P. (2009). Does placement of a connective tissue graft improve the outcomes of coronally advanced flap for coverage of single gingival recessions in upper anterior teeth? A multi-centre, randomized, double-blind, clinical trial. J Clin Periodontol, 36(1), 68-79. doi:10.1111/j.1600-051X.2008.01346.x

Costa, R. S., Rios, F. S., Moura, M. S., Jardim, J. J., Maltz, M., \& Haas, A. N. (2014). Prevalence and risk indicators of dentin hypersensitivity in adult and elderly populations from Porto Alegre, Brazil. J Periodontol, 85(9), 1247-1258. doi:10.1902/jop.2014.130728

Cosyn, J., Eghbali, A., De Bruyn, H., Collys, K., Cleymaet, R., \& De Rouck, T. (2011). Immediate single-tooth implants in the anterior maxilla: 3-year results of a case series on hard and soft tissue response and aesthetics. J Clin Periodontol, 38(8), 746753. doi:10.1111/j.1600-051X.2011.01748.x

de Sanctis, M., \& Zucchelli, G. (2007). Coronally advanced flap: a modified surgical approach for isolated recession-type defects: three-year results. J Clin Periodontol, 34(3), 262-268. doi:10.1111/j.1600-051X.2006.01039.x

de Trey, E., \& Bernimoulin, J.-P. (1980). Influence of free gingival grafts on the health of the marginal gingiva. Journal of Clinical Periodontology, 7(5), 381-393. doi:10.1111/j.1600-051X.1980.tb02011.X

Djeu, G., Hayes, C., \& Zawaideh, S. (2002). Correlation between mandibular central incisor proclination and gingival recession during fixed appliance therapy. Angle Orthod, 72(3), 238-245. doi:10.1043/0003-3219(2002)072<0238:CBMCIP>2.0.CO;2 
Dorfman, H. S., Kennedy, J. E., \& Bird, W. C. (1980). Longitudinal evaluation of free autogenous gingival grafts. Journal of Clinical Periodontology, 7(4), 316-324. doi:10.1111/j.1600-051X.1980.tb01974.x

Dorfman, H. S., Kennedy, J. E., \& Bird, W. C. (1982). Longitudinal Evaluation of Free Autogenous Gingival Grafts: A Four Year Report. Journal of Periodontology, 53(6), 349-352. doi:10.1902/jop.1982.53.6.349

Douglas de Oliveira, D. W., Oliveira-Ferreira, F., Flecha, O. D., \& Gonçalves, P. F. (2013). Is surgical root coverage effective for the treatment of cervical dentin hypersensitivity? A systematic review. J Periodontol, 84(3), 295-306. doi:10.1902/jop.2012.120143

Engelking, G., \& Zachrisson, B. U. (1982). Effects of incisor repositioning on monkey periodontium after expansion through the cortical plate. Am J Orthod, 82(1), 23-32. doi:10.1016/0002-9416(82)90542-5

Ericsson, I., \& Lindhe, J. (1984). Recession in sites with inadequate width of the keratinized gingiva. An experimental study in the dog. J Clin Periodontol, 11(2), 95-103. doi:10.1111/j.1600-051x.1984.tb00837.x

Erley, K. J., Swiec, G. D., Herold, R., Bisch, F. C., \& Peacock, M. E. (2006). Gingival recession treatment with connective tissue grafts in smokers and non-smokers. $J$ Periodontol, 77(7), 1148-1155. doi:10.1902/jop.2006.050252

Espinel, M. C., \& Caffesse, R. G. (1981). Comparison of the results obtained with the laterally positioned pedicle sliding flap-revised technique and the lateral sliding flap with a free gingival graft technique in the treatment of localized gingival recessions. Int J Periodontics Restorative Dent, 1(6), 30-37.

Evans, C. D., \& Chen, S. T. (2008). Esthetic outcomes of immediate implant placements. Clin Oral Implants Res, 19(1), 73-80. doi:10.1111/j.1600-0501.2007.01413.x

Fan, J., \& Caton, J. G. (2018). Occlusal trauma and excessive occlusal forces: Narrative review, case definitions, and diagnostic considerations. J Clin Periodontol, 45 Suppl 20, S199-S206. doi:10.1111/jcpe.12949

Freedman, A. L., Green, K., Salkin, L. M., Stein, M. D., \& Mellado, J. R. (1999). An 18Year Longitudinal Study of Untreated Mucogingival Defects. Journal of Periodontology, 70(10), 1174-1176. doi:10.1902/jop.1999.70.10.1174

Fu, J. H., Yeh, C. Y., Chan, H. L., Tatarakis, N., Leong, D. J., \& Wang, H. L. (2010). Tissue biotype and its relation to the underlying bone morphology. J Periodontol, 81(4), 569-574. doi:10.1902/jop.2009.090591

Gallagher, S. I., \& Matthews, D. C. (2017). Acellular dermal matrix and subepithelial connective tissue grafts for root coverage: A systematic review. J Indian Soc Periodontol, 21(6), 439-448. doi:10.4103/jisp.jisp_222_17

Gorman, W. J. (1967). Prevalence and etiology of gingival recession. J Periodontol, 38(4), 316-322. doi:10.1902/jop.1967.38.4.316

Gottlow, J., Nyman, S., Karring, T., \& Lindhe, J. (1986). Treatment of localized gingival recessions with coronally displaced flaps and citric acid. An experimental study in the dog. J Clin Periodontol, 13(1), 57-63. doi:10.1111/j.1600-051x.1986.tb01415.x

Goutoudi, P., Koidis, P. T., \& Konstantinidis, A. (1997). Gingival recession: a crosssectional clinical investigation. Eur J Prosthodont Restor Dent, 5(2), 57-61.

Greenwell, H., Fiorellini, J., Giannobile, W., Offenbacher, S., Salkin, L., Townsend, C., . . . Genco, R. (2005). Oral reconstructive and corrective considerations in periodontal therapy. J Periodontol, 76(9), 1588-1600. doi:10.1902/jop.2005.76.9.1588

Grupe, H. E. (1966). Modified technique for the sliding flap operation. J Periodontol, 37(6), 491-495. doi:10.1902/jop.1966.37.6.491 
Grupe, H. E., \& Warren Jr., R. F. (1956). Repair of Gingival Defects by a Sliding Flap Operation. The Journal of Periodontology, 27(2), 92-95. doi:10.1902/jop.1956.27.2.92

Guiha, R., el Khodeiry, S., Mota, L., \& Caffesse, R. (2001). Histological evaluation of healing and revascularization of the subepithelial connective tissue graft. $J$ Periodontol, 72(4), 470-478. doi:10.1902/jop.2001.72.4.470

Gunsolley, J. C., Quinn, S. M., Tew, J., Gooss, C. M., Brooks, C. N., \& Schenkein, H. A. (1998). The effect of smoking on individuals with minimal periodontal destruction. J Periodontol, 69(2), 165-170. doi:10.1902/jop.1998.69.2.165

Gusmão, E. S., Queiroz, R. D. C. d., Coelho, R. d. S., Cimões, R., \& Santos, R. L. d. (2011). Relação entre dentes mal posicionados e a condição dos tecidos periodontais. Dental Press Journal of Orthodontics, 16, 87-94.

Haffajee, A. D., \& Socransky, S. S. (2001). Relationship of cigarette smoking to attachment level profiles. J Clin Periodontol, 28(4), 283-295. doi:10.1034/j.1600051x.2001.028004283.x

Haghighati, F., Mousavi, M., Moslemi, N., Kebria, M. M., \& Golestan, B. (2009). A comparative study of two root-coverage techniques with regard to interdental papilla dimension as a prognostic factor. Int J Periodontics Restorative Dent, 29(2), 179189.

Handelman, C. S. (1997). Nonsurgical rapid maxillary alveolar expansion in adults: a clinical evaluation. Angle Orthod, 67(4), 291-305; discussion 306-298. doi:10.1043/0003-3219(1997)067<0291:NRMAEI>2.3.CO;2

Hangorsky, U., \& Bissada, N. F. (1980). Clinical Assessment of Free Gingival Graft Effectiveness on the Maintenance of Periodontal Health. Journal of Periodontology, 51(5), 274-278. doi:10.1902/jop.1980.51.5.274

Harrel, S. K., \& Nunn, M. E. (2004). The Effect of Occlusal Discrepancies on Gingival Width. Journal of Periodontology, 75(1), 98-105. doi:10.1902/jop.2004.75.1.98

Harris, R. J. (1994). The connective tissue with partial thickness double pedicle graft: the results of 100 consecutively-treated defects. J Periodontol, 65(5), 448-461. doi:10.1902/jop.1994.65.5.448

Higgins, J. P., \& Spiegelhalter, D. J. (2002). Being sceptical about meta-analyses: a Bayesian perspective on magnesium trials in myocardial infarction. Int J Epidemiol, 31(1), 96-104. doi:10.1093/ije/31.1.96

Higgins, J. P. T., \& Green, S. (2011). Cochrane Handbook for Systematic Reviews of Interventions: Wiley.

Hofmänner, P., Alessandri, R., Laugisch, O., Aroca, S., Salvi, G. E., Stavropoulos, A., \& Sculean, A. (2012). Predictability of surgical techniques used for coverage of multiple adjacent gingival recessions--A systematic review. Quintessence Int, 43(7), 545-554.

Holbrook, T., \& Ochsenbein, C. (1983). Complete coverage of the denuded root surface with a one-stage gingival graft. Int J Periodontics Restorative Dent, 3(3), 8-27.

Hopps, R. M., \& Johnson, N. W. (1974). Relationship between histological degree of inflammation and epithelial proliferation in macaque gingiva. $J$ Periodontal Res, 9(5), 273-283. doi:10.1111/j.1600-0765.1974.tb00682.x

Hwang, D., \& Wang, H. L. (2006). Flap thickness as a predictor of root coverage: a systematic review. J Periodontol, 77(10), 1625-1634. doi:10.1902/jop.2006.060107

Jepsen, K., Jepsen, S., Zucchelli, G., Stefanini, M., de Sanctis, M., Baldini, N., . . Sanz, M. (2013). Treatment of gingival recession defects with a coronally advanced flap and 
a xenogeneic collagen matrix: a multicenter randomized clinical trial. J Clin Periodontol, 40(1), 82-89. doi:10.1111/jcpe.12019

Johnson, J. D., Houchens, D. P., Kluwe, W. M., Craig, D. K., \& Fisher, G. L. (1990). Effects of mainstream and environmental tobacco smoke on the immune system in animals and humans: a review. Crit Rev Toxicol, 20(5), 369-395. doi:10.3109/10408449009089870

Joss-Vassalli, I., Grebenstein, C., Topouzelis, N., Sculean, A., \& Katsaros, C. (2010). Orthodontic therapy and gingival recession: a systematic review. Orthod Craniofac Res, 13(3), 127-141. doi:10.1111/j.1601-6343.2010.01491.x

Kallestal, C., \& Uhlin, S. (1992). Buccal attachment loss in Swedish adolescents. J Clin Periodontol, 19(7), 485-491. doi:10.1111/j.1600-051x.1992.tb01161.x

Kapferer, I., Benesch, T., Gregoric, N., Ulm, C., \& Hienz, S. A. (2007). Lip piercing: prevalence of associated gingival recession and contributing factors. A crosssectional study. J Periodontal Res, 42(2), 177-183. doi:10.1111/j.16000765.2006.00931.x

Kassab, M. M., \& Cohen, R. E. (2003). The etiology and prevalence of gingival recession. J Am Dent Assoc, 134(2), 220-225. doi:10.14219/jada.archive.2003.0137

Kennedy, J. E., Bird, W. C., Palcanis, K. G., \& Dorfman, H. S. (1985). A longitudinal evaluation of varying widths of attached gingiva. Journal of Clinical Periodontology, 12(8), 667-675. doi:10.1111/j.1600-051X.1985.tb00938.x

Kenney, E. B., Kraal, J. H., Saxe, S. R., \& Jones, J. (1977). The effect of cigarette smoke on human oral polymorphonuclear leukocytes. J Periodontal Res, 12(4), 227-234. doi:10.1111/j.1600-0765.1977.tb00126.x

Khocht, A., Simon, G., Person, P., \& Denepitiya, J. L. (1993). Gingival recession in relation to history of hard toothbrush use. J Periodontol, 64(9), 900-905. doi:10.1902/jop.1993.64.9.900

Kisch, J., Badersten, A., \& Egelberg, J. (1986). Longitudinal observation of "unattached," mobile gingival areas. Journal of Clinical Periodontology, 13(2), 131-134. doi:10.1111/j.1600-051X.1986.tb01445.x

Kitchin, P. C. (1941). Cervical Exposure and Abrasion in Human Teeth for Different Age Classes. Science, 94(2429), 65-66. doi:10.1126/science.94.2429.65

Klukowska, M., Bader, A., Erbe, C., Bellamy, P., White, D. J., Anastasia, M. K., \& Wehrbein, H. (2011). Plaque levels of patients with fixed orthodontic appliances measured by digital plaque image analysis. American Journal of Orthodontics and Dentofacial Orthopedics, 139(5), e463-e470. doi:10.1016/j.ajodo.2010.05.019

Kozlowska, M., Wawrzyn-Sobczak, K., Karczewski, J. K., \& Stokowska, W. (2005). The oral cavity hygiene as the basic element of the gingival recession prophylaxis. $R o c z$ Akad Med Bialymst, 50 Suppl 1, 234-237.

Lang, N. P., \& Löe, H. (1972). The Relationship Between the Width of Keratinized Gingiva and Gingival Health. Journal of Periodontology, 43(10), 623-627. doi:10.1902/jop.1972.43.10.623

Langer, B., \& Calagna, L. J. (1982). The subepithelial connective tissue graft. A new approach to the enhancement of anterior cosmetics. Int $J$ Periodontics Restorative Dent, 2(2), 22-33.

Lawrence, H. P., Hunt, R. J., \& Beck, J. D. (1995). Three-year root caries incidence and risk modeling in older adults in North Carolina. J Public Health Dent, 55(2), 69-78. doi:10.1111/j.1752-7325.1995.tb02335.x 
Lin, L., Zhang, J., Hodges, J. S., \& Chu, H. (2017). Performing Arm-Based Network MetaAnalysis in $\mathrm{R}$ with the pcnetmeta Package. J Stat Softw, 80. doi:10.18637/jss.v080.i05

Lindhe, J., \& Nyman, S. (1980). Alterations of the position of the marginal soft tissue following periodontal surgery. Journal of Clinical Periodontology, 7(6), 525-530. doi:10.1111/j.1600-051X.1980.tb02159.x

Loe, H., Anerud, A., \& Boysen, H. (1992). The natural history of periodontal disease in man: prevalence, severity, and extent of gingival recession. J Periodontol, 63(6), 489-495. doi:10.1902/jop.1992.63.6.489

Löst, C. (1984). Depth of alveolar bone dehiscences in relation to gingival recessions. J Clin Periodontol, 11(9), 583-589. doi:10.1111/j.1600-051x.1984.tb00911.x

Marini, M. G., Greghi, S. L., Passanezi, E., \& Sant'ana, A. C. (2004). Gingival recession: prevalence, extension and severity in adults. J Appl Oral Sci, 12(3), 250-255. doi:10.1590/s1678-77572004000300017

Martinez-Canut, P., Lorca, A., \& Magan, R. (1995). Smoking and periodontal disease severity. J Clin Periodontol, 22(10), 743-749. doi:10.1111/j.1600051x.1995.tb00256.x

Martins, A. G., Andia, D. C., Sallum, A. W., Sallum, E. A., Casati, M. Z., \& Nociti Júnior, F. H. (2004). Smoking may affect root coverage outcome: a prospective clinical study in humans. J Periodontol, 75(4), 586-591. doi:10.1902/jop.2004.75.4.586

Matas, F., Sentís, J., \& Mendieta, C. (2011). Ten-year longitudinal study of gingival recession in dentists. J Clin Periodontol, 38(12), 1091-1098. doi:10.1111/j.1600051X.2011.01799.x

McGuire, M. K., \& Scheyer, E. T. (2010). Xenogeneic collagen matrix with coronally advanced flap compared to connective tissue with coronally advanced flap for the treatment of dehiscence-type recession defects. J Periodontol, 81(8), 1108-1117. doi:10.1902/jop.2010.090698

Melsen, B., \& Allais, D. (2005). Factors of importance for the development of dehiscences during labial movement of mandibular incisors: a retrospective study of adult orthodontic patients. Am J Orthod Dentofacial Orthop, 127(5), 552-561; quiz 625. doi:10.1016/j.ajodo.2003.12.026

Mercado, F., Hamlet, S., \& Ivanovski, S. (2019). Subepithelial connective tissue graft with or without enamel matrix derivative for the treatment of multiple Class III-IV recessions in lower anterior teeth: A 3-year randomized clinical trial. J Periodontol. doi:10.1002/jper.19-0058

Miller, P. D., Jr. (1985). A classification of marginal tissue recession. Int J Periodontics Restorative Dent, 5(2), 8-13.

Miyasato, M., Crigger, M., \& Egelberg, J. (1977). Gingival condition in areas of minimal and appreciable width of keratinized gingival. Journal of Clinical Periodontology, 4(3), 200-209. doi:10.1111/j.1600-051X.1977.tb02273.x

Mlinek, A., Smukler, H., \& Buchner, A. (1973). The Use of Free Gingival Grafts for the Coverage of Denuded Roots. Journal of Periodontology, 44(4), 248-254. doi:10.1902/jop.1973.44.4.248

Moher, D., Liberati, A., Tetzlaff, J., Altman, D. G., \& Group, P. (2009). Preferred reporting items for systematic reviews and meta-analyses: the PRISMA Statement. Open Med, 3(3), e123-130.

Moisa, D. H., Connolly, J. A., Cheng, B., \& Lalla, E. (2019). Impact of connective tissue graft thickness on surgical outcomes: A pilot randomized clinical trial. $J$ Periodontol, 90(9), 966-972. doi:10.1002/jper.18-0741 
Moraschini, V., \& Barboza Edos, S. (2016). Use of Platelet-Rich Fibrin Membrane in the Treatment of Gingival Recession: A Systematic Review and Meta-Analysis. $J$ Periodontol, 87(3), 281-290. doi:10.1902/jop.2015.150420

Muller, H. P., Stadermann, S., \& Heinecke, A. (2002). Gingival recession in smokers and non-smokers with minimal periodontal disease. J Clin Periodontol, 29(2), 129-136. doi:10.1034/j.1600-051x.2002.290207.x

Murtomaa, H., Meurman, J. H., Rytomaa, I., \& Turtola, L. (1987). Periodontal status in university students. J Clin Periodontol, 14(8), 462-465. doi:10.1111/j.1600051x.1987.tb02252.x

Mythri, S., Arunkumar, S. M., Hegde, S., Rajesh, S. K., Munaz, M., \& Ashwin, D. (2015). Etiology and occurrence of gingival recession - An epidemiological study. J Indian Soc Periodontol, 19(6), 671-675. doi:10.4103/0972-124X.156881

Nelson, S. W. (1987). The subpedicle connective tissue graft. A bilaminar reconstructive procedure for the coverage of denuded root surfaces. J Periodontol, 58(2), 95-102. doi:10.1902/jop.1987.58.2.95

Nobuto, T., Imai, H., \& Yamaoka, A. (1988). Microvascularization of the free gingival autograft. J Periodontol, 59(10), 639-646. doi:10.1902/jop.1988.59.10.639

O'Leary, T. J., Drake, R. B., Crump, P. P., \& Allen, M. F. (1971). The incidence of recession in young males: a further study. $J$ Periodontol, 42(5), 264-267. doi:10.1902/jop.1971.42.5.264

O'Leary, T. J., Drake, R. B., Jividen, G. J., \& Allen, M. F. (1967). The incidence of recession in young males: relationship to gingival and plaque scores. SAM-TR-67-97. Tech Rep SAM-TR, 1-4.

Oates, T. W., Robinson, M., \& Gunsolley, J. C. (2003). Surgical therapies for the treatment of gingival recession. A systematic review. Ann Periodontol, 8(1), 303-320. doi:10.1902/annals.2003.8.1.303

Oles, R. D., Ibbott, C. G., \& Laverty, W. H. (1988). Effect of root curettage and sodium hypochlorite treatment on pedicle flap coverage of localized recession. J Can Dent Assoc, 54(7), 515-517.

Oliveira, G. H., \& Muncinelli, E. A. (2012). Efficacy of root surface biomodification in root coverage: a systematic review. J Can Dent Assoc, 78, c122.

Oliver, R. C., Löe, H., \& Karring, T. (1968). Microscopic evaluation of the healing and revascularization of free gingival grafts. $J$ Periodontal Res, 3(2), 84-95. doi:10.1111/j.1600-0765.1968.tb01908.x

Olsson, M., \& Lindhe, J. (1991). Periodontal characteristics in individuals with varying form of the upper central incisors. $J$ Clin Periodontol, 18(1), 78-82. doi:10.1111/j.1600-051x.1991.tb01124.x

Orkin, D. A., Reddy, J., \& Bradshaw, D. (1987). The relationship of the position of crown margins to gingival health. J Prosthet Dent, 57(4), 421-424. doi:10.1016/00223913(87)90006-0

Paniz, G., Nart, J., Gobbato, L., Chierico, A., Lops, D., \& Michalakis, K. (2016). Periodontal response to two different subgingival restorative margin designs: a 12month randomized clinical trial. Clin Oral Investig, 20(6), 1243-1252. doi:10.1007/s00784-015-1616-z

Parma-Benfenali, S., Fugazzoto, P. A., \& Ruben, M. P. (1985). The effect of restorative margins on the postsurgical development and nature of the periodontium. Part I. Int J Periodontics Restorative Dent, 5(6), 30-51.

Patur, B. (1977). The rotation flap for covering denuded root surfaces - a closed wound technique. J Periodontol, 48(1), 41-44. doi:10.1902/jop.1977.48.1.41 
Pearson, L. E. (1968). Gingival height of lower central incisors, orthodontically treated and untreated. Angle Orthod, 38(4), 337-339. doi:10.1043/00033219(1968)038<0337:GHOLCI $>2.0$. CO;2

Pennel, B. M., Higgason, J. D., Towner, J. D., King, K. O., Fritz, B. D., \& Salder, J. F. (1965). OBLIQUE ROTATED FLAP. $J$ Periodontol, 36, 305-309. doi:10.1902/jop.1965.36.4.305

Pfeifer, J. S., \& Heller, R. (1971). Histologic evaluation of full and partial thickness lateral repositioned flaps: a pilot study. $J$ Periodontol, 42(6), 331-333. doi:10.1902/jop.1971.42.6.331

Pini Prato, G. (1999). Mucogingival deformities. Ann Periodontol, 4(1), 98-101. doi:10.1902/annals.1999.4.1.98

Pini Prato, G., Pagliaro, U., Baldi, C., Nieri, M., Saletta, D., Cairo, F., \& Cortellini, P. (2000). Coronally advanced flap procedure for root coverage. Flap with tension versus flap without tension: a randomized controlled clinical study. J Periodontol, 71(2), 188-201. doi:10.1902/jop.2000.71.2.188

Pini Prato, G., Tinti, C., Vincenzi, G., Magnani, C., Cortellini, P., \& Clauser, C. (1992). Guided tissue regeneration versus mucogingival surgery in the treatment of human buccal gingival recession. J Periodontol, 63(11), 919-928. doi:10.1902/jop.1992.63.11.919

Pini Prato, G. P., Baldi, C., Nieri, M., Franseschi, D., Cortellini, P., Clauser, C., . . Muzzi, L. (2005). Coronally advanced flap: the post-surgical position of the gingival margin is an important factor for achieving complete root coverage. J Periodontol, 76(5), 713-722. doi:10.1902/jop.2005.76.5.713

Pini Prato, G. P., Franceschi, D., Cortellini, P., \& Chambrone, L. (2018a). Long-term evaluation (20 years) of the outcomes of subepithelial connective tissue graft plus coronally advanced flap in the treatment of maxillary single recession-type defects. J Periodontol, 89(11), 1290-1299. doi:10.1002/JPER.17-0619

Pini Prato, G. P., Magnani, C., \& Chambrone, L. (2018b). Long-term evaluation (20 years) of the outcomes of coronally advanced flap in the treatment of single recession-type defects. J Periodontol, 89(3), 265-274. doi:10.1002/JPER.17-0379

Pini-Prato, G. (2011). The Miller classification of gingival recession: limits and drawbacks. J Clin Periodontol, 38(3), 243-245. doi:10.1111/j.1600-051X.2010.01655.x

Pini-Prato, G., Baldi, C., Pagliaro, U., Nieri, M., Saletta, D., Rotundo, R., \& Cortellini, P. (1999). Coronally advanced flap procedure for root coverage. Treatment of root surface: root planning versus polishing. J Periodontol, 70(9), 1064-1076. doi:10.1902/jop.1999.70.9.1064

Pini-Prato, G., Franceschi, D., Cairo, F., Nieri, M., \& Rotundo, R. (2010). Classification of dental surface defects in areas of gingival recession. J Periodontol, 81(6), 885-890. doi:10.1902/jop.2010.090631

Powell, R. N., \& McEniery, T. M. (1981). Disparities in gingival height in the mandibular central incisor region of children aged 6--12 years. Community Dent Oral Epidemiol, 9(1), 32-36. doi:10.1111/j.1600-0528.1981.tb01025.x

Raetzke, P. B. (1985). Covering localized areas of root exposure employing the "envelope" technique. J Periodontol, 56(7), 397-402. doi:10.1902/jop.1985.56.7.397

Rajapakse, P. S., McCracken, G. I., Gwynnett, E., Steen, N. D., Guentsch, A., \& Heasman, P. A. (2007). Does tooth brushing influence the development and progression of non-inflammatory gingival recession? A systematic review. J Clin Periodontol, 34(12), 1046-1061. doi:10.1111/j.1600-051X.2007.01149.x 
Rasperini, G., Silvestri, M., Schenk, R. K., \& Nevins, M. L. (2000). Clinical and histologic evaluation of human gingival recession treated with a subepithelial connective tissue graft and enamel matrix derivative (Emdogain): a case report. Int $J$ Periodontics Restorative Dent, 20(3), 269-275.

Ravald, N., \& Hamp, S. E. (1981). Prediction of root surface caries in patients treated for advanced periodontal disease. $J$ Clin Periodontol, 8(5), 400-414. doi:10.1111/j.1600-051x.1981.tb00889.x

Reiker, J., van der Velden, U., Barendregt, D. S., \& Loos, B. G. (1999). A cross-sectional study into the prevalence of root caries in periodontal maintenance patients. J Clin Periodontol, 26(1), 26-32. doi:10.1034/j.1600-051x.1999.260105.x

Renkema, A. M., Fudalej, P. S., Renkema, A., Kiekens, R., \& Katsaros, C. (2013a). Development of labial gingival recessions in orthodontically treated patients. Am J Orthod Dentofacial Orthop, 143(2), 206-212. doi:10.1016/j.ajodo.2012.09.018

Renkema, A. M., Fudalej, P. S., Renkema, A. A., Abbas, F., Bronkhorst, E., \& Katsaros, C. (2013b). Gingival labial recessions in orthodontically treated and untreated individuals: a case - control study. J Clin Periodontol, 40(6), 631-637. doi:10.1111/jcpe. 12105

Renkema, A. M., Navratilova, Z., Mazurova, K., Katsaros, C., \& Fudalej, P. S. (2015). Gingival labial recessions and the post-treatment proclination of mandibular incisors. Eur J Orthod, 37(5), 508-513. doi:10.1093/ejo/cju073

Roccuzzo, M., Bunino, M., Needleman, I., \& Sanz, M. (2002). Periodontal plastic surgery for treatment of localized gingival recessions: a systematic review. J Clin Periodontol, 29 Suppl 3, 178-194; discussion 195-176. doi:10.1034/j.1600051x.29.s3.11.x

Rocha, J. M., Ramazini, C., \& Rösing, C. K. (2011). Analysis of gingival margin esthetic clinical conditions by dental students. Acta Odontol Latinoam, 24(3), 279-282.

Ruben, M. P. (1979). A biologic rationale for gingival reconstruction by grafting procedures. Quintessence Int Dent Dig, 10(11), 47-55.

Ruf, S., Hansen, K., \& Pancherz, H. (1998). Does orthodontic proclination of lower incisors in children and adolescents cause gingival recession? Am J Orthod Dentofacial Orthop, 114(1), 100-106. doi:10.1016/s0889-5406(98)70244-6

Saletta, D., Pini Prato, G., Pagliaro, U., Baldi, C., Mauri, M., \& Nieri, M. (2001). Coronally advanced flap procedure: is the interdental papilla a prognostic factor for root coverage? J Periodontol, 72(6), 760-766. doi:10.1902/jop.2001.72.6.760

Sallum, E. A., Pimentel, S. P., Saldanha, J. B., Nogueira-Filho, G. R., Casati, M. Z., Nociti, F. H., \& Sallum, A. W. (2004). Enamel matrix derivative and guided tissue regeneration in the treatment of dehiscence-type defects: a histomorphometric study in dogs. J Periodontol, 75(10), 1357-1363. doi:10.1902/jop.2004.75.10.1357

Sanavi, F., Weisgold, A. S., \& Rose, L. F. (1998). Biologic width and its relation to periodontal biotypes. $J$ Esthet Dent, 10(3), 157-163. doi:10.1111/j.17088240.1998.tb00351.x

Sangnes, G., \& Gjermo, P. (1976). Prevalence of oral soft and hard tissue lesions related to mechanical toothcleansing procedures. Community Dent Oral Epidemiol, 4(2), 7783. doi:10.1111/j.1600-0528.1976.tb01607.x

Sarfati, A., Bourgeois, D., Katsahian, S., Mora, F., \& Bouchard, P. (2010). Risk assessment for buccal gingival recession defects in an adult population. J Periodontol, 81(10), 1419-1425. doi:10.1902/jop.2010.100102

Scheyer, E. T., Sanz, M., Dibart, S., Greenwell, H., John, V., Kim, D. M., . . Rasperini, G. (2015). Periodontal Soft Tissue Non-Root Coverage Procedures: A Consensus 
Report From the AAP Regeneration Workshop. Journal of Periodontology, 86(2S), S73-S76. doi:10.1902/jop.2015.140377

Schoo, W. H., \& van der Velden, U. (1985). Marginal soft tissue recessions with and without attached gingiva. Journal of Periodontal Research, 20(2), 209-211. doi:10.1111/j.1600-0765.1985.tb00427.x

Serino, G., Wennstrom, J. L., Lindhe, J., \& Eneroth, L. (1994). The prevalence and distribution of gingival recession in subjects with a high standard of oral hygiene. $J$ Clin Periodontol, 21(1), 57-63. doi:10.1111/j.1600-051x.1994.tb00278.x

Silva, C. O., Sallum, A. W., de Lima, A. F., \& Tatakis, D. N. (2006). Coronally positioned flap for root coverage: poorer outcomes in smokers. J Periodontol, 77(1), 81-87. doi:10.1902/jop.2006.77.1.81

Slutzkey, S., \& Levin, L. (2008). Gingival recession in young adults: occurrence, severity, and relationship to past orthodontic treatment and oral piercing. Am J Orthod Dentofacial Orthop, 134(5), 652-656. doi:10.1016/j.ajodo.2007.02.054

Smith, R. G. (1997). Gingival recession. Reappraisal of an enigmatic condition and a new index for monitoring. J Clin Periodontol, 24(3), 201-205. doi:10.1111/j.1600051x.1997.tb00492.x

Sperry, T. P., Speidel, T. M., Isaacson, R. J., \& Worms, F. W. (1977). The role of dental compensations in the orthodontic treatment of mandibular prognathism. Angle Orthod, 47(4), 293-299. doi:10.1043/00033219(1977)047<0293:TRODCI>2.0.CO;2

Staffileno, H., Levy, S., \& Gargiulo, A. (1966). Histologic study of cellular mobilization and repair following a periosteal retention operation via split thickness mucogingival flap surgery. J Periodontol, 37(2), 117-131. doi:10.1902/jop.1966.37.2.117

Stahl, S. S. (1985). Periodontal attachment in health and disease. $J$ West Soc Periodontol Periodontal Abstr, 33(4), 147-157.

Stamm, J. W., Banting, D. W., \& Imrey, P. B. (1990). Adult root caries survey of two similar communities with contrasting natural water fluoride levels. J Am Dent Assoc, 120(2), 143-149. doi:10.14219/jada.archive.1990.0031

Steiner, G. G., Pearson, J. K., \& Ainamo, J. (1981). Changes of the marginal periodontium as a result of labial tooth movement in monkeys. J Periodontol, 52(6), 314-320. doi:10.1902/jop.1981.52.6.314

Stern, I. B. (1981). Current concepts of the dentogingival junction: the epithelial and connective tissue attachments to the tooth. J Periodontol, 52(9), 465-476. doi:10.1902/jop.1981.52.9.465

Sterne, J. A., Hernan, M. A., Reeves, B. C., Savovic, J., Berkman, N. D., Viswanathan, M., . . Higgins, J. P. (2016). ROBINS-I: a tool for assessing risk of bias in nonrandomised studies of interventions. BMJ, 355, i4919. doi:10.1136/bmj.i4919

Sterne, J. A. C., Savovic, J., Page, M. J., Elbers, R. G., Blencowe, N. S., Boutron, I., . . . Higgins, J. P. T. (2019). RoB 2: a revised tool for assessing risk of bias in randomised trials. BMJ, 366, 14898. doi:10.1136/bmj.14898

Stillman, P. R. (1917). The management of pyorrhea.

Stillman, P. R. (1925). What is Traumatic Occlusion and How Can it be Diagnosed and Corrected? The Journal of the American Dental Association (1922), 12(11), 13301338. doi:https://doi.org/10.14219/jada.archive.1925.0304

Stoner, J. E., \& Mazdyasna, S. (1980). Gingival recession in the lower incisor region of 15year-old subjects. J Periodontol, 51(2), 74-76. doi:10.1902/jop.1980.51.2.74 
Sullivan, H. C., \& Atkins, J. H. (1968a). Free autogenous gingival grafts. 3. Utilization of grafts in the treatment of gingival recession. Periodontics, 6(4), 152-160.

Sullivan, H. C., \& Atkins, J. H. (1968b). Free autogenous gingival grafts. I. Principles of successful grafting. Periodontics, 6(3), 121-129.

Susin, C., Haas, A. N., Oppermann, R. V., Haugejorden, O., \& Albandar, J. M. (2004). Gingival recession: epidemiology and risk indicators in a representative urban Brazilian population. $J \quad$ Periodontol, 75(10), 1377-1386. doi:10.1902/jop.2004.75.10.1377

Tatakis, D. N., Chambrone, L., Allen, E. P., Langer, B., McGuire, M. K., Richardson, C. R., . . Z Zadeh, H. H. (2015). Periodontal soft tissue root coverage procedures: a consensus report from the AAP Regeneration Workshop. J Periodontol, $86(2$ Suppl), S52-55. doi:10.1902/jop.2015.140376

Tavelli, L., Barootchi, S., Nguyen, T. V. N., Tattan, M., Ravidà, A., \& Wang, H. L. (2018). Efficacy of tunnel technique in the treatment of localized and multiple gingival recessions: A systematic review and meta-analysis. J Periodontol, 89(9), 10751090. doi:10.1002/jper.18-0066

Tezel, A., Canakci, V., Cicek, Y., \& Demir, T. (2001). Evaluation of gingival recession in left- and right-handed adults. Int $J$ Neurosci, 110(3-4), 135-146. doi:10.3109/00207450108986541

Toker, H., \& Ozdemir, H. (2009). Gingival recession: epidemiology and risk indicators in a university dental hospital in Turkey. Int J Dent Hyg, 7(2), 115-120. doi:10.1111/j.1601-5037.2008.00348.x

Tolmie, P. N., Rubins, R. P., Buck, G. S., Vagianos, V., \& Lanz, J. C. (1991). The predictability of root coverage by way of free gingival autografts and citric acid application: an evaluation by multiple clinicians. Int J Periodontics Restorative Dent, 11(4), 261-271.

Tonetti, M. S., Jepsen, S., \& Working Group 2 of the European Workshop on, P. (2014). Clinical efficacy of periodontal plastic surgery procedures: consensus report of Group 2 of the 10th European Workshop on Periodontology. J Clin Periodontol, 41 Suppl 15, S36-43. doi:10.1111/jcpe.12219

Trentini, C. M., Moriarty, J. D., Phillips, C., \& Tulloch, J. F. C. (1995). Evaluation of the Use of Orthodontic Records to Measure the Width of Keratinized Tissue. Journal of Periodontology, 66(6), 438-442. doi:10.1902/jop.1995.66.6.438

Trombelli, L., \& Scabbia, A. (1997). Healing response of gingival recession defects following guided tissue regeneration procedures in smokers and non-smokers. J Clin Periodontol, 24(8), 529-533. doi:10.1111/j.1600-051x.1997.tb00224.x

Trott, J. R., \& Love, B. (1966). An analysis of localized gingival recession in 766 Winnipeg High School students. Dent Pract Dent Rec, 16(6), 209-213.

Valderhaug, J., \& Birkeland, J. M. (1976). Periodontal conditions in patients 5 years following insertion of fixed prostheses. Pocket depth and loss of attachment. J Oral Rehabil, 3(3), 237-243. doi:10.1111/j.1365-2842.1976.tb00949.x

van Palenstein Helderman, W. H., Lembariti, B. S., van der Weijden, G. A., \& van 't Hof, M. A. (1998). Gingival recession and its association with calculus in subjects deprived of prophylactic dental care. J Clin Periodontol, 25(2), 106-111. doi:10.1111/j.1600-051x.1998.tb02416.x

Vanarsdall, R. L. (1995). Orthodontics and periodontal therapy. Periodontology 2000, 9(1), 132-149. doi:10.1111/j.1600-0757.1995.tb00061.x

Vehkalahti, M. (1989). Occurrence of gingival recession in adults. J Periodontol, 60(11), 599-603. doi:10.1902/jop.1989.60.11.599 
Vignoletti, F., Nuñez, J., Discepoli, N., De Sanctis, F., Caffesse, R., Muñoz, F., . . . Sanz, M. (2011). Clinical and histological healing of a new collagen matrix in combination with the coronally advanced flap for the treatment of Miller class-I recession defects: an experimental study in the minipig. J Clin Periodontol, 38(9), 847-855. doi:10.1111/j.1600-051X.2011.01767.x

Waerhaug, J. (1952). The gingival pocket; anatomy, pathology, deepening and elimination. Odontol Tidskr, 60(Suppl 1), 1-186; 170 figures.

Wennström, J. L. (1987). Lack of association between width of attached gingiva and development of soft tissue recession. Journal of Clinical Periodontology, 14(3), 181-184. doi:10.1111/j.1600-051X.1987.tb00964.x

Wennström, J. L. (1996). Mucogingival therapy. Ann Periodontol, 1(1), 671-701. doi:10.1902/annals.1996.1.1.671

Wennstrom, J. L., Lindhe, J., Sinclair, F., \& Thilander, B. (1987). Some periodontal tissue reactions to orthodontic tooth movement in monkeys. J Clin Periodontol, 14(3), 121-129. doi:10.1111/j.1600-051x.1987.tb00954.x

Wennström, J. L., \& Zucchelli, G. (1996). Increased gingival dimensions. A significant factor for successful outcome of root coverage procedures? A 2-year prospective clinical study. J Clin Periodontol, 23(8), 770-777. doi:10.1111/j.1600051x.1996.tb00608.x

Wilderman, M. N., \& Wentz, F. M. (1965). REPAIR OF A DENTOGINGIVAL DEFECT WITH A PEDICLE FLAP. $J$ Periodontol, 36, 218-231. doi:10.1902/jop.1965.36.3.218

Yared, K. F., Zenobio, E. G., \& Pacheco, W. (2006). Periodontal status of mandibular central incisors after orthodontic proclination in adults. Am J Orthod Dentofacial Orthop, 130(1), 6 e1-8. doi:10.1016/j.ajodo.2006.01.015

Yoneyama, T., Okamoto, H., Lindhe, J., Socransky, S. S., \& Haffajee, A. D. (1988). Probing depth, attachment loss and gingival recession. Findings from a clinical examination in Ushiku, Japan. J Clin Periodontol, 15(9), 581-591. doi:10.1111/j.1600051x.1988.tb02133.x

Zabalegui, I., Sicilia, A., Cambra, J., Gil, J., \& Sanz, M. (1999). Treatment of multiple adjacent gingival recessions with the tunnel subepithelial connective tissue graft: a clinical report. Int J Periodontics Restorative Dent, 19(2), 199-206.

Zucchelli, G., Clauser, C., De Sanctis, M., \& Calandriello, M. (1998). Mucogingival versus guided tissue regeneration procedures in the treatment of deep recession type defects. J Periodontol, 69(2), 138-145. doi:10.1902/jop.1998.69.2.138

Zucchelli, G., Marzadori, M., Mounssif, I., Mazzotti, C., \& Stefanini, M. (2014a). Coronally advanced flap + connective tissue graft techniques for the treatment of deep gingival recession in the lower incisors. A controlled randomized clinical trial. J Clin Periodontol, 41(8), 806-813. doi:10.1111/jcpe.12269

Zucchelli, G., Mounssif, I., Mazzotti, C., Montebugnoli, L., Sangiorgi, M., Mele, M., \& Stefanini, M. (2014b). Does the dimension of the graft influence patient morbidity and root coverage outcomes? A randomized controlled clinical trial. J Clin Periodontol, 41(7), 708-716. doi:10.1111/jcpe.12256

Zucchelli, G., Mounssif, I., Stefanini, M., Mele, M., Montebugnoli, L., \& Sforza, N. M. (2009). Hand and ultrasonic instrumentation in combination with root-coverage surgery: a comparative controlled randomized clinical trial. J Periodontol, 80(4), 577-585. doi:10.1902/jop.2009.080485 
Zucchelli, G., Tavelli, L., Ravidà, A., Stefanini, M., Suárez-López Del Amo, F., \& Wang, H. L. (2018). Influence of tooth location on coronally advanced flap procedures for root coverage. J Periodontol, 89(12), 1428-1441. doi:10.1002/jper.18-0201

Zuhr, O., Fickl, S., Wachtel, H., Bolz, W., \& Hürzeler, M. B. (2007). Covering of gingival recessions with a modified microsurgical tunnel technique: case report. Int $J$ Periodontics Restorative Dent, 27(5), 457-463.

Zweers, J., Thomas, R. Z., Slot, D. E., Weisgold, A. S., \& Van der Weijden, F. G. (2014). Characteristics of periodontal biotype, its dimensions, associations and prevalence: a systematic review. J Clin Periodontol, 41(10), 958-971. doi:10.1111/jcpe.12275 